NUREG/CR-6221

SAND94-0650

\title{
The Valles Natural Analogue Project
}

\author{
1150 \\ $56661223 \exists 0$ \\ व $\triangle \wedge \exists 03 \mathrm{y}$
}

Prepared by

H. Stockman, J. Krumhansl, C. Ho, V. McConnell

Sandia National Laboratories

Operated by

Sandia Corporation

Prepared for

U.S. Nuclear Regulatory Commission 


\section{AVAILABILITY NOTICE}

Availability of Reference Materials Cited in NRC Publications

Most documents clted in NRC publications will be avallable from one of the following sources:

1. The NRC Publle Document Room, 2120 L Street, NW., Lower Level, Washington, DC 20555-0001

2. The Superintendent of Documents, U.S. Government Printing Office, P. O. Box 37082, Washington, DC 20402-9328

3. The National Technical Information Service, Springfleld, VA 22161-0002

Although the listing that follows represents the majority of documents cited in NRC publications, it is not intended to be exhaustive.

Referenced documents avallable for Inspection and copying for a fee from the NRC Public Document Room Include NRC correspondence and internal NRC memoranda; NRC bulletins, circulars, Informatlon notlces, Inspection and investigation notices; licensee event reports; vendor reports and correspondence; Commlssion papers; and appllcant and licensee documents and correspondence.

The following documents In the NUREG serles are avallable for purchase from the Government Printlng Offlce: formal NRC staff and contractor reports, NRC-sponsored conference proceedings, International agreement reports, grantee reports, and NRC booklets and brochures. Also avallable are regulatory guldes, NRC regulatlons in the Code of Federal Regulations, and Nuclear Regulatory Commission Issuances.

Documents avallable from the National Technical information Servlce include NUREG-serles reports and technical reports prepared by other Federal agencles and reports prepared by the Atomic Energy Commission, forerunner agency to the Nuclear Regulatory Commission.

Documents avallable from public and speclal technical libraries Include all open literature items, such as books, journal articles, and transactions. Federal Register notices, Federal and State legislation, and congressional reports can usually be obtained from these librarles.

Documents such as theses, dissertations, foreign reports and translations, and non-NRC conference proceedings are available for purchase from the organization sponsoring the publication cited.

Single coples of NRC draft reports are available free, to the extent of supply, upon written request to the Offlce of Administration, Distribution and Mall Services Section, U.S. Nuclear Regulatory Commission, Washington, DC 20555-0001.

Coples of industry codes and standards used in a substantive manner in the NRC regulatory process are maintained at the NRC Library. Two White Filint North, 11545 Rockville Pike, Rockville, MD 20852-2738, for use by the public. Codes and standards are usually copyrighted and may be purchased from the orlginating organization or, if they are American National Standards, from the American National Standards Institute, 1430 Broadway, New York, NY 10018-3308.

\section{DISCLAIMER NOTICE}

This report was prepared as an account of work sponsored by an agency of the United States Government. Neither the United States Govemment nor any agency thereof, nor any of their employees, makes any warranty, expressed or implied, or assumes any legal liability or responsibility for any third party's use, or the results of such use, of any information, apparatus, product, or process disclosed in this report, or represents that its use by such third party would not infringe privately owned rights. 


\section{DISCLAIMER}

This report was prepared as an account of work sponsored by an agency of the United States Government. Neither the United States Government nor any agency thereof, nor any of their employees, make any warranty, express or implied, or assumes any legal liability or responsibility for the accuracy, completeness, or usefulness of any information, apparatus, product, or process disclosed, or represents that its use would not infringe privately owned rights. Reference herein to any specific commercial product, process, or service by trade name, trademark, manufacturer, or otherwise does not necessarily constitute or imply its endorsement, recommendation, or favoring by the United States Government or any agency thereof. The views and opinions of authors expressed herein do not necessarily state or reflect those of the United States Government or any agency thereof. 


\section{DISCLAIMER}

Portions of this document may be illegible in electronic image products. Images are produced from the best available original document. 
NUREG/CR-6221

SAND94-0650

\section{The Valles Natural Analogue Project}

Manuscript Completed: May 1994

Date Published: December 1994

Prepared by

H. Stockman, J. Krumhansl, C. Ho, V. McConnell*

Sandia National Laboratories

Albuquerque, NM 87185-0750

\section{Prepared for}

Division of Engineering

Office of Nuclear Regulatory Research

U.S. Nuclear Regulatory Commission

Washington, DC 20555-0001

NRC Job Code A1824

*University of Alaska, Fairbanks

Geophysical Institute

Fairbanks, AK 99775-0800 


\begin{abstract}
The contact between an obsidian flow and a steep-walled tuff canyon was examined as an analogue for a high-level waste repository. The analogue site is located on the southwest rim of the Valles Caldera in New Mexico, where the massive Banco Bonito obsidian flow filled a paleocanyon in the Battleship Rock tuff. The obsidian flow provided a heat source, analogous to waste panels or an igneous intrusion in a repository, and caused evaporation and migration of water. The tuff and obsidian samples were analyzed for major and trace elements and mineralogy by INAA, XRF, X-ray diffraction, and scanning electron microscopy and electron microprobe. Samples were also analyzed for $\mathrm{D} / \mathrm{H}$ and ${ }^{39} \mathrm{Ar} /{ }^{40} \mathrm{Ar}$ isotopic composition.
\end{abstract}

Overall, the effects of the heating event seem to have been slight and limited to the tuff nearest the contact. There is some evidence of devitrification and migration of volatiles in the tuff within 10 meters of the contact, but variations in major and trace element chemistry are small and difficult to distinguish from the natural (pre-heating) variability of the rocks. Apart from devitrification, the principal mineralogic change in tuff near the contact is the development of feldspar-silica linings on voids in the pumiceous tuff matrix; we found no significant development of zeolites in the samples examined for this study. Age determinations by ${ }^{39} \mathrm{Ar} /{ }^{40} \mathrm{Ar}$ are ambiguous, and do not provide resolution necessary to map paleoisotherms from the heating event.

A simple model is developed to predict the temperatures in the obsidian and tuff as a function of time. The model predicts the movement of a boiling front several tens of meters into the tuff over several hundred years, and is relatively insensitive to the assumed saturation. Flowing-steam experiments show that $\mathrm{F}$ and $\mathrm{Cl}$ are readily lost by the glassy tuff at temperatures as low as $200^{\circ} \mathrm{C}$. Loss of $\mathrm{F}$ is consistent with diffusion-controlled release, and could produce condensates with tens to hundreds of ppm $F$ in the region behind the boiling zone.

Several mechanisms for producing compositional variations in the tuff are examined. A simple evaporation-capillarity model can explain the concentration of $\mathrm{F}$ above background levels. It is shown that the remobilization of silica, predicted by several workers, would probably not be detected in bulk analyses, and may be masked in microscopic analyses by the effects of alkali metasomatism. Significant gas phase transport of metals at the analogue site is shown to be improbable. 


\section{CONTENTS}

Section

Page

Abstract

1 Introduction

1.1 Yucca Mountain and the Need for Natural Analogues

1.2 Advantages of the Valles Analogue

1.3 Differences Between YMS and the Valles Analogue 4

2 Geologic Background 6

3 Samples and Site Selection 9

3.1 Drill Core from VC-1 9

3.2 Outcrop Samples 10

4 Chemical Analysis of Samples

4.1 Leaching Studies 22

4.2 Instrumental Neutron Activation Analysis (INAA)

4.3 X-ray Fluorescence (XRF) for Major Elements 43

4.4 Analysis of Trace Chlorine, Sulfur and Fluorine 43

4.5 Bulk Water Analysis and Pyrograms $\quad 44$

4.6 D/H Analyses 46

4.7 Electron Microprobe (EMP) Study of Cl, F and Alkali Metasomatism 48

4.8 Heavy Mineral Analysis $\quad 53$

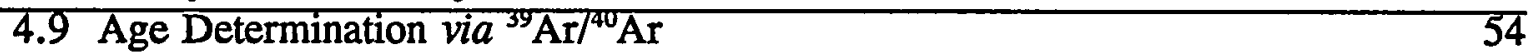

4.10 Scanning Electron Microscopy (SEM) $\quad 57$

$\begin{array}{ll}4.11 & X \text {-ray Diffraction (XRD) } \\ \end{array}$

\begin{tabular}{ll}
\hline Thermal Modeling & 62
\end{tabular}

6 Gas Transport Experiments 69

7 Discussion 76

7.1 Origin of Composition Variations: Overview 76

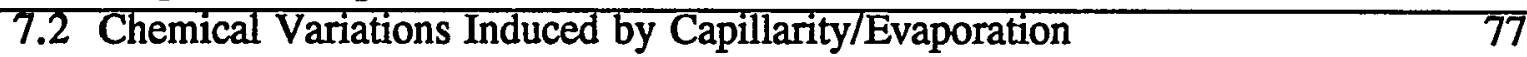

$\begin{array}{ll}7.3 \text { Vapor Phase Transport of Metals } & 86\end{array}$

8 Conclusions and Recommendations $\quad 88$

9 References 91

Appendix: Tables of Sample Analyses $\quad 98$ 
s9

t9

$\varepsilon 9$

09

65

65

85

85

ZS

IS

St

zt

It

0t

$6 \varepsilon$

$8 \varepsilon$

$\llcorner\varepsilon$

$9 \varepsilon$

SE

$7 \varepsilon$

$\varepsilon \mathcal{E}$

$\underline{z \varepsilon}$

$\underline{0 \varepsilon}$

62

82

$\angle Z$

22

$\varepsilon z$

Q2

6 I

LI

2I

SI

tII

$\underline{\varepsilon I}$

ZI

II

L

$\tau$

วริย

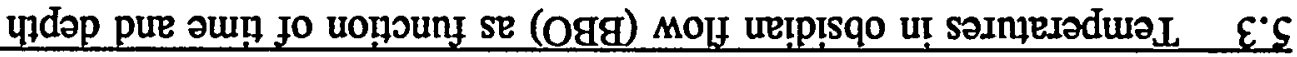

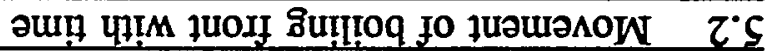

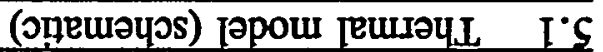

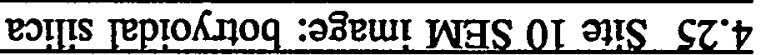

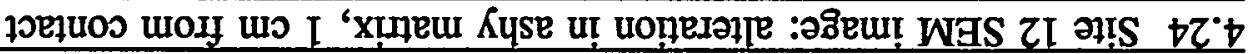

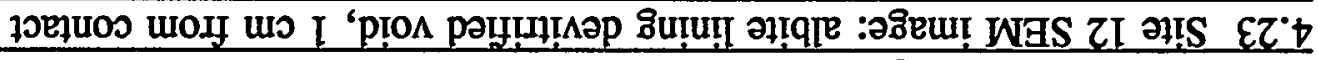

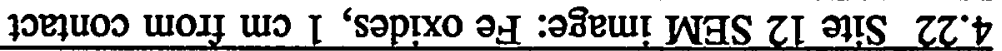

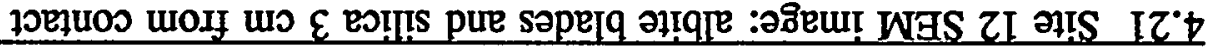

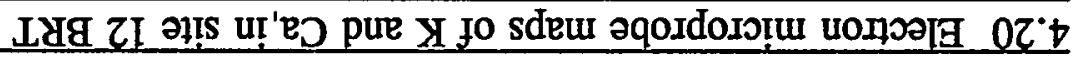

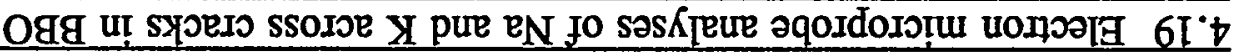

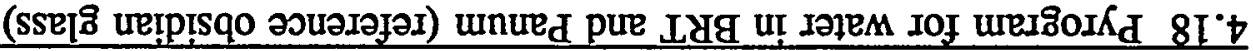

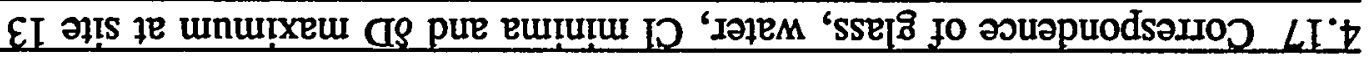

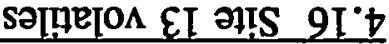

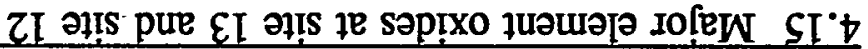

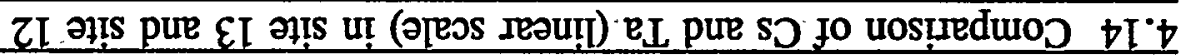

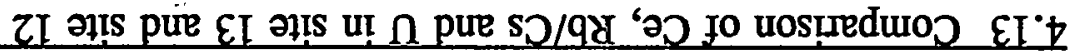

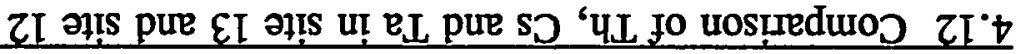

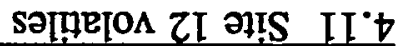

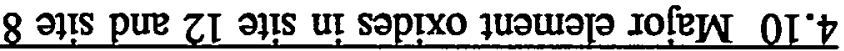

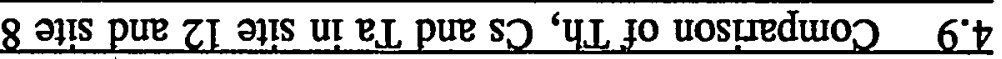

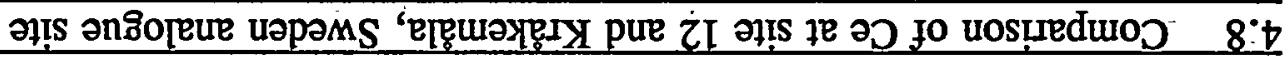

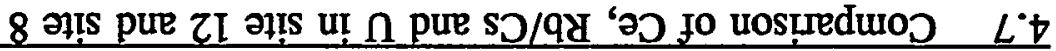
SOILETON 8 गIS $9^{\circ} \mathrm{t}$

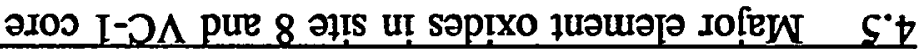

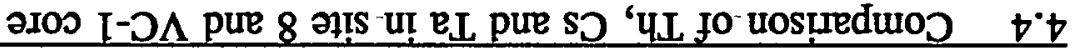

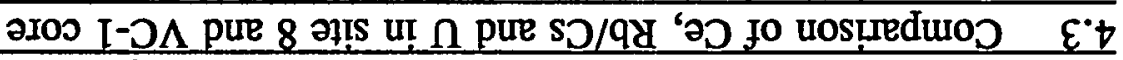

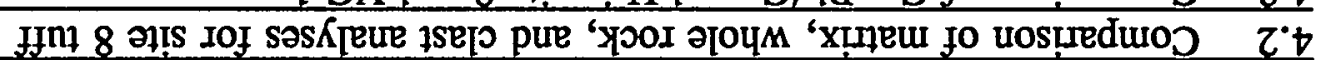
8 əI! te suoture כiqnjos $T^{\circ} \circ$ EI əIIS UOJf LYg snossiund $6^{\circ} \varepsilon$

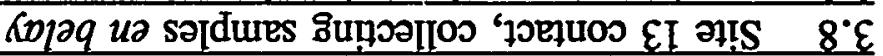
Jjn uI Słse[

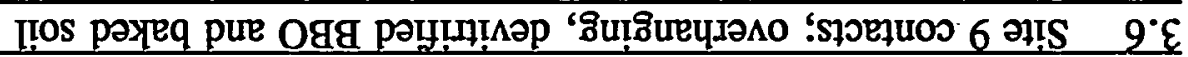

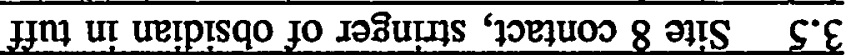

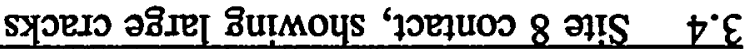

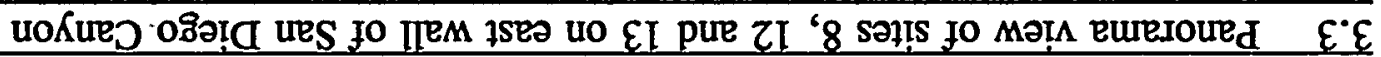

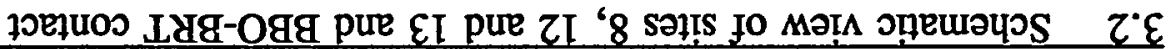

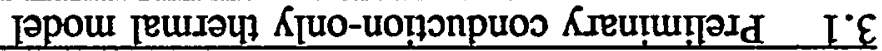

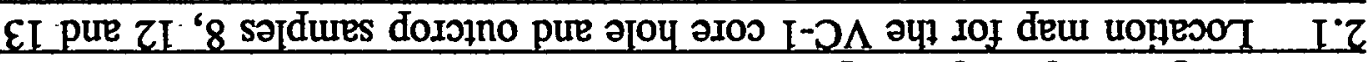

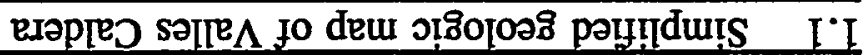
วมnช!: 
5.4 Temperatures in tuff (BRT) as functions of time and depth 66

\begin{tabular}{lll}
\hline 6.1 & Apparatus for flowing gas experiments & 72
\end{tabular}

6.2 Release of $\mathrm{Cl}$ and $\mathrm{F}$ from tuff, as function of temperature, 1st experiment $\quad, 73$

6.3 Apparent partition coefficient for $\mathrm{Cl}$ and $\mathrm{F}$, 1st experiment 74

6.4 Measured release rates and fitted curves at $400^{\circ} \mathrm{C}$, 2nd experiment 75

7.1 Mineral assemblage, as function of temperature, for case 1 (quartz allowed) 82

7.2 Mineral assemblage, as function of temperature, for case 1 (no quartz or tridymite) 82

\begin{tabular}{lll}
7.3 & Solution concentrations for figure 7.1 & 83 \\
\hline
\end{tabular}

\begin{tabular}{lll}
\hline 7.4 & Solution concentrations for figure 7.2 & 83 \\
\hline
\end{tabular}

7.5 Minerals formed with evaporation model, case 1 (high water:rock) 84

7.6 Minerals formed with evaporation model, case 2 (low water:rock)

$\begin{array}{lll}7.7 & \text { Solubility of uranium as oxygen is titrated into system } & 85\end{array}$

\begin{tabular}{lll}
7.8 & Uranium solids and solution composition for figure 7.5 evaporation model & 85 \\
\hline
\end{tabular} 


\section{INTRODUCTION}

\subsection{Yucca Mountain and the Need for Natural Analogues}

The U.S. Department of Energy has selected the Yucca Mountain Site (YMS), located in Nevada, as a potential repository for disposal of high-level commercial radioactive waste. Yucca Mountain is composed of rhyolitic tuffs, in various states of welding and devitrification. To determine the suitability of YMS for safe storage, it is necessary to predict the chemical and physical response of the tuffs to local and site-wide heating for 10,000 years.

For over a decade, scientists have used geochemical, thermal-hydrologic, and geomechanical codes to model the interaction of the tuffs, groundwater, and the radioactive waste. Most models focus on the degradation of the waste containers, dissolution of radionuclides in the waste, and the eventual diffusion, advection and sorption of the dissolved contaminants (Pigford et al., 1992). However, the dissolution of the tuff minerals, and consequent reprecipitation in cooler regions, generation of halogen-rich gases, and polymorphic transitions must also be modeled, since these processes affect permeability and structural integrity of the host rocks (Travis and Nuttall, 1987; Verma and Pruess, 1987).

Two significant sources of heat may drive the interactions between the waste and the repository: the waste itself generates heat through radioactive decay; and basaltic dikes and sills may intrude the site (Barr et al., 1993). Heating from radioactive waste can be controlled through engineering design, by adjusting the number of radioactive canisters placed per unit volume'(the canister "loading"). There is substantial debate about the best canister loading; on one hand, scientists desire a high loading (near-field $\mathrm{T} \approx 250^{\circ} \mathrm{C}$ ), to keep the canisters dry and uncorroded for as long as possible, and to minimize the transport of radionuclides by advection of liquid water; on the other hand, they wish for low loading (near-field $\mathrm{T} \leq 100{ }^{\circ} \mathrm{C}$ ), to reduce reaction rates, minimize the redistribution of radionuclides and corrosive volatiles (Vaniman et al., 1993), and reduce the structural (geomechanical) consequences of heating (NWTRB, 1992). Heating from igneous intrusion is more difficult to model, but presumably yields locally higher temperatures, and potentially greater physical responses than canister heating.

Uncertainty in the models arises from the need to extrapolate from equilibrium conditions, or small-scale experiments performed on the benchtop over days or months, to meter- and kilometer-scale processes occurring in the repository over thousands of years. Radionuclide solubility and sorption calculations are based principally on equilibrium thermodynamics, and a limited number of laboratory tests to assess the rate of important reactions, such as the dissolution of feldspars and quartz or the precipitation of kaolinite (Bruton et al., 1993). The accuracy of the extrapolations can have a dramatic effect on the predicted safety of the repository. For example, some models predict that clinoptilolite, which strongly absorbs Cs and $\mathrm{Sr}$, will form as the tuffs alter; other models predict the formation of less-sorptive mordenite, or even a non-sorptive feldspar-quartz assemblage from the same rocks 


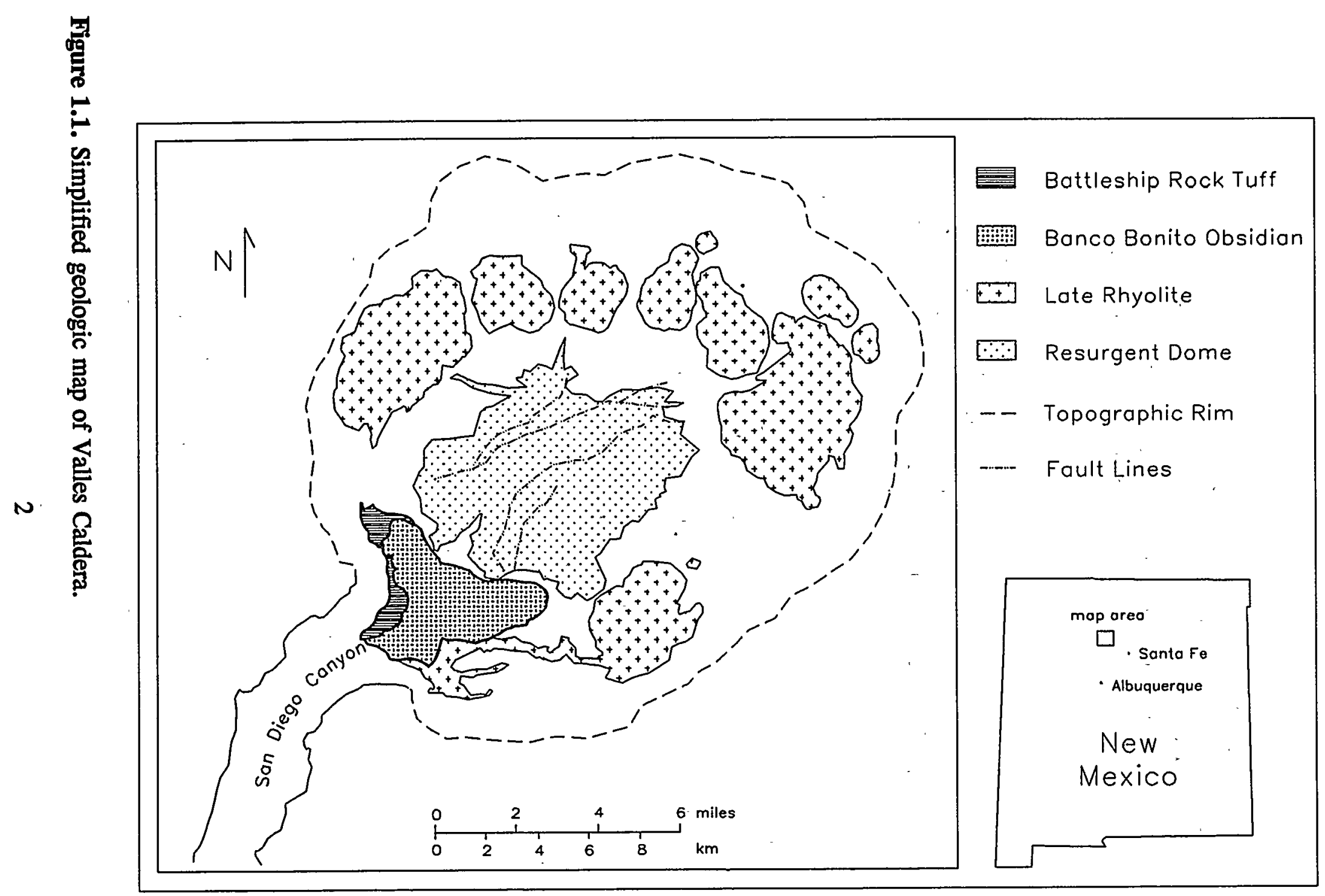


(Criscenti and Arthur, 1991; Arthur and Criscenti,1991). The rate laws used by the models depend on surface area, which is difficult to predict over the course of tuff alteration and waste degradation; passivating coatings may form on mineral grains and waste canisters, isolating the reactants from the solutions and greatly reducing reaction rates.

Small scale laboratory experiments can entirely miss important processes, and give results contrary to large scale tests. For example, laboratory tests have demonstrated a decrease in tuff permeability, due to redistribution of silica, whereas field-scale tests principally show an increase in permeability with heating (Lin, 1993; Ramirez, 1993). The heat pipe model (Verma and Pruess, 1987; Travis and Nuttall, 1987) provides a mechanism for dramatically increasing heat removal from the vicinity of the waste canister, and for changing tuff mineralogy and permeability; countercurrent flow of water vapor, and return of condensed water via capillary action specified by the model, take place on a scale of tens of meters and hundreds of years, and would never develop in bench-scale tests. Clearly much of the uncertainty in the YMS models is an uncertainty of scale.

One means to reduce this uncertainty is to study natural analogues -- large masses of geologic materials that were subject, over hundreds to millions of years, to processes analogous to those expected for the repository. The Valles Caldera, located in the Jemez Mountains of northern New Mexico (figure 1.1), provides a good natural analogue for many of the processes expected at YMS. In the southeast corner of the caldera, the Banco Bonito obsidian (BBO) flow filled a steep-walled canyon cut in the Battleship Rock tuff (BRT), $c a$. 400,000 years ago. The obsidian, initially at temperatures in excess of $850^{\circ} \mathrm{C}$, heated the porous tuff in the canyon walls and vaporized much of the pore water. The goals of the Valles Natural Analogue Project were to: (1) search for evidence of chemical and mineralogic changes in the tuff -- specifically changes that occurred in response to the heating event; (2) provide a well-characterized example for testing chemical migration models; and (3) provide guidance for future analogue studies and code development.

\subsection{Advantages of the Valles Analogue}

There are several features of the Valles Analogue that recommend it for study. In many natural analogue studies, it is difficult to distinguish chemical variations induced by heating, from those that existed before the heating event. For example, Brookins et al. (1983) studied an analogue consisting of a monzonite dike intruding rhyolite tuff country rock; the variations in Cs, Sr and rare earths observed near the contact were attributed to the heating event, but subsequent studies showed even larger random variations in the country rock kilometers from the contact (Brookins, 1986). Prior studies of the BRT showed it to be remarkably uniform in composition (Self et al., 1988), suggesting it would be relatively easy to distinguish compositional changes induced by heat from the Banco Bonito. Analogues based on deepseated dikes or sills often suffer from another problem; these intrusives are inherently biased toward volcanically and hydrothermally active areas, so there is often a preexisting hydrothermal overprint on the country rock, manifest as widespread mineralogic alteration to clays and zeolites. The Battleship Rock tuff is remarkably fresh, with no obvious signs of prior hydrothermal alteration, making it relatively easy to find mineralogic changes induced 


\section{GEOLOGIC BACKGROUND}

The Jemez Mountains are the site of one of the largest calderas in the world, the Valles Caldera. Because this region has been at the focus of numerous geologic investigations it is beyond the scope of this report to provide a detailed review of all the existing literature. However, a brief account of the region's geologic history is necessary to understand the field relationships discussed in this report. More detailed discussions are given by Bailey et al. (1969) and Doell et al. (1968).

Volcanic activity in the region occupied by the Jemez Mountains commenced about 13 million years ago. These early volcanos covered a basement complex of rocks ranging in age from Precambrian to Tertiary. The gross volcanic stratigraphy of the Jemez Mountains can be divided into the Keres, Polvadera and Tewa Groups. The Keres and Polvadera groups are associated with the early stages of Rio Grande Rift growth and range from basalt to rhyolite in composition. The Tewa group comprises those later volcanics associated with formation of the Valles Caldera and post-Caldera resurgent doming that gave rise to the present topography of the region.

The Valles Caldera formed in two stages, corresponding to the eruption of the Otowi and Tshirege Members of the Bandelier Tuff, at 1.45 and $1.1 \mathrm{Ma}$. The rhyolitic Bandelier Tuff is a massive unit $\left(400 \mathrm{~km}^{3}\right)$ that mantles the eastern slopes of the Jemez Mountains. Subsequent to the last major eruption of the Bandelier tuff, the caldera collapsed and a lake formed in the central depression. The Deer Canyon Rhyolite erupted in the central portion of the caldera, accompanied by landslides off the topographic rim, so that approximately $600 \mathrm{~m}$ of fill was deposited over the foundered cauldron floor. As lacustrine deposition waned, a resurgent dome (Redondo Peak) with $\approx 900 \mathrm{~m}$ of relief formed in the central portion of the caldera. Somewhat later a number of rhyolite domes erupted along the ring fracture at the outer margin of the caldera (figures 1.1 and 2.1). The domes at San Antonio and South Mountain were the youngest of these features, and are dated at about $540 \mathrm{ka}$.

The last volcanic activity in the region (and the events of most immediate relevance to this report) commenced after emplacement of the South Mountain Rhyolite. This activity produced a suite of rocks associated with the El Cajete eruptive center west of South Mountain. Detailed stratigraphic relationships within these units are still in doubt because of ambiguities inherent in current dating methods (Self et al., 1988, 1991), the difficulty of tracing contacts in the field, and the fact that the rocks involved all have very similar compositions and appearances. However the main units involved are the uppermost (and youngest) Banco Bonito Obsidian and the Battleship Rock Tuff.

In San Diego Canyon the Banco Bonito can be observed lying directly on top of a deeply incised surface cut into the Battleship Rock tuff (figures 2.1 and 3.2). The tuff has been baked to a pink color for a distance of about 10 meters below the contact, and in many places the tuff is reduced to rubble at the contact. In the VC-1 corehole this picture is complicated by the appearance of a thin tuff unit beneath the Banco Bonito and then a second 


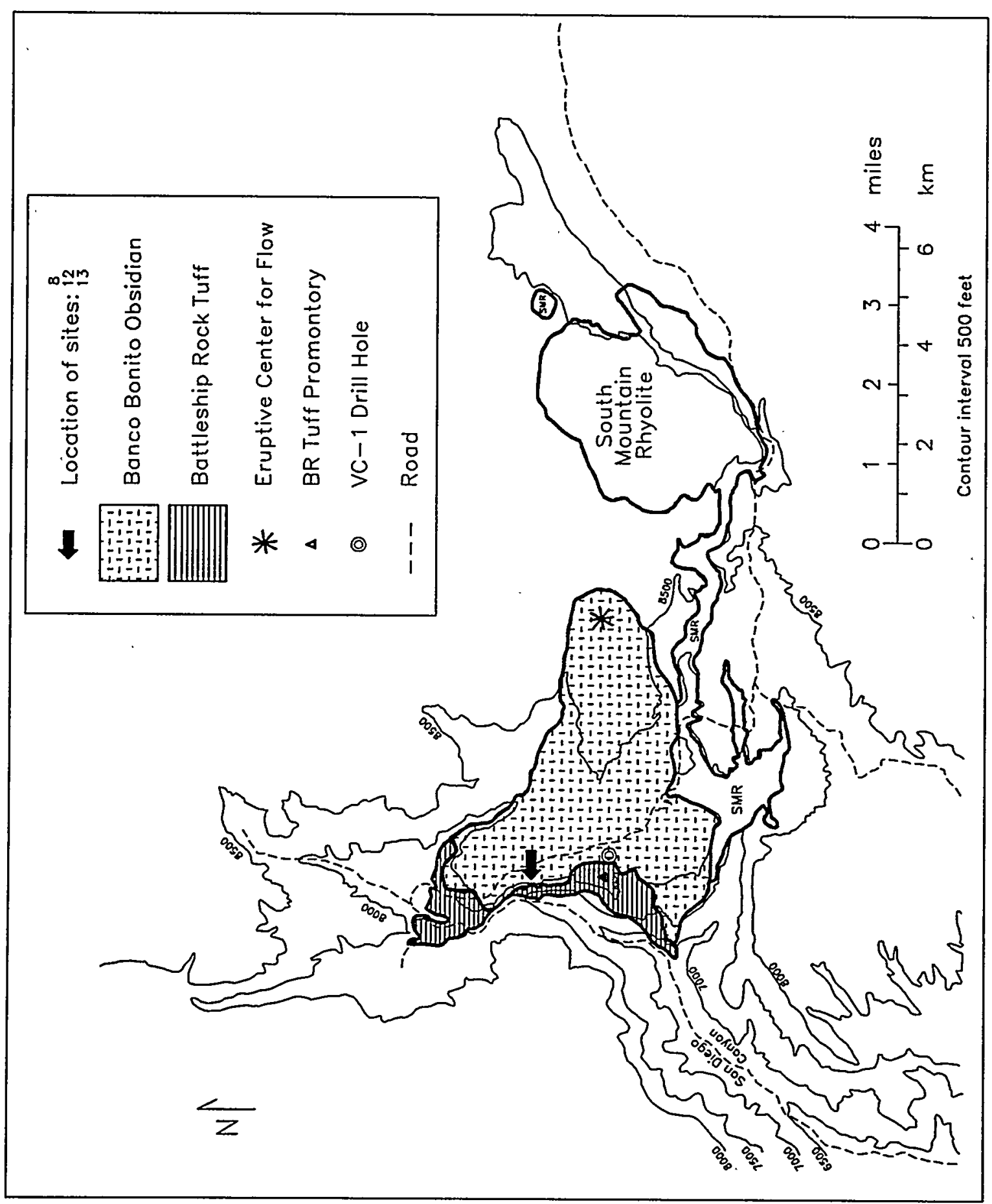

Figure 2.1. Location map for the VC-1 core hole and outcrop sites 8, 12 and 13.' 
unit of obsidian flow (the latter referred to as the VC-1 Rhyolite, or VC1R in this report). A soil horizon has tentatively been identified between the VC1R and the thin tuff overlying it. Beneath the lower obsidian is a thick unit of tuff. The most current interpretation holds that the thick tuffaceous unit below the lower obsidian correlates with the Battleship Rock Tuff. However, earlier interpretations correlated the Battleship Rock tuff with the thin wielded tuff immediately below the Banco Bonito, and postulated a second tuff unit of local extent that did not appear in outcrop around the margins of the flow.

A final stratigraphic complication concerns the uppermost Banco Bonito Obsidian. Early interpretations of the VC-1 stratigraphy (Self et al. 1988) indicate that the VC-1 drill hole actually encountered two flow units within the Banco Bonito. In a detailed study Pense (1977) identified three separate flow units along the south margin of the Banco Bonito. However, most recently Self et al. (1991) reversed earlier conclusions and state that the entire Banco Bonito (at the VC-1 Site) is a single flow unit.

The uncertainty in stratigraphy of the El Cajete series has two implications for this study. First, if the Banco Bonito is really several flow units, then there is substantial uncertainty in the magnitude and sharpness of the thermal pulse produced by its emplacement. Second, a similar problem arises if the BRT and BBO were erupted within a span of years, as originally suggested by Self et al. (1988); substantial heat would remain in the tuff, complicating the thermal profile. The most recent interpretation by Self et al. (1991), if correct, eliminates the latter problem by suggesting that the BBO was emplaced after a substantial hiatus in eruptive activity. The latter interpretation is favored in the current report, since it explains how a rugged topography could be developed in the BRT prior to the emplacement of the BBO. 


\section{SAMPLES AND SITE SELECTION}

\subsection{Drill Core from VC-1}

Initially we obtained samples from the VC-1 corehole (figure 2.1). The VC-1 core log (Gardner et al., 1987; Self et al., 1988) describes two sets of contacts between obsidian and tuff. At a depth of $486 \mathrm{ft}$, contact 1 occurs between the BBO and a thin tuffaceous unit (originally considered to be the BRT). At a depth of $590.6 \mathrm{ft}$, contact 2 occurs between the "VC-1 Rhyolite" (an obsidian flow) and the "VC-1 Tuff" (hereafter referred to as VC1T). The VC1R is known with certainty only in the core. As discussed in section 2, the "VC1T" is now thought by Self et al. (1991) to be the BRT; we retain the older nomenclature for consistency with the core logs. According to the core log, the VC1T under contact 2 was baked pink, apparently from the heat of the overlying obsidian flow. We obtained samples across both contacts from the UNC core repository in Grand Junction, Colorado, and began preliminary petrographic analysis and $\mathrm{X}$-ray diffraction $(\mathrm{XRD})$ studies.

We encountered several problems with the VC-1 core. First, contact 1 proved to be much less obvious in the samples than in the core photos and log. Rather than a sharp, cm-wide contact between tuff and obsidian, there was a thick $(\approx$ meter-wide) breccia zone of altered obsidian chucks, fragments of older, unrelated volcanics, and baked, pumiceous dust. It would be very difficult to determine what compositional variations in this material resulted from heating and mobilization, $v$ s. simple mechanical mixing. Recent drilling studies show that the basal breccia and pumice are expected under rhyolite flows, at least in the region proximal to the vent (e.g. Fink and Manley, 1987); however, one would expect a much smaller breccia layer near the flow margin, since the breccia would be overrun by the fastermoving portions of the flow. Contact 2 is somewhat sharper than contact 1 , with a smaller breccia zone; XRD of VCIT near the contact showed the development of some clays, but the general weathered appearance of the tuff suggested that the clays developed as a low temperature soil, not in response to a heating event; this suggestion is partially confirmed by the remnant magnetization measurements of Geissman (1988). The small diameter of the VC1 core $(\approx 5 \mathrm{~cm})$ also posed a significant problem; it was difficult to obtain representative samples, since the rock fragments were often larger than $10 \mathrm{~cm}$ in length.

Preliminary thermal modeling revealed another potential problem with both VC-1 contacts. Figure 3.1 shows temperatures calculated from a simple conduction model, as a function of depth below the current top of the BBO flow; both the BBO and tuffs are assumed to have the same thermal conductivity. The figure really illustrates two heating events: emplacement of the VC1R flow (initially at $850^{\circ} \mathrm{C}$ ) on top of the VC1T (initially at $0{ }^{\circ} \mathrm{C}$ ); and emplacement of the BBO (initially at $850^{\circ} \mathrm{C}$ ) on top of the BRT, VC1R and VC1T (the latter three initially at $0^{\circ} \mathrm{C}$ ). The dashed lines give temperatures in the VC1T at 10 and 100 years after emplacement of the VC1R flow, and the unbroken lines give temperatures in the lower three units 50,100, and 250 years after emplacement of the BBO. It is clear that much of the thermal signature from the first event might be wiped out by the second heating event. Moreover, the interval of tuff between the BBO and VC1R is so thin, that it would have been effectively isothermal for much of the heating period, and might show relatively little in 
the way of meaningful compositional variation.

In spite of these complications, we did analyze the core for major and trace elements, and mineralogy. However, the problems with the VC-1 core encouraged us to search for surface exposures. The comparison of core and outcrop analyses would later show that the outcrop samples were probably better suited for the analogue study (section 4.2).

\subsection{Outcrop Samples}

To find good exposures of the contact between the BBO and BRT, we walked out the BBOBRT contact from Battleship Rock State Park, to a point approximately 3 kilometers to the north, where the steepness of the cliffs made foot travel impractical. Along this route we found five exposures of the BBO-BRT contact that were suitable for further study; these exposures are referred to as sites 8, 9,10,12 and 13 hereafter. Sites 8, 12 and 13 (figure 2.1) were selected for detailed chemical and mineralogical analysis. Figure 3.2 schematically illustrates different BBO-BRT geometries, as an aid to interpreting the descriptions, and figure 3.3 provides a panorama of sites 8,12 and 13 on the east wall of San Diego Canyon.

Most outcrop samples were taken with hammer and chisel. Early analyses for leachable anions (section 4.1) suggested that the outer surface of the outcrop might be affected by weathering or surficial contamination, so some samples from sites 8 and 12 were subsequently taken with a water-cooled diamond core drill operated off a chainsaw motor (Model D-2801, Pomeroy Industries Unlimited, Menlo Park, CA). We analyzed sections of the cores, and determined that there was no systematic change in composition with depth into the outcrop; therefore we returned to collecting samples by hammer and chisel for our study of site 13 .

At site 8, the BBO-BRT contact is horizontal in exposure. However, the contact actually dips into the canyon wall at roughly $45^{\circ}$. The BRT is baked pink ${ }^{1}$, and is friable except within $\approx 10$ to $20 \mathrm{~cm}$ of the contact. There are several large cracks perpendicular to the contact, 1$10 \mathrm{~cm}$ wide (figures 3.4 and 3.5); these cracks were apparently open at the time the BBO was emplaced, since rounded bulges of obsidian have intruded 1 to $30 \mathrm{~cm}$ into the cracks. Samples could be selected over a vertical interval of about $2 \mathrm{~m}$, and an intact section of the contact was removed for petrographic and electron microprobe analysis. The obsidian appears extremely fresh -- neither perlitic nor devitrified (section 4.7 gives analytical evidence for the freshness of the obsidian). A significant disadvantage of this site is the possibility that the few cm of "tuff" immediately below the contact actually represents a paleosoil, or a weathered surface. In the modern-day San Diego Canyon, soils (with the aid of plant roots) cling to slopes as steep as $45^{\circ}$. This site was used by Doell et al. (1968) for studies of paleomagnetism.

\footnotetext{
${ }^{1}$ Caution is needed when looking for field evidence of "baking"; forest fires have been common in this region, and in areas with abundant burned stumps, the tuff may be baked red from the heat of the fire. However, the latter coloration is very superficial; the tuff is grey a few $\mathrm{cm}$ below the surface.
} 


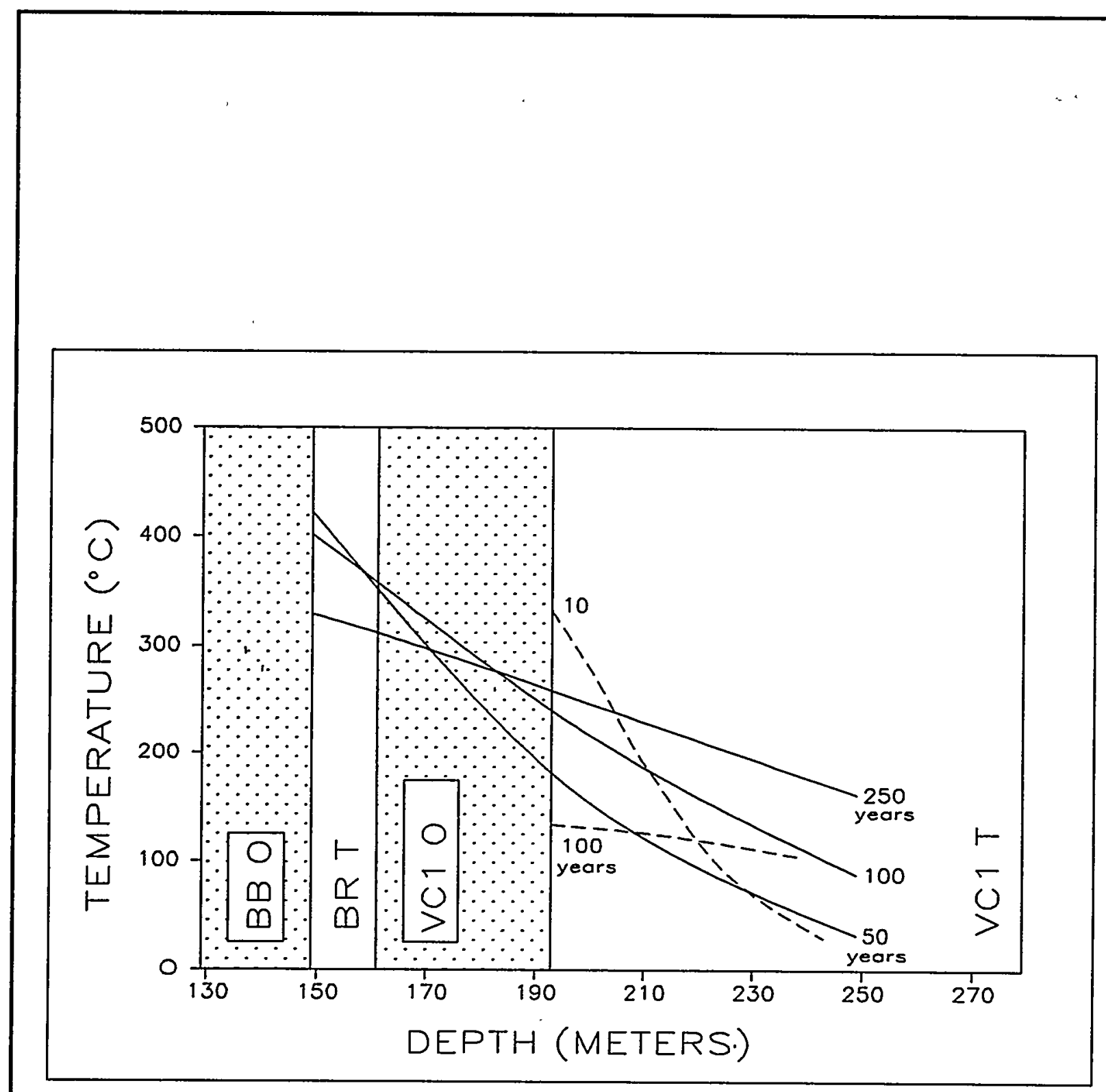

Figure 3.1. Preliminary conduction-only model. Dashed lines are for the VC1R heating event; unbroken lines for the BBO event. More detailed thermal models are discussed in section 5. 


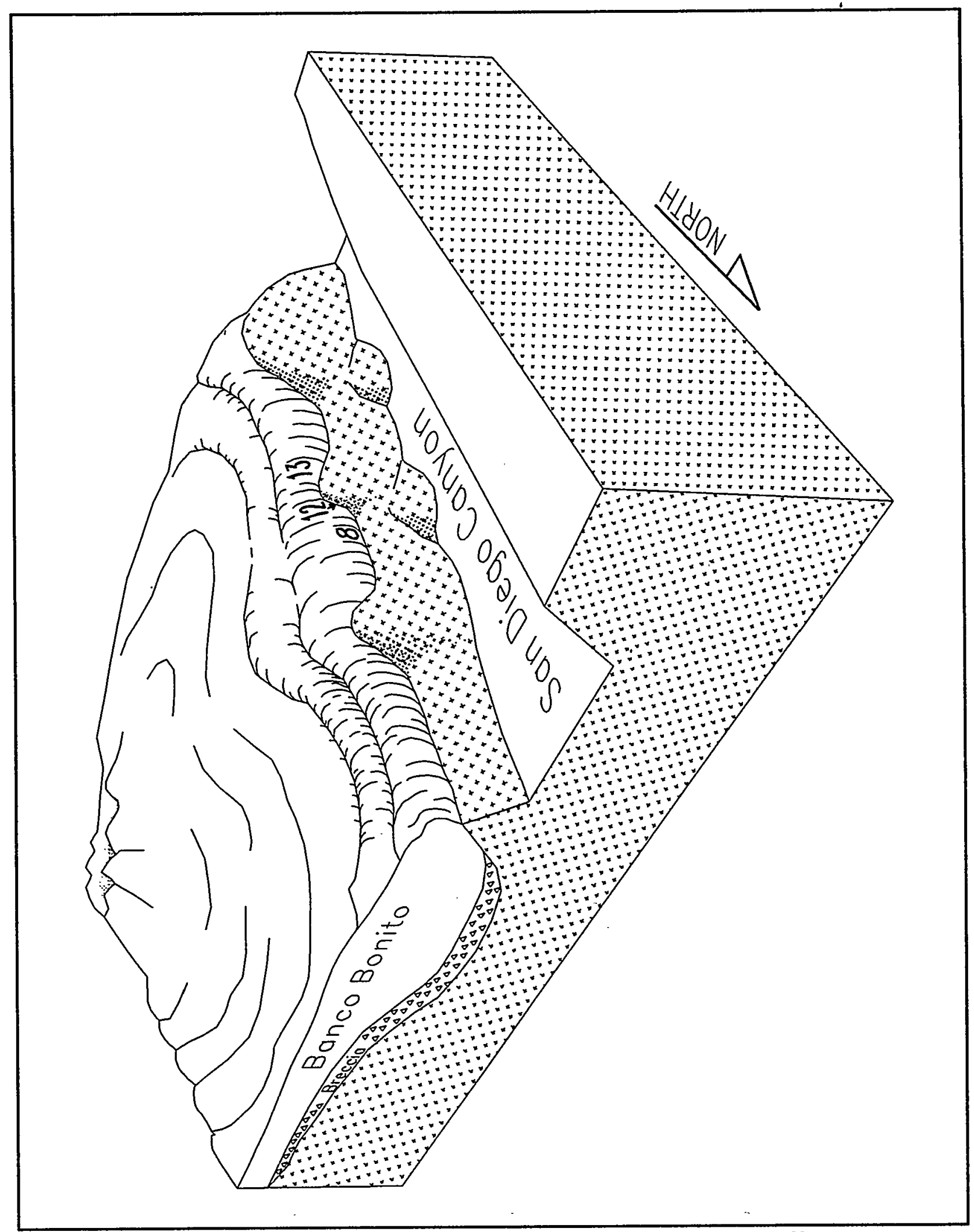

Figure 3.2. Schematic view of sites 8,12 and 13 and the Banco Bonito - tuff contact. 


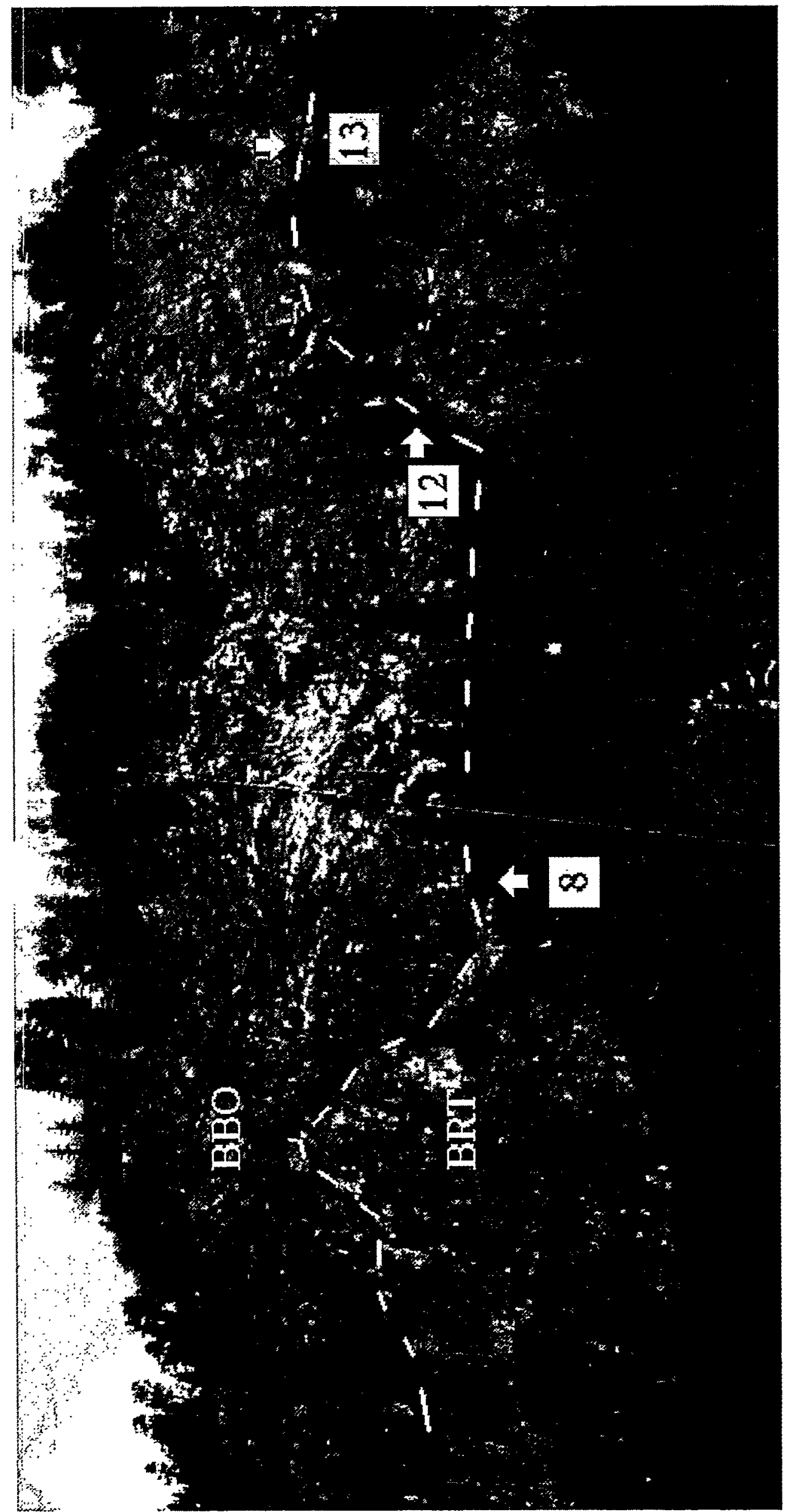

Figure 3.3. View of sites 8,12 and 13; looking east from NM route 4 in San Diego Canyon. 


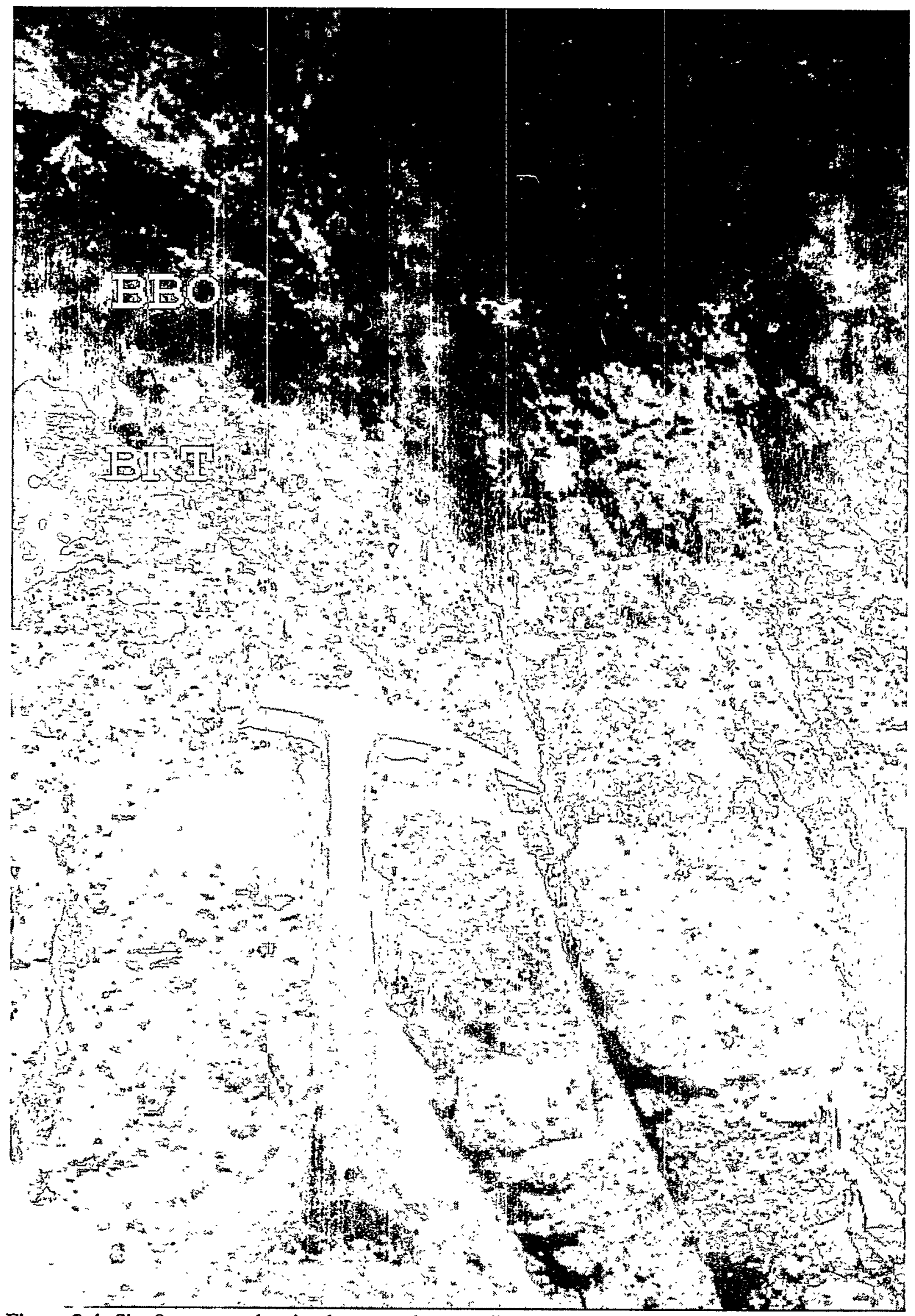

Figure 3.4. Site 8 contact, showing large cracks extending across BBO-BRT contact. 


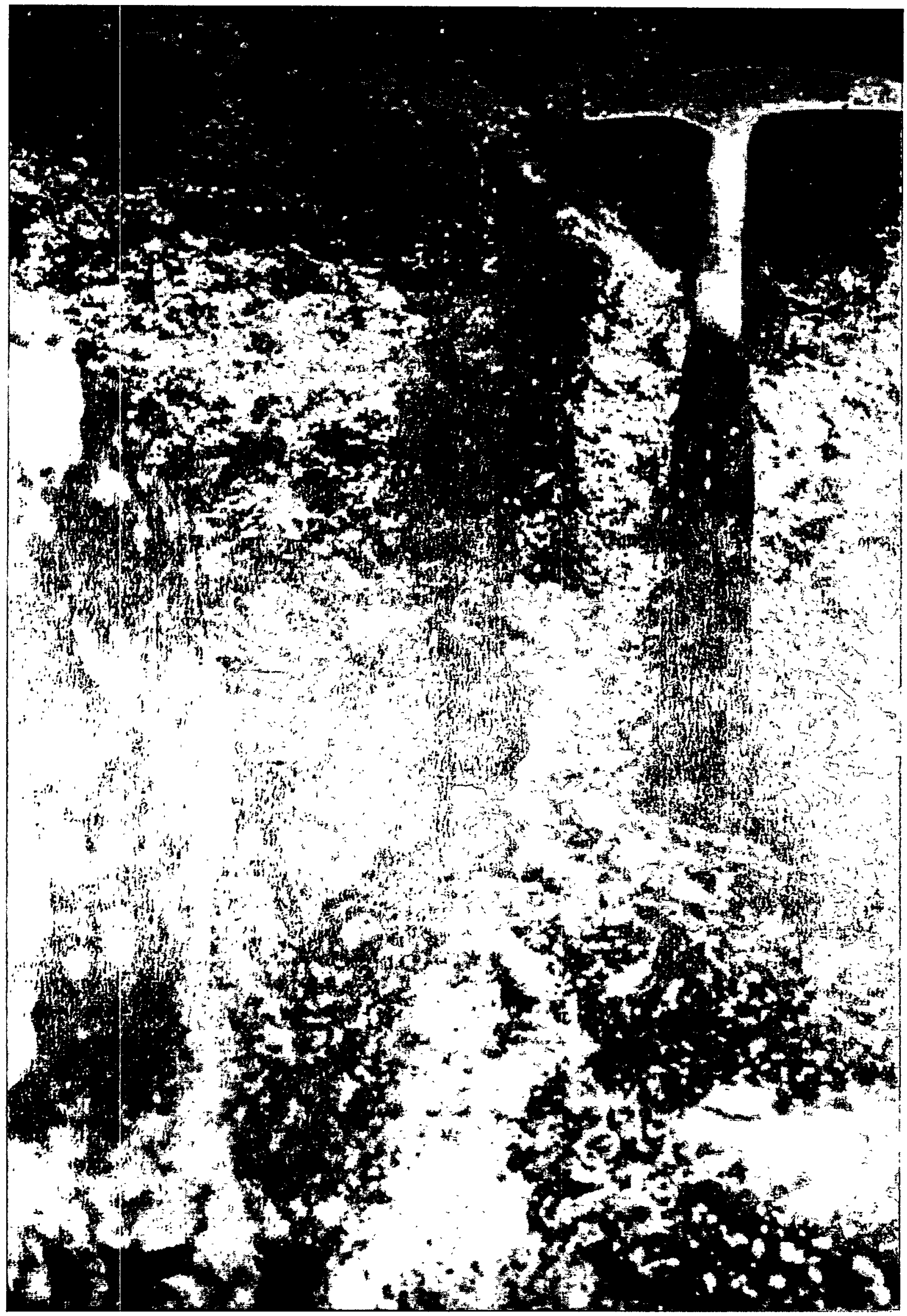

Figure 3.5. Site 8 contact, showing stringer of obsidian intruded into tuff. 


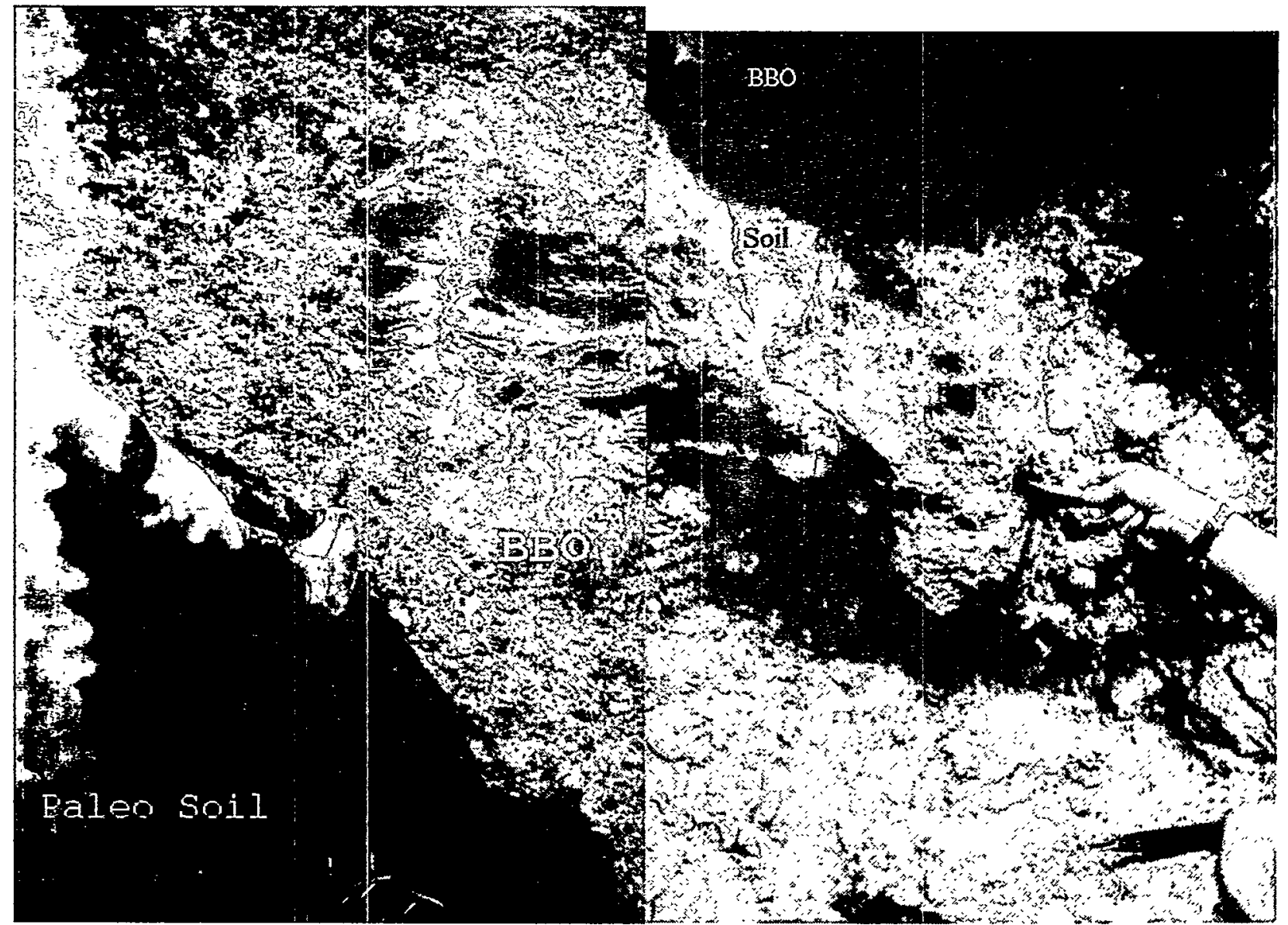

Figure 3.6a. Site 9. Overhanging, devitrified Banco Bonito (BBO) with lithophysae.

Figure 3.6b. Site 9. Baked soil adhering to underside of BBO. 


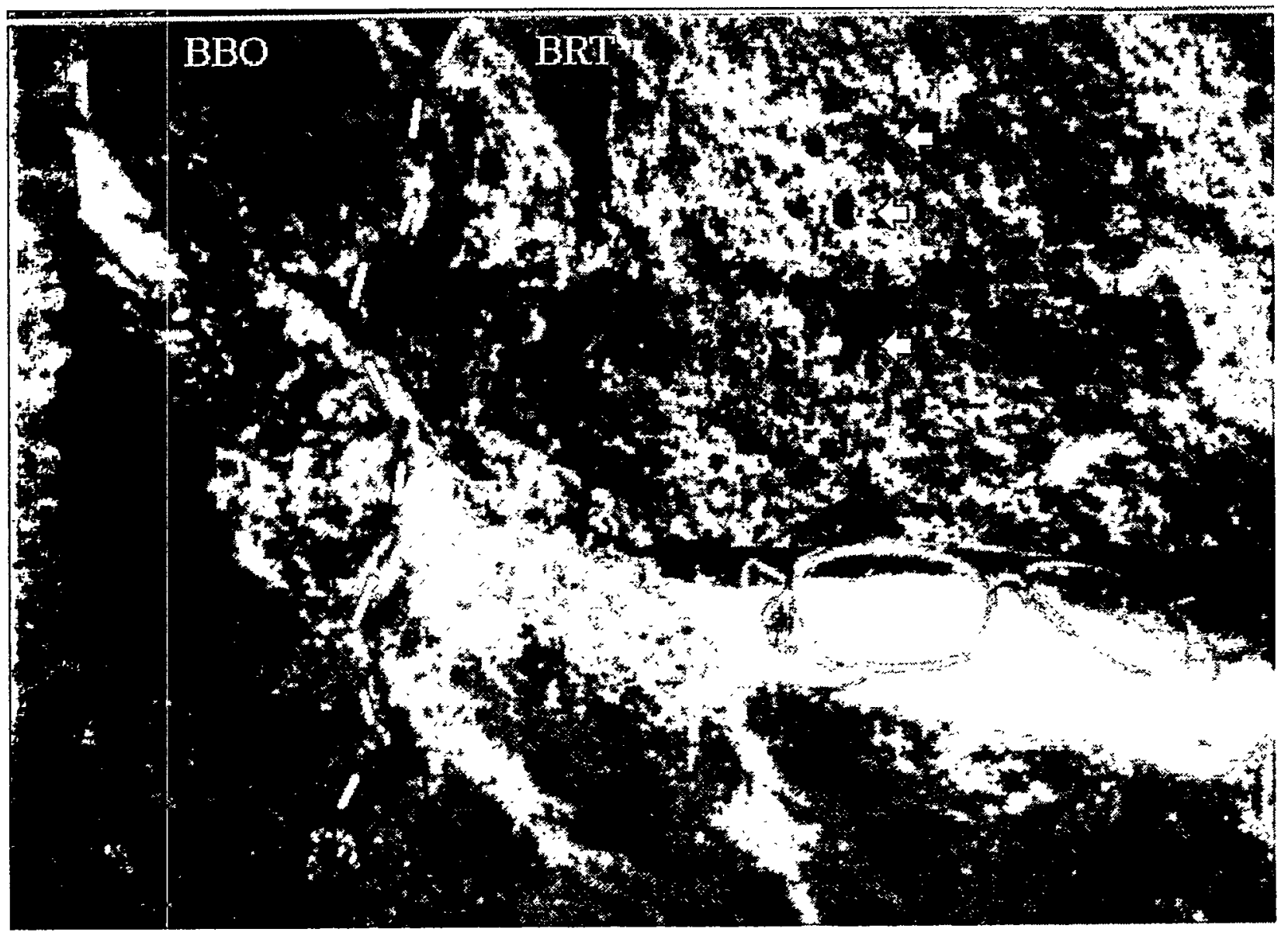

Figure 3.7. Site 12 contact. Arrows point to vertically-oriented obsidian clasts in BRT. 
Site 9 (figure 3.6) is typical of much of the exposed BBO-BRT contact in San Diego Canyon. The contact seems to be nearly horizontal, and there is a breccia zone and baked paleosoil below the contact. Portions of the paleosoil appear to be exotic and highly altered; in particular, there is a maroon-colored cobble layer with a dark green effluorescent alteration. The maroon cobbles appear to be older, crystalline silicic volcanics, and now consist primarily of mm-sized plagioclase and quartz grains. The softer portions of the paleosoil have eroded back into the canyon wall, leaving a shelf above the baked tuff. The $\mathrm{BBO}$ is lithophysal and highly altered and devitrified above the contact. There is reasonably good exposure of the BRT on a cliff below the contact, but the presence of the paleosoil caused us to reject this site for chemical analysis.

Site 10 is a vertical contact between a tall spire of BRT and the BBO. The "contact" is actually a gap, nearly a meter wide at the surface. The tuff bordering this air gap is silicified, and was extremely difficult to sample with a sledge hammer. SEM (scanning electron microscopy) analysis of the hardened tuff showed abundant botryoidal silica on the surfaces of the voids (figure 4.25); however, it was difficult to rule out simple supergene alteration as the source of the silica overgrowths. The gap between the BRT and BBO is currently damp and has a distinct odor of animal excrement. The wide air gap and the uncertain origin of the silicification caused us to rule out site 10 for additional chemical analysis.

The contact at site 12 is nearly vertical (figure 3.7), where a "spire" of tuff has been left standing against the obsidian flow. Unlike site 10, there is no air gap between the flow and tuff; the tuff and obsidian are tightly welded together. Near the contact the tuff is denser and less porous than the tuff several meters away, and the obsidian fragments have a slight tendency to have their long axes oriented parallel to the contact, suggesting plastic deformation of the tuff during heating. Several meters out from the contact is a near-vertical gouge zone and fault; samples taken from the far side of the fault are not plotted in section 4 because these samples appear to be texturally and compositionally distinct. The vertical tuff surface could not sustain a soil horizon, so site 12 has a distinct advantage over site 8 . In addition, we expect the original compositional variations in the tuff were greater in the vertical direction than in the horizontal direction, since tuffs tend to be composed of horizontal layers; thus samples taken perpendicular to a vertical contact are less likely to be biased by original compositional variations. Unfortunately, the fault and width of the spire limits the horizontal distance available for sampling the tuff at site 12 to a few meters. Most of the site 12 samples were obtained with the core drill, which requires a secure standing position for safe operation; the latter condition required us to stand on a ledge that dips down from the contact at $\approx 30^{\circ}$, so the line of core samples also dips at $\approx 30^{\circ}$.

At site 13 (figure 3.8), the intersection of the cliff face and contact appears to be horizontal; however, the actual contact probably dips into the cliff face at an angle exceeding $30^{\circ}$ from the horizontal. The actual contact is not exposed; there is a rubble- and dirt-covered bench, roughly $1 \mathrm{~m}$ wide, separating the top of the BRT cliff and the bottom of the BBO cliff. We dug $\approx 0.5$ meter into the bench without finding the true contact. The advantage of site 13 is 


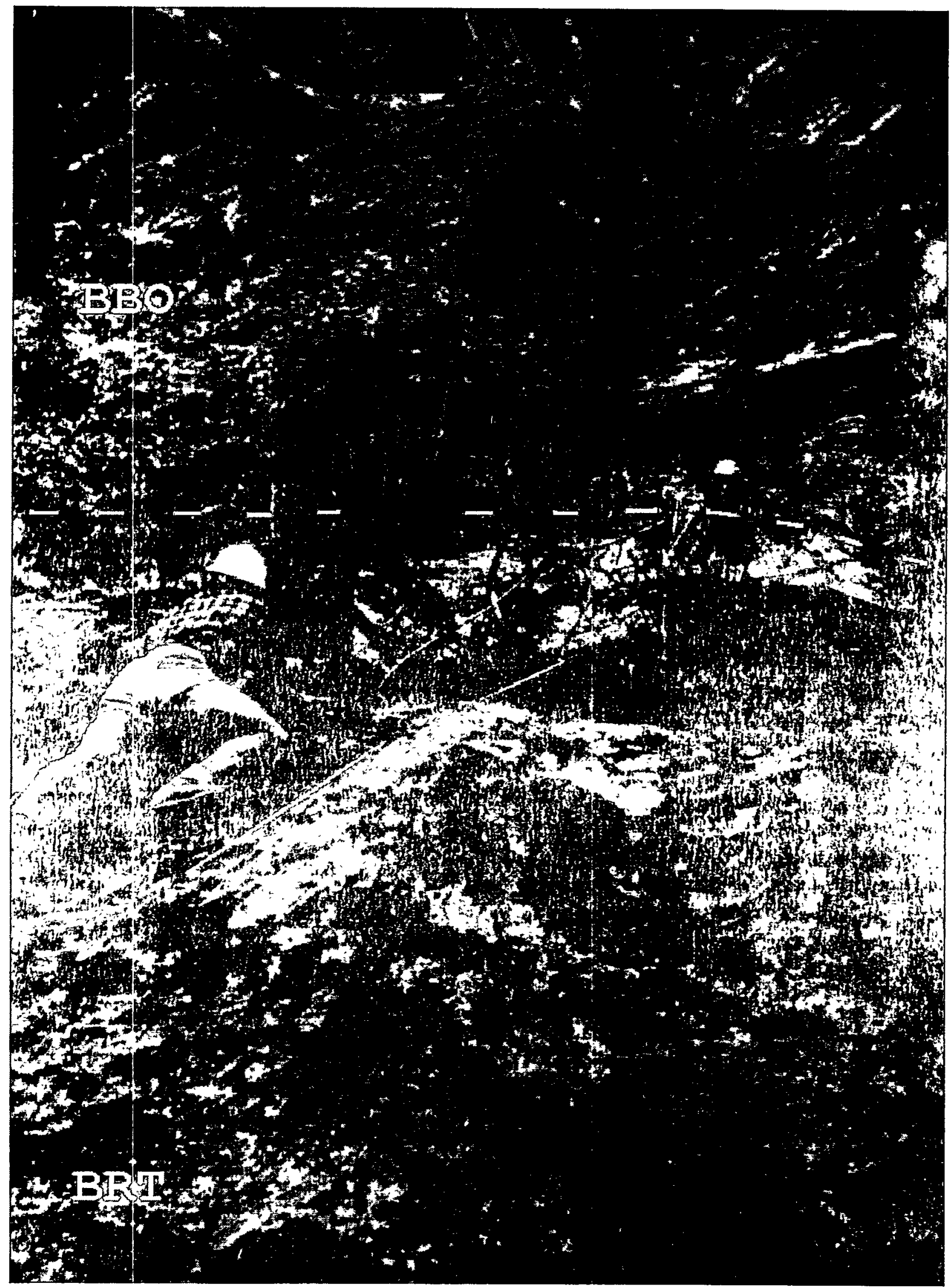

Figure 3.8. Site 13. Belayee is on the BRT (tuff) cliff face. Belayer is sitting on shelf between BRT and $\mathrm{BBO}$ (head of belayer is visible to right, just above contact). 


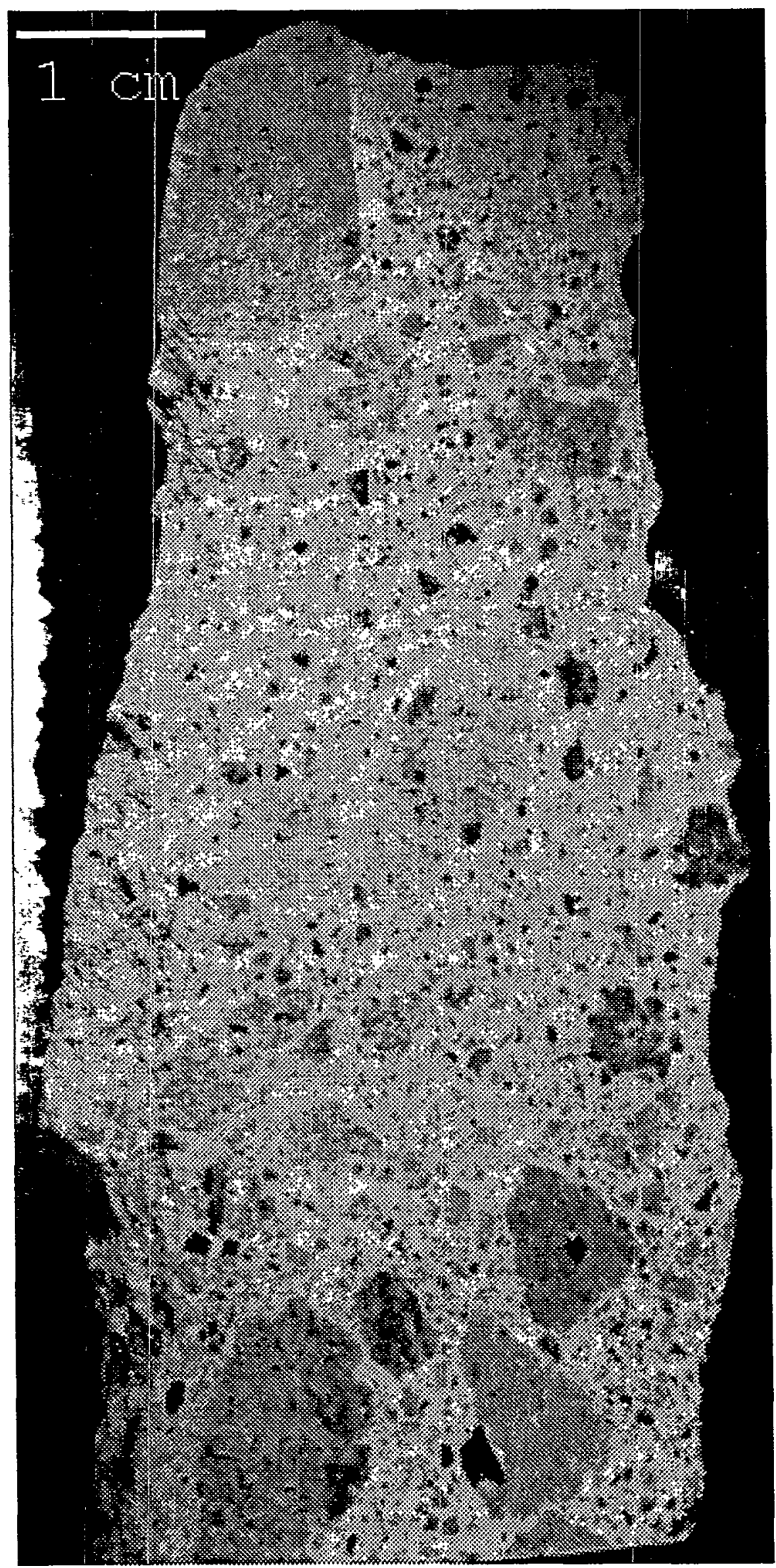

Figure 3.9. Pumiceous BRT from site 13. Light gray is ash matrix; dark gray clasts are pumice; darkest gray-black are fragments of obsidian. 
the extent of the tuff exposure $(\approx 30 \mathrm{~m})$ below the contact, allowing us to search for far-field effects of heating. The disadvantages are that we cannot sample to less than a meter from the contact, and we are not certain of the true dip of the contact. In addition, there is a discontinuous welded zone $11.5 \mathrm{~m}$ below the contact, which may represent an inherent change in lithology and the baseline (pre-heating) composition of the tuff. Most of the site 13 tuffs are low density $\left(\approx 1.4 \mathrm{~g} / \mathrm{cm}^{3}\right)$, consisting of pumice clasts in a matrix of fine pumiceous ash (figure 3.9); compared to sites 8 and 12, there are fewer obsidian clasts. 


\section{CHEMICAL ANALYSIS OF SAMPLES}

This section summarizes the methods used in chemical analysis, and summarizes the results in graphical form. Tables of analytical results are given in the appendix. The primary methods for analysis were INAA (instrumental neutron activation analysis) for trace elements in bulk samples; XRF (X-ray fluorescence) for major elements, S and Cl; XRD (X-ray diffraction) for determination of mineralogy; and SEM (scanning electron microscopy) and EMP (electron microprobe) for microscopic analyses of minerals and glass. D/H and ${ }^{39} \mathrm{Ar} /{ }^{40} \mathrm{Ar}$ analyses were also performed to constrain the degree of interaction with meteoric waters and the emplacement age of the BBO. The text is organized by analytical method; however, figures 4.2 through 4.17 are organized primarily by site, to allow quick comparisons of analyses obtained by many different methods and at different sites.

\subsection{Leaching Studies}

4.1.1 Purpose. We wish to infer if volatile components, such as $\mathrm{Cl}, \mathrm{F}$, and $\mathrm{S}$, were mobilized by the heating event. However, porous rock samples are often superficially contaminated with these species as a result of low-temperature processes. Rain contains small amounts of $\mathrm{Cl}$ (typically about $0.8 \mathrm{ppm}$ ), and decay of organic material introduces $\mathrm{NO}_{3}{ }^{-}$and $\mathrm{SO}_{4}{ }^{2}$ into soils and rock surface; the saturation of a surface with rain and the subsequent drying, repeated over hundreds of years, can cause anion concentrations to build (Kossovich, 1967; Stewart, 1970). Sites 8, 12 and 13 are all within a raptor roosting area, and the abundant bird droppings in some areas undoubtedly add to the anionic contamination. These contaminants are highly leachable; in dry samples they occur on mineral surfaces as salt precipitates. Routine analyses of the washes from BRT samples showed unusually high concentrations of leachable anions; up to $5000 \mathrm{ppm}$ for $\mathrm{Cl}$ in some samples, but more typically $1000 \mathrm{ppm} \mathrm{Cl}$, and 500 to $600 \mathrm{ppm} \mathrm{SO}_{4}{ }^{2}$ and $\mathrm{NO}_{3}{ }^{-}$(figure 4.1). From our previous studies of partially devitrified volcanic glasses (e.g. Westrich $e t$ al., 1988) we expected native glass contents of $200 \mathrm{ppm} \mathrm{Cl}, 50 \mathrm{ppm}$ sulfur, and $0 \mathrm{ppm}$ nitrate. Thus the soluble content represented a very significant contaminant. SEM studies of BRT samples showed discrete $\mathrm{Na}_{2} \mathrm{SO}_{4}$ crystals in the pores of one sample, confirming the superficial nature of the contamination. Therefore it was necessary to develop a means to remove this superficial component without altering the underlying composition of the rock.

4.1.2 Methods. We tested two methods to assess and overcome the contamination problem. First, for outcrop samples obtained via hammer and chisel, we crushed tuff samples to $\leq$ $0.5 \mathrm{~cm}$ diameter fragments, soaked the samples in deionized water (water/rock $\approx 5$ ), then decanted and analyzed the supernate. This process was repeated several times, yielding a curve of solution contaminant concentration $v$ s. leach step. Second, we used a portable, water-cooled, diamiond core drill ( $c . f$. section 3.2), with a 1" diameter, 12" barrel to drill into the outcrop, then analyzed sections of the core for leachable anions, as a function of penetration distance. Analyses for $\mathrm{Cl}^{-}, \mathrm{F}^{-}, \mathrm{SO}_{4}{ }^{2}$ and $\mathrm{NO}_{3}{ }^{-}$were performed with a Dionex $2000 \mathrm{i}$ ion chromatograph; no $\mathrm{F}^{-}$was detected in any of the leachates. On the $\mathrm{Cl}$-rich samples, chloride was also analyzed with by chloridometer; agreement with the ion chromatograph was excellent. 


\section{Site 8 Soluble Anions}

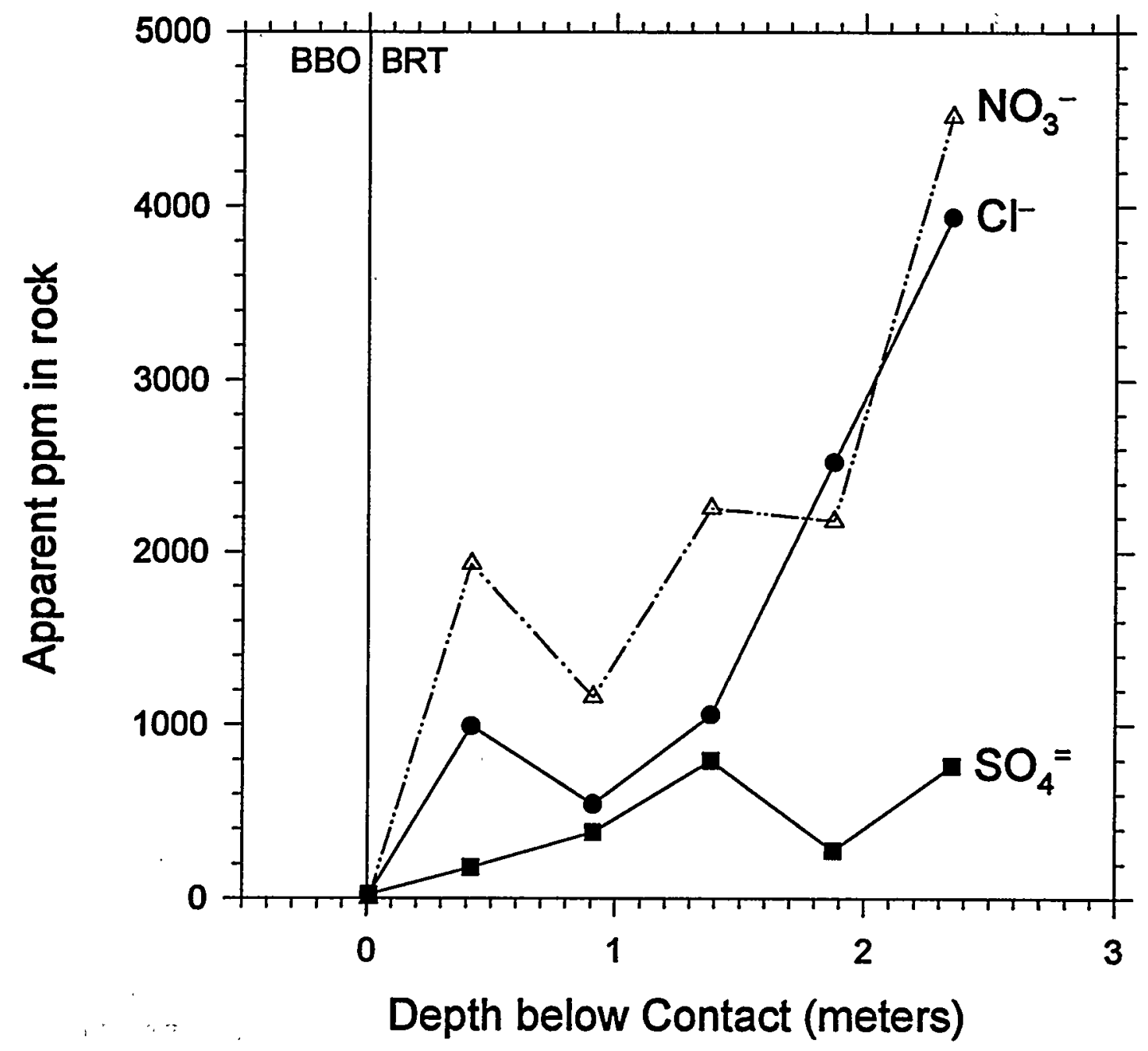

Figure 4.1. Superficial anionic contamination in tuff samples at site 8. The apparent $\mathrm{Cl}$ contents of unwashed samples are $\approx 20$ times the native $\mathrm{Cl}$ contents of the volcanic glass. 
4.1.3 Results. Leaching studies showed that a simple two-step process could remove the bulk of the $\mathrm{Cl}, \mathrm{NO}_{3}{ }^{-}$and $\mathrm{SO}_{4}{ }^{2}$ contamination; two rinses removed more than $99 \%$ of the soluble ions.

The core samples obtained by the second method showed no signs of superficial contamination whatsoever -- the leachates had very low concentrations of anionic contaminants, regardless of depth into the outcrop. This result is not surprising, since it takes at least a liter of cooling water, constantly washing over the core barrel and sample, to obtain a core.

We concluded that coring was not necessary to obtain contamination-free samples. We continued to use the core drill when practical, but when it was necessary to collect samples en belay, or to collect large samples, we used a sledge hammer and chisel and washed the samples thoroughly with DI water.

One potential problem with the washing procedure is the removal of gypsum and other sulfates that might have formed during the heating event; since the tuff was likely unsaturated during heating, oxidation of sulfide to sulfate was likely. Our experience in analyzing desert soils shows that fine-grained gypsum coatings are easily removed by washing with DI water. However, we have never seen gypsum in the microscopic analysis of the samples, and if significant remobilization of sulfur occurred, we would expect to detect a lowering of the glass sulfur content.

\subsection{Instrumental Neutron Activation Analysis (INAA)}

4.2.1 Purpose. Instrumental neutron activation analysis (INAA) is used to determine $\mathrm{Na}, \mathrm{Fe}$, and a variety of trace elements (U, Th, Cs, Rb, Ba, Sc, Co, Ta, Hf, La, Ce, Nd, Sm, Eu, $\mathrm{Tb}, \mathrm{Yb}$ and $\mathrm{Lu}$ ) in bulk samples of rocks, rock clasts and matrix, and mineral separates. Some of the elements in the samples are natural, non-radioactive isotopes that are direct counterparts to radioactive isotopes in spent fuel and other wastes $\left(e . g .{ }^{133} \mathrm{Cs}\right.$ for $\left.{ }^{137} \mathrm{Cs}\right)$, while others are identical to isotopes in spent fuel $\left({ }^{238} \mathrm{U}\right.$ and $\left.{ }^{232} \mathrm{Th}\right)$. Some elements in the tuff have chemical behavior that is roughly analogous to important waste isotopes; e.g., Ce, $\mathrm{U}$ and $\mathrm{Th}$ behave much like Pu under a wide variety of conditions. Thus the behavior and mobility of the naturally-occurring elements in the tuffs, in response to the heating event, bounds the potential mobility of these elements in a repository.

Some elements are useful as indicators of hydrothermal alteration or low-temperature leaching. In the absence of zeolites, both $\mathrm{Cs}$ and $\mathrm{Rb}$ are readily leached from rhyolitic volcanic glasses, and concentrate in the aqueous phase at temperatures below $300^{\circ} \mathrm{C}$ (Ellis and Mahon, 1967; 1977). If zeolites such as analcime or clinoptilolite form, the situation reverses for $\mathrm{Cs}$, but not $\mathrm{Rb}$; the rock may become greatly enriched in Cs relative to the aqueous phase (Keith et al., 1983). On the other hand, illite formation can enrich the rock in $\mathbf{R b}$ (Goguel, 1982). Thus the $\mathrm{Rb} / \mathrm{Cs}$ is a potentially sensitive indicator of zeolite and clay alteration. When rhyolite glass alters to form montmorillonite, $\mathrm{Cs}, \mathrm{Rb}$ and $\mathrm{U}$ concentrations in the rock can be reduced by a factor of ten (Zielinski, 1982). 
Other elements measured by INAA serve the opposite purpose; they are good indicators of magmatic differentiation, yet are fairly immobile in most hydrothermal processes, and can help us determine if the variations in the abundances of other elements are "original" (i.e. due to processes that occurred before the heating event). For example, Ta can vary by a factor of 2 or more in a sequence of silicic magmas from a single source, apparently in response to a magmatic differentiation process (Hildreth, 1981); yet Ta is relatively immobile during low temperature processes. Zielinski (1982) showed that the concentrations of Ta, Th, Hf and most rare earths remain unchanged as rhyolite altered, while the concentration of Co sometimes increased several fold. By measuring the variation in these elements in samples far from the contact, we can establish a baseline for sample heterogeneity.

Apart from the heterogeneity that results from magmatic differentiation, there is also a heterogeneity imposed on tuffs by the acquisition of xenoliths. From petrographic examination, we know that the BRT and VC1T contain fragments of older rhyolites, mafic rocks, and sediments. It is reasonable to expect that the matrix of these rocks, which is composed of fine-grained 'volcanic ash, would be relatively uniform in composition, while the clasts would vary wildly and randomly. Since the matrix is porous and fine-grained, it would sustain most of the alteration in a hydrothermal event, but random variations in the clasts could obscure any systematic trends in composition due to this alteration if the samples were simply ground up and analyzed in bulk. It is therefore important to separate the clasts and matrix, at some distance from the contact, and analyze both to determine the effect of variations in clast composition. If the compositions of matrix and clasts are very different, then the matrix alone should be separated and analyzed for all samples; if the compositions are similar, the whole rock analyses may be taken as representative, saving a great deal of labor.

4.2.2 Methods. Samples massing from 50 to 200 grams were crushed to $\approx 0.1$ to $0.5 \mathrm{~cm}$ pieces with a steel percussion mortar, then leached in deionized water to remove superficial contamination (section 4.1). Some samples (mostly from site 8) were then separated into clasts and fine-grained matrix by hand-picking. The crushed samples were dried at $90-100^{\circ} \mathrm{C}$ and then ground in for 4 minutes in an alumina SPEX shatterbox dish, yielding and average particle size $<80$ mesh. Half gram samples of the powder were sealed in polyethylene vials, wrapped with $\mathrm{Fe}$ wire flux monitors, and irradiated in at the Los Alamos Omega West reactor for 14 hours at a flux of $1.5 \cdot 10^{12} \mathrm{n} /\left(\mathrm{cm}^{2} \cdot \mathrm{sec}\right)$. Three synthetic standards were irradiated with each set as a check on precision. After irradiation, the samples were cooled for 4 to 5 days, then counted on coaxial and planar Ge-crystal $\gamma$ spectrometers. Typically, two to three counts were used for each sample; a first count within 4 to 8 days of irradiation to measure relatively short-lived isotopes, such as ${ }^{24} \mathrm{Na}$ and ${ }^{140} \mathrm{La}$, followed by a count after 13 to 18 days of cooling for relatively long-lived isotopes such as ${ }^{233} \mathrm{Th},{ }^{152} \mathrm{Eu}$ and ${ }^{131} \mathrm{Ba}$. The $\gamma$ spectra were reduced with the NAA (not an acronym) program, based on the IFIT algorithm described by Stockman (1989). For most isotopes, the error from counting statistics is $\approx 1 \%$, and the precision of replicate analyses is 1 to $3 \%$. 


\section{Site 8}

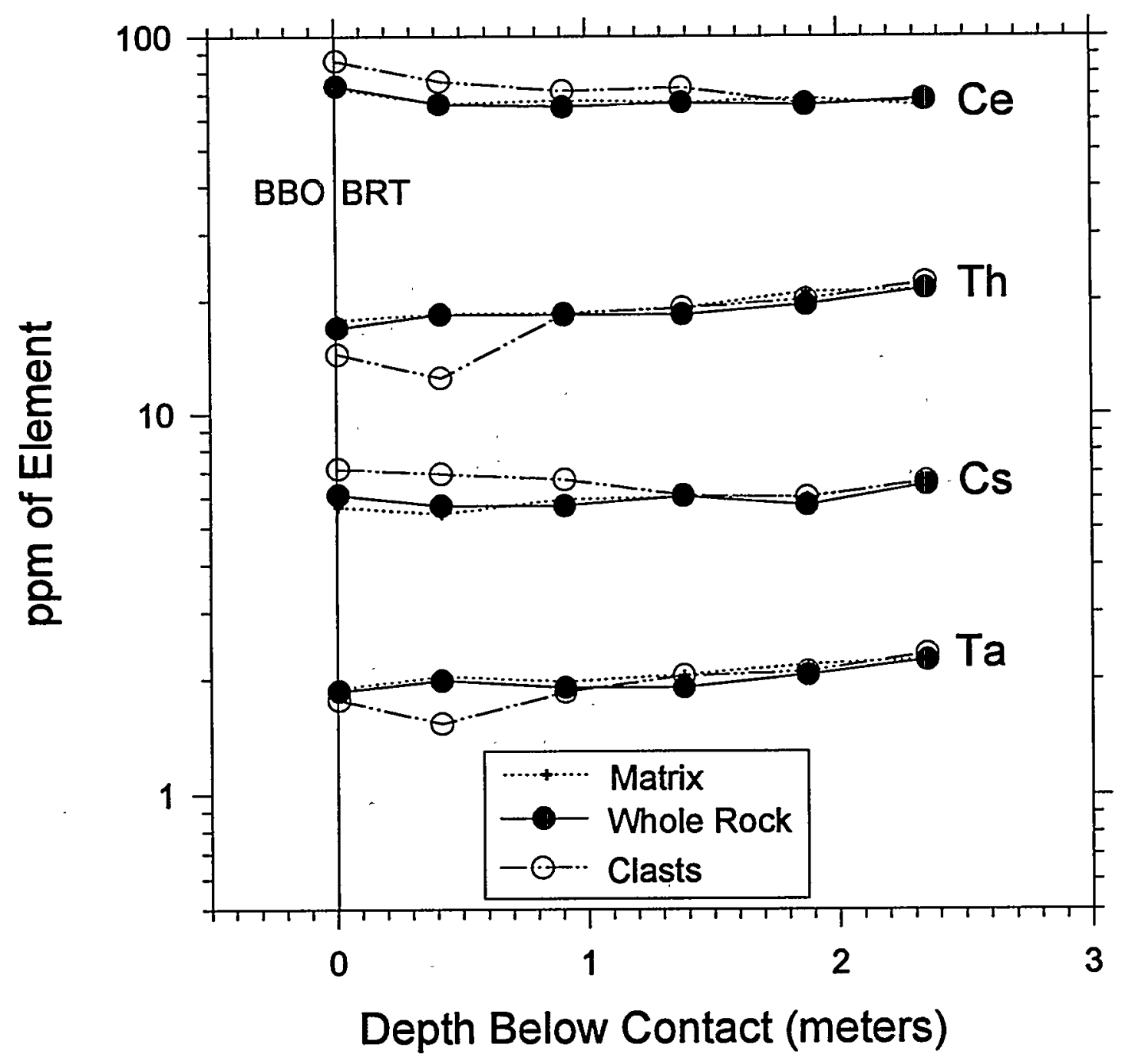

Figure 4.2. Comparison of analyses of tuff matrix, whole rock, and separated clasts. 


\section{Site 8 and VC-1}

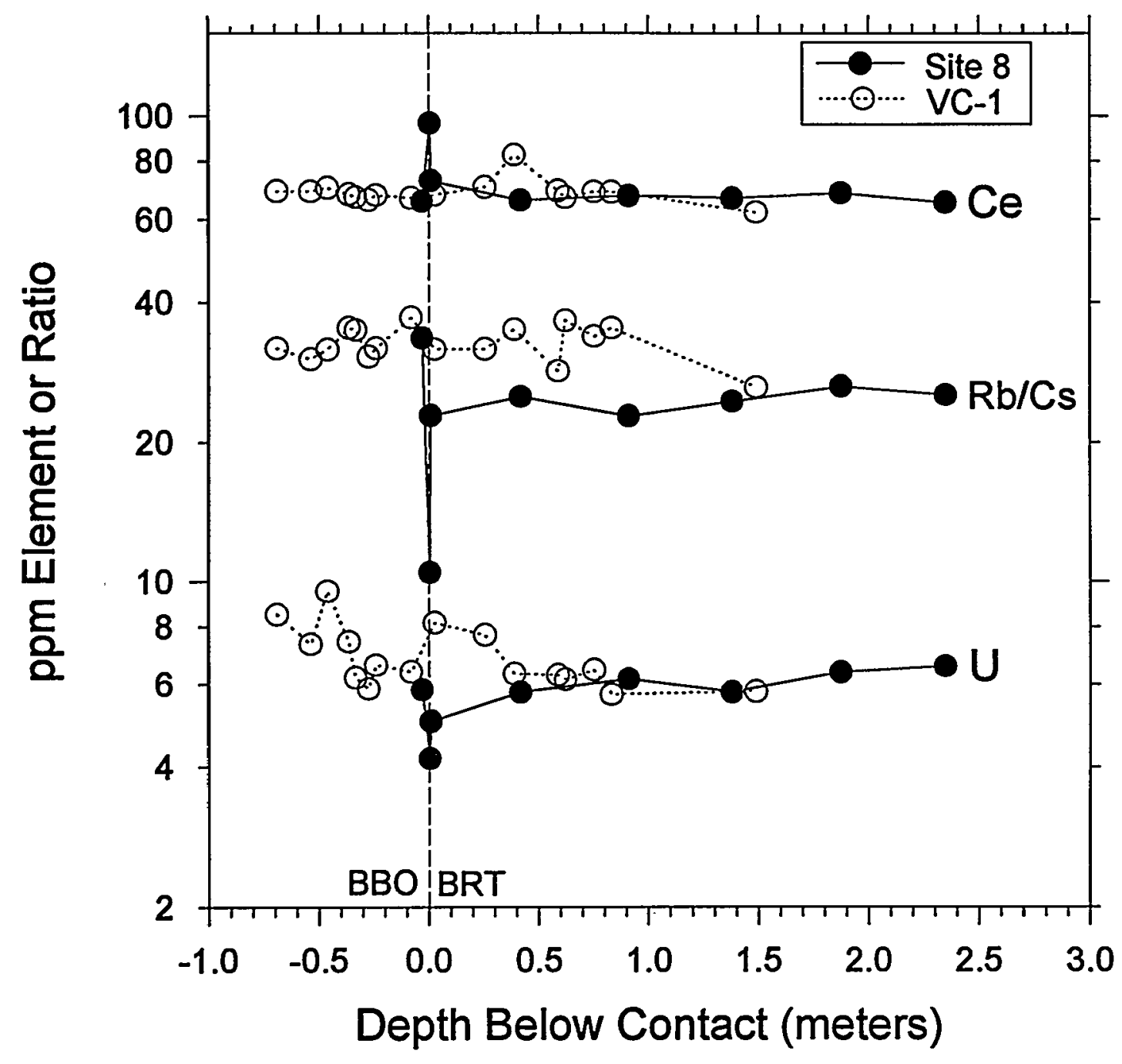

Figure 4.3. Comparison of $\mathrm{Ce}, \mathrm{Rb} / \mathrm{Cs}$ and $\mathrm{U}$ in site 8 (outcrop) and $\mathrm{VC}-1$ (core) samples. 


\section{Site 8 and VC-1}

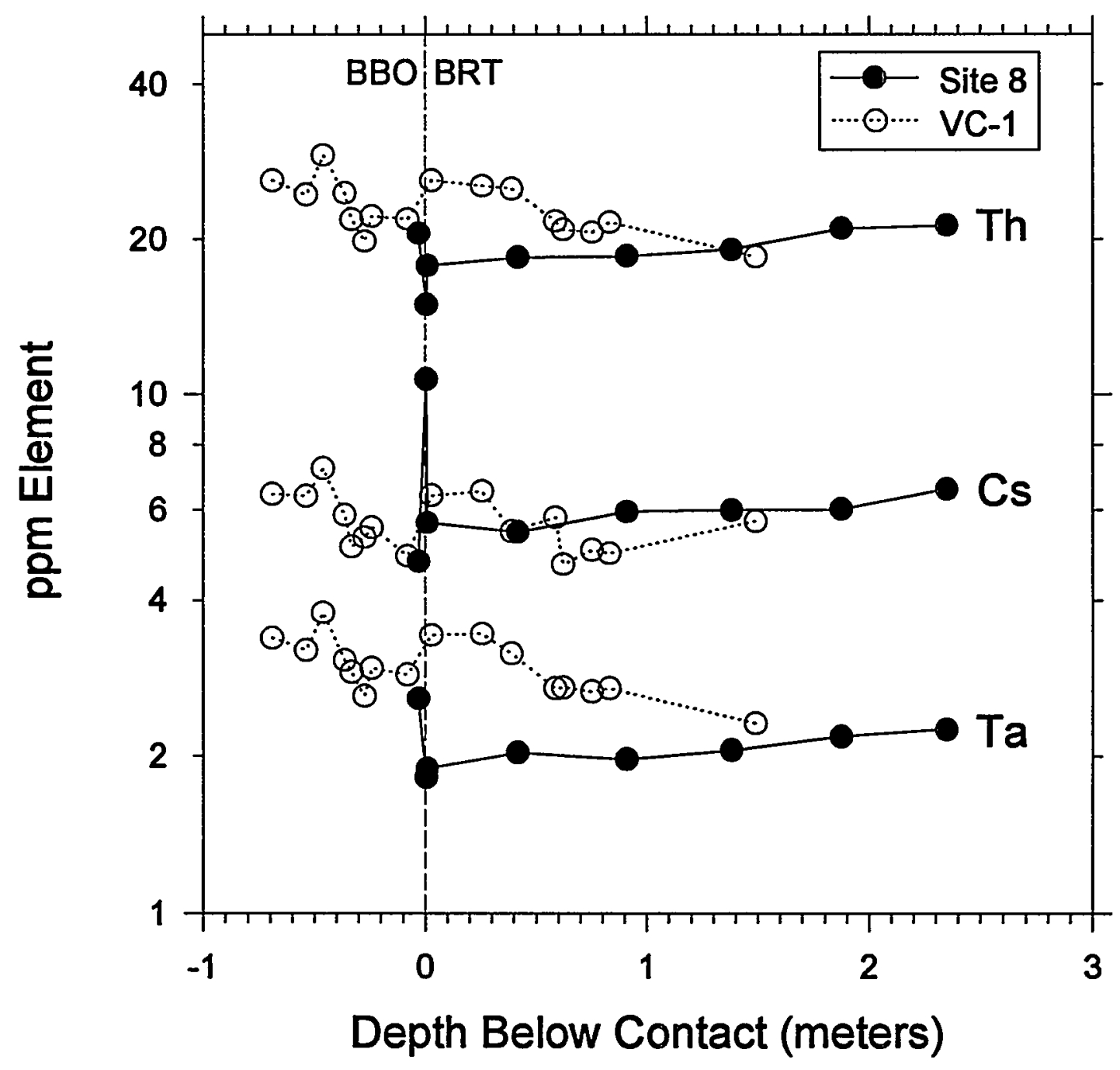

Figure 4.4. Comparison of Th, Cs and Ta in site 8 (outcrop) and VC-1 (core) samples. 


\section{Site 8 and VC-1}

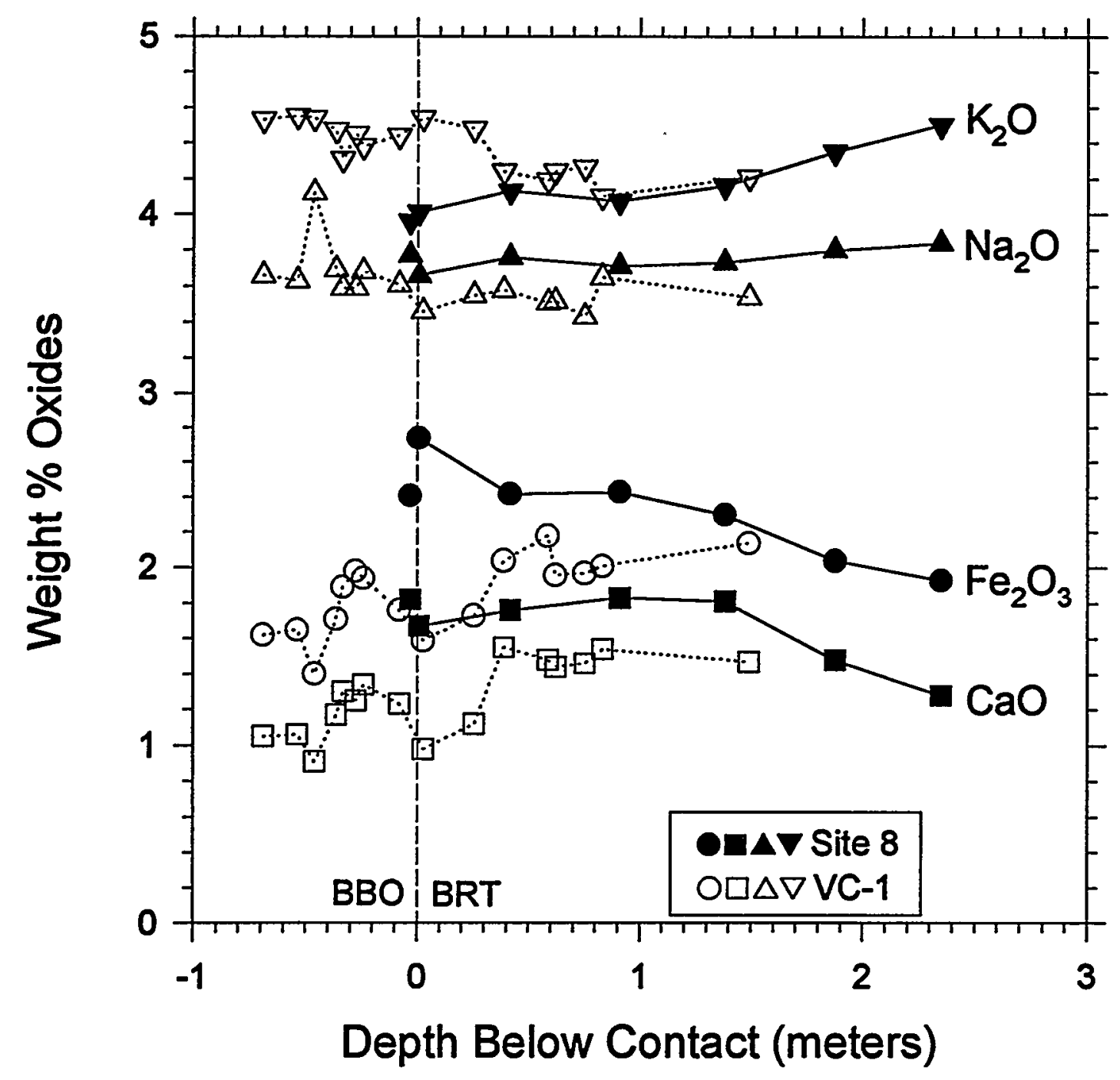

Figure 4.5. Major element oxides in site 8 and VC-1. 


\section{Site 8 Volatiles}

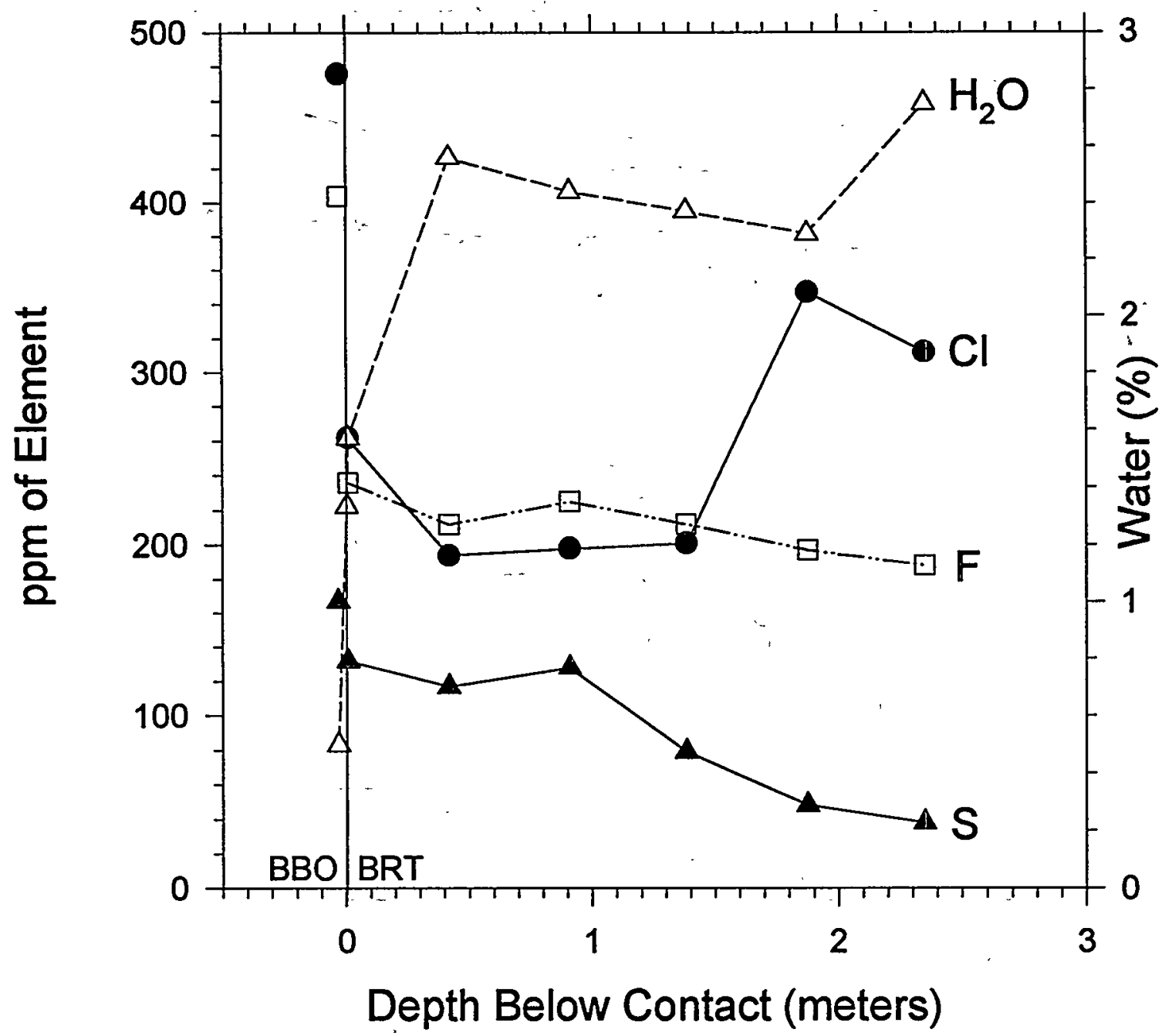

Figure 4.6. Variations in site 8 volatiles near the contact with Banco Bonito obsidian flow. 
4.2.3 Results. Figure 4.2 compares INAA results for selected elements from the bulk rock, clasts and matrix at site 8 . The site 8 matrix analyses do seem more uniform than the whole rock data, but the difference is small, suggesting that the labor of separating out the clasts is probably not warranted for site 8 , where the proportion of clasts is small. There is a slight systematic increase in Th and Ta from the contact to a depth of 2.4 meters, which may reflect an original (pre-heating) compositional change, since these elements are thought to be fairly immobile in the presence of hydrothermal alteration. In the same interval, Cs parallels the Th and Ta variations; thus if there is any hydrothermal remobilization of Cs, it is difficult to distinguish from pre-heating compositional variations. The tuff immediately adjacent to the contact shows a marked compositional change; texturally, this tuff is very different than the underlying unit, and may be a baked soil.

Figures 4.3 through 4.5 compare the chemical variations in the site 8 matrix, $v s$. the VC-1 core. The larger variations in the core analyses support our decision to emphasize the outcrop samples, and probably reflect the presence of an altered basal breccia in the VC-1 core.

Much of the uncertainty at site 8 should be minimized at site 12 , where the vertical contact should eliminate the problem of soil formation and lessen the effect of pre-heating compositional variation ( $c f$ section 3.2). Figures 4.7 and 4.9 compare variations in selected elements as a function of distance from the contacts at sites 8 and 12. Though the scales of the variation are different, a rise in $\mathrm{Ta}$ and $\mathrm{Th}$, with distance from the contact, is observed at both sites in the tuffs immediately adjacent to the contacts. The site 12 results must be interpreted with some caution, however, since the samples were taken with a core drill and there was too little material for separation of matrix from clasts; the plotted site 12 analyses are for whole rock samples. Since the amount of clasts seems to increase with proximity to the site 12 contact, it is possible that some of the chemical variation simply reflects mixing between varied amounts of matrix and obsidian clasts; for example, the clasts analyses in figure 4.2 are poorer in $\mathrm{Ta}$ and $\mathrm{Th}$, so this mechanism might explain the drop in abundances of Th and Ta near the site 12 contact.

With any natural analogue study, there is the question of what constitutes a "significant" chemical variation, or evidence of chemical mobilization; ultimately, this question can be answered only if a particular model for chemical migration is specified, and the natural variations in the rock composition are much less than the predicted variations due to remobilization. Figure 4.8 illustrates the problem by comparing the variation in site $12 \mathrm{Ce}$ abundances with those found by Smellie et al. (1986) for a natural analogue study in Kråkemåla, Sweden. In the latter study, it was concluded that Ce in the Kråkemåla granite samples showed no evidence of mobilization; yet the chemical variations at Kråkemåla appear random, and are approximately 10 times the magnitude of the slight but apparently systematic variations seen at site 12 . Undoubtedly, much of the variation in the Kråkemåla ' study stems from sampling statistics; the granites are composed of coarse crystals of feldspars, quartz, mica and Ce-rich monazites, and the small size of the core samples ensures that there will be substantial variations in the proportions of each mineral included in a particular analysis. 


\section{Site 12 and Site 8}

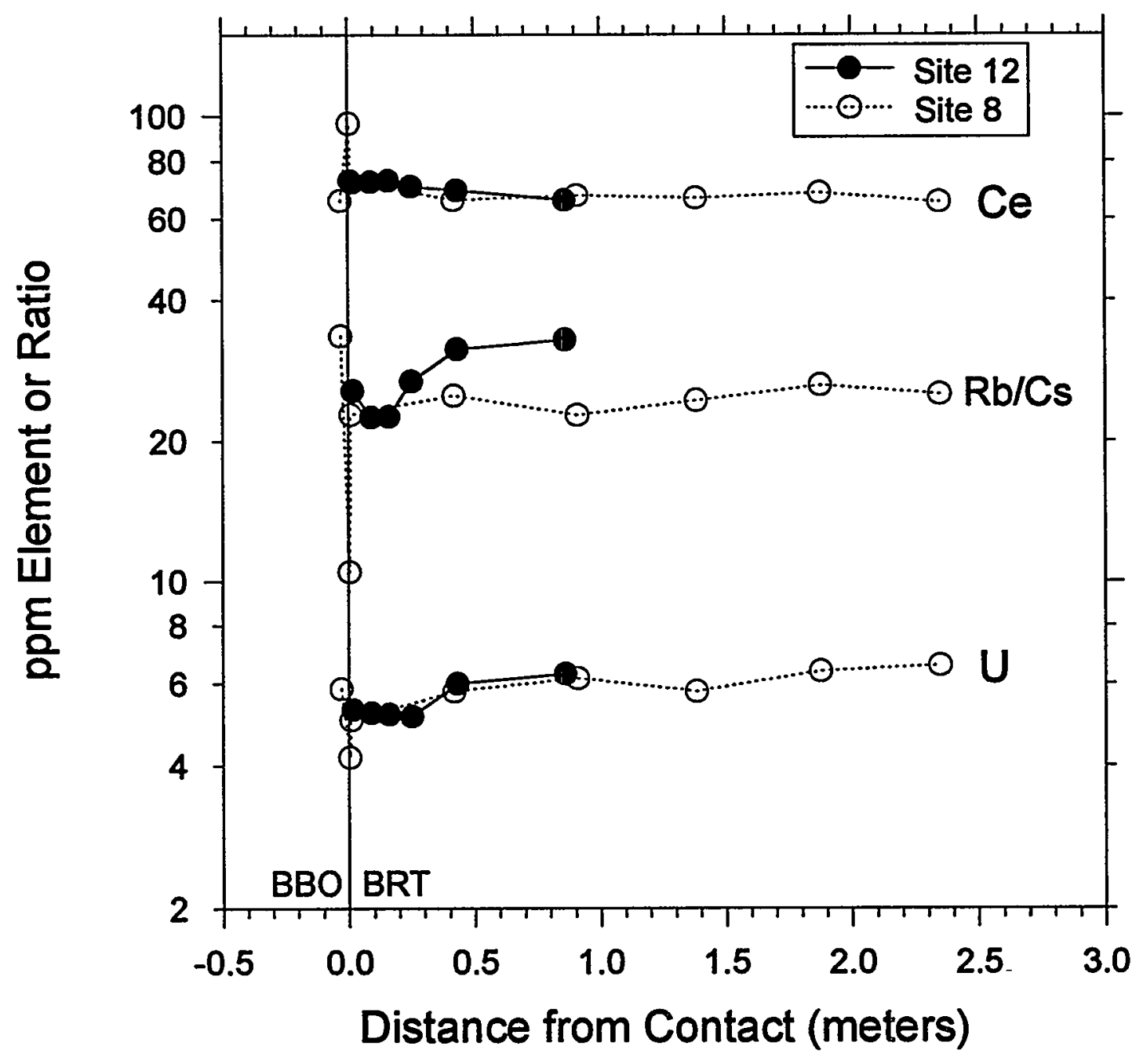

Figure 4.7. Comparison of $\mathrm{Ce}, \mathrm{Rb} / \mathrm{Cs}$ and $\mathrm{U}$ at sites 8 ("horizontal" contact) and site 12 (vertical contact). 


\section{Site 12 and Kråkemåla}

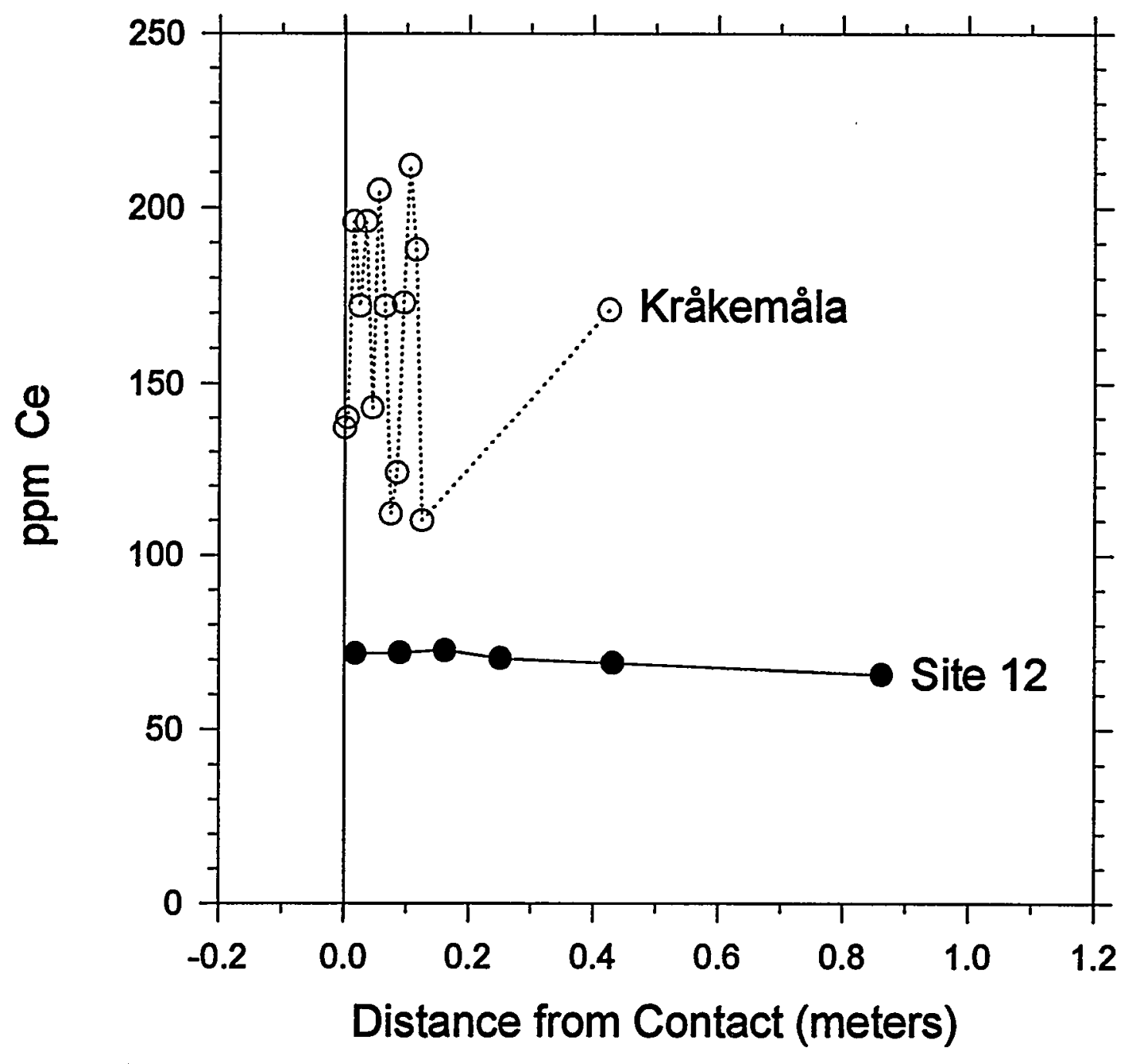

Figure 4.8. Comparison of Ce variations at site 12 with variations observed in margins of a crack at an analogue site in Kråkemåla, Sweden. 
Site 12 and Site 8

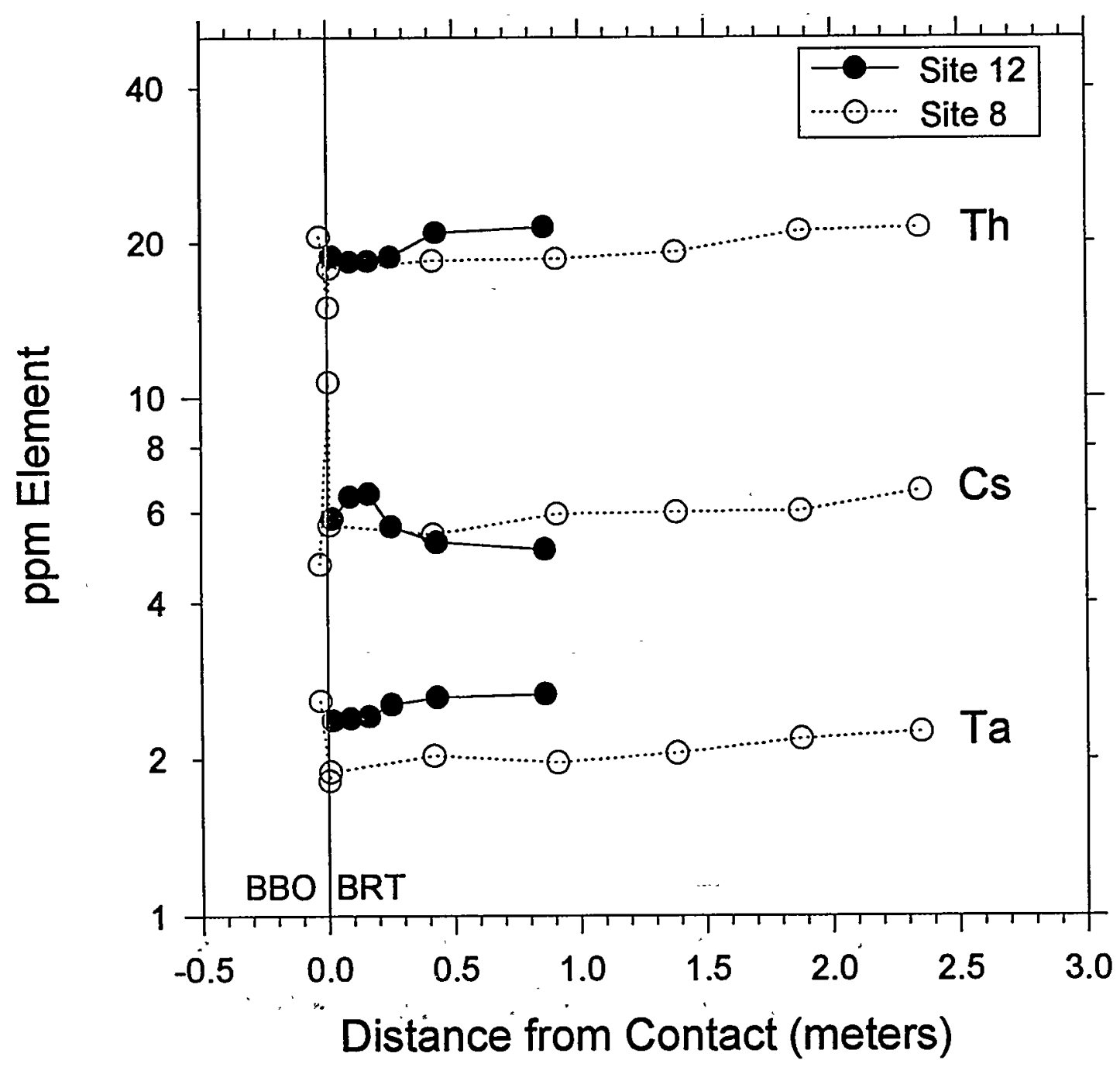

Figure 4.9. Th, Cs and Ta variations compared for sites 8 and 12 . 


\section{Site 12 and Site 8}

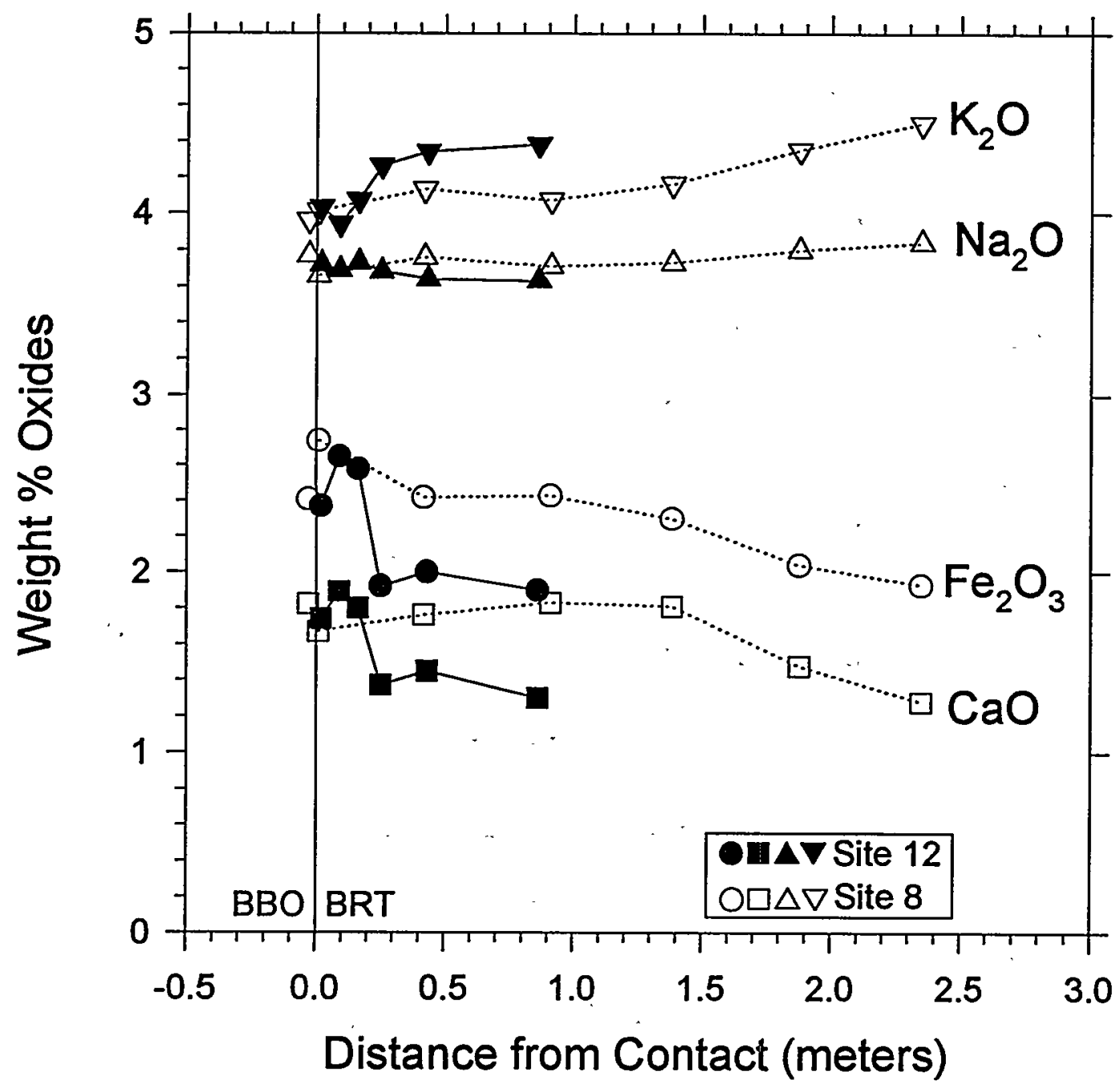

Figure 4.10. Major element oxide variations near contact at sites 12 and 8 . 


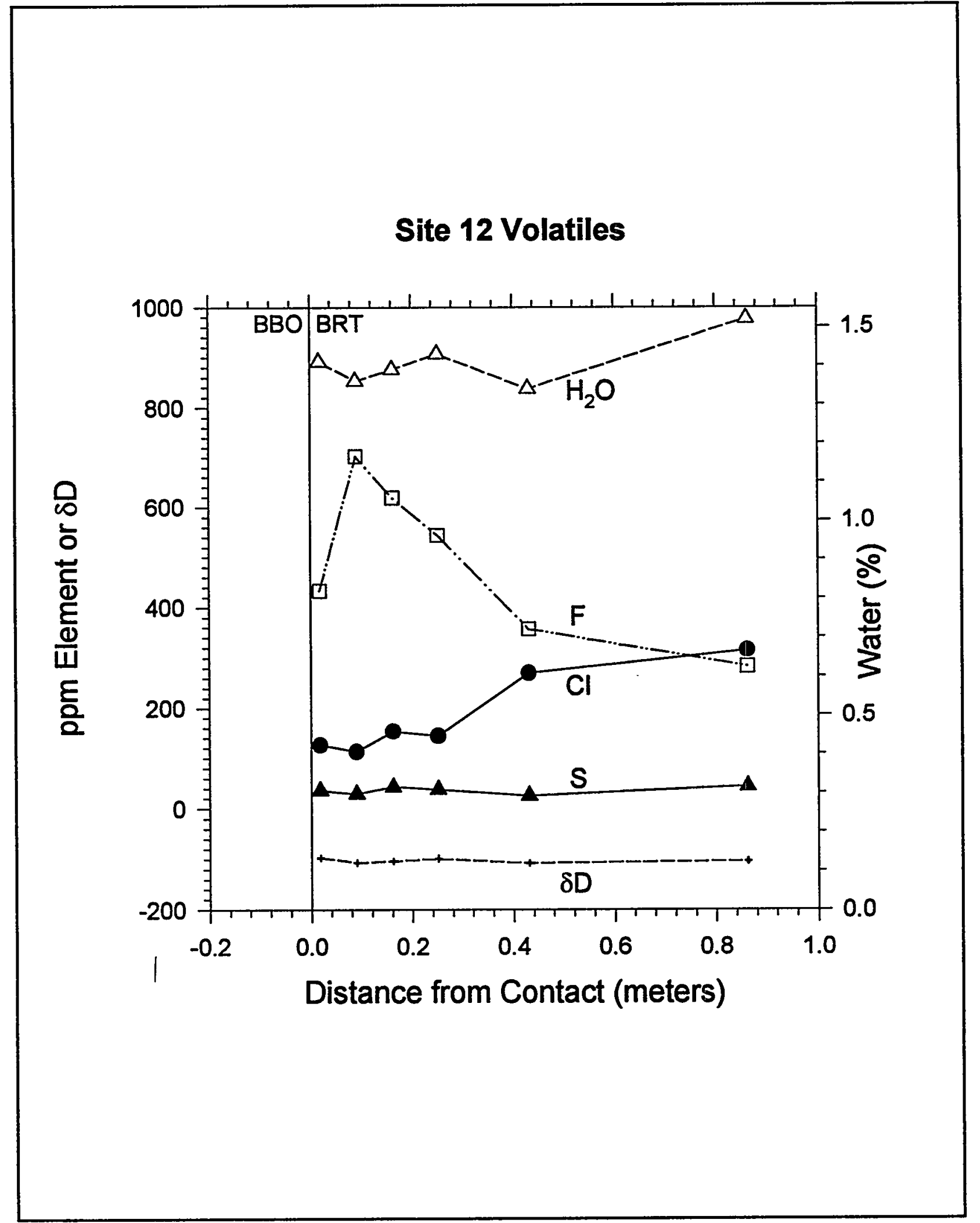

Figure 4.11. Variations in volatile contents and $\delta \mathrm{D}$ near vertical contact at site 12. 


\section{Site 13 and Site 12}

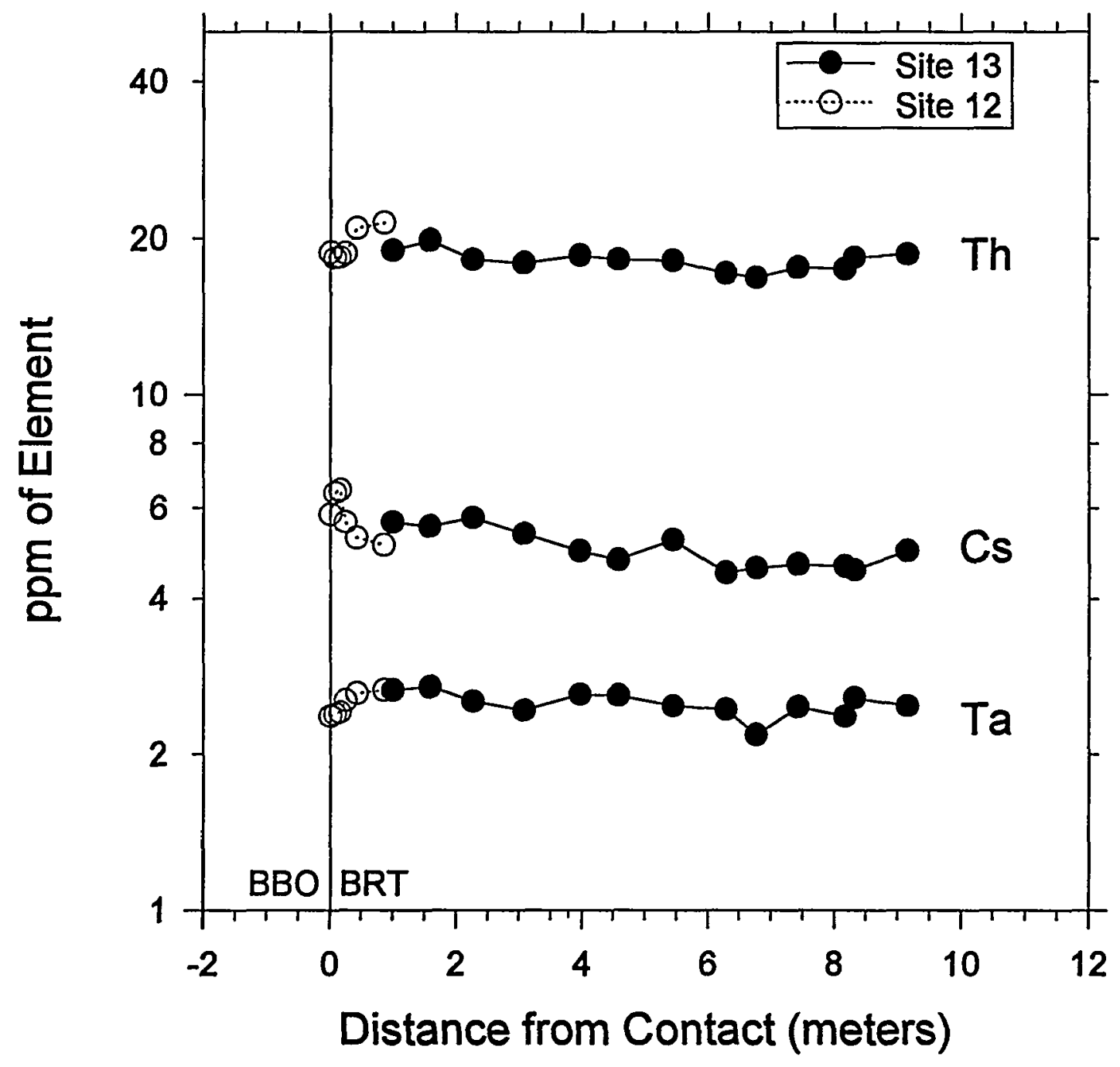

Figure 4.12. Comparison of $\mathrm{Th}, \mathrm{Cs}$ and $\mathrm{Ta}$ variations at sites 13 and 12 (log scale). 


\section{Site 13 and Site 12}

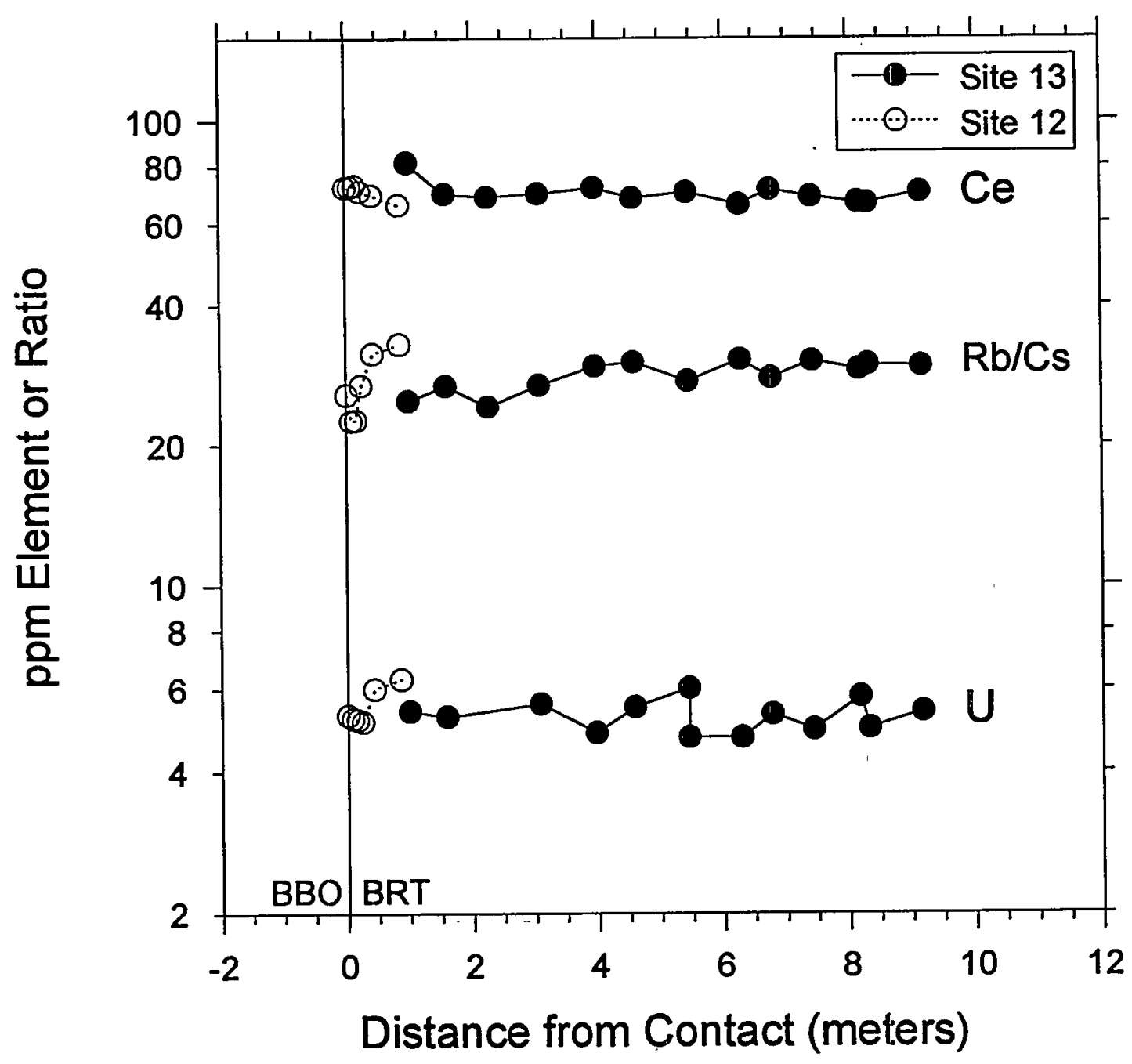

Figure 4.13. Comparison of $\mathrm{Ce}, \mathrm{Rb} / \mathrm{Cs}$ and $\mathrm{U}$ at sites 13 and 12 . 
Site 13 and Site 12

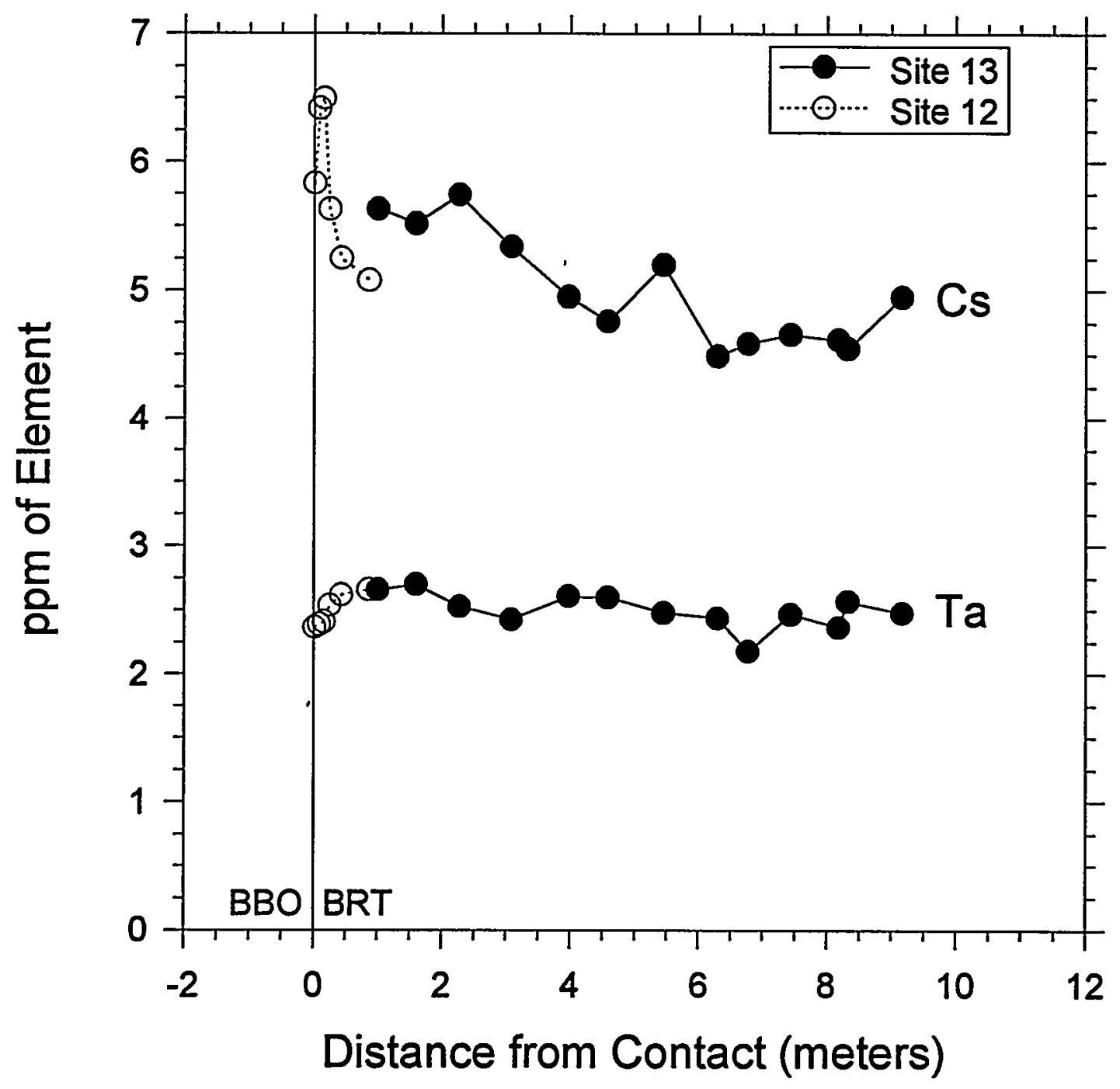

Figure 4.14. Comparison of Cs and Ta variations (linear scale) at sites 13 and 12. 
Site 13 and Site 12

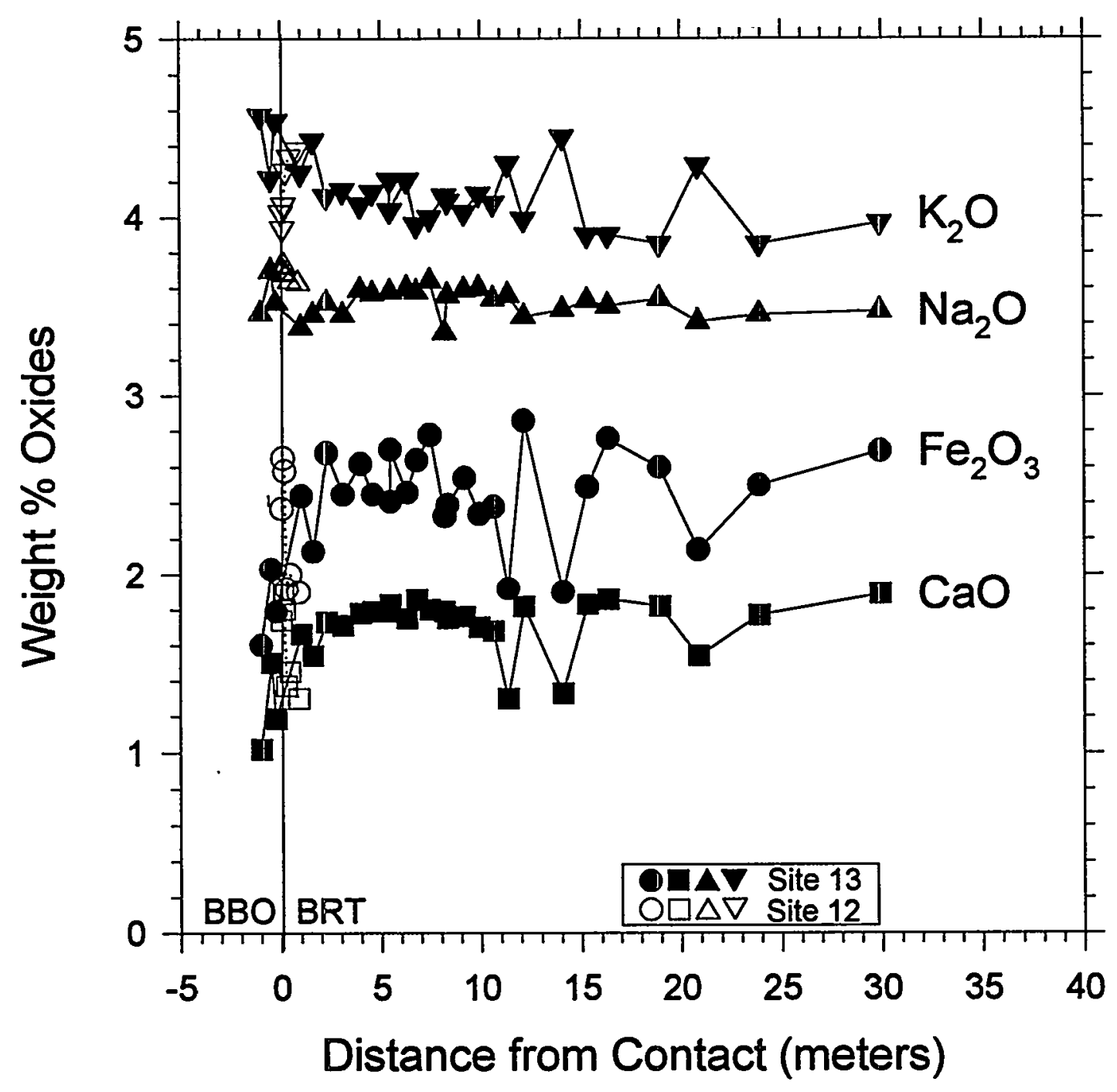

Figure 4.15. Major element oxides at sites 13 and 12 . 


\section{Site 13}

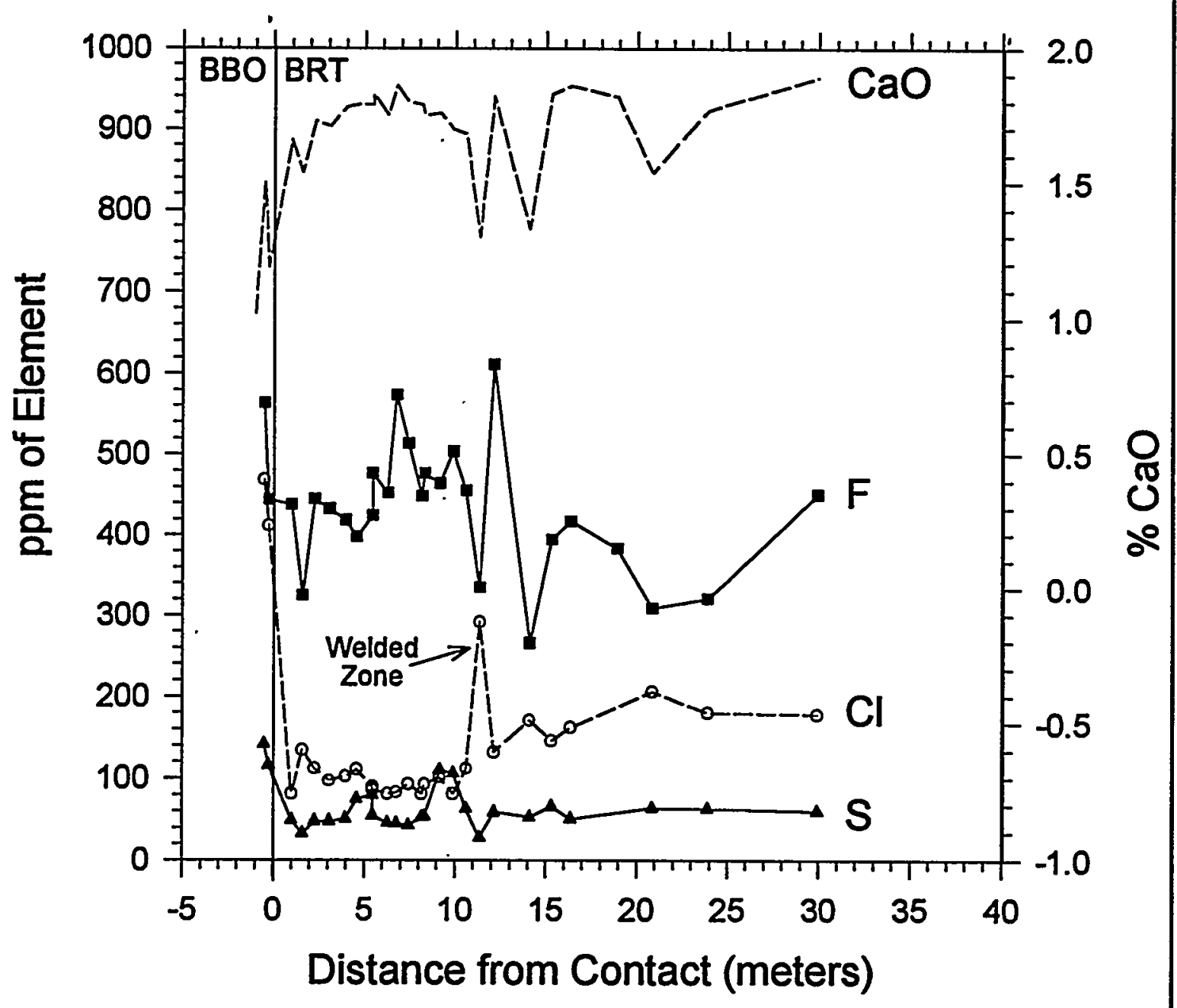

Figure 4.16. Variations in volatile components below contact at site 12. Note correspondence of whole rock $\mathrm{CaO}$ and $\mathrm{F}$. 


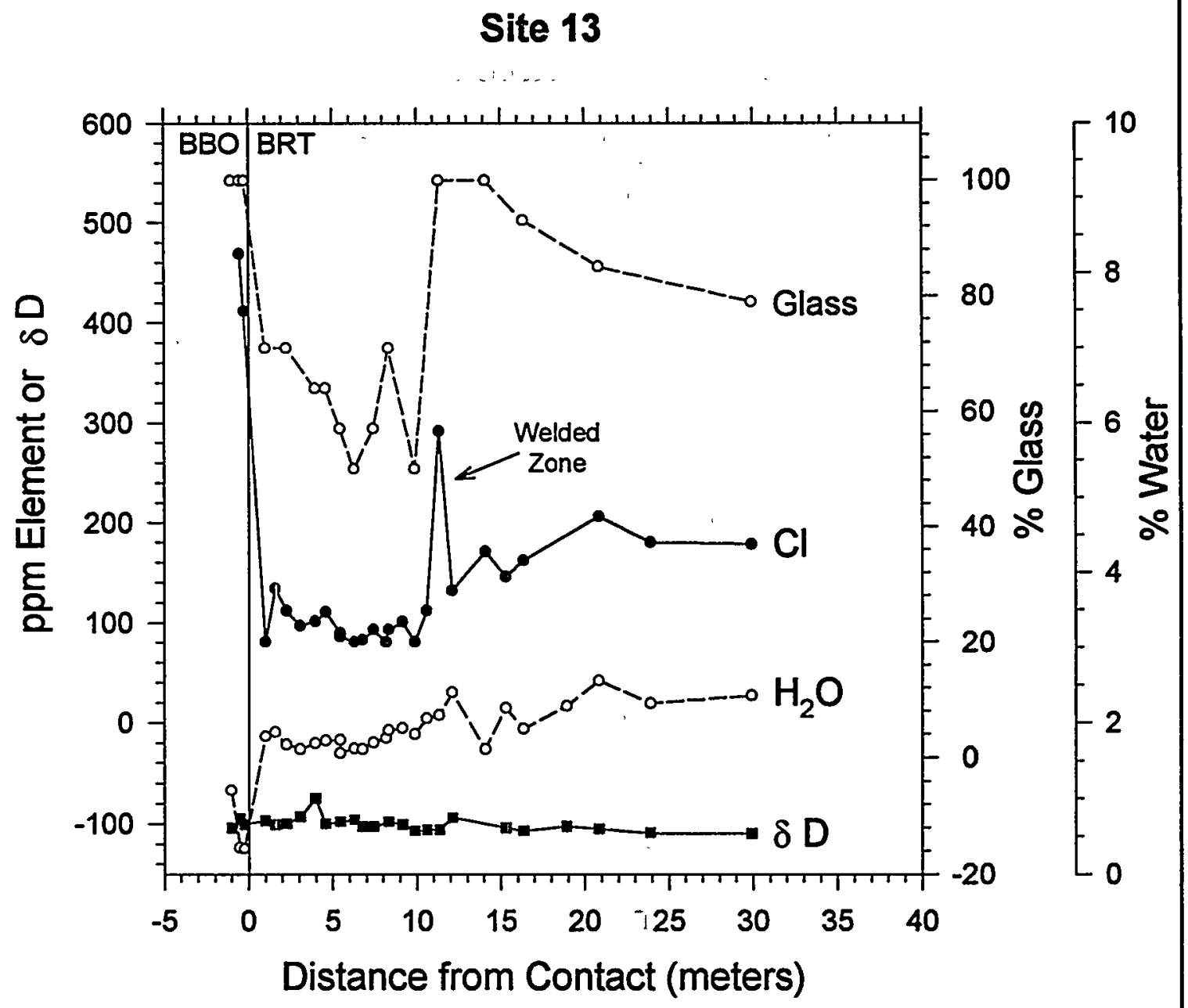

Figure 4.17. Correspondence of minima for glass and water contents, $\mathrm{Cl}$, and $\delta \mathrm{D}$ near contact at site 13 . 
Selected INAA data for site 13 are compared with site 12 data in figures 4.12 through 4.14. Covariations in elemental abundances are similar to sites 8 and 12, but occur over a much larger scale. It is important to recognize that the meter of tuff nearest the contact could not be sampled at site 13; in contrast, the entire sampling interval at site 12 is within a meter of the contact.

\subsection{X-Ray Fluorescence (XRF) for Major Elements}

4.3.1 Purpose. XRF on fused glass discs was used to establish the overall compositional variability of the samples, and to determine if the tuff had been contaminated by acquisition of xenoliths. In addition, variations in $\mathrm{Na} / \mathrm{K}$ (Ellis and Mahon, 1966, 1977; Westrich et al., 1988) and the $\mathrm{SiO}_{2}$ content (Travis and Nuttall, 1987) may be expected for some hydrothermal processes.

4.3.2 Methods. Samples were processed as for INAA ( $c f$ section 4.2.2), and aliquants were sent to Phil Kyle at New Mexico Institute of Mining and Technology for analysis. The samples were fused with a $\mathrm{Li}$ borate- $\mathrm{La}_{2} \mathrm{O}_{3}$ flux in a $1: 6$ sample:flux ratio and analyzed with a Rh tube against USGS rock standards. A separate aliquant of each sample was heated to determine loss on ignition (LOI).

4.3.3 Results. Figures $4.5,4.10$ and 4.15 compare selected major element variations at VC1 and each outcrop site; significance of the variations will be discussed in the following sections.

\subsection{Analysis of Trace Chlorine, Sulfur and Fluorine}

4.4.1 Purpose. When glassy and devitrified rhyolites are heated in liquid water and steam, they can release substantial amounts of chloride, fluoride and sulfate (Ellis and Mahon, 1967; Westrich $e t a l ., 1988)$. The anionic species may be released into pore waters, or may escape as gases (e.g. HF), which may recondense at some distance from the heat source. By forming complexes (e.g. $\mathrm{PuSO}_{4}{ }^{++}, \mathrm{AmSO}_{4}{ }^{+}$and $\mathrm{PuF}_{3}{ }^{+}$), the anionic species can increase the solubility of some radionuclides; by inducing precipitation of insoluble solids (e.g. $\left.\mathrm{RaSO}_{4}\right)$ they may reduce solubility; they also contribute to the ionic strength of the pore waters and can change the local $\mathrm{pH}$, accelerating alteration. The mobilization of anionic elements is also of interest to the extent that they are analogues for isotopes in waste; for example, $\mathrm{Cl}$ and $\mathrm{F}$ may be analogues for ${ }^{129} \mathrm{I}$, and sulfur may be a reasonable analogue for ${ }^{79} \mathrm{Se}$. The $\mathrm{Cl} / \mathrm{F}$ may also be a useful indicator of the extent of devitrification; Westrich et al. (1988) found that $\mathrm{Cl} / \mathrm{F}$ tended to drop during devitrification of rhyolite glasses, as fluorine was more readily incorporated in minerals.

4.4.2 Methods. Chlorine and sulfur were analyzed in bulk rock samples by XRF. Aliquants . of the INAA powders were ground in a McCrone micronizing mill, which reduced the average particle size to $<5 \mu \mathrm{m}$. The micronized powders were pressed into Boric acidbacked pellets, and analyzed at Sandia on a Siemens XRF unit equipped with a $\mathrm{Cr}$ tube. The USGS RGM-1 rhyolite was used as a standard for $\mathrm{Cl}$ analyses; for sulfur analyses, we prepared standards by mixing analyzed, stoichiometric $\mathrm{FeS}_{2}$ (pyrite from the Isle of Elba) 
and $\mathrm{BaSO}_{4}$ (synthetic) into an analyzed rhyolite glass (from Panum Crater, CA). The glass and added sulfur compounds were micronized together to assure thorough mixing.

Fluoride was determined with an ion-specific electrode (Bodkin, 1977). Aliquants of the samples ground for INAA (section 4.2) were fused with lithium metaborate, dissolved in dilute acid, and analyzed by the standard addition method.

4.4.3 Results. Figures 4.6, 4.11, 4.16 and 4.17 show the variations in $\mathrm{Cl}, \mathrm{S}$ and $\mathrm{F}$ concentrations at the three sites, along with variations in selected major elements, water content, and (for site 13) the fraction glass. There is no obvious trend in the behavior of sulfur that spans all three sites. However, there is a slight antipathetic behavior for $\mathrm{Cl}$ and $\mathrm{F}$; at all three sites, the minima of $\mathrm{Cl}$ concentrations correspond to the maxima of $\mathrm{F}$ concentration, despite the difference in scale between sites 12 and 13. At sites 12 and 13, the peaks in $\mathrm{F}$ concentration seem to correspond to peaks in $\mathrm{Fe}$ and $\mathrm{Ca}$. At all three sites, the lowest $\mathrm{Cl}$ contents occur closest to the contacts, and coincide with the lowest water contents, suggesting both $\mathrm{Cl}$ and water were driven off by the heating event. At site 13, the low-water, low-Cl tuffs are also those with the least glass, suggesting the tuffs nearest the contact devitrified in response to the heating event.

\subsection{Bulk Water Analyses and Pyrograms}

4.5.1 Purpose. Of all the chemical components in the BRT and BB, water is most likely to have been mobilized and transported in response to the heating event. The history of interaction between tuff and steam, the amount of steam and its origin, can often be constrained by stable isotopic analyses $\left(\mathrm{D} / \mathrm{H}\right.$ and $\left.{ }^{18} \mathrm{O} /{ }^{16} \mathrm{O}\right)$. Before undertaking such analyses, it is useful to first determine if the samples contain dominantly high-temperature, or "magmatic" water, or loosely-bound water associated with low-temperature alteration. Our laboratory has analyzed numerous volcanic glasses for water release as a function of temperature (e.g. Westrich, 1987); we generally find that in young, unaltered magmatic samples (e.g. bombs from recent eruptions), peak water release occurs above $400{ }^{\circ} \mathrm{C}$ in a standard pyrogram whereas water is released from perlitic samples with a peak at 100-200 ${ }^{\circ} \mathrm{C}$. Our plans to use ${ }^{40} \mathrm{Ar} /{ }^{39} \mathrm{Ar}$ dating on glass samples also required that we assess the extent of low-temperature alteration, since that technique is known to be most accurate with samples that contain little low-temperature water.

4.5.2 Methods. Approximately 20 samples of BB obsidian, the BRT, and fiamme were analyzed for water content. Hand-picked fragments were crushed in a mortar and pestle, sieved to -100 and +200 mesh, and $\approx 0.1 \mathrm{~g}$ aliquants were promptly analyzed to minimize hydration of fresh-ground surfaces with ambient moisture. Two methods were used for analysis: initially we used DuPont $\mathrm{P}_{2} \mathrm{O}_{5}$-cell water analysis, then later used the more sensitive Karl-Fischer titration method.

4.5.3 Results. We expected the fiamme, which have low porosity, would be the least altered and most suitable for subsequent ${ }^{40} \mathrm{Ar} /{ }^{39} \mathrm{Ar}$ analysis. Surprisingly, the water contents of fiamme and bulk tuff were not significantly different. A typical pyrogram for bulk BRT is 


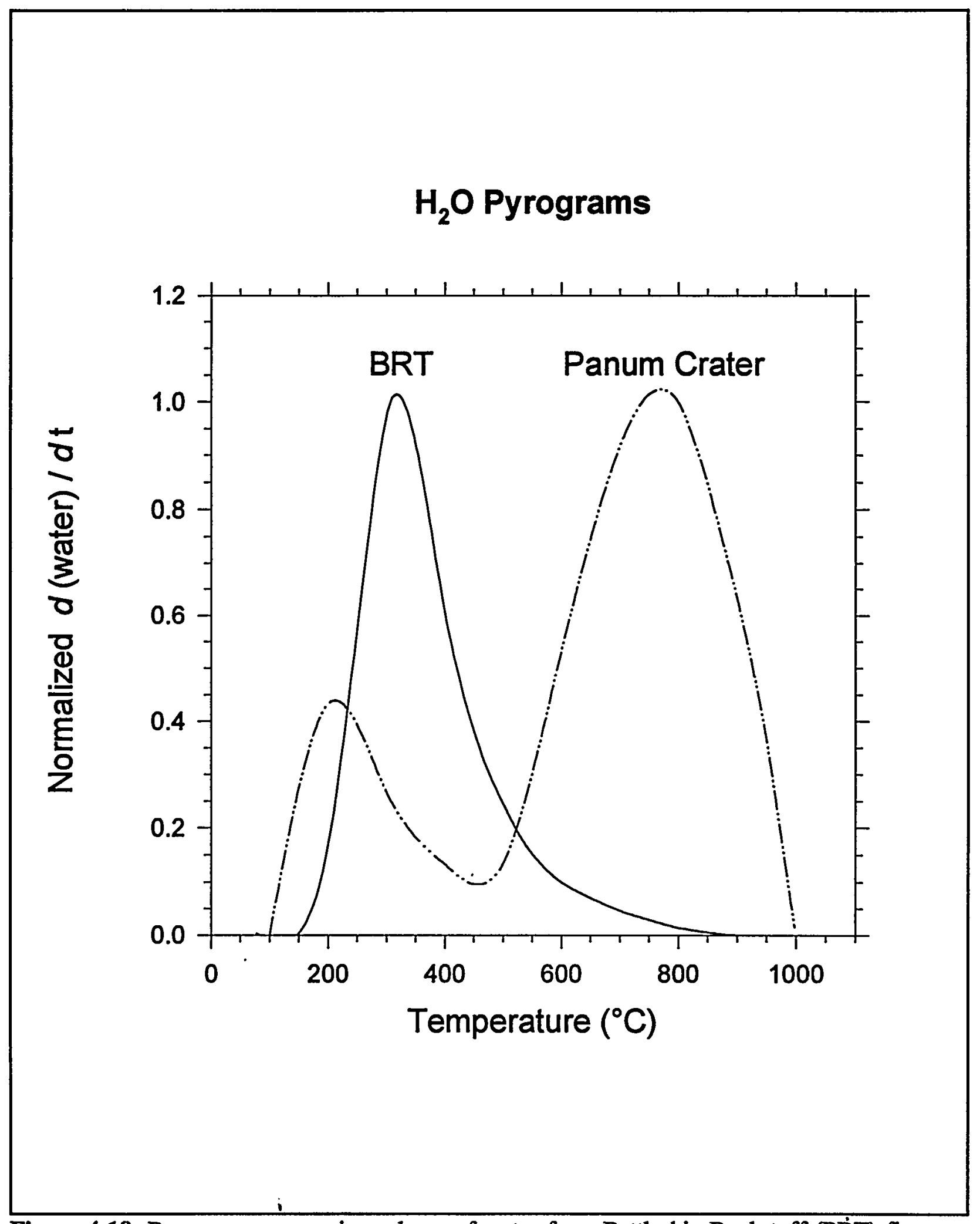

Figure 4.18. Pyrograms comparing release of water from Battleship Rock tuff (BRंT) fiamme, and obsidian glass from Panum Crater, California. 
shown in figure 4.18 , along with the pyrogram for a well characterized obsidian sample from Panum Crater, CA; the two release curves have been normalized to the same height, though the water content of the BRT is actually about 10 times that of the obsidian. The obsidian shows a typical pattern, with one peak at $200{ }^{\circ} \mathrm{C}$, corresponding to loosely bound "molecular" water, and a second peak at $\approx 750{ }^{\circ} \mathrm{C}$, corresponding to hydroxyl water. In contrast, the BRT shows only one peak at $300^{\circ} \mathrm{C}$, higher than expected for superficial alteration, but below the temperature for loss of hydroxyl from sheet silicates such as clays and micas. The water contents of the BB obsidian were low $(\leq 0.4 \%)$ as expected, with relatively high release temperatures, suggesting relatively little alteration since eruption.

\subsection{D/H Analyses}

4.6.1 Purpose. The $\mathrm{D} / \mathrm{H}$ for meteoric and magmatic waters can be very different, and it is sometimes possible to track the alteration of a volcanic sequence, and even estimate the effective water/rock, by comparing the $\mathrm{D} / \mathrm{H}$ of fresh, unaltered igneous rocks and their altered counterparts (Taylor, 1974; Lambert and Epstein, 1980). If a volcanic sample were altered by interaction with steam or liquid water at a sub-magmatic temperature, the final $\mathrm{D} / \mathrm{H}$ of the sample would depend on the initial $\mathrm{D} / \mathrm{H}$ of the rock and the water, the average water/rock seen by the sample, and the partition coefficient $\alpha$ between the sample and steam or liquid water. If the samples have been altered in a thermal gradient, the $\mathrm{D} / \mathrm{H}$ could be expected to vary systematically across the gradient, since $\alpha$ is a function of temperature, and at substantial distances from the source the $\mathrm{D} / \mathrm{H}$ should reach some background value, perhaps reflecting low-temperature equilibration. If the initial $\mathrm{D} / \mathrm{H}$ of the end members and $\alpha$ can be estimated, the average water/rock and temperature of the alteration can be constrained.

$\mathrm{D} / \mathrm{H}$ data are much more powerful when combined with ${ }^{18} \mathrm{O} /{ }^{16} \mathrm{O}$ analyses. To model the analog site with $\mathrm{D} / \mathrm{H}$ data alone, it is necessary to infer the $\mathrm{D} / \mathrm{H}$ of meteoric waters during the thermal event, $200 \mathrm{kA}$ to $500 \mathrm{kA}$ before the present. Modern Valles meteoric water has $\delta \mathrm{D} \approx-90$ (Lambert and Epstein, 1980). Given the uncertainty in the age of the heating event (section 4.9), and the uncertainties in dating the ice ages (e.g. Pecora and Rubin, 1967), the heating event could have occurred during an interglacial period with near-modern temperatures, or during a glaciation. In the latter case, the ambient meteoric $\delta \mathrm{D}$ could have been as low as -130 . Combining $\mathrm{D} / \mathrm{H}$ with ${ }^{18} \mathrm{O} /{ }^{16} \mathrm{O}$ data could resolve much of this ambiguity, because the meteoric fractionation curve defines the relationship between $\delta \mathrm{D}$ and $\delta^{18} \mathrm{O}$ in rainfall, and the curve is invariant with time. 
4.6.2 Methods. Tuff and obsidian samples from sites 12 and 13 were ground in an alumina shatterbox, air dried at a nominal $90^{\circ} \mathrm{C}$, and submitted to Geochron Labs (a division of Krueger Enterprises, Inc.; 24 Blackstone St., Cambridge, MA 02139) for D/H. Results are expressed in terms of $\delta \mathrm{D}$ "per mil":

$$
8 D \%_{\infty 0}=\left(\frac{(D / H)_{\text {sample }}}{(D / H)_{\text {standard }}}-1\right) \times 1000
$$

where the standard is SMOW (standard mean ocean water), with $\mathrm{D} / \mathrm{H}=0.000316$. Analytical precision is estimated as $\pm 2 \%$; this estimate is based on analyses of three replicates (the replicates submitted with different sample names, so the analyst would be unaware that we were testing precision). Samples from site 13 included 2 compact, glassy obsidians with low water content, taken from the overhanging BBO flow, and a sample of perlite obtained from the BBO just a few meters north of the site 13 vertical profile. Samples from site 12 were obtained both with a coring drill and with sledge hammer, and included tuff and fiamme fragments hand-picked from individual specimens.

4.6.3 Results. The $\mathrm{D} / \mathrm{H}$ are plotted with distance from the BBO-BRT contact in figures 4.11 and 4.17. For site $12, \delta \mathrm{D}$ averaged $103.25 \pm 4.22$; for site $13, \delta \mathrm{D}$ averaged $-101.95 \pm$ 4.79 , excepting sample $13 \mathrm{~J}$, which had $\delta \mathrm{D}=-75.5$ (average of two determinations, -75 and -76). There is nothing remarkable about sample $13 \mathrm{~J}$ to account for its distinct $\delta \mathrm{D}$; petrographic analysis shows the sample is nearly identical to $13 \mathrm{~K}$ and $13 \mathrm{~L}(\delta \mathrm{D}=-93$ and 100 ), containing red-stained, flattened and equant pumices and some quartz pheno- or xenocrysts. At site 13 , the perlitic obsidian $\left(13 \mathrm{Z}, 1.11 \% \mathrm{H}_{2} \mathrm{O}, \delta \mathrm{D}=-104\right)$ is slightly lighter than the two "fresh" obsidians $\left(13 \mathrm{X}, 0.35 \% \mathrm{H}_{2} \mathrm{O}, \delta \mathrm{D}=-95\right.$ and $13 \mathrm{~W}, 0.34 \% \mathrm{H}_{2} \mathrm{O}, \delta \mathrm{D}=$ $-101)$, but the number of samples is too small to determine if the difference is significant. All obsidians are far from the "magmatic" range of -50 to -80 , but as discussed below, we would not expect even fresh obsidian to have a magmatic $\delta \mathrm{D}$. While it may not be obvious from figure 4.17, there is a significant difference between the site 13 tuffs closest to the contact, and those farther away. The upper 10 samples (not including 13J) average $-98.9 \pm$ 3.14 , and the lower 11 average $-104.73 \pm 4.38$; the " $t$ " test shows these populations are significantly different at the $0.5 \%$ confidence level (i.e., there is a $0.5 \%$ chance the difference is not significant). The samples closer to the contact also have lower average $\mathrm{H}_{2} \mathrm{O}$, $\mathrm{Cl}$, and \% glass; there is little obvious alteration to clay minerals, and most of the water (and deuterium) in the samples is probably in the remaining glass.

It is beyond the scope of this report to model the partitioning of deuterium and hydrogen among the BBO, BRT and steam during the heating event. However, we can make some general comments that constrain the interpretation of the D/H data. First, given the age of the tuff, and its permeability and high specific surface area, it is probable that since the heating event there has been at least some equilibration between the glass and the pore waters, which are presumably of meteoric origin. However, we cannot take it for granted that the non-magmatic $\delta \mathrm{D}$ of the $\mathrm{BBO}$ and $\mathrm{BRT}$ reflects low-temperature alteration; fresh 
obsidian flows and pumices often have $\delta \mathrm{D}<-90$, far "lighter" than the -50 to -80 range for magma. For example, rhyolite flows from Inyo Domes, Mono Craters, and Medicine Lake in California have $\delta \mathrm{D}$ from -100 to -130 ; the eruption process apparently involves foaming and open system distillation, which enriches the exsolved water vapor in deuterium at the expense of the glass (Taylor et al., 1983; Dobson et al., 1989). Second, while modern Valles surface waters have $\delta \mathrm{D} \approx-90$ (Lambert and Epstein, 1980), it is probable that meteoric water at the time of the heating event had $\delta \mathrm{D}<-90$, since the average climate between 200kA and $500 \mathrm{kA}$ b.p. was cooler than at present (Shackleton and Updike, 1973; Pecora and Rubin, 1967). If we use the ${ }^{40} \mathrm{Ar} /{ }^{39} \mathrm{Ar}$ date of $\approx 440 \mathrm{kA}$ b.p., and accept the chronology of Shackleton and Updike, the heating event may have occurred in an interglacial period with climate much like the present. Third, the steam that interacted with the BBO and BRT, near the contact, could be derived from two sources: (1) boiling of pore waters, which can account for 2 to $20 \%$ of the mass of rocks in the vadose zone, and (2) dehydration of glass; we presume the former process is the more important. Steam should be enriched in deuterium relative to ground water, but the extent of the enrichment is not easy to predict; In modern hydrothermal environments, $\delta \mathrm{D}$ of steam can be similar to $\delta \mathrm{D}$ of contempbrary meteoric water (e.g. Lambert and Epstein, 1980, 1992). Fourth, there are two components of water in volcanic glass that must be considered in estimating the composition of coexisting steam: hydroxyl water, which dominates in relatively anhydrous samples, like the flow obsidian $\left(\mathrm{H}_{2} \mathrm{O} \approx 0.35 \%\right)$; and molecular water, which would dominate in the tuff glasses $\left(\mathrm{H}_{2} \mathrm{O} \approx 2 \%\right)$. The fractionation factors of these two components can be very different. For the hydroxyl component, $\alpha=\left((\mathrm{D} / \mathrm{H})_{\text {steam }} /(\mathrm{D} / \mathrm{H})_{\text {glass }}\right) \approx 1.05$ at $530{ }^{\circ} \mathrm{C}$, but for the molecular component $\alpha \approx 1.000$. Thus if we assume that the tuff near the BBO-BRT equilibrated with steam, it is possible $\delta \mathrm{D}_{\text {steam }} \approx \delta \mathrm{D}_{\text {glass. }}$.

\subsection{Electron Microprobe (EMP) Study of $\mathrm{Cl}, \mathrm{F}$ and Alkali Metasomatism}

4.7.1 Purpose. There are two reasons to examine the obsidians overlying site 8 for evidence of alkali and halide transport. First, as discussed in section 7.3, it is possible that devitrification of the BBO flow produced halogen- and Fe-rich gases, which subsequently migrated into the tuffs and caused the Fe and $\mathrm{F}$ enrichments observed in the BRT near the contact (e.g., figures 4.10 and 4.11); presumably the transport of these gases through fractures in the obsidian flow would have left some trace along the walls of the cracks. Second, we wished to determine the age of the obsidian via ${ }^{40} \mathrm{Ar} /{ }^{39} \mathrm{Ar}$ dating, and that method works best on samples that show little evidence of alkali redistribution and hydration (Cerling et al., 1985).

At site 12 , we wished to analyze the tuff adjacent to the contact, rather than the obsidian, for evidence of alkali and fluorine metasomatism. The $\mathrm{K}$ and $\mathrm{Rb}$ contents of these samples decrease toward the contact (figures 4.7 and 4.10), and the minimum in $\mathrm{K}$ concentration corresponds to the maximum of $\mathrm{Ca}, \mathrm{Cs}$ and $\mathrm{F}$. As discussed in sections 4.2 and 4.3, these trends in alkali ratios are consistent with alkali metasomatism reported for geothermal regions. However, there is always the possibility that the variations represent original and chance variations in the pre-heating composition of the tuff. The bulk fluoride content of the tuff near the contact is substantially higher than the average tuff F content (section 4.4), and 
suggests fluoride transport and metasomatism. These F-rich samples consist of relatively large black glass fragments in a fine-grained pink matrix. Oskarsson (1980) suggested that in Hekla tuffs altered by F-rich plume gases, the enrichment could be attributed to $\mathrm{CaF}_{2}$ or $\mathrm{CaSiF}_{6}$ adhering to the surfaces of tephra fragments, even at gas temperatures up to $1000{ }^{\circ} \mathrm{C}$; the highest $\mathrm{F}$ concentrations were associated with the very fine-grained fraction of the tephra. If the site 12 samples were enriched by similar gases, we might expect the metasomatic $F$ component to be enriched in the fine-grained porous matrix. The matrix is a relatively small portion of these samples by volume; if the large glass fragments have $\mathrm{F}$ contents typical of the local obsidian $(\approx 400 \mathrm{ppm}$ ), the matrix could have F contents well over $1000 \mathrm{ppm}$, detectable by EMP. We note, however, that the failure to find a $F$ enrichment in the matrix would not rule out a metasomatic origin for the bulk $F$ enrichment of the site 12 samples. Compared to the Hekla air-fall tephras, the site 12 samples may have been held at high temperature for much longer periods of time, homogenizing the $\mathrm{F}$ contents among clasts and matrix.

4.7.2 Methods. A large (several $\mathrm{kg}$ ) piece of $\mathrm{BBO}$, with attached tuff, was taken from the site 8 contact and potted in low-viscosity epoxy. The sample was sectioned roughly perpendicular to the tuff-obsidian interface; petrographic examination revealed numerous cracks in the obsidian partly filled with pink tuff dust, and with slightly reddish surfaces. It seems reasonable that these cracks were extant at the time the tuff was overridden and heated by the obsidian flow, and are not artifacts of some later process. Polished mounts were prepared from the potted sample, and traces across the cracks were analyzed for major elements on the Sandia electron microprobe (EMP; Cameca model MBX), with emphasis on detecting $\mathrm{Cl}, \mathrm{Na}$ and $\mathrm{K}$ variations, or low totals indicating hydration, near the crack boundaries.

At site 12, we are not interested in examining the BBO-BRT contact, but rather in searching for patterns in the spatial distribution of $\mathrm{F}$ and alkalis that are consistent with metasomatic alteration. We expect the fine-grained and very porous matrix to be the locus of alteration, since it is much more permeable and has a much larger specific surface area than the glassy clasts, if the trends in bulk composition reflect hydrothermal alteration rather than original, pre-heating variations. Thus the probe mount for site 12 consists of a tuff sample taken several $\mathrm{cm}$ from the contact, sectioned to include several large glassy clasts as well as finegrained, porous matrix.

4.7.3 Results. The $\mathrm{Na}$ and $\mathrm{K}$ profiles for two scans of the site 8 obsidian are shown in figure 4.19. The "small" crack (figure 4.19, top) is $40-50 \mu \mathrm{m}$ wide, and shows no variation in $\mathrm{K}$, $\mathrm{Na}$ or "water" content (i.e., in the analysis total) up to the very edge of the crack. If there is an alteration zone, it is smaller than the $17 \mu \mathrm{m}$ step size of the scan. The scan for the "large" crack (figure 4.19 , bottom) actually crossed several subparallel cracks. The high $\mathrm{Na}$ region in the center of the large crack has stoichiometry $(\mathrm{Na}, \mathrm{K}, \mathrm{Ca}, \mathrm{Fe})_{0.9953}(\mathrm{Si}, \mathrm{Al})_{4.0047} \mathrm{O}_{8}$, and is clearly an albite grain, not a region of altered glass. Thus the samples show no evidence of alkali metasomatism or hydration near cracks (at least at the scale analyzed), and should be well-suited for ${ }^{40} \mathrm{Ar} /{ }^{39} \mathrm{Ar}$ dating. 
For our analyses of the site 8 obsidian, the EMP was configured for long counts on the $\mathrm{Cl}$ $\mathrm{K}_{\alpha}$ peak and adjacent backgrounds, at high beam current ( 22 to $44 \mathrm{nA}$ ) and low potential (15 $\mathrm{KV}$ ), to obtain spatially well-resolved and sensitive chloride analyses. We analyzed 5 pairs of positions on opposite sides of the cracks. The analyses were obtained as close to the cracks as possible (i.e., so the $99 \%$ electron excitation volume of the primary beam -- $\approx 5 \mu \mathrm{m}$ for $\mathrm{Cl}$ at $15 \mathrm{kV}$-- was entirely within the obsidian). These 10 analyses averaged $442.6 \pm 19.6$ $\mathrm{ppm} \mathrm{Cl}$ (counting statistics predicted an error of $\pm 21 \mathrm{ppm}$ for each count). Next we analyzed 8 points in the center of obsidian fragments, as far from cracks as possible; these analyses averaged $469.5 \pm 13 \mathrm{ppm}$ ( $\pm 30 \mathrm{ppm}$ counting statistics). As a check on the accuracy of the microprobe analyses, we performed bulk XRF analyses of the same obsidian. The XRF results were $476 \pm 6$ and $479 \pm 6 \mathrm{ppm}$ for two samples, in good agreement with the microprobe analysis of the fragment centers. Thus, there is no evidence for chloride enrichment in the cracks; the cracks have slightly lower $\mathrm{Cl}$ analyses, but the difference is not statistically significant.

To search for a microscopic manifestation of hydrothermal $F$ enrichment in the site 12 tuffs, we compared $\mathrm{F}$ contents of the fine-grained matrix and the large glass clasts, via EMP analysis, using both the Sandia microprobe and the University of New Mexico JEOL 733 Superprobe. On the Sandia probe, we found no significant difference in the F contents, but the counting statistics of the analyses were poor $(171 \pm 35$ counts on the matrix, $188 \pm 38$ counts on the clast). The JEOL $F$ analyses suffered from an unresolvable background interference from the $\mathrm{Fe} \mathrm{L}_{\alpha}$ line, and were inconclusive. Our current analyses are unable to determine whether the matrix is enriched in $\mathrm{F}$. Analyses of an apatite crystal in the sample gave an $\mathrm{F}$ content of $\approx 3 \mathrm{wt} \%(30,000 \mathrm{ppm})$. However, the small $\mathrm{P}_{2} \mathrm{O}_{5}$ content of the bulk rock $(0.09 \mathrm{wt} \%)$ indicates that apatites cannot be a significant source of $F$ in this sample.

To search for evidence of alkali metasomatism in the site 12 tuff, we configured the JEOL probe to perform $\mathrm{K}, \mathrm{Na}$ and $\mathrm{Ca}$ scans on a 128 by 128 pixel ( $2^{14}$ point) grid. Figure 4.20 shows the results for $\mathrm{Ca}$ and $\mathrm{K}$. The sample consists of a low-porosity obsidian clast on the left, surrounded by fine-grained matrix containing fragments of plagioclase, pyroxene and mica. The matrix is irregularly enriched in $\mathrm{Ca}$ (and $\mathrm{Na}$ as well), and is also deficient in $\mathrm{K}$ relative to the obsidian clast. The ratio ( $\mathrm{K}$ in clast)/(K in matrix) is $\approx 2$ to 4 , compared with a ratio of $\approx 1$ seen in bulk analyses for obsidians/ tuffs. Thus it seems likely that differences in alkali contents are due to some metasomatic process altering the matrix, rather than an inherent difference between the compositions of tuff and obsidian. 

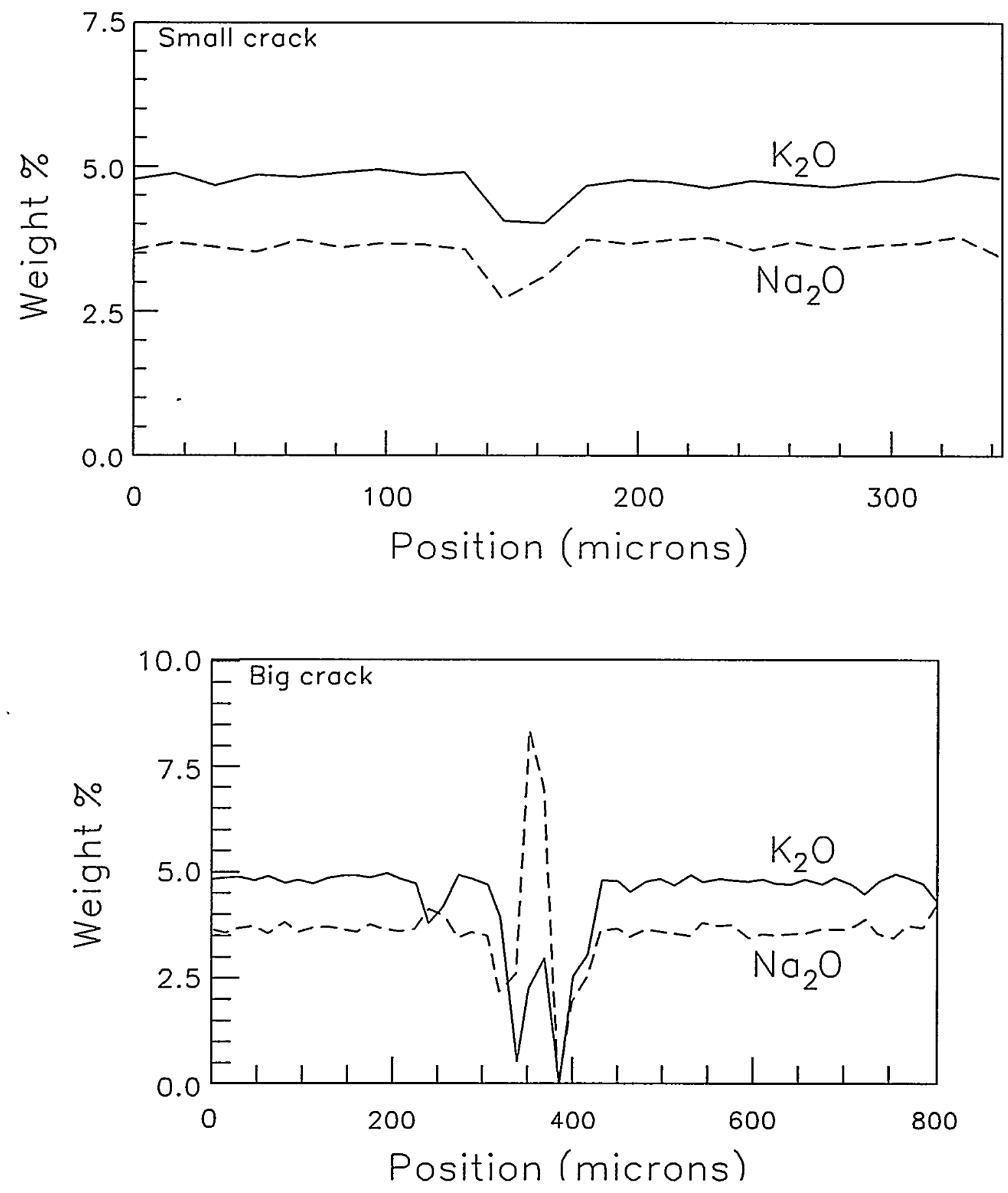

Figure 4.19. Electron microprobe trace across cracks in the Banco Bonito obsidian overlying site 8. There is no evidence of alkali metasomatism. 


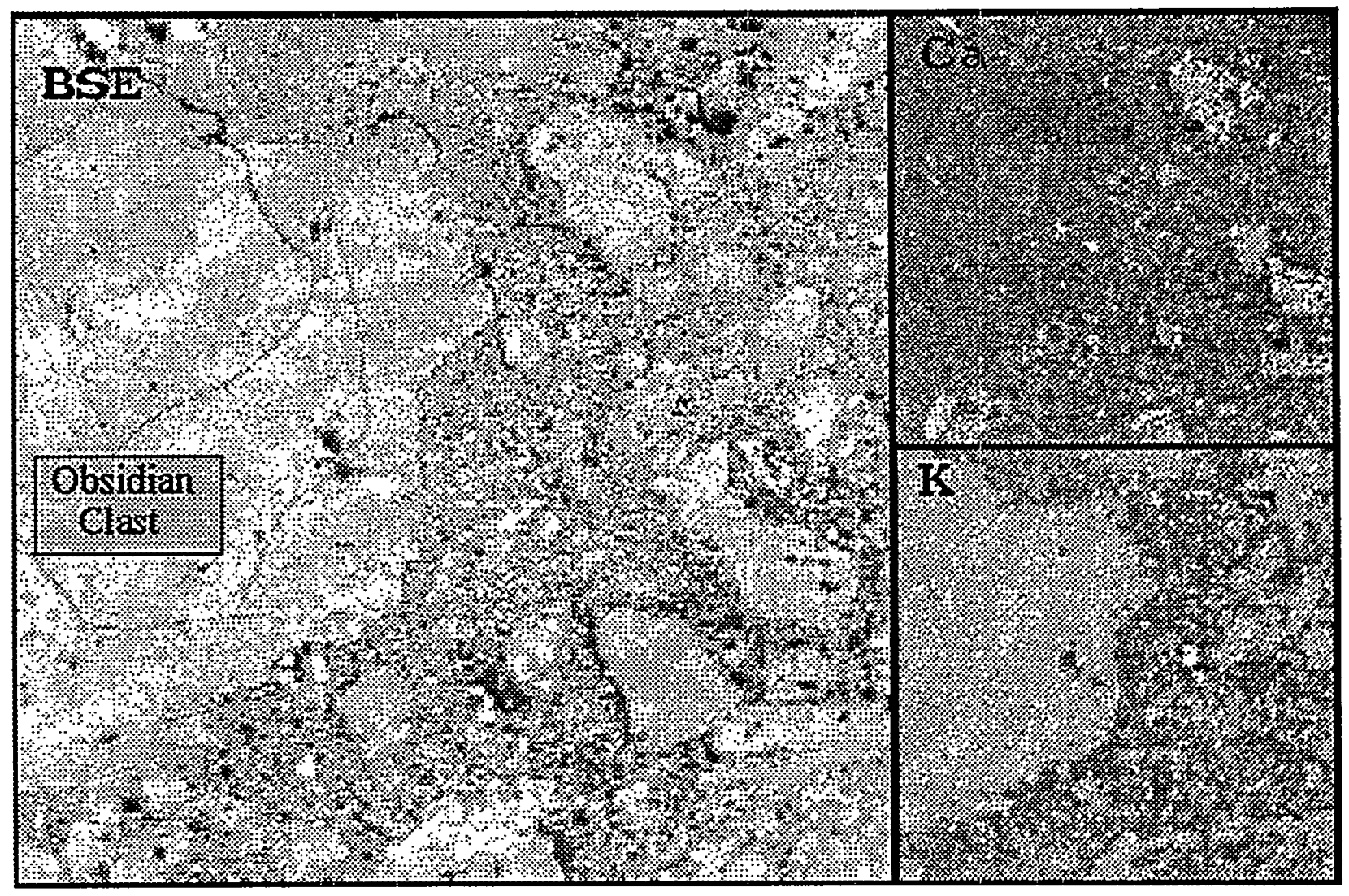

Figure 4.20. Electron microprobe map of $\mathrm{K}$ and $\mathrm{Ca}$ is site 12 tuff sample, $3 \mathrm{~cm}$ from contact. 


\subsection{Heavy Mineral Analysis}

4.8.1 Purpose. A major goal of this project is to determine whether radionuclide simulants -$\mathrm{U}$, Th, and non-radioactive isotopes of $\mathrm{Cs}$, rare earths and other elements -- can be mobilized in an environment simulating the near-field of a waste repository. An early concern in this project was the possibility that some of these elements might occur principally in the durable, insoluble minor assessory minerals (such as pyroxenes, zircons, apatites monazites or sphenes), as suggested in the study by Self et al. (1991) and Smellie et al. (1986). If the latter were the case, small variations in accessory mineral content could cause large variations in the bulk analyses, and since these minerals are relatively immune to alteration, the concentrations of radionuclide simulants would appear to be independent of the extent of alteration of the tuffs. In addition, it is possible that the heavy minerals settled at different speeds than the glass during the deposition of the tuff, and concentrated at some particular stratigraphic level, resulting in whole-rock compositional variations that were independent of glass chemistry.

4.8.2 Methods. Heavy minerals were separated from 6 samples from outcrop 8, and characterized by optical microscopy, SEM/EDS (energy dispersive spectroscopy), EMP, and INAA. The separation involved grinding the samples to -80 mesh, mixing the ground tuff with bromoform $\left(\rho=2.89 \mathrm{~g} / \mathrm{cm}^{3}\right)$, and allowing the heavies to settle for several hours, while the sample was constantly agitated with an overhead stirrer. The slurry was periodically mixed by hand, and the edge of the settling funnel was vibrated to keep particles from sticking to the sides. When settling slowed to a few particles/minute, the heavies were withdrawn via a double pinchcock, washed, and weighed. In samples $8 \mathrm{~A}$ through $8 \mathrm{~F}$, the heavy separates comprised from 0.23 to $1.41 \%$ of the samples by weight. Sample 8B was subsequently separated into magnetic and non-magnetic components with a strong hand magnet; the magnetic fraction was $49 \%$ of the mass. The non-magnetic and magnetic fractions from sample 8B were processed by INAA, as described in section 4.2.2.

4.8.3 Results. The magnetic fraction was lost by LANL, so we do not have a complete mass balance; however, the magnetic fraction consisted largely of magnetite, which is unlikely to have high rare earth content. The analysis of the non-magnetic fraction is given in table A-10 in the appendix. Some approximate enrichment factors for the non-magnetic separate, relative to the site 8 whole rock analyses, are: $\mathrm{Co}=46, \mathrm{Hf}=35, \mathrm{Sc}=12, \mathrm{Lu}=9, \mathrm{Yb}=6, \mathrm{Ce}=4.5$, $\mathrm{U}=3, \mathrm{Th}=2, \mathrm{Ta}=1.5$, and $\mathrm{Cs}=0.5$. The high $\mathrm{Co}$ and $\mathrm{Sc}$ enrichments, and the greater enrichment for heavy $v s$. light rare earths, is not surprising for pyroxene-rich materials. The high Hf enrichment may indicate the presence of zircon in the separates. This fraction constitutes $0.57 \%$ of the bulk rock by mass, so for the most enriched element (Co), it can account for $26 \%$ of the whole rock abundance; for the light rare earths, it accounts for only $2.5 \%$ of the whole rock abundance.

It is conceivable that the higher $\mathrm{F}$ contents observed near the contacts at sites 8 and 12 represent chance accumulations of F-rich phases, such as micas, amphiboles or apatites. To test this hypothesis, we performed analyses of heavy mineral separates on the University of 
New Mexico JEOL 733 Superprobe (tables A-9 and A-10 in Appendix A). Phase analysis was performed with the Oxford FeatureScan software. Sample 8A contained too many polymineralic grains for a good image analysis, but sample 8B yielded $4.272 \%$ amphibole, $0.571 \%$ apatite, $4.476 \%$ ilmenite, $59.328 \%$ "oxide" (dominantly magnetite), $2.789 \%$ plagioclase, $10.849 \%$ clinopyroxene, $14.710 \%$ orthopyroxene, $1.303 \%$ biotite, and $1.701 \%$ unclassified phases. The highest $\mathrm{F}$ contents were in apatite (average $25,200 \mathrm{ppm}$ ), biotite (average $6733 \mathrm{ppm}$ ) and amphibole (average $4353 \mathrm{ppm}$ ). In general, the total heavy mineral separate was less than $2 \%$ of the bulk rock. Thus the apatite, biotite and amphibole can contribute no more than $8.35 \mathrm{ppm}$ of the bulk rock fluorine content, which is much smaller than the observed variation.

\subsection{Age Determination via ${ }^{40} \mathrm{Ar} /{ }^{39} \mathrm{Ar}$}

4.9.1 Purpose. It is important to know the age of the BRT and BBO in order to assess the likelihood of alteration, to establish the stratigraphic relationships at the site, and to constrain the climate and stable isotopic composition of precipitation at the time of the heating event. At the start of this study, there was substantial uncertainty in the ages of both the BBO and BRT; K/Ar dates placed the BRT at $278 \pm 52 \mathrm{kA}$ (Goff et al., 1989), whereas fission track methods placed the BRT at $147 \pm 67 \mathrm{kA}$, and the BBO at $135 \pm 75 \mathrm{kA}$ (Marvin and Dobson, 1979; Miyachi et al., 1985). Self et al. (1988) suggested the BBO and BRT were part of an eruptive sequence spanning as little a few tens of years. While this latter interpretation might seem improbable, given that the BBO was emplaced in a hundred meter-deep canyon cut into the BRT, Self $e t$ al. gave examples of several recent eruptions where deep canyons were cut through soft ash in tens of years. If this latter interpretation were correct, it would be very difficult to model the effects of the thermal pulse. The study by Cerling $e$ t al. (1985) suggested the ${ }^{39} \mathrm{Ar} /{ }^{40} \mathrm{Ar}$ method would provide a much better constraint on the age of the units, and might resolve whether the BBO and BRT were really erupted so close in time. In addition, by comparing the ${ }^{39} \mathrm{Ar} /{ }^{40} \mathrm{Ar}$ ages of biotites in tuff close and far from the contact, it should be possible to establish the maximum extent of the heating pulse. The blocking temperature of biotite is $\approx 300^{\circ} \mathrm{C}$, so the ages of biotites in the tuff would be reset to the age of the obsidian flow in any region where the tuff was heated above $300^{\circ} \mathrm{C}$ for more than a few years.

4.9.2. Methods. Seven samples were analyzed for argon isotopic composition by the Geochronology Center/Institute of Human Origins (IHO) in Berkeley, CA. The samples included: a piece of $\mathrm{BBO}$ from the VC-1 corehole; $\mathrm{BBO}$ from the site 8 outcrop, stratigraphically lower than the core BBO sample; two site 8 BRT samples, from a position several $\mathrm{cm}$ below the contact (8A), and from two meters below (8F); a BRT sample from the type locality at Battleship Rock State Park; a sample of the VC1O, from the VC-1 corehole; and a sample of obsidian from the 600 year-old flow at Obsidian Dome near Mammoth Lakes, CA. The last sample was included as a check on the accuracy of the dating method, since the emplacement age of Obsidian Dome is very well constrained by ${ }^{14} \mathrm{C}$ dating. The IHO separated fresh glass, sanidine, plagioclase and biotite from the samples, and obtained over 100 individual ages by bulk analysis or by step-wise, laser-induced heating. 
4.9.3 Results. Table 1 summarizes the ages determined by IHO. In general, there was wide variation in the ages. The errors reported by IHO are somewhat misleading, since the analysts arbitrarily omitted some "anomalous" samples with very low of very high ages. Only the BBO biotite dates for site 8, the BRT sanidine dates from sample 8A, the BRT biotite dates for sample 8F, and the BRT sanidine dates from the type locale at Battleship Rock State Park showed any consistency, and were free from "anomalous" ages; these four dates are shown in bold in the table. The only significant difference between the ages found for biotites in the site $8 \mathrm{BBO} v$ s. the site $8 \mathrm{BRT}$, was the high degree of ${ }^{36} \mathrm{Ar}$ contamination for the latter, indicating a much greater degree of atmospheric exchange. Since the ages of the BRT and BBO are essentially identical within experimental error, it is not possible to determine the extent of the thermal pulse from resetting of the biotite ages.

The errors inherent in the ${ }^{39} \mathrm{Ar} /{ }^{40} \mathrm{Ar}$ dates can be judged by the date obtained for the Obsidian Dome sample: IHO obtained an age of $34 \pm 6 \mathrm{kA}$, whereas the true age is $0.6 \mathrm{kA}$. It seems probable that the glassy obsidians in the BBO and BRT have become contaminated with substantial amounts of "old" argon, perhaps acquired by assimilation of country rock or exchange within the magma chamber. We have noted that both the obsidians and tuffs contain abundant xenocrysts, including wormy-textured feldspars with highly eroded margins. It seems likely that these feldspars were out of equilibrium with the melt, and represent contamination.

It is notable that Self $e t$ al. published additional ${ }^{39} \mathrm{Ar} /{ }^{40} \mathrm{Ar}$ dates in 1991 , along with a reinterpretation of the timing of the $\mathrm{BBO}$ and $\mathrm{BRT}$ eruptions. Their new $\mathrm{BBO}$ dates range from 205 to $1300 \mathrm{kA}$, with a cluster at $418 \pm 45 \mathrm{kA}$. Self $e t$ al. now regard the $\mathrm{BBO}$ and BRT as distinct eruptions, separated perhaps by tens of thousands of years. 


\begin{tabular}{|l|l|l|l||}
\hline \multicolumn{1}{|c|}{ Location } & Mineral & Age (kA) & \multicolumn{1}{c|}{ Comments } \\
\hline BBO, VC-1 core, upper flow & glass & $235 \pm 37$ & \\
\hline BBO, site 8 outcrop & $\begin{array}{l}\text { biotite } \\
\text { plagioclase } \\
\text { glass }\end{array}$ & $\begin{array}{l}451 \pm 23 \\
515 \pm 112 \\
439 \pm 20\end{array}$ & $\begin{array}{l}\text { Plag and glass dates do } \\
\text { not include 5 (of 9) } \\
\text { "anomalously old" }\end{array}$ \\
\hline $\begin{array}{l}\text { BRT, site 8 outcrop (8A, 0.01 } \\
\text { m below contact) }\end{array}$ & sanidine & $555 \pm 21$ & \\
\hline $\begin{array}{l}\text { BRT, site 8 outcrop (8F, 2.35 } \\
\text { m below contact) }\end{array}$ & $\begin{array}{l}\text { biotite } \\
\text { plagioclase }\end{array}$ & $\begin{array}{l}464 \pm 56 \\
241 \pm 43\end{array}$ & $\begin{array}{l}\text { Plag date does not } \\
\text { include 6 (of 10) } \\
\text { "anomalous" }\end{array}$ \\
\hline BRT welded, type locale & $\begin{array}{l}\text { sanidine } \\
\text { biotite }\end{array}$ & $\begin{array}{l}410 \pm 56 \\
280 \pm 54\end{array}$ & $\begin{array}{l}\text { Biotites vary from 89 to } \\
403 \text { kA }\end{array}$ \\
\hline VC10, vC-1 core & glass & $800 \pm 19$ & \\
\hline
\end{tabular}

Table 1. Ages determined by ${ }^{39} \mathrm{Ar} /{ }^{40} \mathrm{Ar}$ method, listed in approximate stratigraphic order. 


\subsection{Scanning Electron Microscopy (SEM)}

4.10.1 Purpose. Scanning electron microscopy with energy dispersive spectroscopy (EDS) was used primarily to search for alteration minerals (clays, zeolites, or silica polymorphs) on the glass shards in the tuff, and for evidence of leachable, superficial contamination (such as $\mathrm{Na}_{2} \mathrm{SO}_{4}$ crystals). Höller and Wirsching (1978) found that montmorillonite formed on rhyolite glass shards in 40 to 56 days at $150^{\circ} \mathrm{C}$ in liquid water, in both closed and open system experiments. Similar results were found by Daniels et al. (1982) for $150{ }^{\circ} \mathrm{C}$. Thus the absence of clay alteration minerals suggests that the glass was not exposed to liquid water $\geq$ $150^{\circ} \mathrm{C}$ for any appreciable amount of time. Formation of silica polymorphs is of interest, because silica metasomatism is predicted to occur in heated tuffs (Travis and Nuttall, 1987). However, the local change in the bulk silica concentration may be below detection limits for whole rock analysis (section 7.2), and the formation of $\mathrm{SiO}_{2}$ polymorphs may be detectable only through microscopic analysis. Lastly, the SEM can be used to determine the feasibility of vapor phase transport models for $\mathrm{Fe}$, which would require the deposition of Fe-rich minerals (e.g. hematite or magnetite) in the abundant voids of the tuff matrix.

4.10.2 Methods. Samples were examined on a JEOL model JSM-T300 SEM, equipped with a Tracor-NorthernlNoran model TN-98 EDS (energy dispersive spectroscopy) system for semi-quantitative analyses. While the analyses were performed in "standardless" mode, we ran orthoclase and obsidian glass samples of known composition as checks on the accuracy of the analysis method. In general, the analyses of standards proved to be remarkably good, in part because low accelerating potentials ( 15 to $20 \mathrm{kV}$ ) were used to minimize the size of the electron excitation volume. The main limit on the accuracy of the EDS analyses is the geometry of the mineral surfaces. The correction program assumes a flat, polished surface perpendicular to the electron beam, when in fact we typically analyzed crystals that projected above the surface. Depending on the detector take-off angle and the position of the analyzed crystal (e.g., in the bottom of a pore, $v s$. on its rim), the correction program may overestimate or underestimate the size of the absorption correction. The problem seems to be most serious for $\mathrm{Na}$, which seems to be underestimated by a factor 1.0 to 1.3 in some samples, and for $\mathrm{K}$, which seems to be overestimated by a similar factor.

4.10.3 Results. Secondary electron images from several samplès are shown in figures 4.21 through 4.25. The significance of the minerals and textures is discussed in section 7 . 


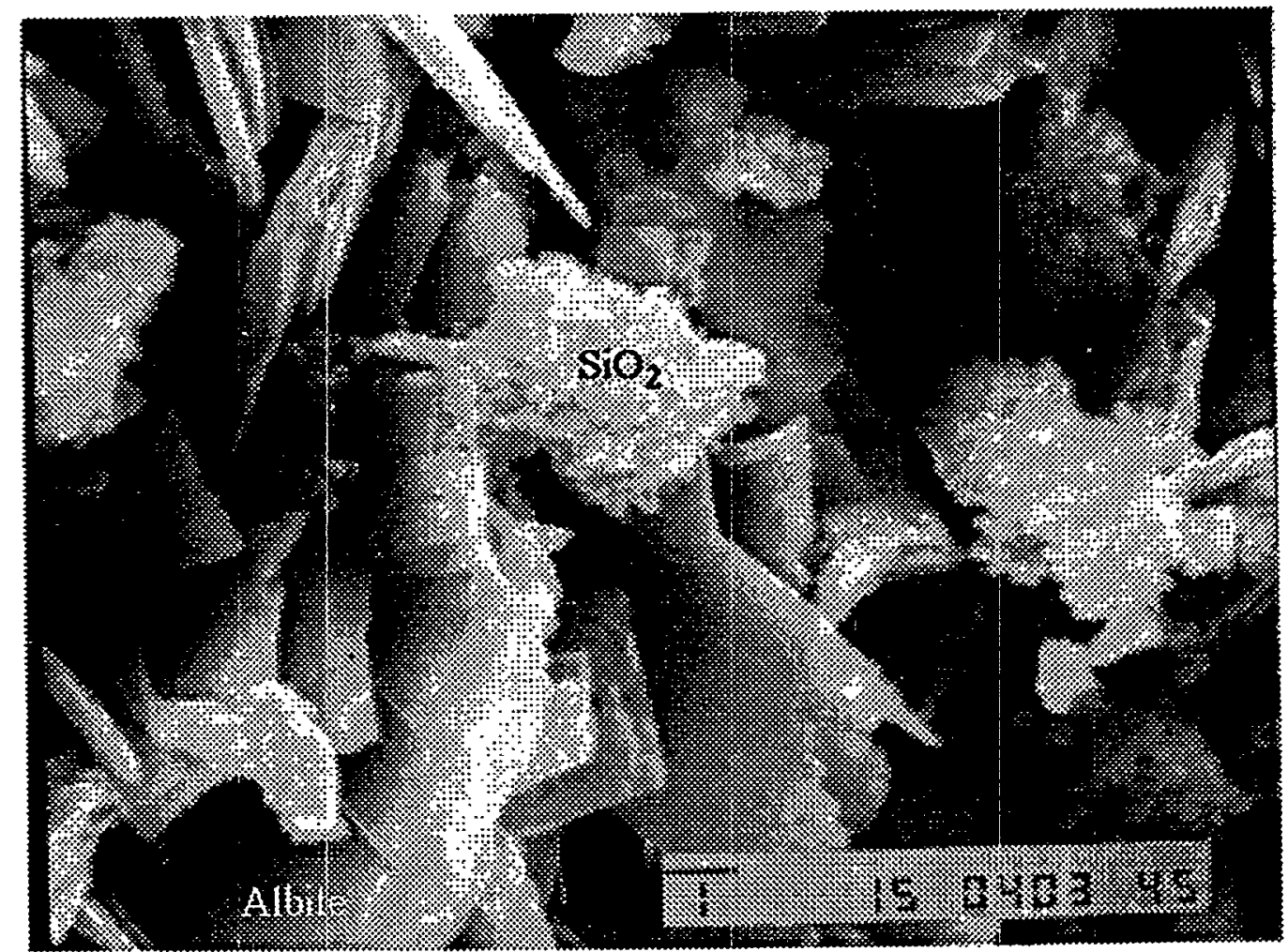

Figure 4.21. Site 12, SEM image, $3 \mathrm{~cm}$ from contact. Scale bar is $1 \mu \mathrm{m}$. Albite blades with perched clusters of $\mathrm{SiO}_{2}$.

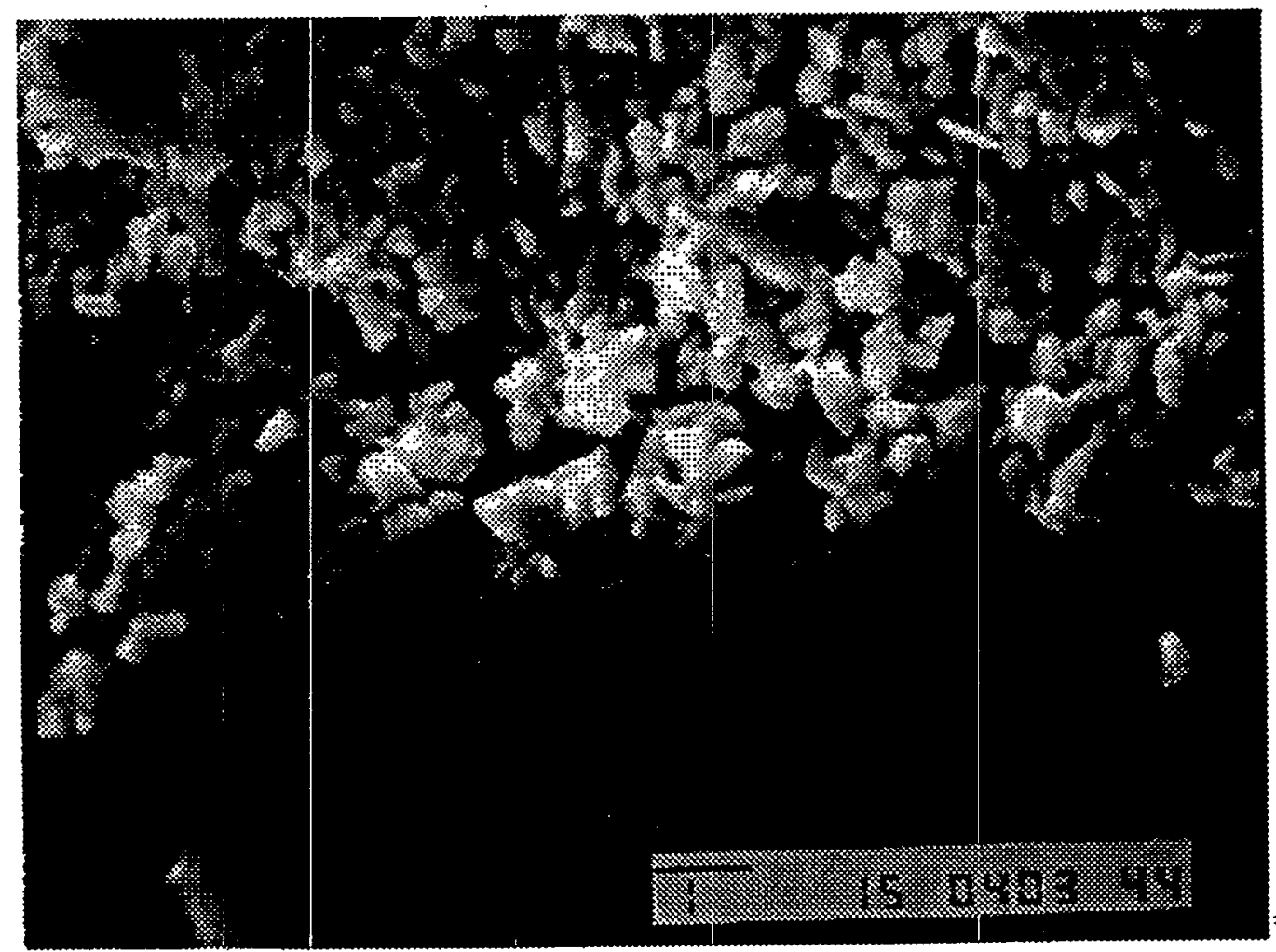

Figure 4.22. Site 12, SEM image, $1 \mathrm{~cm}$ from contact. Equant crystals are Fe-oxide, probably magnetite. Scale bar is $1 \mu \mathrm{m}$. 


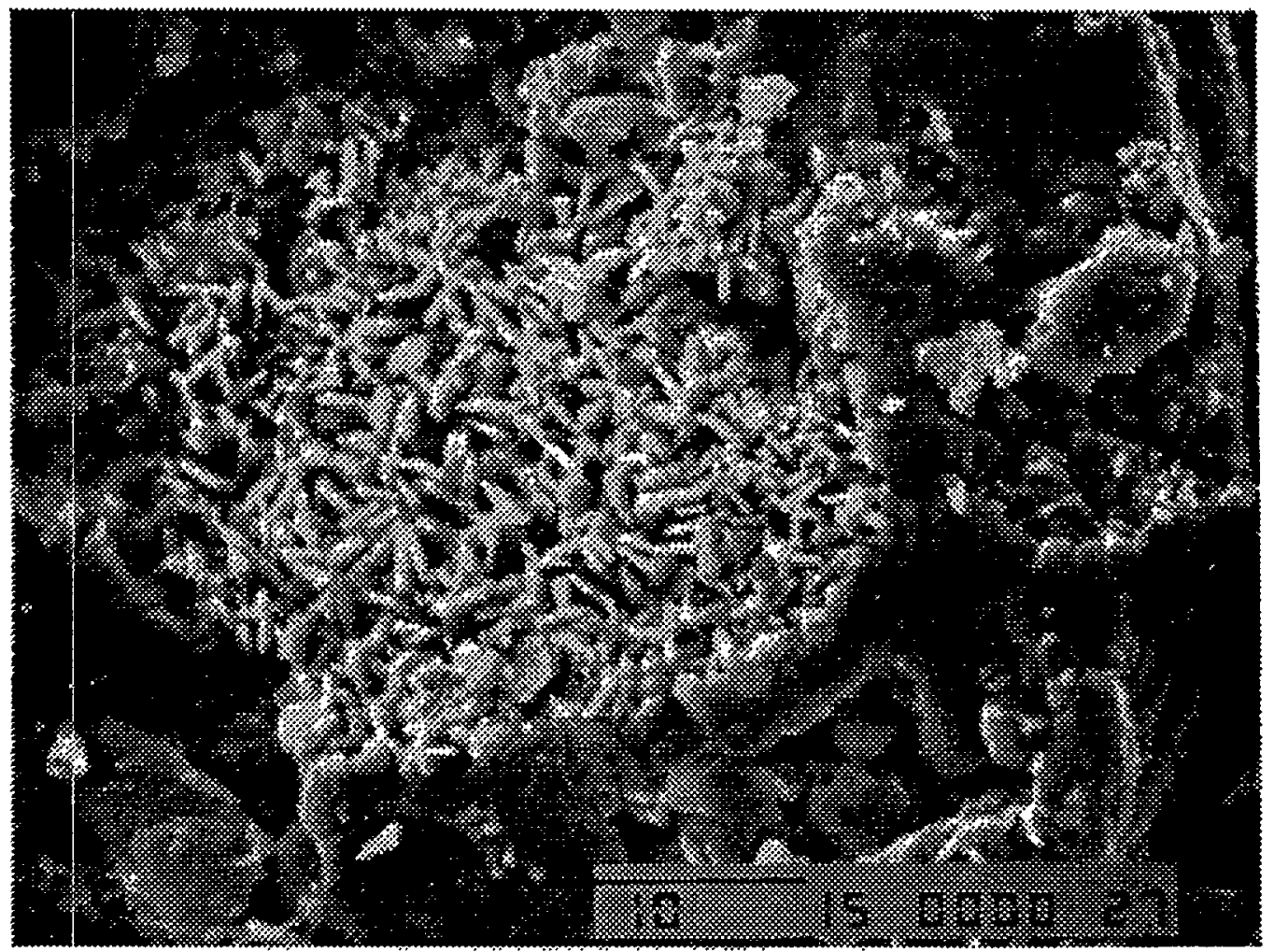

Figure 4.23. Site 12, SEM image, $1 \mathrm{~cm}$ from contact. Albite blades lining voids in devitrified, pumiceous ash. Scale bar is $10 \mu \mathrm{m}$.

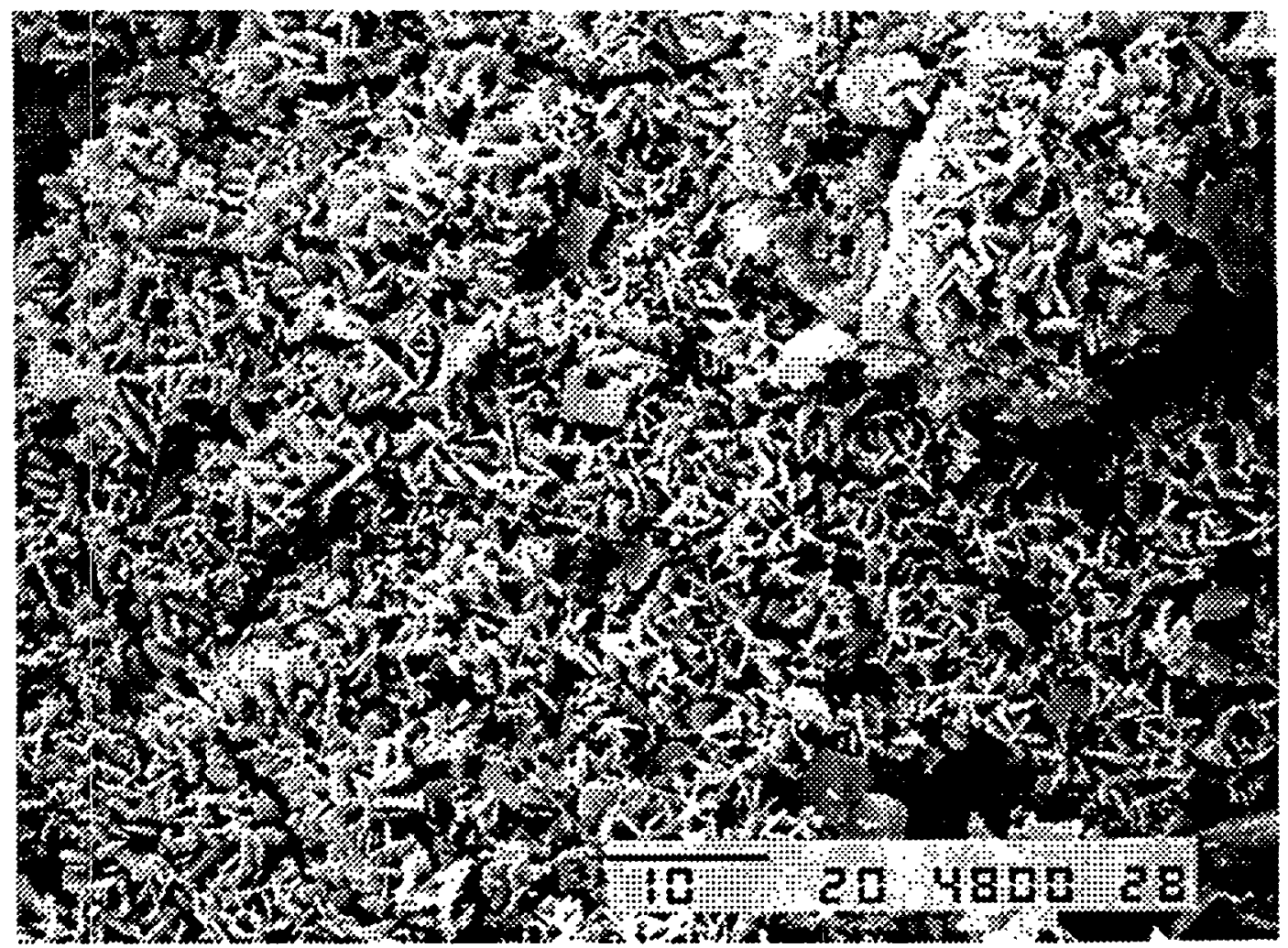

Figure 4.24. Site 12, SEM image, $1 \mathrm{~cm}$ from contact. Alteration lining void in ashy matrix; principally albite. Scale bar is $10 \mu \mathrm{m}$. 


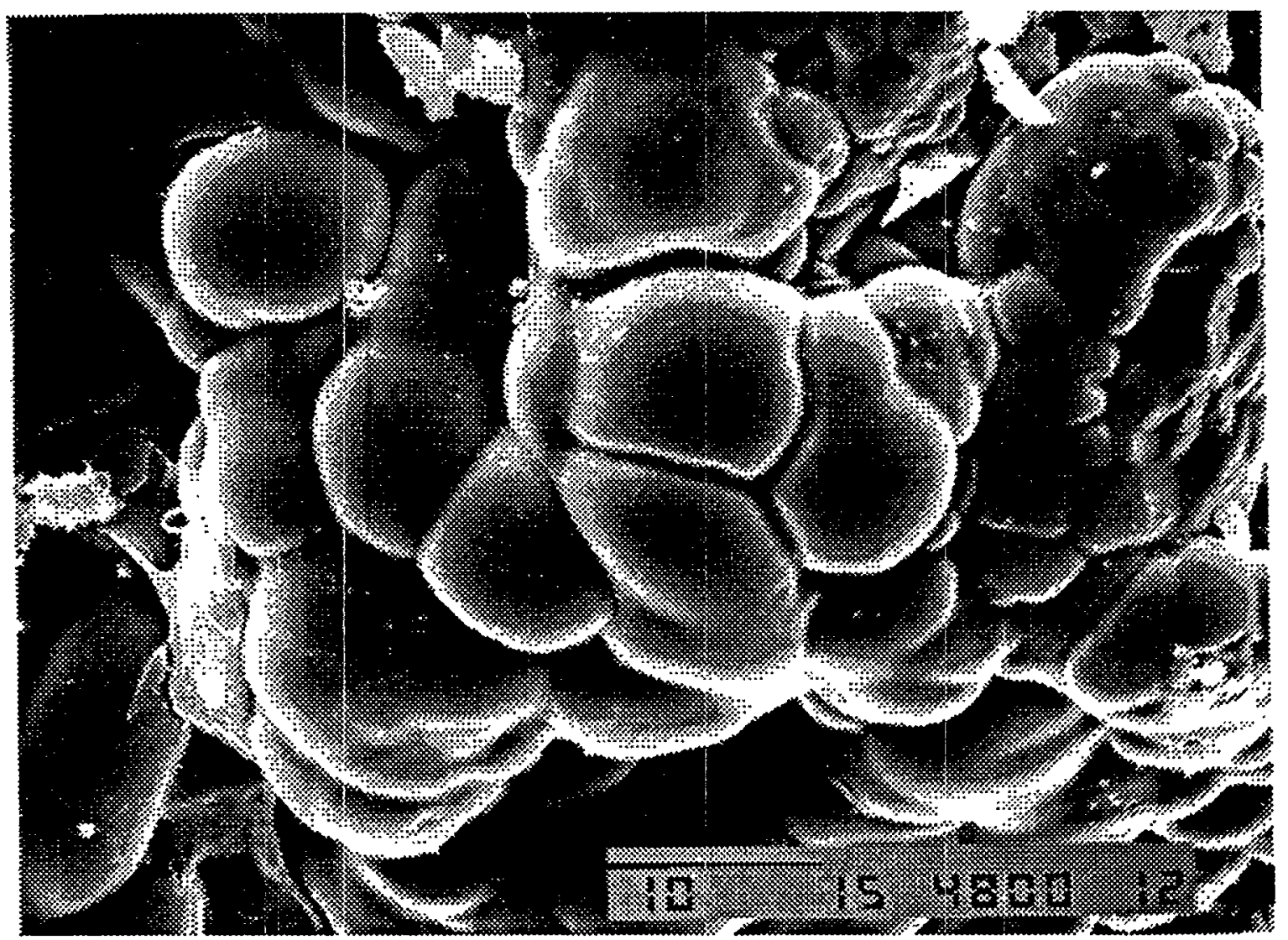

Figure 4.25. Site 10, SEM image. Botryoidal silica. Scale bar is $10 \mu \mathrm{m}$. 


\subsection{X-ray Diffraction (XRD)}

4.11.1 Purpose. In this study, XRD was used principally to determine the fraction of glass in tuff samples, or to search for evidence of hydrothermal and low temperature alteration in the form of clays and zeolites. The temperatures predicted by the thermal models (section 5), applied over hundreds of years, should be adequate to devitrify the tuffs between the boiling front ( $c . f$. section 5 ) and the BBO-BRT contact. Thus a significant decrease in the fraction of glass nearest the BBO-BRT contact, combined with experimental rates of devitrification, could help constrain the intensity and duration of the heating pulse. Conversely, if the heating pulse is considered to be well-known and accurately modeled, but experimental data are lacking, the extent of devitrification at the analogue site could be used to estimate rates of devitrification and water release in heated repository tuffs. For those tuffs out beyond the boiling front, where liquid water is present, a period of a few hundred years near boiling should produce alteration minerals such as clays, fine-grained feldspar and silica, or zeolites. Since the mineralogy of the alteration products greatly affects the sorption coefficient for radionuclides such as $\mathrm{Cs}$ and $\mathrm{Sr}$, it is useful to compare the minerals that form against the predictions of equilibrium codes used to model YMS and other repositories.

4.11.2 Methods. All XRD analyses were performed with a vintage Phillips goniometer/generator combination, using a $\mathrm{Cu}$ tube and $\mathrm{Ni}$ filter at 40 to $50 \mathrm{kV}$ accelerating potential and 20 to $25 \mathrm{~mA}$ filament current. A post-sample graphite monochromator was used to greatly reduce fluorescence effects and provide a very low background in the low-angle portion of the spectrum. For glass analyses, finely ground samples were packed into aluminum well slides, and analyzed against a standard of Panum Crater Obsidian (100\% rhyolite glass) and NIM-G granite (100\% crystalline, approximately rhyolite composition) as the background. Several positions on the broad glass peak at $\approx 15$ to $25^{\circ} 2 \theta$ were used for analysis, depending on the extent of interference from silica polymorphs and crystalline feldspars. To detect clays and other alteration minerals, we used both bulk samples in well slides, and water-settled samples drifted onto aluminum or quartz slides (the quartz slides are cut at a non-diffracting angle, and yield extremely low backgrounds). To obtain the highest sensitivity, the samples were finely ground in a shatterbox or McCrone micronizing mill, then centrifuged in deionized water to leave the sub- $10 \mu \mathrm{m}$ particles in suspension. The supernatant was then filtered through a $0.25 \mu \mathrm{m}$ nucleopore filter, and the "clay" paste transferred from the filter to a quartz slide.

4.11.3 Results. Results of XRD analyses are discussed elsewhere. In general, we found clays only in VC-1 core samples from the VC1O and VC1T. The clays were principally illite, and may represent a weathering surface (also identified in the core log, Gardner et al. 1987) rather than a zone of hydrothermal alteration. 


\section{THERMAL MODELING}

The interpretation of chemical variations at sites 8,12 and 13 requires estimates of the tuff temperatures as a function of distance from the BBO-BRT contact and time. Early in the project, we calculated the temperatures below a horizontal, infinite 150 meter-thick sheet of obsidian, assuming all heat transfer was by conduction, and a conductivity of $2.5 \mathrm{~W} /(\mathrm{m} \cdot \mathrm{K})$ for all rocks (figure 3.1); these calculations were intended for the VC-1 corehole samples, where much of the interval below the BBO is dense, low permeability volcanic rock. The early calculations predicted that broad regions of the tuff would be subject to moderately high temperatures $\left(300-400{ }^{\circ} \mathrm{C}\right)$ and shallow thermal gradients for long time periods. These predictions seemed inconsistent with the relatively narrow zones of devitrification and $\mathrm{Cl}$ depletion described in section 4, and the limited extent of the pink coloration seen in the outcrop samples. In addition, the apparent plastic deformation of the site 12 tuffs seemed inconsistent with the relatively low boundary temperatures $\left(\leq 450^{\circ} \mathrm{C}\right)$ predicted by the early model. The glass point of rhyolite at $1 \mathrm{~atm}$ is $\approx 670^{\circ} \mathrm{C}$ (Jambon, 1982; and unpublished data of H.R. Westrich, Sandia National Laboratories). Below that temperature, plastic deformation is unlikely. As the emphasis of the project shifted to the outcrop samples, it became clear that the early calculations were inappropriate, and must be modified to account for the high porosity and low thermal conductivity of the tuffs, as well as the latent heat of vaporization of pore waters.

The modified thermal model breaks the problem into two calculation steps, and three temperature regions $\left(T_{1}, T_{2}\right.$ and $T_{3}$, shown in figure 5.1). The first step obtains the temperature $T_{1}(t, z)$ in the BBO flow, as a function of time $t$ and depth $z$. To calculate $T_{1}$, we assume that the tuff is comparatively insulating, and heat loss is dominated by convection, radiation and evaporative heat effects near the BBO-air interface. In the second step, a Stefan solution (Crank, 1984) is calculated for $T_{2}(t, z)$ and $T_{3}(t, z)$ in the dry and wet regions of the tuff, respectively; the values of $T_{1}(t, z)$ at $z=$ the BBO-BRT interface supply one of the needed boundary conditions. The position of the boiling front, relative to the BBO-BRT contact is denoted as $\delta(t)$ (figure 5.2); the Stefan solution requires that the temperature $\mathrm{T}_{2}(\mathrm{t}, \delta(\mathrm{t}))=\mathrm{T}_{3}(\mathrm{t}, \delta(\mathrm{t}))$, and also requires energy balance of the form $\mathrm{h}_{\mathrm{g}} \rho_{\mathrm{g}} \phi(\mathrm{d} \delta(\mathrm{t}) / \mathrm{dt})=$ $\mathrm{k}_{3}\left(\partial \mathrm{T}_{3}(\mathrm{t}, \delta(\mathrm{t})) / \partial \mathrm{z}\right)-\mathrm{k}_{2}\left(\partial \mathrm{T}_{2}(\mathrm{t}, \delta(\mathrm{t})) / \partial \mathrm{z}\right)$, where $\mathrm{z}$ is distance along the vertical axis, $\mathrm{h}_{\mathrm{g}}$ is the latent heat of water, $\rho_{\mathrm{g}}$ is the density of steam, $\phi$ is the fractional porosity, and $k_{2}$ and $k_{3}$ are the effective conductivities through the dry and wet tuff zones, respectively. It is assumed that the excess volume of steam is removed from the system, and there are no provisions for capillarity or transient pressures above $1 \mathrm{~atm}$.

Figure 5.3 (top) shows the calculated temperatures $T_{1}(t, z)$ in the flow at $1,10,100$ and 500 years after emplacement. The initial temperature of the flow was taken as $850^{\circ} \mathrm{C}$, the density of the flow as $2300 \mathrm{~kg} / \mathrm{m}^{3}$, the heat capacity as $1000 \mathrm{~J} /(\mathrm{kg} \cdot \mathrm{K})$ and the conductivity as 2 $\mathrm{W} /(\mathrm{m} \cdot \mathrm{K})$. The density and thermal properties are consistent with the values reported by Guzowski et al. (1983) for half-devitrified, half-glassy obsidians. Rainfall was estimated as $0.38 \mathrm{~m} \mathrm{(15")} \mathrm{per} \mathrm{year,} \mathrm{approximately} \mathrm{the} \mathrm{modern-day} \mathrm{precipitation,} \mathrm{and} \mathrm{average} \mathrm{wind} \mathrm{speed}$ 


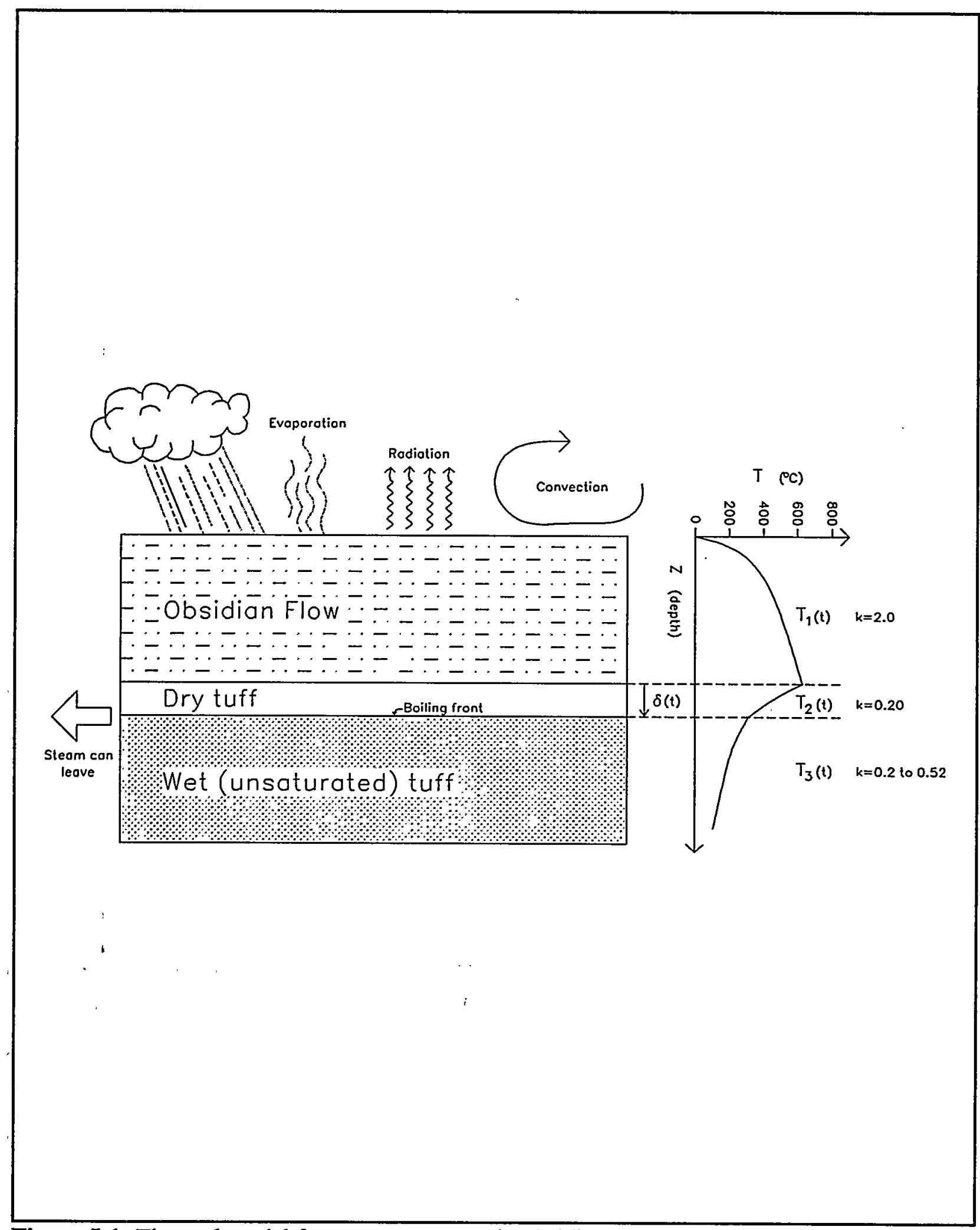

Figure 5.1. Thermal model for temperatures $T_{1}$ in obsidian flow, $T_{2}$ in dry tuff, and $T_{3}$ in partly saturated tuff. 


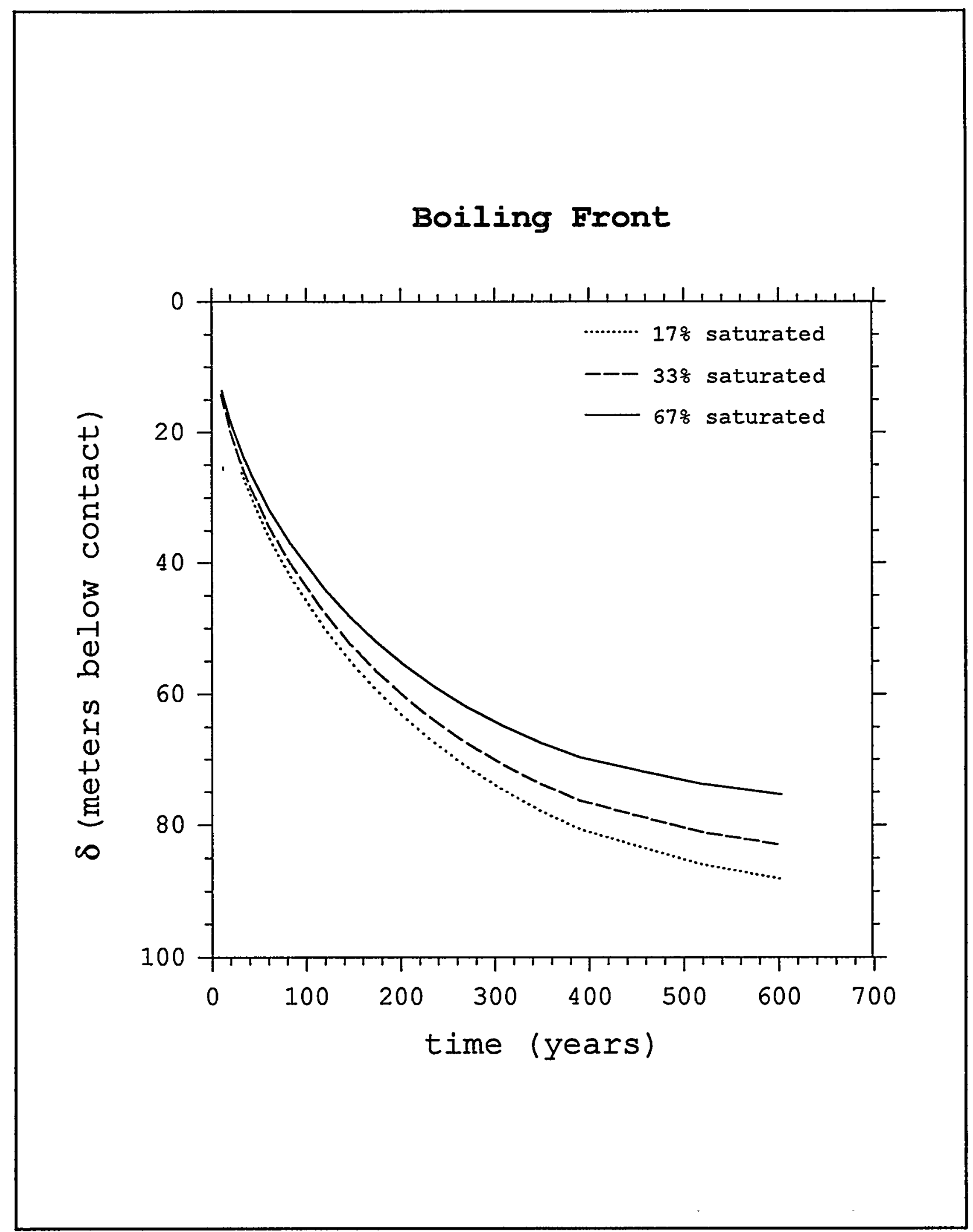

Figure 5.2. Movement of boiling front with time, for three different saturations. 


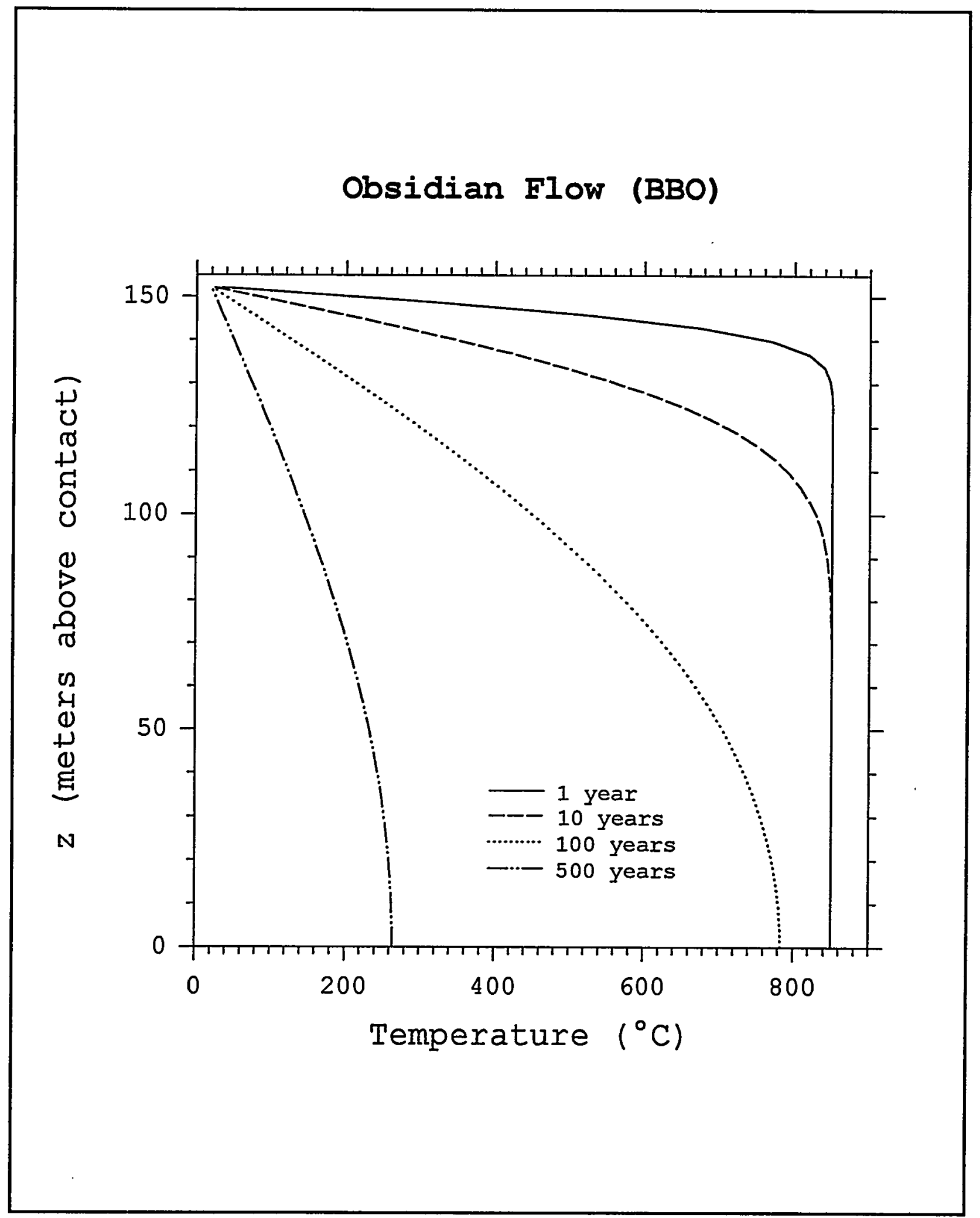

Figure 5.3. Temperature in the Banco Bonito obsidian (BBO) as a function of time and distance from the BBO-BRT contact. 
Tuff (BRT)

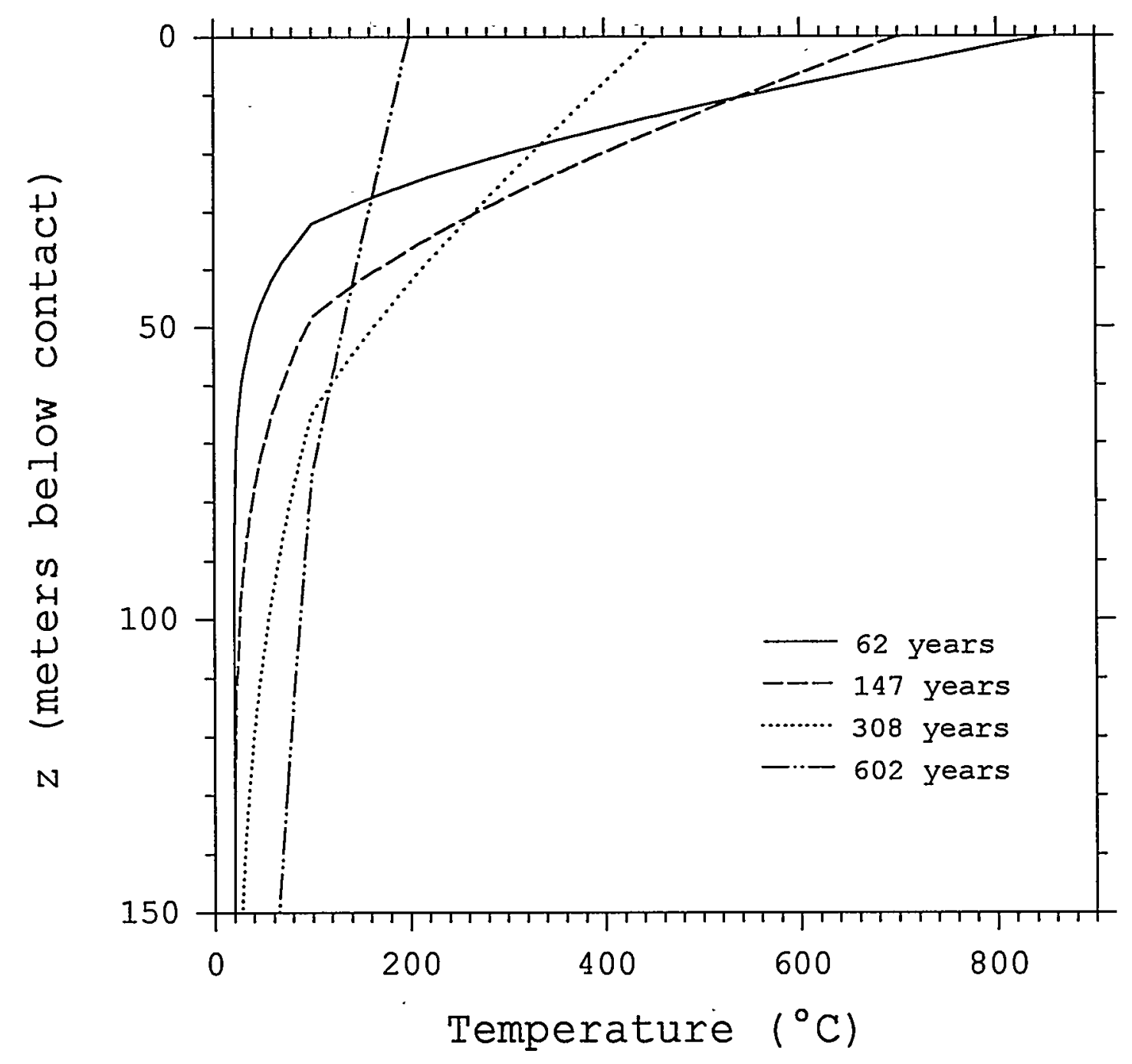

Figure 5.4. Temperature in the Battleship Rock tuff (BRT) as a function of time and distance from the BBO-BRT contact. 
was assumed to be $2.315 \mathrm{~m} / \mathrm{sec}(5 \mathrm{mph})$. The heat transfer coefficients for radiation and convection were estimated to be 28 and $1.95 \mathrm{~W} /\left(\mathrm{m}^{2 \circ} \mathrm{K}\right)$, and the average evaporative heat transfer q" $=31 \mathrm{~W} / \mathrm{m}^{2}$ for both sensible and latent heat. Heat loss from the top of the flow proves to be very effective, and indicates that future models can simply set the top boundary condition as $\mathrm{T}=20^{\circ} \mathrm{C}$. Because we are considering the lower contact to be an insulator, the temperature of the lower contact starts off much higher than was predicted by the early conduction model.

Figure 5.3 (bottom) shows the results of the Stefan calculations for temperature below the BBO-BRT contact. The grain density of the tuff was taken as $2450 \mathrm{~kg} / \mathrm{m}^{3}$, assuming the tuffs averaged roughly $2 / 3$ glass and $1 / 3$ quartz and feldspar. The average measured density of two site 13 tuffs was $1350 \mathrm{~kg} / \mathrm{m}^{3}$, corresponding to $45 \%$ porosity. We don't know the percent saturation of the tuffs at the time of heating, but assuming precipitation and recharge were similar to current values, it is reasonable to use values of $16.6 \%, 33.3 \%$, and $66.6 \%$ to bound the calculation (the latter is consistent with the average at YMS, Flint et al. 1993). From recent measurements on similar YMS tuffs (data provided by Connie Chocas, Sandia National Labs, Albuquerque), the average conductivity of the dry tuffs is taken as 0.2 $\mathrm{W} /\left(\mathrm{m}^{2 \circ} \mathrm{K}\right)$; this latter value may seem remarkably low, but we feel it reasonably reflects the glassiness and texture of the tuffs, with relatively small contact points between the matrix shards. The conductivity of fully saturated tuff was taken as $0.52 \mathrm{~W} /\left(\mathrm{m}^{2} \cdot \mathrm{K}\right)$, based on the correlations given in Guzowski et al. (1983). Figure 5.2 shows the position of the boiling front, as a function of time, for the three different saturations. The curves are quite close to one another, because the lower conductivity of the tuff at low saturation compensates for the lower rate of heat loss from evaporation. Thus the calculations are relatively insensitive to the assumed saturation. The dry zone expands rapidly to a depth greater than the entire extent sampled at any of the outcrop sites. During heat-up, the time for liquid water interactions in the sampled areas was relatively short, perhaps just days to a few years for samples within 1 to 10 meters of the contact. Figure 5.3 (bottom) shows the temperature profiles as a function of depth below the contact for the case of $2 / 3$ saturation, at three times. Temperatures near the contact stay above the glass point for over 100 years.

For comparison, Wilder (1993) gives positions of the boiling front in YMS tuffs surrounding a typical spent fuel rod. The front is $\approx 8 \mathrm{~m}$ from the fuel rod after 25 years, and $20 \mathrm{~m}$ from the rod after 400 years. The simple model given above predicts the front is $20 \mathrm{~m}$ from the contact after 25 years, and 75 meters from the contact after 400 years. Capillarity is included in the calculations presented by Wilder.

The new thermal model probably overestimates the time-averaged temperature of the tuffs near the site 8,12 and 13 contacts, for at least two reasons. First, the model is really designed to predict temperatures below an infinite slab of rhyolite, $152 \mathrm{~m}$ thick; edge effects would yield more rapid cooling at sites 8 through 13 . Second, the model does not account for capillary effects described by Bixler and Carrigan (1986) and others. Rapid boiling can force pressurized steam into the tuff, while capillarity tends to draw water back into the boiling front. The steam formed by evaporation may simply recondense a few meters into the tuff, 
enhancing the cycle of heat loss through evaporation and suction. However, it is also possible that the steam may travel hundreds of meters before condensing, and will interact with large masses of tuff and become enriched in volatile components. The resulting "heat pipe" could produce thermal gradients much steeper than those shown in figure 5.3, and yield a dry zone, only a few meters wide, that is stable over several hundred years (Bixler and Carrigan, 1986). As discussed in section 7.2, the development of a semi-stable boiling front, with water replenishment due to capillarity, may be consistent with the fluorine enrichment patterns observed at several of the sites, and should be modeled in future work.

Our simple thermal model also fails to account for the inevitable replenishment of the tuff with water, through simple recharge; the significance of this process is debatable. Rates of reaction depend strongly on temperature; for example, the dissolution of albite at $\mathrm{pH} 8$ is at least 10 times faster at $70^{\circ} \mathrm{C}$ than at $25^{\circ} \mathrm{C}$ (Knauss and Wolery, 1986). If the time scale of recharge is relatively short (tens to hundreds of years), the tuff will still be warm (say, 70 to $110^{\circ} \mathrm{C}$ ) as the wetting front collapses back toward the contact, and this "cool-down" stage may be a period of substantial hydrothermal alteration. However, if the time scale of recharge is more like thousands of years, the tuff may be so cool that little alteration is effected as it is rewet. But even if the tuff averages $70^{\circ} \mathrm{C}$ for 1000 years, the reactions that occur in this time may still be swamped by the reactions that occur in the subsequent 400,000 years at roughly $25^{\circ} \mathrm{C}$ - the factor of ten increase in reaction rates, at $70 \mathrm{vs} .25^{\circ} \mathrm{C}$, can't compete with the factor of 400 in time. 


\section{GAS TRANSPORT EXPERIMENTS}

Thermal modeling suggests two distinct processes for producing chemical alteration. The first is reactions between tuff and liquid water at temperatures of 20 to $100^{\circ} \mathrm{C}$, in and behind the boiling front, perhaps enhanced by capillarity and the effects of evaporation. This process is amenable to conventional reaction path modeling, and will be discussed in section 7. The second process involves interaction of the tuff with steam at 100 to $850{ }^{\circ} \mathrm{C}$. Because the steam will eventually recondense, the second process links into the first, and must be considered when we estimate the composition of the pore waters in the boiling/evaporation front. The second process is not easily handled by reaction path modeling, since thermodynamic data are sparse at high temperatures, and the release of volatiles from heated tuff may well be diffusion dominated and poorly modeled by equilibrium calculations. Thus it is necessary to perform experiments to constrain the interactions between tuff and steam. The analytical results from section 4 hint at transport of halogens in the heated tuff, and since there are many volatile halogen compounds, we designed experiments to measure the release of halogens (and some metals) from heated tuff.

The experimental apparatus is shown in figure 6.1. A sample of washed, crushed BRT $(0.25 \mathrm{~mm} \leq$ particle diameter $\leq 1 \mathrm{~mm})$ is placed between two wads of $\mathrm{SiO}_{2}$ wool, in the center of a $2.5 \mathrm{~cm}$ diameter silica glass tube, which is in turn placed in a clamshell tube furnace. The large tube is fitted with teflon caps, and a narrow silica tube penetrates the outlet cap and serves as a thermocouple well. A peristaltic pump feeds stock solution (in these experiments, deionized water) through a silica carburetor in the inlet cap. Water entering the carburetor vaporizes, travels through the heated tuff, and recondenses in the outlet fitting, where it drains into the collection vial. The apparatus is tilted down from the inlet at an angle of $\approx 5^{\circ}$ to ensure the carburetor and outlet drain properly. The linear speed of gas through the system $m_{i}$ can be quite high, and very little moisture condenses before reaching the outlet fitting.

Two experiments were run in this apparatus. In the first, temperature was ramped incrementally from 125 to $800^{\circ} \mathrm{C}$, and held at each increment for several hours. One to 6 fluid samples were taken at each temperature, and a total of $1383 \mathrm{~g}$ of steam was passed through $33.2 \mathrm{~g}$ of rock in 15 days. In the second experiment, the large silica tube and cap assembly was dropped into a pre-heated furnace, then the system was rapidly ramped to. $400^{\circ} \mathrm{C}$ and held at that temperature for 54 hours; $172 \mathrm{~g}$ of steam was passed through $33.8 \mathrm{~g}$ of rock in that time. Both experiments used a homogenized tuff sample taken far from the BBO-BRT contact.

Figure 6.2 shows the concentrations of $\mathrm{Cl}$ and $\mathrm{F}$ in the steam as a function of temperature, for the first experiment. Release" of $\mathrm{F}$ increases with temperature till $\approx 600^{\circ} \mathrm{C}$, then decreases; $\mathrm{Cl}$ release rises until $800{ }^{\circ} \mathrm{C}$. At any given temperature, the release rate declines with time, making the curves jagged. The dotted lines and small symbols on the lower part of the plot show the results of a "blank" experiment, run with all components of the system except the tuff sample. Except at the lowest temperatures, contamination from the apparatus 
(e.g., teflon plugs) appears to be insignificant. The main point is that significant amounts of both halogens are released over a course of hours, and that $\mathrm{F}$ release dominates $\mathrm{Cl}$ up to about $600^{\circ} \mathrm{C}$, when the pattern reverses. Figure 6.3 shows the same data recast as the apparent steam/rock partition coefficients for $\mathrm{F}$ and $\mathrm{Cl}$. Partition coefficients at higher temperatures are less certain, because there is poor control on the mass balance when the rock becomes very depleted in $\mathrm{F}$ and $\mathrm{Cl}$. Except at the very highest temperatures, the $\mathrm{K}_{\mathbf{p}}$ 's are substantially less than one. We recognize that these are not true partition coefficients; the sawtooth appearance of the curves suggests release is partly diffusion-limited, thus the " $K_{D}$ " may depend on the flow rate of steam through the system.

The second type of experiment was designed to investigate the kinetic effect more systematically. The results in figure 6.4 are cast as ppm of $\mathrm{Cl}$ and $\mathrm{F}$ lost from the rock per second. SEM examination of pre- and post-test samples shows that the tuff matrix consists of pumiceous fragments, and the septa separating the voids average $\approx 10 \mu \mathrm{m}$ in thickness; the pumice remains glassy (does not devitrify) for the duration of the experiment. We model diffusion of $\mathrm{F}$ and $\mathrm{Cl}$ through the septa as diffusion from a planar sheet of rhyolite glass, and we assume the rate of steam flow is so great that the surface of the septum is maintained at zero concentration. By differentiating equation 4.18 in Crank (1975), it is easily shown that the average concentration ' $C$ of halogen in the pumice follows:

$$
\frac{d C}{d t}=\frac{2 D C_{0}}{w^{2}} \sum_{n=0}^{\infty} \exp \left[\frac{-D(2 n+1)^{2} \pi^{2} t}{4 w^{2}}\right]
$$

where $C_{0}$ is the initial average concentration, $w$ is the width of a septum $(10 \mu \mathrm{m}), D$ is the diffusion coefficient, and $t$ is time. At the conditions of the $400{ }^{\circ} \mathrm{C}$ experiment, the first term dominates, such thạt

$$
\ln \left(\frac{d C}{d t}\right) \approx \ln \left(\frac{2 C_{0} D}{w^{2}}\right)-\left(\frac{D \pi^{2}}{4 w^{2}}\right) t
$$

Thus by fitting straight lines to the logs of the loss data in figure 6.4 , one can obtain both the initial concentration $C_{0}$ and the diffusion coefficient; in practice, it is better to use a nonlinear fitting routine to avoid putting over-emphasis on the low loss rates, which are more strongly influenced by contamination. Three fitted lines are superposed on figure 6.4 ; at the top is a dash-dot-dot-dash line for $\mathrm{F}$, which yields $C_{0}=177 \mathrm{ppm}$ and $D=1.5 \cdot 10^{-12}$ $\mathrm{cm}^{2} / \mathrm{sec}$. The fitted concentration is quite close to the real rock concentration of $\approx 300 \mathrm{ppm}$, especially when we consider that some fraction of the rock F content (roughly $100 \mathrm{ppm}$ ) is locked up in large obsidian clasts and is not available for transport on the time scale of the experiment. At the bottom of figure 6.4 are two fits for $\mathrm{Cl}$ : the solid line is for all data and yields $D=6.3 \cdot 10^{-12} \mathrm{~cm}^{2} / \mathrm{sec}$ and $C_{0}=2.7 \mathrm{ppm}$, and the dashed line fits the last 6 points 
and yields $D=1.6 \cdot 10^{-12} \mathrm{~cm}^{2} / \mathrm{sec}$ and $C_{0}=4.2 \mathrm{ppm}$. Obviously, 2.7 to $4.2 \mathrm{ppm}$ is far below the whole rock average of $\approx 300 \mathrm{ppm}$, and suggests the model is either inappropriate for $\mathrm{Cl}$, or a large fraction of the $\mathrm{Cl}$ in the sample is effectively unavailable for diffusion at $400^{\circ} \mathrm{C}$.

Sodium concentrations in the condensed steam (measured by DCP, or Direct Current Plasma Spectrometry) were low, typically less that one tenth the Cl concentrations. INAA of concentrated condensates showed extremely low levels of all metals, effectively at the level of the blank. Since the amount of metals in the steam is so small, the halogens must have been transported as neutral species, probably $\mathrm{HF}$ and $\mathrm{HCl}$.

The diffusion and partition coefficients derived from this study are qualitative indicators at best, since very few experiments were performed and the samples are inherently complex and inhomogeneous. However, our results are within the range of the very limited $\mathrm{F}$ and $\mathrm{Cl}$ diffusion coefficients reported in the literature. We first note that diffusion coefficients in rhyolite glasses covary with the glass water content (Jambon, 1982). Tuff glasses start at $\approx 2 \% \mathrm{H}_{2} \mathrm{O}$, and dehydrate to $\approx 0.3 \%$ at $800^{\circ} \mathrm{C}$ in the presence of $1 \mathrm{~atm}$ steam pressure, so it is reasonable to expect a drop in the diffusion coefficient with increases in time and temperature in these experiments. Diffusion measurements for halogens in silicate glasses are sparse, and most are for anhydrous or water-poor systems. Hermann et al. (1987) suggest diffusion coefficients for $\mathrm{Cl}$ will be several orders of magnitude larger than those for $\mathrm{F}$; however, their $\mathrm{Cl}$ data are suspect due to the high measured $\mathrm{Cl}$ solubility, the peculiar pressure dependence, and the use of $\mathrm{Cl}_{2}$ gas. Dingwell and Scarfe (1985) measured $\mathrm{F}$ diffusion in three anhydrous $\mathrm{Na}_{2} \mathrm{O}-\mathrm{Al}_{2} \mathrm{O}_{3}-\mathrm{SiO}_{2}$ melts; a tenuous extrapolation of data for their "albite" composition to $400^{\circ} \mathrm{C}$ yields $\mathrm{D} \approx 10^{-13} \mathrm{~cm}^{2} / \mathrm{sec}$, but there was a strong dependence on glass composition in this limited set of experiments, suggesting the need to obtain data for compositions that more closely match the BRT glasses. Jambon (1982) measured diffusion coefficients for a variety of cations in obsidian glasses and melts, and concluded that the activation energies were largely dependent on the squared formal charge and the ionic radius. Using Jambon's correlation and the ionic radii given in Bloss (1971), one obtains $\mathrm{D} \approx 10^{-11}$ $\mathrm{cm}^{2} / \mathrm{sec}$ for $\mathrm{F}^{-}$at $400^{\circ} \mathrm{C}$. Mitra and Parker (1984) modeled $\mathrm{Na}_{2} \mathrm{O}-\mathrm{SiO}_{2}$ melts via molecular dynamics, and concluded the diffusion coefficient for $\mathrm{F}^{-}$should be about one half the coefficient for $\mathrm{Na}^{+}$.

The most significant finding of these experiments is that it is easy to produce a gas with tens to even hundreds of ppm $\mathrm{Cl}$ and $\mathrm{F}$, by interacting steam with glassy tuffs near the BBO-BRT contact. These results (particularly the high $\mathrm{F} / \mathrm{Cl}$ at low temperature) are consistent with the recent study by Vaniman et al. (1993), who measured volatile releases from tuffs heated at $50-400{ }^{\circ} \mathrm{C}$ over a 3.4 year period. Given the apparent diffusion-dependence of the release, the concentration of halogens in the steam will depend heavily on the steam flow rate through the system. 


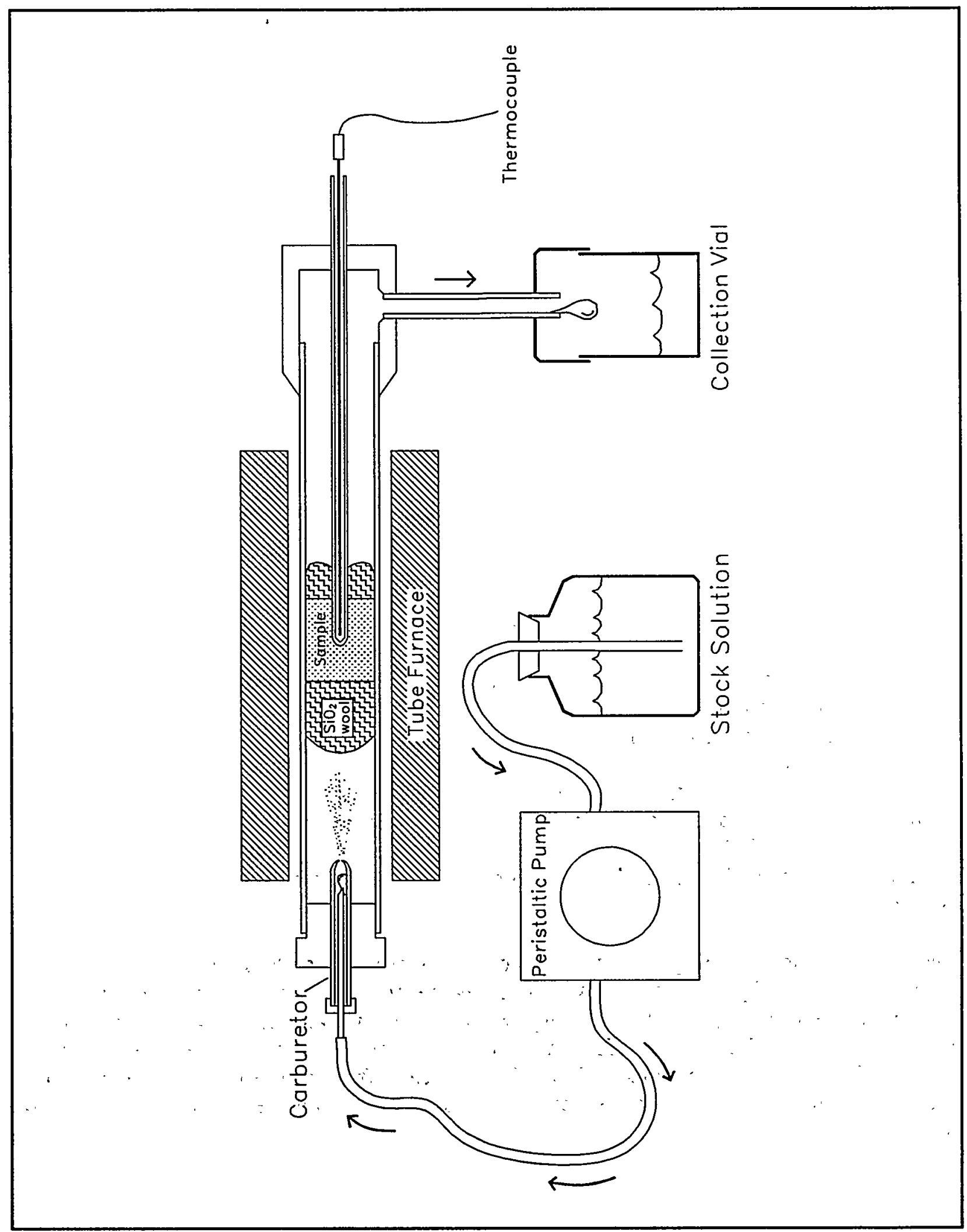

Figure 6.1. Apparatus for flowing gas experiments. 


\section{$\mathrm{F}$ and $\mathrm{Cl}$ in Flowing Gas Experiment}

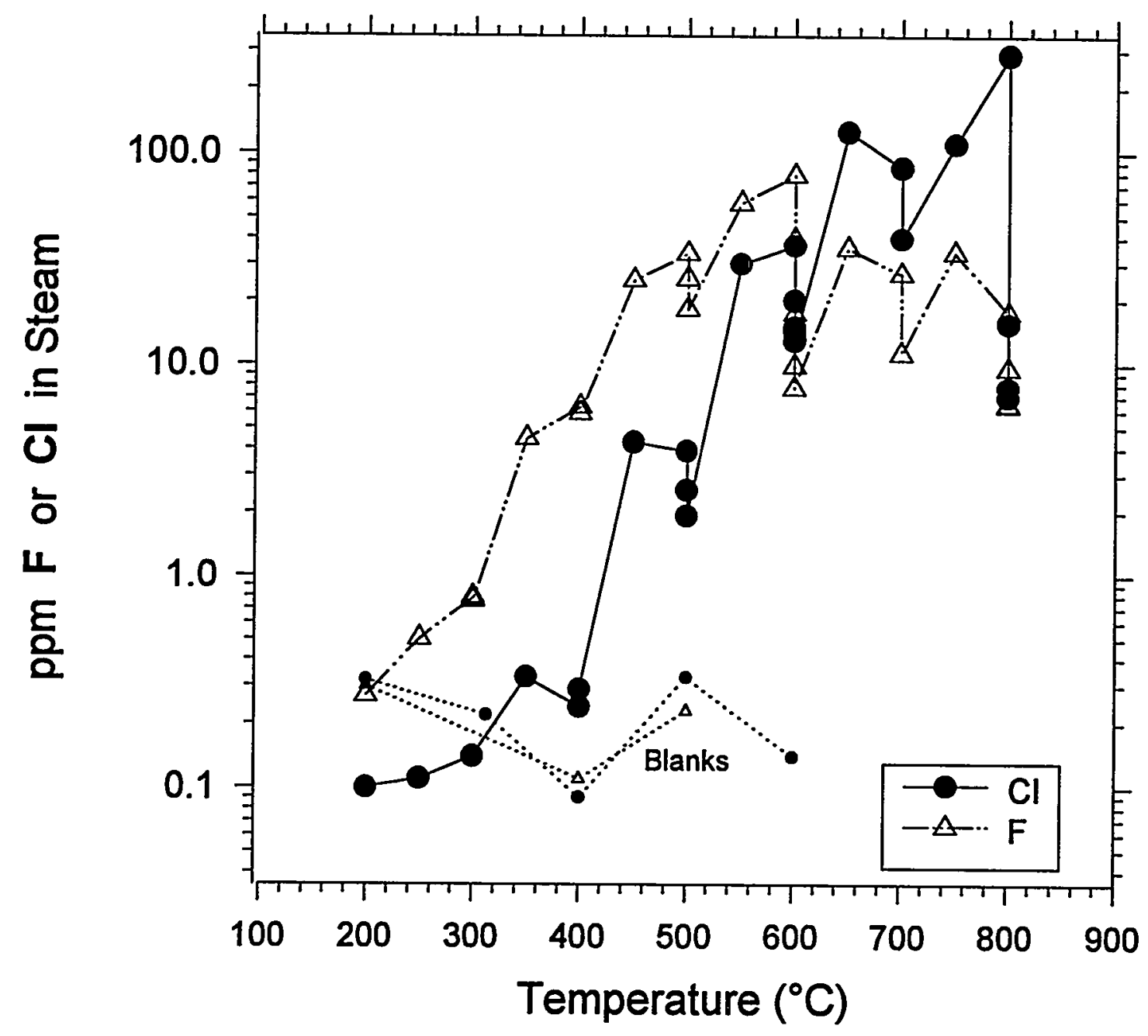

Figure 6.2. Release of $\mathrm{Cl}$ and $\mathrm{F}$ from tuff, as a function of temperature, from first experiment. 


\section{Apparent Gas/Rock $\mathrm{K}_{\mathrm{D}}$ for $\mathrm{Cl}$ and $\mathrm{F}$}

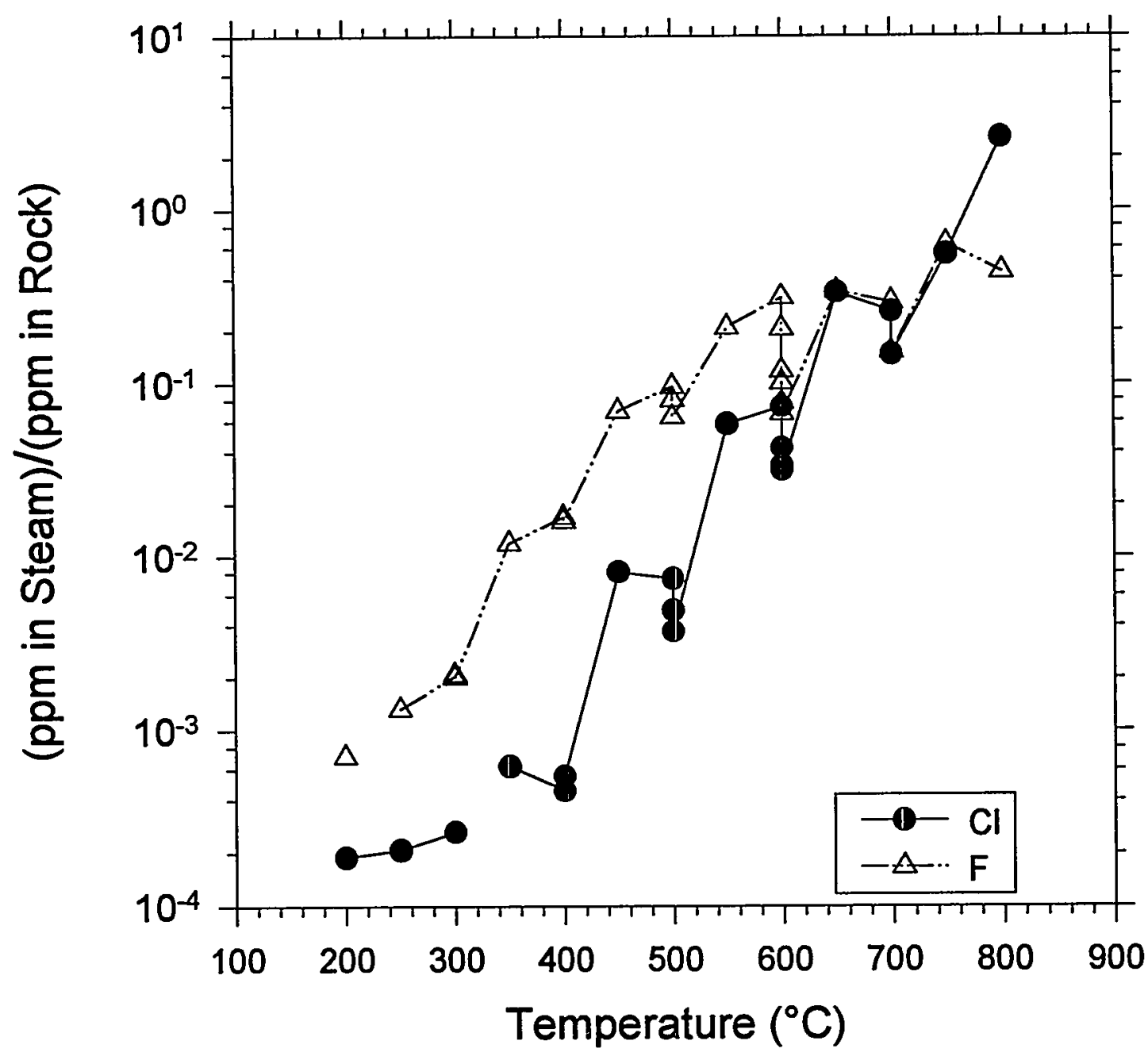

Figure 6.3. Apparent partition coefficients for ( $\mathrm{F}$ or $\mathrm{Cl}$ in steam)/(F or $\mathrm{Cl}$ in rock). 


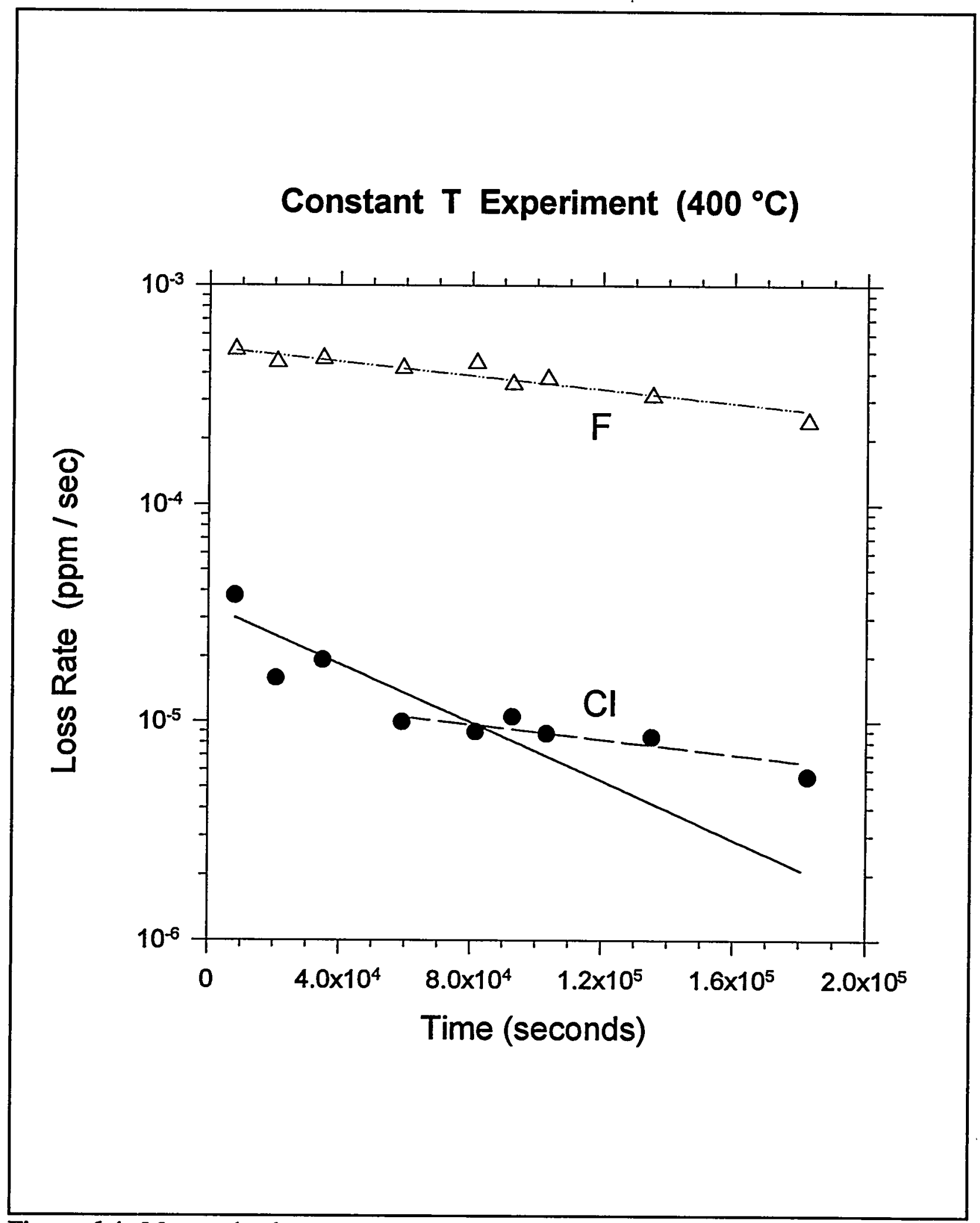

Figure 6.4. Measured release rates and fitted release curves for second experiment $(\mathrm{T}=$ $\left.400^{\circ} \mathrm{C}\right)$. 


\section{DISCUSSIION}

\subsection{Origin of Composition Variations: Overview}

In all three sites where we obtained fluoride and chloride analyses, there is a distinct decrease in fluoride with distance from the contact, and an increase in chloride (figures 4.6, $4.11,4.16)$. At site 13 , where the decrease in $\mathrm{F}$ is barely statistically significant, there is still a distinct antipathy between $\mathrm{Cl}$ and $\mathrm{F}$; local peaks in $\mathrm{F}$ concentration are likely to be local minima in $\mathrm{Cl}$ concentration. The scales of these variations are very different among the sites; e.g. $1.2 \mathrm{~m}$ at site $12, \mathrm{vs}$. $>6 \mathrm{~m}$ at site 13 . Since the width of the high-temperature boundary layer may vary radically between vertical and "horizontal" contacts, and will also vary dramatically with the local permeability, the difference in scales does not mean the halogen variations are unrelated to the heating event. The depletion in $\mathrm{Cl}$ corresponds to regions of lower bulk water and glass contents, and probably results from $\mathrm{Cl}$ loss during devitrification (Westrich et al., 1988).

It might be suggested that the $\mathrm{F}$ and $\mathrm{Cl}$ variations existed before the heating event, but the evidence is somewhat contradictory. Fluorine covaries with $\mathrm{Ca}, \mathrm{Fe}$ and $\mathrm{Mg}$ at sites 8 and 12 . At site 13 , the concentration maxima and minima coincide for $\mathrm{F}, \mathrm{Ca}, \mathrm{Fe}$ and $\mathrm{MgO}$. This covariance suggests some fraction of the $\mathrm{F}$ is controlled by amphiboles and biotite. However, such minerals make up only a percent of the rock at most; as shown in section 4.8, they are unlikely to account for more than $10 \mathrm{ppm}$ of the whole rock fluorine. Both $\mathrm{Cl}$ and $\mathrm{F}$ can be fractionated during the evolution and sequential eruption of silicic tuffs (Hildreth, 1981), but the two halogens usually vary sympathetically. Both $\mathrm{Cl}$ and $\mathrm{F}$ are released during simple devitrification, so compositional variations for the two halogens cannot be explained by devitrification alone.

The variations in $\mathrm{Th}, \mathrm{Ta}$ and $\mathrm{Fe}$ are difficult to explain by any single mechanism. All three elements tend to be inert in low-temperature hydrothermal processes. We used the EQ3/6 database to calculate $\mathrm{Th}$ and Fe solubility in an aqueous phase in equilibrium with typical tuff alteration minerals (see section 7.2 for details), varying temperature from 60 to $200^{\circ} \mathrm{C}$, and $\mathrm{O}_{2}$ fugacity from $10^{-50}$ to 0.2 atm. The highest solubilities were $10^{-7.6}$ molal for $\mathrm{Fe}$ and $10^{-13}$ molal for Th. The observed variation in Fe concentration is about $0.5 \% \mathrm{Fe}$ by weight at sites 8 and 12 . To increase the tuff Fe concentration by $0.5 \%$, by removing $\mathrm{Fe}$ from solutions with $10^{-7.6}$ molal $\mathrm{Fe}$, would require exchanging $\approx 10^{7}$ pore volumes. It is possible to produce small variations in the concentrations of all three inert elements by dilution. Suppose, for example, that albite and $\mathrm{SiO}_{2}$ were precipitated in the pore spaces of the tuffs. These phases would contain very little $\mathrm{Fe}$, Th or $\mathrm{Ta}$. If the amount of intra-pore precipitation decreased with distance from the contact, there would be a systematic increase in the bulk contents of all three elements with distance from the contact; a variation of $20 \%$ down to $0 \%$ intra-pore filling would yield a commensurate $20 \%$ increase in contents of inert elements. However, while Ta and Th do indeed show such an increase, Fe contents show the opposite trend. 
It could be argued that the variations in major and trace elements seen at sites 8 and 12 represent simple mixing between tuff and obsidian; for several reasons, this origin appears unlikely. The compositions of the tuffs near the contact don't fall on any simple mixing line. At sites 8 and 12, tuff $\mathrm{CaO}$ increases as one nears the contact, to a value higher than the average obsidian value, and $\mathrm{K}_{2} \mathrm{O}$ decreases to a value lower than the average obsidian value - this is the exact opposite of the expected mixing trend (figure 4.10). Large cracks at site 8 (figure 3.5) contain fragments of intruded obsidian, or slight bulges of obsidian at the BBOBRT interface; clearly these cracks were open at the time the obsidian flow was emplaced, and thus the upper meter of tuff cannot represent a mere rubble zone of tuff and obsidian fragments.

\subsection{Chemical Variations Induced by Capillarity/Evaporation}

The existence of a boiling front can create complex compositional variations in heated tuffs. Travis and Nuttall (1987) calculated the distribution of $\mathrm{SiO}_{2}$ and chloride in fractured and porous tuff, as functions of time and distance from the waste canister heat source. A hot, dry zone forms immediately around the canister; the boiled water condenses several meters away, yielding a concentric zone of saturation. Capillary action draws the water outward from the condensation zone; not only is the water drawn away from the heat source, out into the cooler tuff, but it is also drawn back towards the heat source. At a given time, whole rock $\mathrm{SiO}_{2}$ and $\mathrm{Cl}$ tend to peak on both sides of the condensation zone; on the hot side, evaporation tends to concentrate the solutions and cause $\mathrm{SiO}_{2}$ precipitation, whereas in the cool region, the inherent decrease in $\mathrm{SiO}_{2}$ solubility with decreasing temperature also causes a $\mathrm{SiO}_{2}$ buildup. As the boiling front advances, the previous distribution of silica and chloride is partially reequilibrated with the new thermal conditions, complicating the pattern of $\mathrm{SiO}_{2}$ enrichment. Though Travis and Nuttall did not model the eventual contraction of the boiling front back to the waste canister, presumably that process would further complicate the compositional variations. :

The calculations by Travis and Nuttall suggest one should search for regions of silica and halide enrichment as proof of the capillarity/evaporation model. In this section, we attempt to constrain the magnitude of the elemental enrichments, assess the likelihood that these enrichments could be observed within analytical error and the natural variations in the rocks, and compare the actual variations in the rocks with a simple model for concentration by evaporation in the boiling zone. The example is focussed on site 12 , since that site shows the most obvious signs of alteration near the contact, but the calculations are more broadly relevant to the entire Valles analogue.

First it is necessary' to establish the mineralogy of the alteration at site 12 as a limiting factor in the assumptions we make for our reaction model. SEM scans show the alteration minerals occur overwhelmingly as coatings of tiny, euhedral crystals inside the pores of the pumiceous matrix (figures 4.21 through 4.25). The coatings are composed of extremely fine bladed crystals of $\mathrm{Na}-\mathrm{K}-\mathrm{Ca}$ aluminosilicates, and less abundant lumps of tiny $\mathrm{SiO}_{2}$ crystals. An average of $7 \mathrm{EDS}$ analyses of the blades gives $10.30 \pm 0.78 \% \mathrm{Na}_{2} \mathrm{O}, 2.62 \pm 0.98 \% \mathrm{~K}_{2} \mathrm{O}$, $1.68 \pm 0.47 \% \mathrm{CaO}, 0.32 \pm 0.25 \% \mathrm{FeO}, 18.51 \pm 1.14 \% \mathrm{Al}_{2} \mathrm{O}_{3}$ and $66.45 \pm 1.69 \% \mathrm{SiO}_{2}$, 
suggesting albite. A few euhedral crystals of Fe-rich and Ca-rich silicates (the latter possibly zeolites) have also been found. Sensitive XRD analyses of these samples are dominated by albite, K-feldspar, cristobalite, quartz and minor mica even when the samples are processed to collect the fine fraction (section 4.11); we have seen no sign of smectites, zeolites or epidote at site 12 . However, the latter minerals diffract poorly compared to $\mathrm{SiO}_{2}$ polymorphs and feldspars, and could be present in the samples to a few percent each without being detected by XRD. Overall, the pore coatings average no more than $5 \%$ of the whole rock mass. In samples $12 \mathrm{~A}$ and $12 \mathrm{H}$, the SEM shows that the "glass" matrix has developed the tiny pores typical of devitrification, suggesting that the "glass" walls of the voids may be dominantly feldspars and silica.

To model interactions between the site 12 samples and solutions, we need to estimate an appropriate water:rock ratio. On one extreme (case 1), we can assume that the solutions principally interact with the coatings on the walls of the voids; for this situation, the water:rock (volume for volume) is taken to be 100:3.5 at half saturation (pores half-filled with water), or 100:7 at full saturation. On the other extreme (case 2), we recognize that in some of the site 12 samples, the matrix has devitrified and become microporous, and may also have interacted with the solutions; in this case we assume a water:rock of 100:30. As we will show, the assumption of case 1 or case 2 has little effect on the minerals that form or the composition of the coexisting solution. In both cases, a substantial portion of the rock is assumed to be inert ( $94 \%$ for case 1, and $75 \%$ for case 2); this assumption is consistent with the petrography of the samples, which shows the large obsidian and xenolith clasts are relatively unaltered. The small size of the albite and $\mathrm{SiO}_{2}$ crystals in the pores $(\approx 0.3 \mu \mathrm{m}$ in breadth) suggests that the minerals would equilibrate with the aqueous phase in months to years, so we can use equilibrium-based reaction path modeling. We use the thermodynamic database data0.3245r46 of Wolery (1992), with the addition of newer data for uranium silicates and halide gases. Most of the equilibrium calculations were made with the react code developed by Bethke (1992).

Figures 7.1 and 7.2 show the major minerals that would form from a glass of rhyolite composition, for case 1, as a function of temperature. Figure 7.1 assumes that quartz, the most thermodynamically stable polymorph of silica, will form. Figure 7.2 suppresses the formations of quartz and tridymite, allowing chalcedony to form instead; the higher silica activity allows the zeolite clinoptilolite to form. Altered silicic tuffs often contain clinoptilolite, and have silica activities typical of metastable equilibrium with amorphous silica, cristobalite or chalcedony (Bowers and Burns, 1990). Clinoptilolite is a strong sorbant for $\mathrm{Cs}$ and $\mathrm{Sr}$, so the slight difference in assumption of $\mathrm{SiO}_{2}$ activity can have a major impact on the sorptive capacity of the bulk rock, and the expected enrichment patterns for some trace elements. It should be remembered that we have never found clinoptilolite in any of the analogue samples, especially not in the proportions implied in figure 7.2. Some calculations showed mordenite forming in preference to clinoptilolite. Even when clinoptilolite formed instead of mordenite, the solutions were typically at least $98 \%$ saturated with mordenite, and formation of mordenite is favored with the high $\mathrm{Na}$ concentrations predicted by the evaporation model described below. While the distinction between mordenite and 
clinoptilolite has little consequence in the following discussion, it should be noted that the two minerals have substantially different sorption capacities for $\mathrm{Cs}$ and $\mathrm{Sr}$, and the distinction could prove important for modeling waste repositories (Arthur and Criscenti, 1991). Fluorite (not shown) is stable across the entire temperature range, and controls the activity of $\mathrm{F}^{-}$. The calculations assume a fixed $\mathrm{CO}_{2}$ pressure of $10^{-3.5}$ atm and an $\mathrm{O}_{2}$ pressure of $0.2 \mathrm{~atm}$ (the ambient). The chosen $\mathrm{CO}_{2}$ pressure reflects our belief that most of the hot water available for alteration will be locally heated meteoric water, rather than deep-seated geothermal waters. A $\mathrm{CO}_{2}$ pressure of $10^{-3.5}$ atm implies only about $50 \mathrm{ppm}$ dissolved $\mathrm{HCO}_{3}^{-}$at $100{ }^{\circ} \mathrm{C}$, whereas

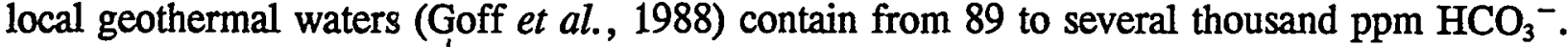
However, most of the local geothermal waters have traversed carbonate aquifers, \$o their bicarbonate contents are probably inappropriate for modeling the BRT-water interactions. In the model system, higher bicarbonate will generally require higher cation contents, typically higher $\mathrm{Na}^{+}$; performing the calculations without $\mathrm{p} \mathrm{CO}_{2}=0$ drops the amount of dissolved $\mathrm{Na}^{+}$by a factor of $\approx 2$. The effect of changing the assumed $\mathrm{O}_{2}$ fugacity is small, except on the calculated solubility of uranium.

Figures 7.3 and 7.4 show calculated solution compositions coexisting with the mineral assemblages in figures 7.1 and 7.2. The principal point of these plots is that the same basic pattern of relative concentration prevails, whether the alteration minerals are dominated by zeolites, or by a mixture of albite, quartz and $\mathrm{K}$-feldspar. The solutions have high $\mathrm{Na} / \mathrm{K}$ relative to the rock,' and dissolved $\mathrm{Na}$ dominates dissolved $\mathrm{Si}$. While the concentration of dissolved $\mathrm{Si}$ increases with temperature, $\mathrm{F}$ concentration is less affected, and $\mathrm{Na}$ concentration changes very little over temperatures from 80 to $180^{\circ} \mathrm{C}$. The $\mathrm{F}$ concentration is derived from the fluorine originally contained in the rhyolite glass, and is buffered by fluorite $\left(\mathrm{CaF}_{2}\right)$ to $43 \mathrm{ppm}$ at $100^{\circ} \mathrm{C}$.

It is instructive to compare the concentrations predicted in figure 7.4 against those measured in hydrothermal experiments. We placed finely ground rhyolite glass (from Panum Crater, $\mathrm{CA}$ ) in an autoclave for 11 months at $150^{\circ} \mathrm{C}$, then analyzed the coexisting solutions. The solution (as analyzed by DCP) contained $263 \mathrm{ppm} \mathrm{Si,} 78 \mathrm{ppm} \mathrm{Na}, 7 \mathrm{ppm} \mathrm{K}, 0.52 \mathrm{ppm} \mathrm{Ca}$ and $8.4 \mathrm{ppm} \mathrm{Al}$. Figure 7.4 predicts $89 \mathrm{ppm} \mathrm{SiO}_{2}, 145 \mathrm{ppm} \mathrm{Na}, 5 \mathrm{ppm} \mathrm{K}, 0.14 \mathrm{ppm} \mathrm{Ca}$ and $0.044 \mathrm{ppm} \mathrm{Al}$. The higher $\mathrm{Na}$ in the calculations is consistent with the lack of $\mathrm{CO}_{2}$ in the experiment. The modest discrepancy in $\mathrm{Si}$, and the extreme discrepancy in $\mathrm{Al}$ concentrations simply indicates that the hydrothermal experiments were supersaturated with aluminosilicates after 11 months. SEM examination of the glass shards showed that no alteration minerals of any kind had formed on the glass shards. If we repeat the calculations with no $\mathrm{CO}_{2}$ and assume silicon concentration is buffered by amorphous $\mathrm{SiO}_{2}$, we obtain $157 \mathrm{ppm} \mathrm{Si}$ and 84 ppm $\mathrm{Na}$, in closer agreement with the experimental results.

We now consider how a simple evaporation process, near the boiling front, might affect the bulk fluorine, $\mathrm{SiO}_{2}$ and $\mathrm{Na}_{2} \mathrm{O}$ contents, and the mineralogy. We consider that there is a relatively large, wet source region, where pore water equilibrates with tuff at $\approx 100{ }^{\circ} \mathrm{C}$. This water is drawn in toward the BBO-BRT contact, where it evaporates and consequently becomes enriched in dissolved ions such as $\mathrm{Na}^{+}$. We do not specify the size of the 
evaporation region. Howover, according to Bixler and Carrigan (1986), the "boiling front" may actually be a two-phase zone, of gradually decreasing liquid water content, roughly $1 \mathrm{~m}$ wide. The solutions in the boiling front are allowed to continually react with the minerals lining the pores; that is, there is no "armoring" effect to prevent previously deposited minerals form entering in the reaction. As figures $4.21-4.24$ show, the pore linings are fine and porous, so the assumption of continuous equilibrium between minerals and solutions is reasonable.

Figures 7.5 and 7.6 track the amounts of the alteration minerals as a function of the number of pore volumes evaporated, for cases 1 and 2, where quartz is allowed to form. The plot for case 2 is essentially just a truncated version of the plot for case 1 ; since a larger fraction of the rock is allowed to equilibrate with the solutions in case 2, it takes a larger number of pore volumes to have the same effect for case 2. Evaporation of 100 pore volumes does change the relative fractions of albite, quartz and $\mathrm{K}$-feldspar; but the effect on the abundance of fluorite is much more profound. When we include the inert clasts and matrix, the changes in the bulk rock composition for case 2 are: $+0.094 \% \mathrm{SiO}_{2},+0.081 \% \mathrm{Na}_{2} \mathrm{O}$, and +437 $\mathrm{ppm} \mathrm{F}$, after evaporation of 30 pore volumes; and $+0.204 \% \mathrm{SiO}_{2},+0.182 \% \mathrm{Na}_{2} \mathrm{O}$, and $+864 \mathrm{ppm} \mathrm{F}$, after 60 pore volumes. Results prove to be very similar for case 1 , and for calculations where we suppress the formation of quartz and tridymite to increase $\mathrm{SiO}_{2}$ solubility.

It is useful to consider if these changes in composition, predicted by the evaporation model, could be detected in our whole rock analysis. We must consider two types of uncertainty in the chemical analysis: inherent analytical error, and the natural variability of the rock in the absence of alteration. To estimate the analytical error, we performed replicate analyses on aliquants of finely ground and thoroughly homogenized samples from site 13 . The analytical uncertainty estimated by this method is $\pm 0.042 \% \mathrm{SiO}_{2}, \pm 0.035 \% \mathrm{Na}_{2} \mathrm{O}$, and \pm 1.7 to 6.5 $\mathrm{ppm}$ F. To estimate the effects of natural variability, we analyzed two kg-sized samples, separated by a horizontal distance of a few tens of $\mathrm{cm}$, at a vertical position $10 \mathrm{~m}$ from the BBO-BRT contact. The uncertainty from the latter analyses is $\pm 0.587 \% \mathrm{SiO}_{2}, \pm 0.148 \%$ $\mathrm{Na}_{2} \mathrm{O}$, and $\pm 11 \mathrm{ppm} \mathrm{F}$. Thus the predicted changes are larger than the analytical uncertainty for all three components. However, the predicted changes in $\mathrm{SiO}_{2}$ and $\mathrm{Na}_{2} \mathrm{O}$ are totally insignificant compared to the inherent, random variability of the rock. These calculations suggest that fluorine abundance may be a sensitive indicator of boiling fronts, but the bulk $\mathrm{SiO}_{2}$ and alkali contents will be nearly useless for this end. It is notable that the predicted change in $\mathrm{F}$ content after evaporation of 30 pore volumes is approximately the enrichment seen near the contact at site 12 (figure 4.11).

The evaporation model can produce high $\mathrm{Cl}$ contents, though the enrichment may be impossible to detect in routine chemical analysis 400,000 years after the event. Tuffs at the boiling front become enriched in $\mathrm{F}$ through precipitation of fluorite or substitution for $\mathrm{OH}^{-}$; there is no similar insoluble phase to accumulate $\mathrm{Cl}$. After 100 pore volumes of evaporation, the pore fluid contains $\approx 1 \% \mathrm{NaCl}$ by weight. If the tuff were removed from the system, and dried and analyzed at this point, the analysis would show several thousand $\mathrm{ppm} \mathrm{Cl}$. 
However, nearly all the $\mathrm{Cl}$ would be in highly soluble minerals, and would probably be removed by the washing procedure we use to remove superficial contamination -- if it had not already been removed by the 400,000 years of recharge since the heating event. It is quite possible that part of the soluble $\mathrm{Cl}$ "contamination" shown in figure 4.1 represents $\mathrm{Cl}$ accumulation at a boiling front, but it would be difficult to prove that possibility without drilling several meters into the outcrop to obtain samples of uncontaminated tuff.

We have assumed that the $\mathrm{F}$ in the source fluids is derived from the $\mathrm{F}$ content of the original rhyolite glass, and is subsequently buffered by fluorite. This is a critical assumption, since the buildup of $F$ in the evaporation zone is proportional to the $F$ concentration in the source fluids, before they are drawn into the evaporation region. It could be argued that this $F$ content is too high, since the thermochemical calculations have failed to consider the adsorption of $\mathrm{F}$ in silicates or stable, unidentified F-rich minerals. However, according to the model posed by Travis and Nuttall (1987), the ultimate source of these fluids is condensation of gases produced in the dry-out zone; as shown in figure 6.2, the condensate can easily achieve $\mathrm{F}$ concentrations of tens of ppm, even without the contribution from the local rhyolite glass.

The behavior of uranium in the evaporation model depends principally on the availability of oxygen. Figure 7.7 shows the solubility of $\mathrm{U}$ as $\mathrm{O}_{2}$ is titrated into a $\mathrm{kg}$ of pore fluid coexisting with the case 1 alteration minerals. It is assumed that in the initial rhyolite glass, the $\mathrm{Fe}^{+2}: \mathrm{Fe}^{+3}$ ratio is $1: 1$ (iron is initially placed in the rock as magnetite; the reaction path code redistributes most of the $\mathrm{Fe}$ into nontronite and other silicates). Uranium does not achieve an appreciable solubility until the $\mathrm{Fe}^{+2}$ has been consumed (and the stable $\mathrm{U}$ mineral changes from uraninite to schoepite), which requires 0.0031 moles of $\mathrm{O}_{2}$, or 0.47 liters of air (at $100^{\circ} \mathrm{C}$ ) per $\mathrm{kg}$ pore fluid. Thus if the pores were initially only $2 / 3$ saturated with fluid, the trapped air would be enough to oxidize all the $\mathrm{Fe}$ and ensure relatively high $\mathrm{U}$ solubility. Figure 7.8 shows the behavior of $U$ in solution and precipitates as the evaporation model proceeds, for the case 1 water:rock. The reaction path code predicts precipitation of $\mathrm{Na}_{2} \mathrm{U}_{2} \mathrm{O}_{7}$, but many other hexavalent $\mathrm{U}$ oxides are near saturation, so the exact nature of the precipitating phase is immaterial. If the evaporation model proceeds far enough, the bulk rock could become enriched by several tens of ppm U. However, at a subsequent point in the evaporation, the $\mathrm{Na}_{2} \mathrm{U}_{2} \mathrm{O}_{7}$ completely redissolves; this point corresponds to the steep increase in $\mathrm{pH}$ (figure 7.5) when Na nontronite (a smectite) forms from Ca nontronite. The sharpness of this break is an artifact of the inability of the reaction path code to model solid solution, but the general principle is reasonable; when the $\mathrm{pH}$ rises above $\approx 9.2$, the stability of anionic $U$ complexes increases, and $U$ becomes relatively soluble. Thus the simple evaporation process could produce very complex $U$ concentration patterns. 


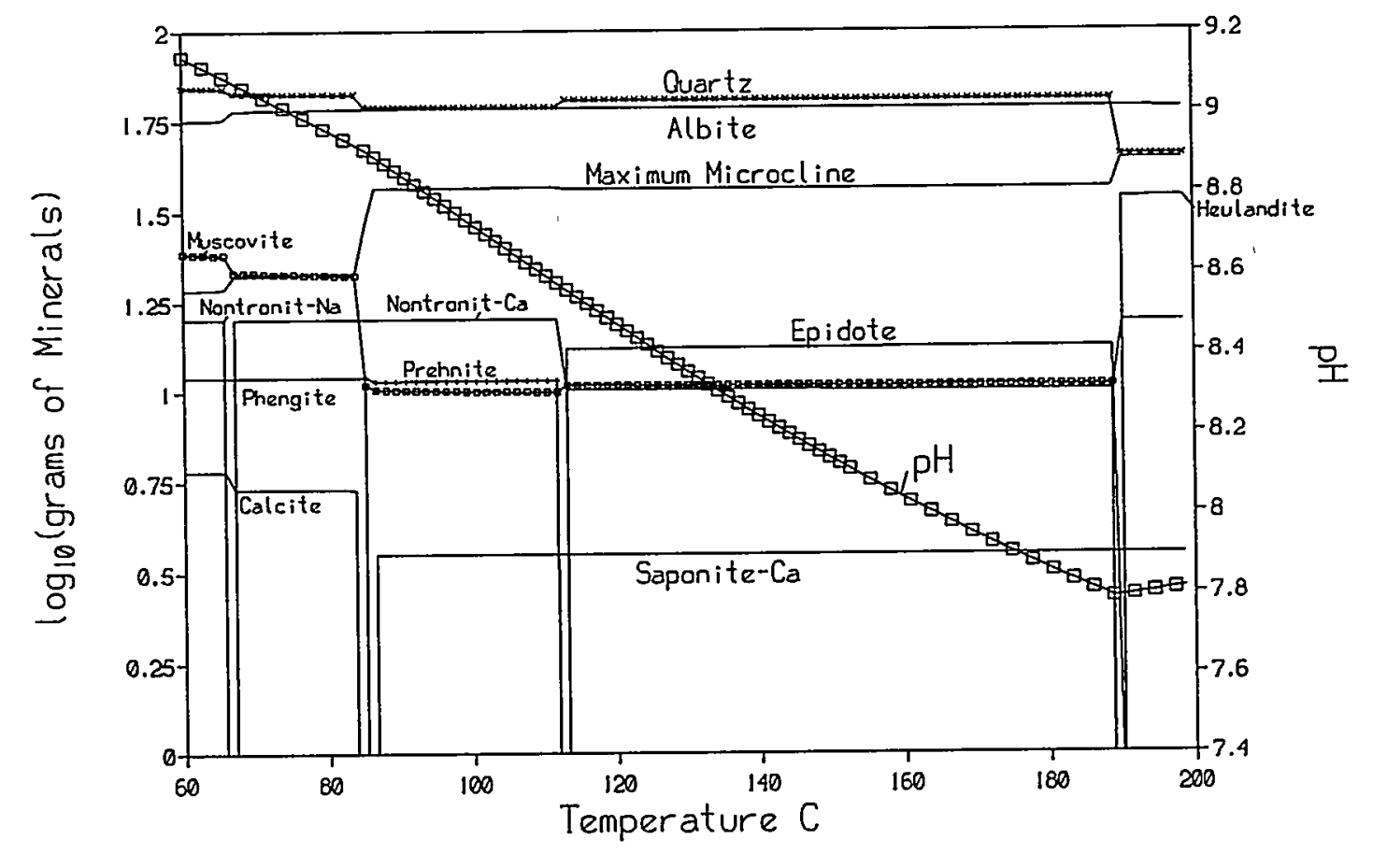

Figure 7.1. Mineral assemblage for case 1, as a function of temperature, when quartz is allowed to form.

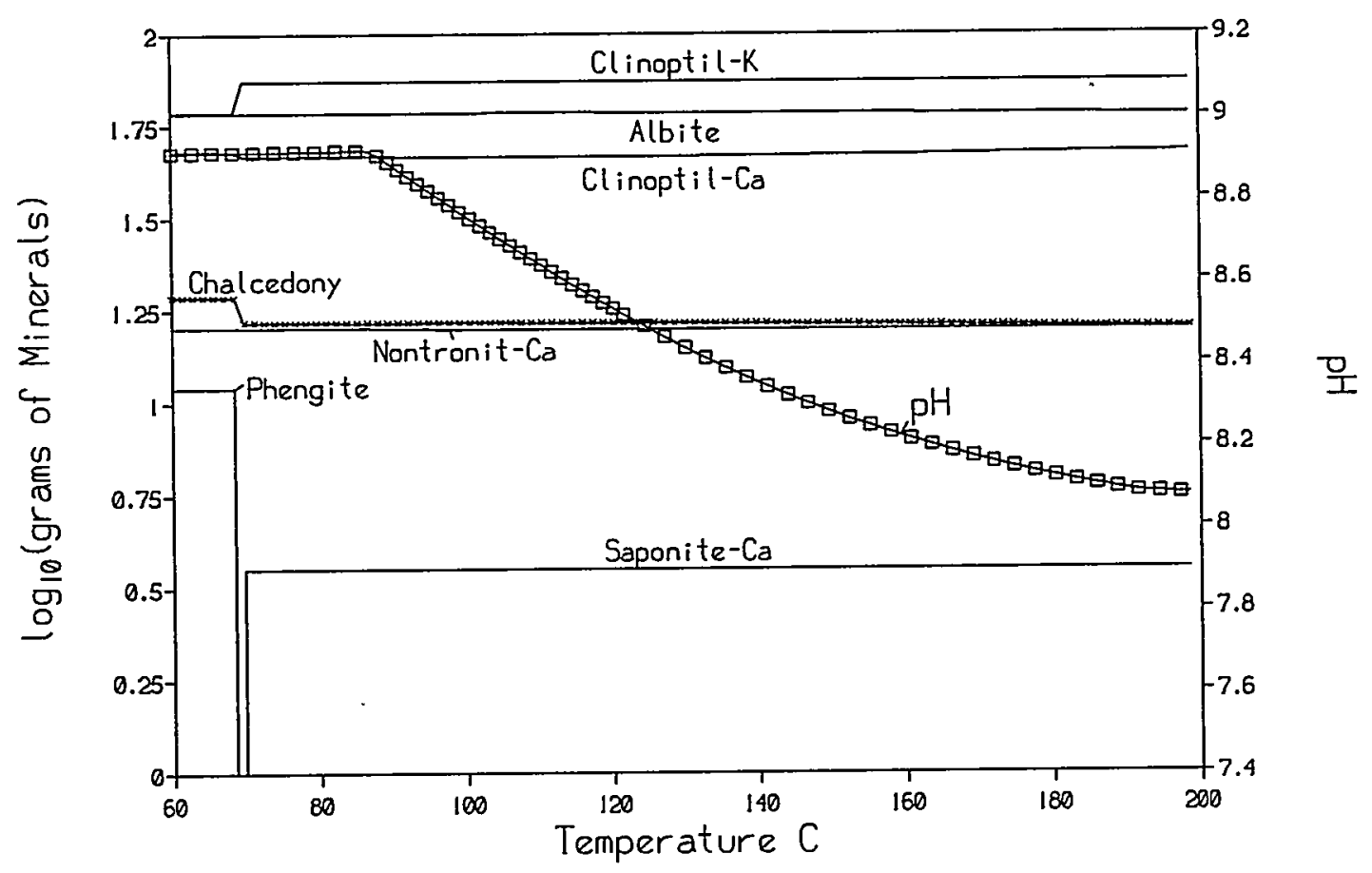

Figure 7.2. Mineral assemblage for case 1, as a function of temperature, when precipitation of quartz and tridymite is suppressed. 


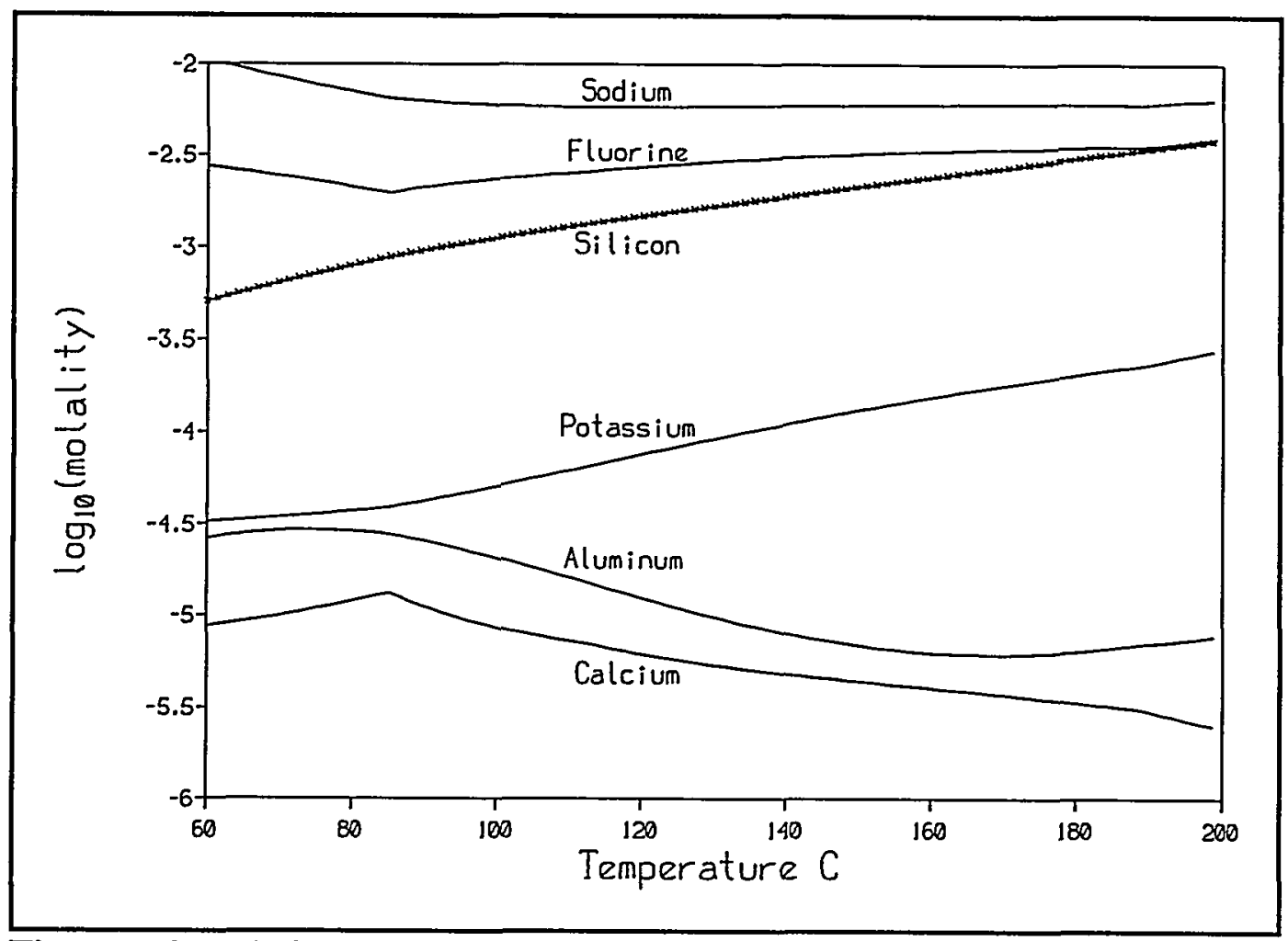

Figure 7.3. Solutions concentrations for figure 7.1.

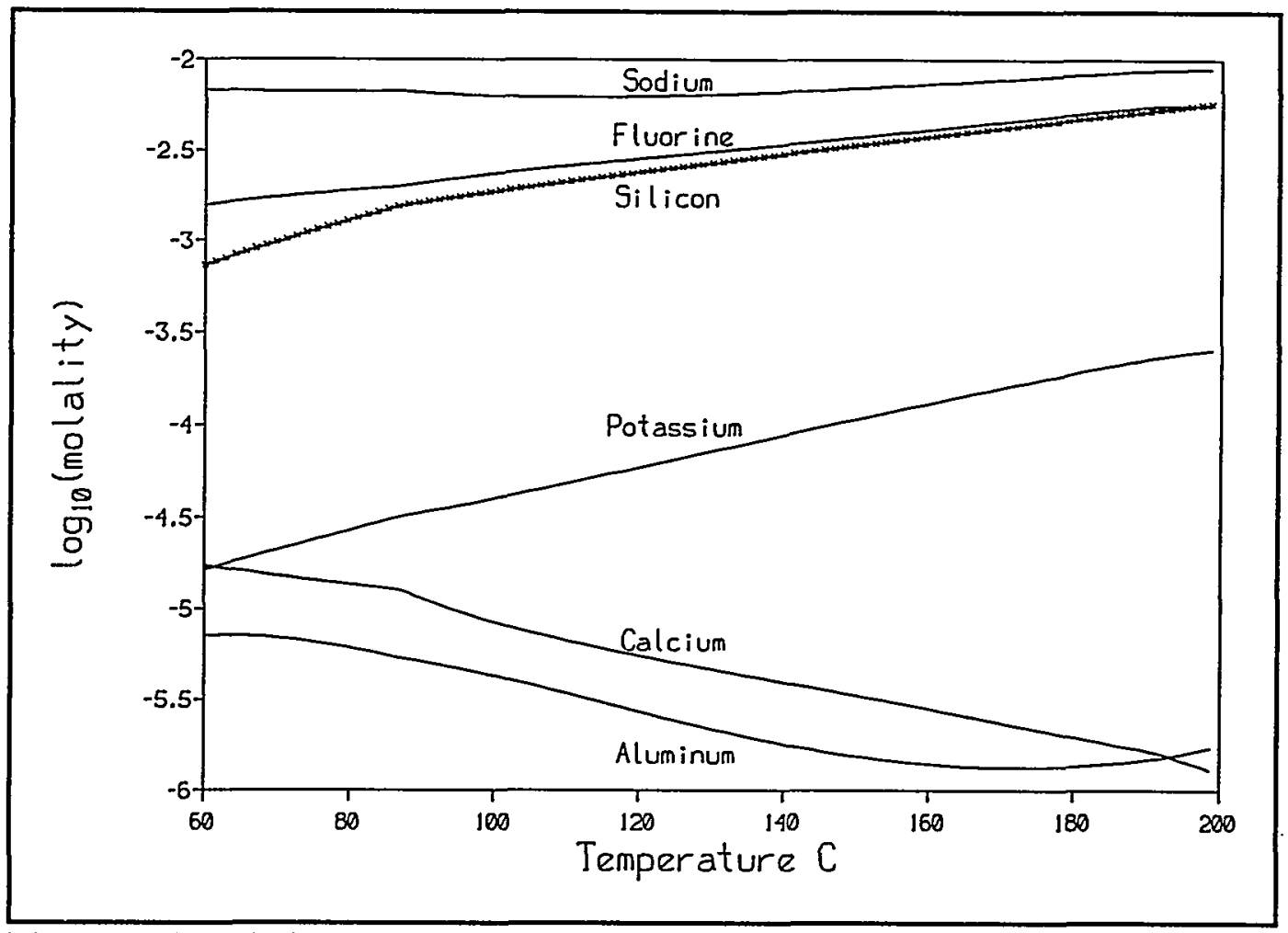

Figure 7.4. Solutioh concentrations for figure 7.2. 


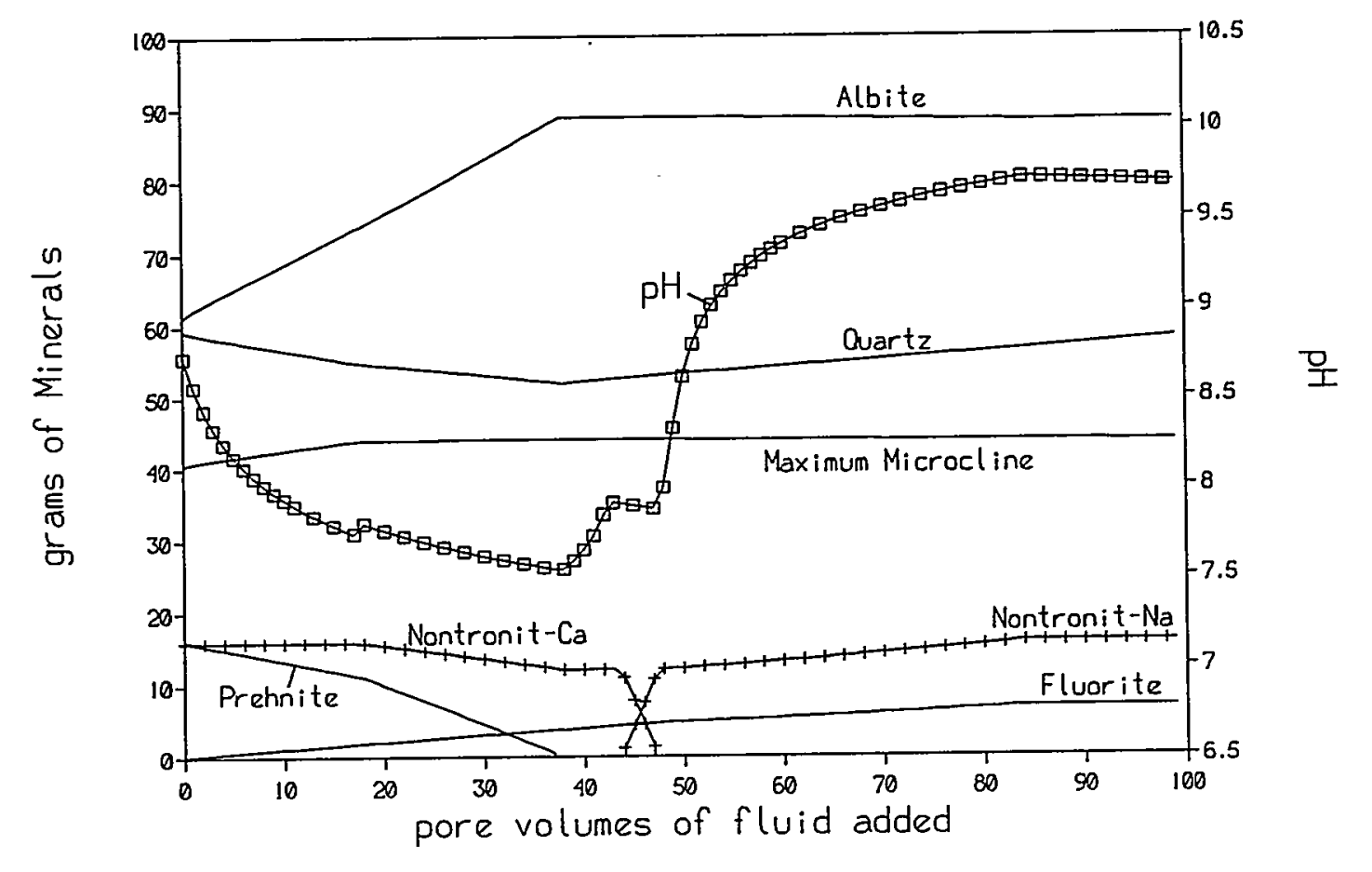

Figure 7.5. Minerals formed with evaporation model, case 1 (high water:rock), quartz allowed to form, $100^{\circ} \mathrm{C}$.

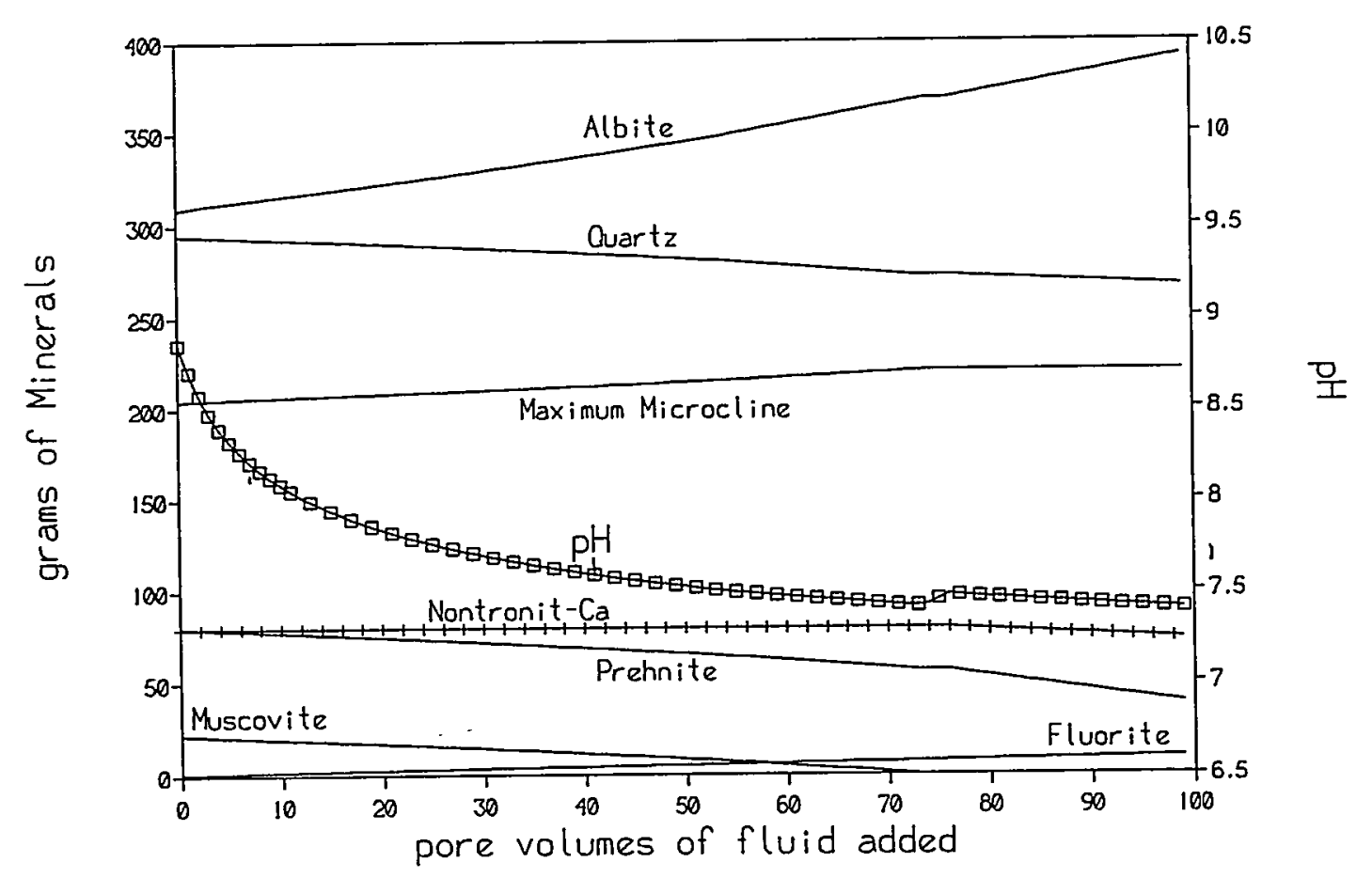

Figure 7.6. Minerals formed with evaporation model, case 2 (low water:rock), quartz allowed to form, $100^{\circ} \mathrm{C}$. 


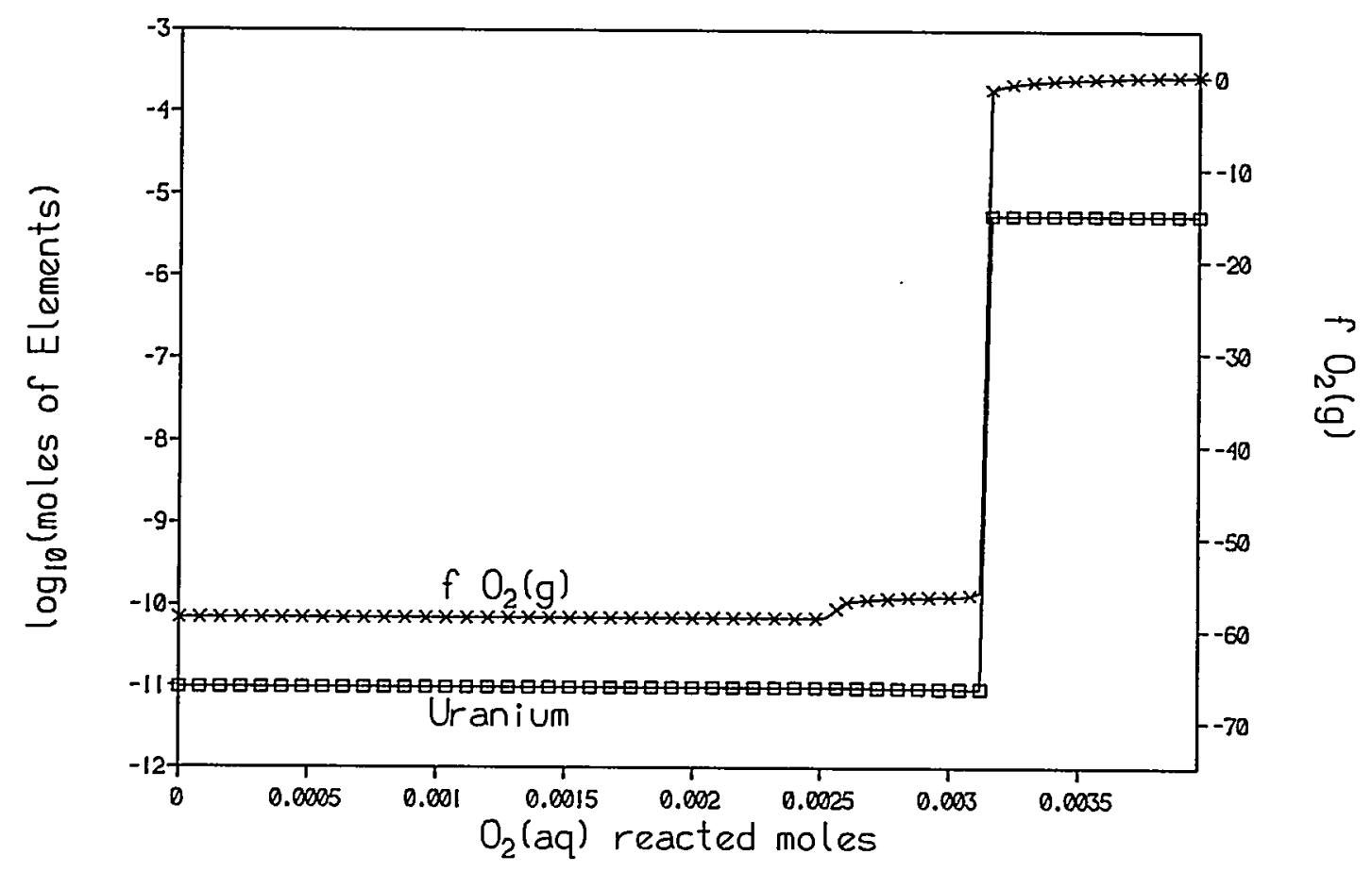

Figure 7.7. Solubility of uranium for case 1 water:rock, as oxygen is titrated into pore waters formed in equilibrium with altered rhyolite glass.

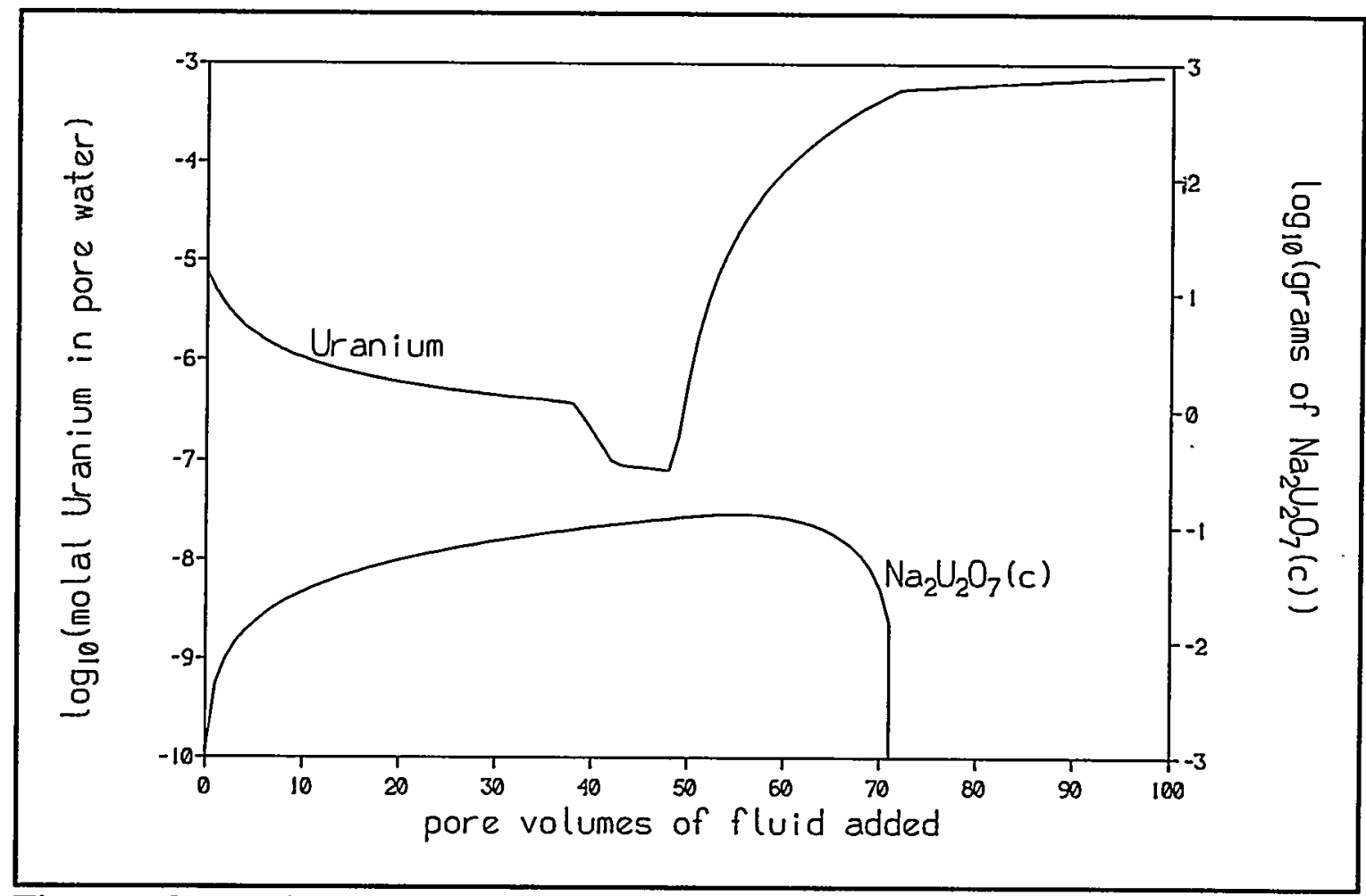

Figure 7.8. Uranium solids and solution composition for fig. 7.5 evaporation model. 


\subsection{Vapor Phase Transport of Metals}

The iron enrichment near the BBO-BRT contact might be explained by high-temperature vapor transport of $\mathrm{Fe}$ halides released from the obsidian flow; there is extensive field evidence for vapor transport of $\mathrm{Fe}$ and other metals in other silicic domes and flows. For example, Lufkin $(1972 ; 1976 ; 1977)$ describes hematite concentrations in lithophysae and veins of the Black Range rhyolites in New Mexico. The hematite is associated with sanidine, silica polymorphs, fluorite and topaz, indicating that the transport of Fe was associated with high fluorine concentrations. Symonds et al. (1987) modeled metal transport in fumarolic gases from the andesitic Merapi volcano in Indonesia, and showed that substantial amounts of iron can be transported as volatile $\mathrm{FeCl}_{2}$, down to $400{ }^{\circ} \mathrm{C}$. Analyses of fumarolic sublimates and condensates showed that substantial Cs and $\mathrm{Rb}$ were carried in the gas, down to $530^{\circ} \mathrm{C}$ (the lowest temperature sampled). These gases ranged from 3100 to $3800 \mathrm{ppm} \mathrm{Cl}, 110$ to $310 \mathrm{ppm} \mathrm{F}$, and up to $11 \mathrm{ppm} \mathrm{Fe}$, with water as the bulk of the gas.

It is conceivable that devitrification of the $\mathrm{BBO}$ produced gases capable of transporting $\mathrm{Fe}$ into the tuff. High-temperature devitrification of rhyolite domes and flows is thought to release $\mathrm{F}-$ and $\mathrm{Cl}$-rich gases, and these gases have apparently metasomatized the underlying pyroclastics in several topaz-rhyolite localities (Burt et al., 1982). At some locations, there are extensive zones of devitrification and red staining at or within a few meters of the BBOBRT contact (figure 3.6); the VC-1 core logs (Gardner et al., 1987) indicate at least $50 \mathrm{~m}$ of the flow are devitrified to some extent, so there probably was an ample supply of Cl- and Frich gas given off as the Valles flow cooled. The thin plates of feldspar found at site 12 (figures 4.21-4.24) are reminiscent of lithopysae textures, suggesting the tuffs adjacent to the contact were subject to alteration by high-temperature gases.

We can estimate the mass of steam, and rate of transport through the tuff, required to produce the observed Fe enrichment at site 12 . To simplify the calculation, we consider a $0.5 \mathrm{~m}$-thick zone of tuff, enriched over the background by $0.5 \%$ or $5000 \mathrm{ppm}$ Fe. For heuristic purposes, we take a steam Fe content of $10 \mathrm{ppm}$, consistent with the measurements and calculations of Symonds et al. (1987). The actual composition of the steam would depend on the oxygen fugacity, but it is reasonable to assume the same buffering oxide minerals (magnetites and ilmenites) existed at the BBO and the Merapi andesites. Thus the steam/rock mass ratio required to create the observed enrichment would be $(5000 \mathrm{ppm}) /(10$ $\mathrm{ppm})=500$. The time available for this transport would be the time that the contact area stayed above $\approx 400^{\circ} \mathrm{C}$, since the thermodynamic calculations of Symonds et al. indicate the $\mathrm{Fe}$ content of the gases drops off rapidly below this temperature. The calculations presented in section 5 suggest this time period might be from 100 to 1000 years. At $400^{\circ} \mathrm{C}$, the volume ratio of steam to rock would be $\approx 2.5 \cdot 10^{6}$; to get this much steam through the $0.5 \mathrm{~m}$-wide layer of tuff, in 100 to 1000 years, would require a Darcy speed of about 0.16 to 1.6 $\mathrm{mm} / \mathrm{second}(0.00016$ to $0.0016 \mathrm{~m} / \mathrm{sec})$. While these Darcy speeds are totally reasonable for such permeable rocks, this mass of steam is probably absurd from heat balance considerations, unless the iron enrichment is extremely local. First consider whether this amount of steam could be derived from devitrification of the obsidian. Obsidian contains roughly $0.4 \%$ water; thus for every $\mathrm{kg}$ of tuff subjected to the $500: 1$ steam:rock ratio, one 
would need $125000 \mathrm{~kg}$ of devitrifying obsidian to supply the water; therefore the source of water would need to be meteoric. To turn one $\mathrm{kg}$ of meteoric water at $20^{\circ} \mathrm{C}$ into steam at $400^{\circ} \mathrm{C}$ requires the heat content obtained by cooling $7.4 \mathrm{~kg}$ of obsidian from 850 to $400^{\circ} \mathrm{C}$; to obtain $500 \mathrm{~kg}$ of steam for every $\mathrm{kg}$ of Fe-enriched tuff requires removing the heat from $3700 \mathrm{~kg}$ of obsidian. To produce a meter-wide Fe enrichment zone with any appreciable lateral extent would require the heat from roughly 2000 meters of obsidian.

If vapor transport is responsible for the Fe-enrichment of the tuff at sites 8 and 12, there should be microscopic evidence, in the form of Fe-oxides or Fe-rich silicates coating pores and cracks. There should also be evidence of halide metasomatism in the overlying BBO, since we speculate gaseous halide complexes as the means of transport. As discussed in section 7.2, the minerals coating the pores typically make up less than $5 \%$ of the whole rock volume, and the coatings are only a few crystals thick. The pore coatings would need to average $10 \% \mathrm{Fe}$ by mass, or $5 \%$ by volume (assuming the density of hematite). However, extensive SEM examination of the most Fe-rich samples from site 12 (in both back-scattered and secondary electron modes) failed to show such an abundance of Fe-rich minerals. Iron oxides were found growing on blades of feldspar, but at no more than a fraction of a percent. A single occurrence of tiny Fe-oxide cubes (magnetite?) was found on a fracture surface (figure 4.22). Semi-quantitative EDS analyses gave an average Fe content of only $1.4 \%$ for the site 12 mineral coatings. As for halide metasomatism in the BBO, the results of section 4.7 indicate that the margins of cracks in the site $8 \mathrm{BBO}$ have the same $\mathrm{Cl}$ content as the bulk rock, and appear remarkably unaltered. Thus it appears that the vapor-deposition hypothesis is an unlikely explanation for the Fe enrichments found near the BBO-BRT contacts. 


\section{CONCLUSIONS AND RECOMMENDATIONS}

The most striking aspect of the Valles natural analogue is the general lack of alteration. There is evidence for devitrification in the 10 meters closest to the contact, limited remobilization of halogens, precipitation of very fine-grained phases in the pores, and plastic deformation of the tuffs closest to the contact. A simple evaporation model, which assumes the boiled solutions are replenished by capillary action, can account for some of the observed chemical variations.

Based on this study, several processes thought to affect YMS (discussed in the introduction) may prove to be relatively inconsequential. In the Valles analogue, evidence of mechanical effects from heating is slight, and the possible migration of halogen-rich fluids seems to have produced very little metasomatism of the surrounding rocks. Perhaps the greatest caution raised by this study concerns the validity of reaction-path calculations for YMS, particularly those that assume the formation of metastable zeolites. We found no evidence for formation of clinoptilolite or mordenite; rather, we saw widespread alteration to albite and silica polymorphs, an assemblage with little capacity for sorbing Cs and Sr. However, even the latter finding may be of little consequence, -since at YMS there will still be a large mass of unheated, zeolite-rich tuff between the waste panels and the water table. In addition, the maximum temperatures experienced by the Valles analogue may greatly exceed those experienced at YMS. We must stress that these concerns with reaction path calculations do not reflect an inadequacy of the codes or approach, but stem from the modelers' viewpoints and assumptions.

This study was planned to provide multiple tests of hypotheses. We obtained analytical data from four different contact zones, and tried to eliminate problems of contamination and soil formation through sample preparation and by testing both "horizontal" and vertical contacts. We tested the method of age determination by submission of a similar obsidian with an extremely well-constrained age. The study implicitly minimized the effects of hydrothermal overprinting that can affect deep intrusive analogues, since the analogue tuff was far from the eruptive center, on the edge of the caldera, near the surface, and out of the region of intense hydrothermal activity. Initial analyses (Self $e t$ al., 1988) suggested the baseline composition of the tuff was extremely uniform, so compositional variations from heating should be readily apparent. We studied the hydraulic properties and predicted temperatures for YMS, and chose a site that was probably unsaturated like YMS and would provide reasonable overlap on the predicted YMS thermal profiles.

Despite these cautions, the Valles Analogue still suffers from ambiguities that may affect many other analogue sites. The stratigraphy and chronology of volcanic activity in the area were completely revised - several times during the course of this study -- by experts in the field. The uncertainty in the ${ }^{39} \mathrm{Ar} /{ }^{40} \mathrm{Ar}$ ages is notable, given that the samples seemed to met all the criteria for accurate analysis. The tuffs proved to be less homogenous than was implied by earlier studies, and it became difficult to determine whether the slight compositional variations existed in the tuffs prior to the heating event. Most important, there 
was no way to judge, at the start of the project, what would constitute a "significant" chemical variation.

Natural analogue studies should be planned to test a specific model, and the predictions of that model should be available as the analogue study commences. It is particularly important that the predictions identify the chemical parameters that are likely to show significant variation above background. It is unlikely that these models will be able to predict accurately the chemical variations for every contact or environment; the alteration predicted by evaporation--capillarity models (Travis and Nuttall, 1987) is likely to be complex, timevarying, and highly dependent on local hydraulic and thermal conductivity. However, it should be possible to predict the range of variations expected, and to identify significant chemical indicators through a sensitivity analysis. To be defensible, such an analysis may require geochemists and hydrologists to develop probability distributions for parameters such as permeability, thermal conductivity and mineral reaction rates, which will be sampled by Latin Hypercube or Monte Carlo methods. Geochemists should then determine if chemical indicators identified by the sensitivity analysis are likely to survive from the time of the analogue event, or if detection of the indicators will require special sampling procedures. For example, in the present study, we may have altered our procedures for washing samples and for collecting samples deep into the outcrop, if we had known Travis' and Nuttall's (1987) predictions for $\mathrm{Cl}$ concentration at the boiling front. The feedback process just described is, in effect, iterative performance assessment.

The evaporation-capillarity or "heat pipe" models developed by Travis and Nuttall (1987) and Verna and Pruess (1987) should be refined to include more realistic interactions between the tuff and aqueous solutions. As shown in section 7, there is a need to consider the dissolution and precipitation of phases other than silica, particularly if the model is to be tested against natural analogues or field experiments. It is also important to recognize that the condensate may be enriched in halogens (section 6), and while this enrichment may have little effect on the integrity of the site, it can serve as a detectable test of the model.

The sensitivity analysis must include the error implicit in thermochemical and kinetic data used in reaction path models. There is substantial uncertainty in very basic thermochemical data, such as the stability constants for zeolites, aqueous aluminum species, and uranium silicates. By using different generations of the thermodynamic database, we obtained a 7 order of magnitude variation in the predicted solubility of $U$, and a discrepancy of $3 \mathrm{pH}$ units. Some data sets predicted solution $\mathrm{pH}$ 's up to 12 -- high enough to cause significant chemical alteration and attack. Generous assistance from Lawrence Livermore Laboratory, and the generally excellent documentation of the EQ3/6 database, helped us track down the subtle inconsistencies that caused the wide range in calculated solubilities. Arthur and Criscenti (1991) have shown how slight uncertainties in free energies of zeolites can result in large changes in the predicted sorptive capacities of alteration minerals. Clearly it will be pointless to develop complex chemical interaction models unless the thermodynamic database has been thoroughly tested. 
Lastly, the simple thermal model developed in this study should be extended to a full 2-D model with capillarity. It is particularly important to establish the width and longevity of the dry-out zone, and the rate of steam transport near horizontal and vertical contacts, since these parameters will determine the likelihood of the various proposed mechanisms for producing chemical variations. A more accurate thermal history may help explain the simple albite-silica alteration at the Valles site, and determine if this assemblage will develop in the boiling zone at YMS. The TOUGH2 or VTOUGH codes of Pruess (1987) and Nitao (1989), with modifications to handle temperatures above $400^{\circ} \mathrm{C}$ would provide much more advanced thermal modeling. 


\section{REFERENCES}

Arthur, R.C. and Criscenti, L.J. (1991) Error evaluation in reactive-solute transport calculations, Radiochimica Acta $\mathbf{5 2}$, pp 507-512.

Bailey, R.A.; Smith, R.L. and Ross, C.S. (1969) Stratigraphic nomenclature of volcanic rocks in the Jemez Mountains, New Mexico, U.S. Geol Surv. Bull. v 1274-P, pp 119.

Barnard, R.; Wilson, M.L.; Dockery, H.A.; Gauthier, J.H.; Kaplan, P.G.; Eaton, R.R.; Bingham,F.W. and Robey, T.H. (1992) TSPA: An Initial Total-System Performance Assessment for Yucca Mountain.. SAND 91-2795, Sandia National Laboratories, Albuquerque, NM 87185.

Barr, G.E.; Dunn, E.; Dockery, H.; Valentine, G. and Crowe, B. (1993) Scenarios for Basaltic Igneous Activity at Yucca Mountain and Vicinity. SAND91-1653, Sandia National Laboratories, Albuquerque, NM 87185.

Bethke, C. (1992) The Geochemist's Workbench: A Users Guide to Rxn, Act2, Tact, React, and Gtplot. Hydrogeology Program, University of Illinois, $174 \mathrm{pp}$.

Bixler, N.E. and Carrigan, C.R. (1986) Enhanced heat transfer in partially-saturated hydrothermal systems, Geophys. Res. Lett. v 13, pp 42-45.

Bloss, F.D. (1971) Crystallography and Crystal Chemistry, Holt, Rinehart and Winston, Inc., New York, 545 pp.

Bodkin, J.B. (1977) Determination of fluorine in silicates by use of an ion-selective electrode following fusion with lithium metaborate, The Analyst $\mathbf{v} 102$, pp 409-413.

Bowers, T.S. and Burns, R.G. (1990) Activity diagrams for clinoptilolite: susceptibility of this zeolite to further diagenetic reactions, Amer. Mineralogist, v 75, pp 601-619.

Brookins, D.G. (1986) Natural analogues for radwaste disposal: elemental migration in igneous contact zonies, Chemical Geology v 55, pp 337-344.

Brookins, D.G.; Abashian, M.S.; Cohen, L.H.; Williams, A.E.; Wollenberg, H.A. and Flexser, S. (1983) Natural analogues: Alamosa River monzonite intrusive into tuffaceous and andesitic rocks, in: D.G. Brookins (ed.), Scientific Basis for Nuclear Waste Management v 6, Elsevier, New York, pp 299-306.

Bruton, C.; Glassley, W.E. and Viani, B.E. (1993) Geochemistry, in: D.G. Wilder (ed.) Preliminary Near-Field Environment Report Volume II: Scientific Overview of Near- 
Field Environment and Phenomena. UCRL-LR-107476 v 2, Lawrence Livermore National Laboratory, Livermore, CA 94551, pp 37-60.

Burt, D.M.; Sheridan, M.F.; Bikun, J.V. and Christiansen, E.H. (1982) Topaz rhyolites distribution, origin, and significance for exploration, Economic Geology $\vee 77$, pp 1818-1836.

Cerling, T.E.; Brown, F.H. and Bowman, J.H. (1985) Low-temperature alteration of volcanic glass: hydration, $\mathrm{Na}, \mathrm{K},{ }^{18} \mathrm{O}$ and Ar mobility, Chemical Geology, $\mathrm{v} 52$, pp 281-293.

Crank, J. (1975) The Mathematics of Diffusion. Clarendon Press, Oxford, 414 pp.

Crank, J. (1984) Free and Moving Boundary Problems. Clarendon Press, Oxford, 425 pp.

Criscenti, L.J. and Arthur, R.C. (1991) The calculated effects of isothermal boiling on tuffwater interactions, Radiochimica Acta $\vee 52$, pp 513-517.

Daniels, W.R. et al. (1982) Summary Report on the Geochemistry of Yucca Mountain and Environs. LA-9328-MS, Los Alamos National Laboratory, Los Alamos NM 87545.

Dingwell, D.B. and Scarfe, C.M. (1985) Chemical diffusion of fluorine in melts in the system $\mathrm{Na}_{2} \mathrm{O}-\mathrm{Al}_{2} \mathrm{O}_{3}-\mathrm{SiO}_{2}$, Earth and Planetary Science Letters $\mathbf{v}$ 73, pp 377-384.

Dobson, P.F.; Epstein, S. and Stolper, E.M. (1989) Hydrogen isotope fractionation between coexisting vapor and silicate melts at low pressure, Geochimica et Cosmochimica Acta v 53, pp 2723-2730.

Doell, R.R.; Dalrymple, G.B; Smith, R.L. and Bailey, R.A. (1968) Paleomagnetísm, potassium-argon ages, and geology of rhyolites and associated rocks of the Valles Caldera, New Mexico, Mem. Geol. Soc. Amer., v 116, pp 211-248.

Ellis, A.J. and Mahon, W.A.J. (1967) Natural hydrothermal systems and experimental hot water/rock interactions (Part II), Geochimica et Cosmochimica Acta v 31, pp 519-538.

Ellis, A.J. and Mahon, W.A.J. (1977) Chemistry and Geothermal Systems. Academic Press, New York, 392 pp.

Fink, J.H. and Manley, C.R. (1987) Origin of pumiceous and glassy textures in rhyolite flows and domes, Geol. Soc. Amer. Special Paper 212, pp 77-87.

Flexser, S. and Wollenberg, H.A. (1992) Radioelements and Their Occurrence with Secondary Minerals in Heated and Unheated Tuff at the Nevada Test Site. LBL- 
31666, Lawrence Berkeley Laboratory, Berkeley, CA 94720.

Flint, A.L.; Flint, L.E. and Hevesi, J.A. (1993) The influence of long term climate change on net infiltration at Yucca Mountain, Nevada, in: Proceedings of the Fourth Annual International Conference on High Level Radioactive Waste Management, American Nuclear Society, La Grange Park, IL.

Gardner, J.N.; Goff, F.; Goff, S.; Maasen, L.; Mathews, K.; Wachs, D. and Wilson, D. (1987) Core Lithology, Valles Caldera \#1, New Mexico. LA-10957-OBES (UC-66b), Los Alamos National Laboratory, Los Alamos, New Mexico, 87545.

Geissman, J.W. (1988) Paleomagnetism and rock magnetism of Quaternary volcanic rocks and late Paleozoic strata, VC-1 core hole, Valles Caldera, New Mexico, with emphasis on remagnetization of late Paleozoic strata, Jour. Geophysical Research $\mathbf{v}$ 93, pp 6001-6025.

Goff, F.; Shevenell, L.; Gardner, J.N.; Vuataz, F-D. and Grigsby, C.O. (1988) The hydrothermal outflow plume of Valles Caldera, New Mexico, and a comparison with other outflow plumes, Jour. Geophysical Research v 93, pp 6041-6058.

Goff, F.; Gardner, J.N.; Baldridge, W.S.; Hulen, J.B.; Neilson, D.L.; Vaniman, D.; Heiken, G.H.; Dungan, M.A. and Broxton, D. (1989) Excursion 17B: volcanic and hydrothermal evolution of Pleistocene Valles caldera and Jemez volcanic field, in: C.E. Chapin and J. Zidik (eds.), Field Excursions to Volcanic Terranes in the Western United States, Volume I: Southern Rocky Mountain Region. Mem. N.M. Bureau of Mines and Mineral Resources \# 46, pp 381-434 [cited in Self et al. 1991].

Goguel, R. (1982) The rare alkalies in hydrothermal alteration at Wairakei and Broadlands, geothermal fields, N.Z., Geochimica et Cosmochimica Acta $\vee$ 47, pp 429-437.

Guzowski, R.V.; Nimick, F.B.; Siegel, M.D. and Finley, N.C. (1983) Repository Site Data Report for Tuff: Yucca Mountain, Nevada. SAND82-2105 (NUREG/CR-2937), Sandia National Laboratories, Albuquerque, NM 87185.

Hermann, W.; Raith, A. and Rau, H. (1987) Diffusion of fluorine in silica, Ber. Bunsenges Chem., v 91, pp 56-58.

Hildreth, W. (1981) Gradients in silicic magma chambers: implications for lithospheric magmatism, Jour. Geophysical Research v 86, pp 10153-10192.

Höller, H. and Wirsching, U. (1978) Experiments on the formation of zeolites by hydrothermal alteration of volcanic glass, in L.B. Sand and F.A. Mumpton (eds.) Natural Zeolites (Occurrence, Properties, Use), Pergammon Press, Oxford, pp 329336. 
Jambon, A. (1982) Tracer diffusion in granitic melts: experimental results for $\mathrm{Na}, \mathrm{K}, \mathrm{Rb}$, $\mathrm{Cs}, \mathrm{Ca}, \mathrm{Sr} \mathrm{Ba}, \mathrm{Ce}, \mathrm{Eu}$ to $1300^{\circ} \mathrm{C}$ and a model of calculation, Jour. Geophysical Research $\nabla$ 87, pp 10797-10810.

Keith, T.E.C.; Thompson, J.M. and Mays, R.E. (1983) Selective concentration of cesium in analcime during hydrothermal alteration, Yellowstone National Park, Wyoming, Geochimica et Cosmochimica Acta $\vee 47$, pp 795-804.

Knauss, K.G. and Wolery, T.J. (1986) Dependence of albite dissolution kinetics on $\mathrm{pH}$ and time at $25^{\circ} \mathrm{C}$ and $70^{\circ} \mathrm{C}$, Geochimica et Cosmochimica Acta v 50, pp 2481-2497.

Kossovich, P.S. (1967) A Short Course of General Soil Science (2nd Posthumous Edition). Translated from Russian, Israel Program for Scientific Translations, Jerusalem; available from U.S. Dept. Commerce, 223 pp.

Lambert, S.J. and Epstein, S. (1980) Stable isotope investigations of an active geothermal system in Valles Caldera, Jemez Mountains, New Mexico, Jour. Volcanology and Geothermal Res. v 8, pp 111-129.

Lambert, S.J. and Epstein, S. (1992) Stable-isotope studies of rocks and secondary minerals in a vapor-dominated hydrothermal system at The Geysers, Sonoma County, California, accepted Jour. Volcanology and Geothermal Res.

Lin, W. (1993) Hydrologic properties, in: D.G. Wilder (ed.) Preliminary Near-Field Environment Report Volume II: Scientific Overview of Near-Field Environment and Phenomena. UCRL-LR-107476 v 2, Lawrence Livermore National Laboratory, Livermore, CA 94551, pp 29-36.

Lufkin, J.L. (1972) Tin Mineralization within Rhyolite Flow Domes, Black Range, New Mexico. Unpublished Ph.D. thesis, Stanford University, 148 pp.

Lufkin, J.L. (1976) Oxide minerals in miarolitic rhyolite, Black Range, New Mexico, Amer. Mineralogist $\mathbf{v}$ 61, pp 425-430.

Lufkin, J.L. (1977) Chemistry and mineralogy of wood tin, Black Range, New Mexico, Amer. Mineralogist v 62, pp 100-106.

Marvin, R.F. and Dobson, S.W. (1979) Radiometric ages: compilation B, U.S. Geological Survey, Isochron West v 26, p 25 [cited in Self et al. 1991].

Mitra, S.K. and Parker, J.M. (1984) Molecular dynamics simulation of a soda-silica glass containing fluorine, Physics and Chemistry of Glasses V 25, pp 95-99.

Miyachi, M.; Izett, G.A.; Naeser, C.W.; Naeser, N.D. and Andreissen, P.A.M. (1985) 
Zircon fission track ages on some volcanic rocks and pyroclastic flow deposits on the Jemez Mountains, New Mexico, Bull. Volcanol. Soc. Japan v 30, p 90 [cited in Self et al. 1991].

Nitao, J. (1989) V-TOUGH - An Enhanced Version of the TOUGH Code for the Thermal and Hydrologic Simulation of Large-Scale Problems in Nuclear Waste Isolation. UCID-21954, Lawirence Livermore National Laboratory, Livermore, CA 94551.

NWTRB (1992) Fifth Report to the U.S. Congress and the U.S. Secretary of Energy. Nuclear Waste Technical Review Board, 1100 Wilson Blvd., Suite 910, Arlington, VA 22209.

Oskarsson, N. (1980) The interaction between volcanic gases and tephra: fluorine adhering to tephra of the 1970 Hekla eruption, Jour. Volcanology and Geothermal Res. $\mathbf{8} 8$, pp 251-266.

Pecora, W.T. and Rubin, M. (1967) Absolute dating and the history of man, in: Time and Stratigraphy in the Evolution of Man. NAS-NRC 1469, pp 43-56.

Pense, G.M. (1977) The Volcanic Stratigraphy of the Banco Bonito Vitrophyre: $A$ Petrochemical. Study of a Rhyolite Lava Flow. Masters thesis, Texas Christian University, 55 pp.

Pigford, T.H.; Chambré, P.L. and Lee, W. W.-L. (1992) A review of near-field mass transfer in geologic disposal systems, Radioactive Waste Management and the Nuclear Fuel Cycle, v 16, pp 175-276.

Pruess, K. (1987) TOUGH User's Guide. NUREG/CR-4645 (LBL-20700, SAND86-7104), Lawrence Berkeley Laboratory, Berkeley, CA 94720.

Ramirez, A.L. (1993) Field Tests, in: D.G. Wilder (ed.) Preliminary Near-Field Environment Report Volume 1I: Scientific Overview of Near-Field Environment and Phenomena. UCRL-LR-107476 v 2, Lawrence Livermore National Laboratory, Livermore, CA 94551, pp 95-109..

Self, S.; Kircher, D.E. and Wolff, J.A. (1988) The El Cajete series, Valles Caldera, New Mexico, Jour. Geophysical Research v 93, pp 6113-6127.

Self, S.; Wolff, J.A.; Spell, T.L.; Skuba, C.E. and Morrissey, M.M. (1991) Revisions to the stratigraphy and volcanology of the post- $0.5 \mathrm{Ma}$ units and the volcanic section of the VC-1 core hole, Valles Caldera, New Mexico, Jour. Geophysical Research v 96, pp 4107-4116.

Shackleton, N.J. and Updike, N.D. (1973) Oxygen isotope and paleomagnetic stratigraphy of equatorial Pacific core V28-238; oxygen isotopic temperature and ice volumes in a 
$10^{5}$ to $10^{6}$ year scale, Quaternary Res. v 3, pp 39-55.

Smellie, J.A.T.; Mackenzie, A.B. and Scott, R.D. (1986) An analogue validation study of natural radionuclide migration in crystalline rocks using uranium-series disequilibrium studies, Chemical Geology v 55, pp 233-254.

Stewart, B.A. (1970) A look at agricultural practices in relation to nitrate accumulations, in: O.P. Engelstad (ed.), Nutrient Mobility in Soils: Accumulation and Losses. Soil Science Society of America, Inc., Madison, Wisconsin, pp 47-60.

Stockman, H.W. (1989) Stockman, H.W. (1989) Microprocessor-based reduction of gamma spectra: a fast method for deconvolution of overlapped peaks, Nuclear Instrumentation and Methods v A274, pp 314-318.

Symonds, R.B.; Rose, W.I.; Reed, M.H.; Lichte, F.E. and Finnegan, D.L. (1987) Volatilization, transport and sublimation of metallic and non-metallic elements in high temperature gases at Merapi Volcano, Indonesia, Geochimica et Cosmochimica Acta, v 51, pp 2083-2101.

Taylor, B.E.; Eichelberger, J.C. and Westrich, H.R. (1983) Hydrogen isotopic evidence of rhyolitic magma degassing during shallow intrusion and eruption, Nature $\mathbf{v} 306$, pp 541-545.

Taylor, H.P. (1974) The application of oxygen and hydrogen isotope studies to problems of hydrothermal alteration and ore deposition, Economic Geology v 69, pp 843-883.

Travis, B.J. and Nuttall, H.E. (1987) Two-Dimensional Numerical Simulation of Geochemical Transport in Yucca Mountain. LA-10532-MS, Los Alamos National Laboratory, Los Alamos NM 87545.

Vaniman, D.; Bish, D. and Chipera, S. (1993) Dehydration and rehydration of a tuff vitrophyre, Jour Geophysical Research $\mathbf{9 8}$, pp 22,309-22,320.

Verma, A. and Pruess, K. (1987) Effects of silica redistribution on performance of high-level nuclear waste repositories in saturated geologic formations, in: C.-F. Tsang (ed.), Coupled Processes Associated. with Nuclear Waste Repositories. Academic Press, Inc., Orlando, pp 541-563.

Westrich, H.R. (1987) Determination of water in volcanic glasses by Karl-Fischer titration, Chemical Geology v 63, pp 335-340.

Westrich, H.R.; Stockman, H.W. and Eichelberger, J.C. (1988) Degassing of rhyolitic magma during ascent and emplacement, Jour. Geophysical Research v 93, pp 65036511. 
Wilder, D.G. (1993) Preliminary Near-Field Environment Report Volume I: Technical Bases for EBS design. UCRL-LR-107476 Vol 1, Lawrence Livermore National Laboratory, Livermore, CA 94551, pp 14-17.

Wolery, T.J. (1992) EQ3/6, A Software Package for Geochemical Modeling of Aqueous Systems: Package Overview and Installation Guide (Version 7.0). UCRL-MA-110662 PT1, Lawrence Livermore National Laboratory, Livermore, CA 94551, 66 pp.

Zielinski, R.A. (1982) The mobility of uranium and other elements during alteration of rhyolite ash to montmorillonite: a case study in the Troublesome Formation, Colorado, U.S.A., Chemical Geology v 35, pp 185-204. 


\section{Appendix. Tables of Sample Analyses}

"ND" means "not determined" in the following tables.

\begin{tabular}{|c|c|c|c|c|c|c|c|c|c|c|c|}
\hline \multicolumn{12}{|c|}{ Table A-1a. VC-1 INAA Data } \\
\hline \multirow[t]{2}{*}{ sample } & \multirow{2}{*}{$\begin{array}{l}\text { meters } \\
\text { below } \\
\text { contact }\end{array}$} & ${ }^{24} \mathrm{Na}$ & ${ }^{46} \mathrm{Sc}$ & ${ }^{59} \mathrm{Fe}$ & ${ }^{60} \mathrm{Co}$ & ${ }^{86} \mathrm{Rb}$ & ${ }^{131} \mathrm{Ba}$ & ${ }^{134} \mathrm{Cs}$ & ${ }^{140} \mathrm{La}$ & ${ }^{141} \mathrm{Ce}$ & ${ }^{147} \mathrm{Nd}$ \\
\hline & & $\not$ & ppm & $\%$ & ppm & ppm & ppm & $\mathrm{ppm}$ & ppm & $\mathrm{ppm}$ & $\mathrm{ppm}$ \\
\hline 1vc.1 & -5.944 & 3.02 & 3.64 & 1.46 & 3.88 & 155.77 & 404.40 & 4.52 & 38.61 & 67.73 & 22.49 \\
\hline $1 \mathrm{vc} .4$ & -2.442 & 3.07 & 3.67 & 1.48 & 3.91 & 163.52 & 430.69 & 4.65 & 37.86 & 70.70 & 23.88 \\
\hline $1 v c .8$ & -0.689 & 2.98 & 3.11 & 1.14 & 2.72 & 204.74 & 314.17 & 6.43 & 37.97 & 69.04 & 21.18 \\
\hline 1vc.11 & -0.537 & 2.73 & 3.05 & 1.17 & 2.59 & 192.67 & 323.60 & 6.38 & 38.72 & 69.01 & 21.28 \\
\hline 1vc.13 & -0.460 & 2.91 & 3.00 & 1.09 & 2.29 & 228.50 & 270.06 & 7.21 & 39.95 & 70.16 & 22.15 \\
\hline 1vc.15 & -0.363 & 2.78 & 3.24 & 1.25 & 2.96 & 206.49 & 365.94 & 5.86 & 37.34 & 68.00 & 22.77 \\
\hline 1vc.16 & -0.332 & 2.86 & 3.43 & 1.41 & 3.64 & 177.51 & 405.95 & 5.09 & 37.87 & 66.99 & 25.25 \\
\hline 1vc.18 & -0.274 & 2.76 & 3.46 & 1.40 & 3.69 & 162.16 & 421.48 & 5.30 & 36.86 & 66.06 & 23.48 \\
\hline 1vc.19 & -0.241 & 2.87 & 3.40 & 1.31 & 3.20 & 176.63 & 353.30 & 5.54 & 37.28 & 67.71 & 21.98 \\
\hline 1vc.21 & -0.079 & 2.88 & 3.25 & 1.26 & 3.07 & 180.91 & 383.77 & 4.88 & 37.25 & 66.73 & 22.35 \\
\hline $1 \mathrm{vc} .22$ & 0.027 & 2.81 & 3.11 & 1.12 & 2.72 & 202.61 & 292.82 & 6.39 & 36.94 & 67.77 & 21.58 \\
\hline $1 \mathrm{vc} .23$ & 0.256 & 2.79 & 3.37 & 1.23 & 2.98 & 206.83 & 363.36 & 6.51 & 38.21 & 70.37 & 24.53 \\
\hline $1 \mathrm{vc} .24$ & 0.390 & 2.89 & 4.29 & 1.73 & 4.58 & 190.78 & 501.22 & 5.45 & 37.96 & 82.64 & 27.78 \\
\hline $1 \mathrm{vc} .29$ & 0.588 & 2.89 & 3.83 & 1.49 & 4.33 & 164.90 & 418.28 & 5.79 & 39.48 & 69.07 & 22.36 \\
\hline $1 \mathrm{vc} .30$ & 0.622 & 2.85 & 3.51 & 1.37 & 3.53 & 171.70 & 406.62 & 4.70 & 38.12 & 66.93 & 22.21 \\
\hline 1vc.33 & 0.753 & 2.78 & 3.52 & 1.39 & 3.68 & 169.33 & 434.03 & 5.01 & 38.83 & 68.72 & 23.68 \\
\hline 1vc. 35 & 0.832 & 2.66 & 3.56 & 1.46 & 3.73 & 173.50 & 421.61 & 4.93 & 35.33 & 68.69 & 22.11 \\
\hline 1vc.44 & 1.491 & 2.68 & 3.42 & 1.35 & 3.68 & 149.54 & 388.58 & 5.70 & 37.75 & 62.08 & 20.33 \\
\hline
\end{tabular}




\begin{tabular}{|c|c|c|c|c|c|c|c|c|c|c|}
\hline \multicolumn{11}{|c|}{ Table A-1b. VC-1 INAA Data (cont.) } \\
\hline \multirow[t]{2}{*}{ sample } & \multirow{2}{*}{$\begin{array}{l}\text { meters } \\
\text { below } \\
\text { contact }\end{array}$} & ${ }^{152} \mathrm{Eu}$ & ${ }^{153} \mathrm{Sm}$ & ${ }^{160} \mathrm{~Tb}$ & ${ }^{169} \mathrm{Yb}$ & ${ }^{17} \mathrm{Lu}$ & ${ }^{181} \mathrm{Hf}$ & ${ }^{182} \mathrm{Ta}$ & ${ }^{233} \mathrm{Th}$ & ${ }^{239} \mathrm{U}$ \\
\hline & & ppm & $\mathrm{ppm}$ & $\mathrm{ppm}$ & $\mathrm{ppm}$ & $\mathrm{ppm}$ & ppm & ppm & ppm & $\mathrm{ppm}$ \\
\hline 1vc.1 & -5.944 & 0.593 & 4.07 & 0.629 & 2.87 & 0.492 & 4.93 & 2.64 & 20.09 & 6.21 \\
\hline $1 \mathrm{vc} .4$ & -2.442 & 0.588 & 3.99 & 0.810 & 2.97 & 0.517 & 5.64 & 2.69 & 21.51 & 6.05 \\
\hline $1 \mathrm{vc.8}$ & -0.689 & 0.390 & 4.00 & 0.604 & 3.30 & 0.615 & 4.95 & 3.38 & 26.09 & 8.50 \\
\hline 1vc.11 & -0.537 & 0.407 & 3.85 & 0.573 & 3.23 & 0.589 & 4.56 & 3.20 & 24.46 & 7.33 \\
\hline $1 \mathrm{vc.} .13$ & -0.460 & 0.353 & 4.02 & 0.585 & 3.67 & 0.666 & 5.18 & 3.78 & 29.18 & 9.53 \\
\hline 1vc.15 & -0.363 & 0.448 & 3.93 & 0.651 & 3.27 & 0.613 & 5.59 & 3.06 & 24.65 & 7.42 \\
\hline Ivc.16 & -0.332 & 0.494 & 4.12 & 0.728 & 3.12 & 0.538 & 5.00 & 2.90 & 21.91 & 6.20 \\
\hline 1vc. 18 & -0.274 & 0.490 & 4.00 & 0.616 & 3.06 & 0.515 & 4.81 & 2.61 & 19.82 & 5.87 \\
\hline 1vc.19 & -0.241 & 0.491 & 3.95 & 0.659 & 3.14 & 0.547 & 5.04 & 2.95 & 22.18 & 6.60 \\
\hline 1vc.21 & -0.079 & 0.459 & 3.90 & 0.695 & 2.99 & 0.527 & 4.94 & 2.87 & 21.93 & 6.39 \\
\hline 1vc. 22 & 0.027 & 0.379 & 3.90 & 0.801 & 3.32 & 0.579 & 5.08 & 3.42 & 26.09 & 8.15 \\
\hline $1 \mathrm{vc} .23$ & 0.256 & 0.440 & 4.15 & 0.695 & 3.60 & 0.598 & 5.02 & 3.44 & 25.45 & 7.67 \\
\hline 1vc. 24 & 0.390 & 0.689 & 4.11 & 0.949 & 3.47 & 0.599 & 6.60 & 3.15 & 25.13 & 6.33 \\
\hline 1ve. 29 & 0.588 & 0.538 & 4.22 & 0.797 & 2.84 & 0.522 & 4.86 & 2.70 & 21.74 & 6.28 \\
\hline 1vc.30 & 0.622 & 0.517 & 3.97 & 0.695 & 2.88 & 0.494 & 4.79 & 2.71 & 20.90 & 6.15 \\
\hline $1 \mathrm{vc.33}$ & 0.753 & 0.522 & 4.05 & 0.616 & 2.89 & 0.527 & 5.24 & 2.66 & 20.64 & 6.44 \\
\hline 1ve. 35 & 0.832 & 0.572 & 3.93 & 0.604 & 2.93 & 0.53 & 4.73 & 2.70 & 21.60 & 5.71 \\
\hline $1 \mathrm{vc.} 44$ & 1.491 & 0.508 & 3.96 & 0.731 & 2.64 & 0.486 & 4.82 & 2.31 & 18.47 & 5.79 \\
\hline
\end{tabular}




\begin{tabular}{|c|c|c|c|c|c|c|c|c|c|c|c|c|c|}
\hline \multicolumn{14}{|c|}{ Table A-2. VC-1 XRF Data } \\
\hline \multirow[t]{2}{*}{ sample } & \multirow{2}{*}{$\begin{array}{l}\text { meters } \\
\text { below } \\
\text { contact }\end{array}$} & $\mathrm{SiO}_{2}$ & $\mathrm{TiO}_{2}$ & $\mathrm{Al}_{2} \mathrm{O}_{3}$ & $\mathrm{Fe}_{2} \mathrm{O}_{3}$ & $\mathrm{MnO}$ & $\mathrm{MgO}$ & $\mathrm{CaO}$ & $\mathrm{Na}_{2} \mathrm{O}$ & $\mathrm{K}_{2} \mathrm{O}$ & $\mathrm{P}_{2} \mathrm{O}_{3}$ & LOI & Total \\
\hline & & $\mathscr{\%}$ & $\%$ & $\%$ & $\%$ & $\%$ & $\%$ & $\mathscr{H}$ & $\%$ & $\%$ & $\%$ & $\%$ & $\%$ \\
\hline 1vc.1 & -5.944 & 73.03 & 0.33 & 13.61 & 2.00 & 0.06 & 0.82 & 1.60 & 3.82 & 4.22 & 0.08 & 0.50 & 100.07 \\
\hline 1vc. 4 & -2.442 & 72.88 & 0.34 & 13.48 & 2.03 & 0.06 & 0.87 & $1: 77$ & 3.93 & 4.13 & 0.08 & 0.49 & 100.06 \\
\hline $1 \mathrm{vc} .8$ & -0.689 & 74.05 & 0.27 & 12.41 & 1.62 & 0.05 & 0.62 & 1.05 & 3.66 & 4.53 & 0.05 & 1.60 & 99.91 \\
\hline 1vc.11 & -0.537 & 73.51 & 0.29 & 12.47 & 1.65 & 0.05 & 0.67 & 1.06 & 3.63 & 4.55 & 0.06 & 2.16 & 100.10 \\
\hline Ivc.13 & -0.460 & 73.82 & 0.25 & 12.41 & 1.40 & 0.05 & 0.54 & 0.91 & 4.12 & 4.54 & 0.05 & 1.92 & 100.01 \\
\hline $1 \mathrm{vc} .15$ & -0.363 & 73.23 & 0.28 & 12.54 & 1.71 & 0.05 & 0.69 & 1.17 & 3.69 & 4.47 & 0.06 & 2.10 & 99.99 \\
\hline $1 \mathrm{vc.} 16$ & -0.332 & 72.98 & 0.32 & 12.55 & 1.89 & 0.06 & 0.79 & 1.30 & 3.59 & 4.31 & 0.06 & 2.22 & 100.07 \\
\hline 1vc.18 & -0.274 & 72.59 & 0.34 & 12.54 & 1.98 & 0.06 & 0.83 & 1.25 & 3.59 & 4.45 & 0.07 & 2.43 & 100.13 \\
\hline 1vc.19 & -0.241 & 72.91 & 0.31 & 12.81 & 1.94 & 0.05 & 0.77 & 1.34 & 3.68 & 4.38 & 0.06 & 1.89 & 100.14 \\
\hline 1vc.21 & -0.079 & 73.16 & 0.29 & 12.74 & 1.76 & 0.05 & 0.72 & 1.23 & 3.61 & 4.44 & 0.06 & 2.19 & 100.25 \\
\hline 1vc.22 & 0.027 & 73.74 & 0.27 & 12.32 & 1.59 & 0.05 & 0.64 & 0.98 & 3.46 & 4.54 & 0.05 & 2.42 & 100.06 \\
\hline $1 \mathrm{vc} .23$ & 0.256 & 73.08 & 0.29 & 12.69 & 1.73 & 0.05 & 0.71 & 1.12 & 3.55 & 4.48 & 0.06 & 2.55 & 100.31 \\
\hline 1vc.24 & 0.390 & 71.84 & 0.33 & 13.18 & 2.04 & 0.05 & 0.87 & 1.55 & 3.58 & 4.24 & 0.08 & 2.35 & 100.11 \\
\hline $1 \mathrm{vc} .29$ & 0.588 & 72.00 & 0.35 & 13.02 & 2.18 & 0.05 & 0.92 & 1.48 & 3.51 & 4.19 & 0.08 & 2.35 & 100.13 \\
\hline $1 \mathrm{vc} .30$ & 0.622 & 72.14 & 0.32 & 13.05 & 1.96 & 0.06 & 0.84 & 1.44 & 3.52 & 4.24 & 0.07 & 2.39 & 100.03 \\
\hline $1 \mathrm{vc} .33$ & 0.753 & 72.52 & 0.33 & 12.99 & 1.97 & 0.06 & 0.85 & 1.46 & 3.43 & 4.26 & 0.07 & 2.32 & 100.26 \\
\hline $1 \mathrm{vc} .35$ & 0.832 & 72.13 & 0.33 & 13.35 & 2.01 & 0.05 & 0.85 & 1.54 & 3.65 & 4.10 & 0.07 & 2.24 & 100.32 \\
\hline 1vc.44 & 1.491 & 72.09 & 0.35 & 12.98 & 2.14 & 0.06 & 0.95 & 1.47 & 3.54 & 4.21 & 0.08 & 2.41 & 100.28 \\
\hline
\end{tabular}




\begin{tabular}{|c|c|c|c|c|c|c|c|c|c|c|}
\hline \multicolumn{11}{|c|}{ Table A-3a. Site 8 Matrix INAA Data } \\
\hline \multirow[t]{2}{*}{ Sample } & \multirow{2}{*}{$\begin{array}{l}\text { meters } \\
\text { below } \\
\text { contact }\end{array}$} & ${ }^{46} \mathrm{Sc}$ & ${ }^{59} \mathrm{Fe}$ & ${ }^{60} \mathrm{Co}$ & ${ }^{86} \mathrm{Rb}$ & ${ }^{131} \mathrm{Ba}$ & ${ }^{134} \mathrm{Cs}$ & ${ }^{141} \mathrm{Ce}$ & ${ }^{147} \mathrm{Nd}$ & ${ }^{152} \mathrm{Eu}$ \\
\hline & & ppm & $\%$ & ppm & ppm & ppm & ppm & ppm & $\mathrm{ppm}$ & $\mathrm{ppm}$ \\
\hline 8randobs & -0.030 & 3.36 & 1.35 & 3.82 & 159.63 & 417 & 4.76 & 65.64 & 20.22 & 0.484 \\
\hline 8randtuf & 0.005 & 6.03 & 2.34 & 19.19 & 111.93 & 544.9 & 10.69 & 96.43 & 44.20 & 1.180 \\
\hline $8 \mathrm{am}$ & 0.009 & 4.45 & 1.95 & 6.53 & 129.28 & 489.5 & 5.66 & 72.65 & 28.39 & 0.730 \\
\hline $8 \mathrm{bm}$ & 0.419 & 4.00 & 1.72 & 5.34 & 136.20 & 432.7 & 5.43 & 65.97 & 22.47 & 0.591 \\
\hline $8 \mathrm{~cm}$ & 0.910 & 4.29 & 1.81 & 5.66 & 135.17 & 478.3 & 5.94 & 67.41 & 23.05 & 0.628 \\
\hline $8 \mathrm{dm}$ & 1.383 & 4.18 & 1.76 & 5.48 & 146.45 & 462.8 & 5.99 & 66.55 & 22.36 & 0.610 \\
\hline $8 \mathrm{em}$ & 1.876 & 3.52 & 1.44 & 4.25 & 158.52 & 451.7 & 6.02 & 68.25 & 22.17 & 0.522 \\
\hline $8 \mathrm{fm}$ & 2.349 & 3.46 & 1.42 & 4.11 & 165.97 & 394.7 & 6.58 & 65.24 & 20.91 & 0.487 \\
\hline
\end{tabular}

\begin{tabular}{||l|l|r|r|r|r|r|r|r|r||}
\hline \multicolumn{8}{|c|}{ Table A-3b. Site 8 Matrix INAA Data (cont.) } \\
\hline \hline Sample & $\begin{array}{l}\text { meters } \\
\text { below } \\
\text { contact }\end{array}$ & ${ }^{153} \mathrm{Sm}$ & ${ }^{160} \mathrm{~Tb}$ & ${ }^{169} \mathrm{Yb}$ & ${ }^{17} \mathrm{Lu}$ & ${ }^{181} \mathrm{Hf}$ & ${ }^{182} \mathrm{Ta}$ & ${ }^{233} \mathrm{Th}$ & ${ }^{239} \mathrm{U}$ \\
\cline { 2 - 11 } & $\mathrm{ppm}$ & $\mathrm{ppm}$ & $\mathrm{ppm}$ & $\mathrm{ppm}$ & $\mathrm{ppm}$ & $\mathrm{ppm}$ & $\mathrm{ppm}$ \\
\hline 8randobs & -0.030 & 3.70 & 0.516 & 2.92 & 0.480 & 4.91 & 2.58 & 20.54 & 5.85 \\
\hline 8randtuf & 0.005 & 7.60 & 1.080 & 3.62 & 0.643 & 8.10 & 1.82 & 14.91 & 4.17 \\
\hline 8am & 0.009 & 5.39 & 0.715 & 3.08 & 0.529 & 6.41 & 1.89 & 17.76 & 5.00 \\
\hline $8 \mathrm{bm}$ & 0.419 & 4.12 & 0.651 & 3.01 & 0.498 & 5.61 & 2.03 & 18.42 & 5.77 \\
\hline $8 \mathrm{~cm}$ & 0.910 & 4.77 & 0.644 & 3.06 & 0.526 & 6.47 & 1.97 & 18.53 & 6.16 \\
\hline $8 \mathrm{dm}$ & 1.383 & 4.34 & 0.657 & 2.98 & 0.512 & 5.21 & 2.05 & 19.09 & 5.77 \\
\hline $8 \mathrm{em}$ & 1.876 & 4.21 & 0.600 & 3.05 & 0.521 & 5.57 & 2.18 & 21.02 & 6.37 \\
\hline $8 \mathrm{fm}$ & 2.349 & 3.91 & 0.583 & 3.18 & 0.533 & 5.36 & 2.25 & 21.34 & 6.56 \\
\hline \hline
\end{tabular}




\begin{tabular}{|c|c|c|c|c|c|c|c|c|c|c|c|c|c|}
\hline \multicolumn{14}{|c|}{ Table A-4. Site 8 Matrix XRF Data } \\
\hline \multirow[t]{2}{*}{ Sample } & \multirow{2}{*}{$\begin{array}{l}\text { meters } \\
\text { below } \\
\text { contact }\end{array}$} & $\mathrm{SiO}_{2}$ & $\mathrm{TiO}_{2}$ & $\mathrm{Al}_{2} \mathrm{O}_{3}$ & $\mathrm{Fe}_{2} \mathrm{O}_{3}$ & $\mathrm{MnO}$ & MgO & $\mathrm{CaO}$ & $\mathrm{Na}_{2} \mathrm{O}$ & $\mathrm{K}_{\mathbf{2}} \mathrm{O}$ & $\mathrm{P}_{2} \mathrm{O}_{5}$ & LOI & Total \\
\hline & & $\mathscr{\%}$ & $\%$ & $\%$ & $\%$ & $\%$ & $\%$ & $\%$ & $\%$ & $\%$ & $\%$ & $\%$ & $\%$ \\
\hline 8randobs & -0.030 & 71.94 & 0.39 & 13.60 & 2.41 & 0.06 & 0.98 & 1.82 & 3.77 & 3.96 & 0.09 & 0.50 & 99.52 \\
\hline 8randtuf & 0.005 & ND & ND & ND & ND & ND & ND & ND & ND & ND & ND & 1.34 & ND \\
\hline $8 \mathrm{am}$ & 0.009 & 70.98 & 0.42 & 13.69 & 2.74 & 0.08 & 1.03 & 1.67 & 3.66 & 4.01 & 0.11 & 1.57 & 99.96 \\
\hline $8 \mathrm{bm}$ & 0.419 & 70.48 & 0.38 & 13.42 & 2.42 & 0.06 & 0.94 & 1.76 & 3.76 & 4.13 & 0.10 & 2.56 & 100.01 \\
\hline $8 \mathrm{~cm}$ & 0.910 & 70.80 & 0.38 & 13.45 & 2.43 & 0.06 & 0.99 & 1.83 & 3.71 & 4.07 & 0.09 & 2.44 & 100.25 \\
\hline $8 \mathrm{dm}$ & 1.383 & 71.02 & 0.36 & 13.46 & 2.30 & 0.06 & 0.92 & 1.81 & 3.73 & 4.16 & 0.09 & 2.37 & 100.28 \\
\hline $8 \mathrm{em}$ & 1.876 & 71.74 & 0.32 & 13.13 & 2.04 & 0.05 & 0.78 & 1.48 & 3.80 & 4.35 & 0.07 & 2.29 & 100.05 \\
\hline $8 \mathrm{fm}$ & 2.349 & 71.88 & 0.30 & 12.77 & 1.93 & 0.06 & 0.73 & 1.28 & 3.84 & 4.50 & 0.07 & 2.75 & 100.11 \\
\hline
\end{tabular}

\section{Table A-5. Site 8 Matrix Volatiles Data}

\begin{tabular}{|c|c|c|c|c|}
\hline \multirow[t]{2}{*}{ Sample } & \multirow{2}{*}{$\begin{array}{l}\text { meters } \\
\text { below } \\
\text { contact }\end{array}$} & $\mathrm{Cl}$ & $F$ & $s$ \\
\hline & & ppm & ppm & ppm \\
\hline 8randobs & -0.030 & 476 & 404 & 167 \\
\hline $8 \mathrm{am}$ & 0.009 & 262 & 236 & 132 \\
\hline $8 \mathrm{bm}$ & 0.419 & 194 & 212 & 117 \\
\hline $8 \mathrm{~cm}$ & 0.910 & 198 & 225 & 128 \\
\hline 8dm & 1.383 & 201 & 212 & 79 \\
\hline $8 \mathrm{em}$ & 1.876 & 347 & 197 & 48 \\
\hline $8 \mathrm{fm}$ & 2.349 & 312 & 188 & 38 \\
\hline
\end{tabular}




\begin{tabular}{|c|c|c|c|c|c|c|c|c|c|c|}
\hline \multicolumn{11}{|c|}{ Table A-6a. Site 8 Whole Rock INAA Data } \\
\hline \multirow[t]{2}{*}{ Sample } & \multirow{2}{*}{$\begin{array}{l}\text { meters } \\
\text { below } \\
\text { contact }\end{array}$} & ${ }^{46} \mathrm{Sc}$ & ${ }^{59} \mathrm{Fe}$ & ${ }^{60} \mathrm{Co}$ & ${ }^{86} \mathrm{Rb}$ & ${ }^{131} \mathrm{Ba}$ & ${ }^{134} \mathrm{Cs}$ & ${ }^{141} \mathrm{Ce}$ & ${ }^{147} \mathbf{N d}$ & ${ }^{152} \mathrm{Eu}$ \\
\hline & & $\mathrm{ppm}$ & $\%$ & ppm & ppm & ppm & ppm & ppm & ppm & ppm \\
\hline $8 a w$ & 0.009 & 4.37 & 1.86 & 6.07 & 123.97 & 463.7 & 6.09 & 73.59 & 28.95 & 0.751 \\
\hline $8 \mathrm{bw}$ & 0.419 & 4.00 & 1.69 & 5.20 & 137.87 & 451.2 & 5.71 & 66 & 23.9 & 0.586 \\
\hline $8 \mathrm{cw}$ & 0.910 & 4.20 & 1.78 & 5.50 & 136.97 & 433.7 & 5.72 & 64.96 & 23.31 & 0.617 \\
\hline $8 d w$ & 1.383 & 4.27 & 1.79 & 5.78 & 142.70 & 453.8 & 6.04 & 66.63 & 22.26 & 0.627 \\
\hline $8 \mathrm{ew}$ & 1.876 & 3.56 & 1.49 & 4.25 & 152.44 & 415.6 & 5.73 & 65.62 & 21.95 & 0.522 \\
\hline $8 \mathrm{fw}$ & 2.349 & 3.45 & 1.36 & 3.86 & 171.34 & 409.4 & 6.49 & 68.01 & 22.52 & 0.474 \\
\hline
\end{tabular}

\begin{tabular}{|c|c|c|c|c|c|c|c|c|c|}
\hline \multicolumn{10}{|c|}{ Table A-6b. Site 8 Whole Rock INAA Data (cont.) } \\
\hline \multirow[t]{2}{*}{ Sample } & \multirow{2}{*}{$\begin{array}{l}\text { meters } \\
\text { below } \\
\text { contact }\end{array}$} & ${ }^{153} \mathrm{Sm}$ & ${ }^{160} \mathrm{~Tb}$ & ${ }^{169} \mathrm{Yb}$ & ${ }^{177} \mathrm{Lu}$ & ${ }^{181} \mathrm{Hf}$ & ${ }^{182} \mathrm{Ta}$ & ${ }^{233} \mathrm{Th}$ & ${ }^{239} \mathrm{U}$ \\
\hline & & $\mathrm{ppm}$ & ppm & ppm & ppm & ppm & ppm & ppm & $\mathrm{ppm}$ \\
\hline 8aw & 0.009 & 5.52 & 0.766 & 3.17 & 0.511 & 5.71 & 1.86 & 16.94 & 5.28 \\
\hline $8 \mathrm{bw}$ & 0.419 & 4.54 & 0.693 & 2.92 & 0.512 & 5.92 & 1.98 & 18.39 & 5.53 \\
\hline $8 \mathrm{cw}$ & 0.910 & 4.55 & 0.628 & 2.94 & 0.503 & 5.73 & 1.90 & 18.33 & 5.58 \\
\hline $8 \mathrm{dw}$ & 1.383 & 4.77 & 0.722 & 2.95 & 0.489 & 5.81 & 1.90 & 18.37 & 5.19 \\
\hline $8 \mathrm{ew}$ & 1.876 & 3.91 & 0.609 & 3.01 & 0.479 & 5.00 & 2.05 & 19.48 & 5.75 \\
\hline $8 f w$ & 2.349 & 4.59 & 0.605 & 3.12 & 0.536 & 5.71 & 2.24 & 21.52 & 7.63 \\
\hline
\end{tabular}




\begin{tabular}{||l|r|r|r|r|r|r|r|r|r|r||}
\hline \multicolumn{10}{|c|}{ Table A-7a. Site 8 Clasts INAA Data } \\
\hline \hline Sample & $\begin{array}{l}\text { meters } \\
\text { below } \\
\text { contact }\end{array}$ & ${ }^{46} \mathrm{Sc}$ & ${ }^{59} \mathrm{Fe}$ & ${ }^{60} \mathrm{Co}$ & ${ }^{86} \mathrm{Rb}$ & ${ }^{131} \mathrm{Ba}$ & ${ }^{134} \mathrm{Cs}$ & ${ }^{141} \mathrm{Ce}$ & ${ }^{147} \mathrm{Nd}$ & ${ }^{152} \mathrm{Eu}$ \\
\cline { 3 - 12 } & & $\%$ & $\mathrm{ppm}$ & $\mathrm{ppm}$ & $\mathrm{ppm}$ & $\mathrm{ppm}$ & $\mathrm{ppm}$ & $\mathrm{ppm}$ & $\mathrm{ppm}$ \\
\hline $8 \mathrm{ac}$ & 0.009 & 5.38 & 2.21 & 7.42 & 109.86 & 533.3 & 7.15 & 85.85 & 39.82 & 1.040 \\
\hline $8 \mathrm{bc}$ & 0.419 & 3.86 & 1.82 & 5.37 & 84.78 & 437.9 & 6.93 & 75.81 & 33.78 & 0.874 \\
\hline $8 \mathrm{cc}$ & 0.910 & 3.99 & 1.66 & 4.90 & 128.09 & 481.5 & 6.69 & 71.41 & 24.54 & 0.674 \\
\hline $8 \mathrm{dc}$ & 1.383 & 4.20 & 1.57 & 4.58 & 138.49 & 464.6 & 6.08 & 72.87 & 24.78 & 0.609 \\
\hline $8 \mathrm{ec}$ & 1.876 & 3.57 & 1.44 & 4.18 & 152.44 & 416.4 & 6.00 & 66.06 & 21.93 & 0.524 \\
\hline $8 \mathrm{fc}$ & 2.349 & 3.22 & 1.27 & 3.43 & 179.65 & 401.7 & 6.62 & 67.52 & 21.13 & 0.447 \\
\hline \hline
\end{tabular}

\begin{tabular}{|c|c|c|c|c|c|c|c|c|c|}
\hline \multicolumn{10}{|c|}{ Table A-7b. Site 8 CLasts INAA Data (cont.) } \\
\hline \multirow[t]{2}{*}{ Sample } & \multirow{2}{*}{$\begin{array}{l}\text { meters } \\
\text { below } \\
\text { contact }\end{array}$} & ${ }^{153} \mathrm{Sm}$ & ${ }^{160} \mathrm{~Tb}$ & ${ }^{169} \mathrm{Yb}$ & ${ }^{177} \mathrm{Lu}$ & ${ }^{181} \mathrm{Hf}$ & ${ }^{182} \mathrm{Ta}$ & ${ }^{233} \mathrm{Th}$ & ${ }^{239} \mathrm{U}$ \\
\hline & & ppm & ppm & ppm & ppm & ppm & $\mathrm{ppm}$ & ppm & ppm \\
\hline $8 \mathrm{ac}$ & 0.009 & 7.13 & 0.921 & 3.11 & 0.513 & 7.24 & 1.76 & 14.40 & 3.98 \\
\hline $8 \mathrm{bc}$ & 0.419 & 5.86 & 0.789 & 2.74 & 0.441 & 6.75 & 1.53 & 12.49 & 4.90 \\
\hline $8 \mathrm{cc}$ & 0.910 & 4.55 & 0.629 & 2.91 & 0.493 & 5.70 & 1.85 & 18.41 & 5,49 \\
\hline $8 \mathrm{dc}$ & 1.383 & 4.67 & 0.746 & 3.15 & 0.500 & 5.50 & 2.04 & 19.09 & 6.12 \\
\hline $8 \mathrm{ec}$ & 1.876 & 4.50 & 0.574 & 3.00 & 0.492 & 5.18 & 2.09 & 20.09 & 6.16 \\
\hline $8 \mathrm{fc}$ & 2.349 & 3.90 & 0.583 & 3.06 & 0.511 & 4.59 & 2.33 & 22.34 & 6.88 \\
\hline
\end{tabular}




\begin{tabular}{|c|c|c|c|c|c|c|c|c|c|c|c|c|}
\hline \multirow[t]{2}{*}{ Point } & \multirow[t]{2}{*}{ Label } & $\mathrm{F}$ & $\mathrm{Na}_{2} \mathrm{O}$ & $\mathrm{MgO}$ & $\mathrm{Al}_{2} \mathrm{O}_{3}$ & $\mathrm{SiO}_{2}$ & $\mathrm{~K}_{2} \mathrm{O}$ & $\mathrm{CaO}$ & $\mathrm{TiO}_{2}$ & $\mathrm{MnO}$ & $\mathrm{FeO}$ & Total \\
\hline & & ppm & $\%$ & $\mathscr{\%}$ & $\mathscr{0}$ & $\not$ & $\%$ & $\%$ & $\%$ & $\%$ & $\%$ & $\%$ \\
\hline 1 & Amp1 & 0.4476 & 1.565 & 14.40 & 6.17 & 46.26 & 0.596 & 11.29 & 1.350 & 0.5799 & 13.12 & 95.77 \\
\hline 2 & Ampla & 0.4866 & 1.592 & 14.08 & 6.20 & 46.81 & 0.630 & 11.25 & 1.371 & 0.6542 & 12.98 & 96.06 \\
\hline 3 & Amp2 & 0.3146 & 1.715 & 15.04 & 8.05 & 45.78 & 0.592 & 11.19 & 2.066 & 0.3104 & 11.13 & 96.19 \\
\hline 4 & $? ?$ & 0.8266 & 1.061 & 20.13 & 16.52 & 35.86 & 3.559 & 1.26 & 0.054 & 0.0920 & 9.41 & 88.78 \\
\hline 5 & $? ?$ & 0.7414 & 1.063 & 19.26 & 16.66 & 36.13 & 3.401 & 1.36 & 0.010 & 0.0601 & 9.67 & 88.37 \\
\hline 6 & Amp3 & 0.2954 & 1.393 & 15.29 & 6.01 & 47.37 & 0.450 & 10.91 & 1.347 & 0.6037 & 11.85 & 95.51 \\
\hline 7 & ?? & 0.0322 & 5.406 & 1.730 & 21.44 & 48.82 & 3.438 & 2.25 & 0.501 & 0.0781 & 9.73 & 93.42 \\
\hline 8 & $? ?$ & 0.1754 & 4.750 & 5.630 & 21.26 & 49.98 & 4.210 & 1.59 & 0.098 & 0.0858 & 5.34 & 93.11 \\
\hline 9 & $? ?$ & 0.3110 & 2.687 & 5.140 & 6.62 & 26.22 & 1.171 & 1.11 & 0.388 & 3.6011 & 32.41 & 79.66 \\
\hline 10 & $? ?$ & 0.9040 & 1.201 & 21.90 & 15.92 & 40.51 & 3.452 & 0.21 & 0.017 & 0.1446 & 6.95 & 91.21 \\
\hline 11 & $? ?$ & 0.3348 & 0.449 & 22.44 & 18.11 & 41.41 & 1.736 & 0.59 & 0.000 & 0.5445 & 8.28 & 93.89 \\
\hline 12 & Bio4 & 0.6644 & 0.624 & 16.60 & 13.90 & 38.09 & 8.677 & 0.00 & 4.892 & 0.0970 & 11.70 & 95.24 \\
\hline 13 & Bio4a & 0.7601 & 0.588 & 17.24 & 13.13 & 38.69 & 8.624 & 0.00 & 4.667 & 0.1335 & 11.60 & 95.42 \\
\hline 14 & Amp4 & 0.3422 & 2.112 & 14.42 & 9.26 & 43.69 & 0.597 & 11.15 & 2.886 & 0.2832 & 11.29 & 96.04 \\
\hline 15 & Epidote & 0.0000 & 0.001 & 0.070 & 23.34 & 36.97 & 0.000 & 23.54 & 0.000 & 0.0827 & 10.71 & 94.71 \\
\hline 16 & Amp5 & 0.4143 & 1.689 & 15.26 & 7.20 & 46.59 & 0.507 & 10.91 & 1.707 & 0.4511 & 10.98 & 95.71 \\
\hline 17 & Amp6 & 0.4722 & 1.620 & 13.81 & 6.51 & 46.31 & 0.702 & 10.78 & 1.439 & 0.6983 & 12.92 & 95.27 \\
\hline 18 & Amp7 & 0.2980 & 2.026 & 13.57 & 10.05 & 42.50 & 0.779 & 11.33 & 2.828 & 0.3592 & 11.78 & 95.52 \\
\hline 19 & Opx & 0.0761 & 0.014 & 23.76 & 0.36 & 52.16 & 0.000 & 0.76 & 0.126 & 1.4433 & 18.24 & 96.94 \\
\hline 20 & Opx & 0.0950 & 0.000 & 25.20 & 0.21 & 52.80 & 0.000 & 1.06 & 0.082 & 1.3743 & 16.99 & 97.80 \\
\hline
\end{tabular}




\begin{tabular}{|c|c|c|c|c|c|c|c|c|c|c|c|c|}
\hline \multicolumn{13}{|c|}{ Table A-9a. Site 8 Microprobe Data on Heavy Minerals, Sample 8B } \\
\hline Point & Label & $F$ & $\mathrm{Na}_{2} \mathrm{O}$ & $\mathrm{MgO}$ & $\mathrm{Al}_{2} \mathrm{O}_{3}$ & $\mathrm{SiO}_{2}$ & $\mathrm{~K}_{2} \mathrm{O}$ & $\mathrm{CaO}$ & $\mathrm{TiO}_{2}$ & $\mathrm{MnO}$ & $\mathrm{FeO}$ & Total \\
\hline & & $\%$ & $\%$ & $\%$ & $\%$ & $\%$ & $\%$ & $\%$ & $\%$ & $\%$ & $\%$ & $\%$ \\
\hline 4 & Pyx & 0.0000 & 0.3516 & 13.64 & 0.688 & 51.92 & 0.0068 & 21.20 & 0.2888 & 0.4521 & 10.92 & 99.46 \\
\hline 5 & Amp3 & 0.3440 & 2.3507 & 12.19 & 11.696 & 41.16 & 0.8036 & 11.14 & 3.8467 & 0.3485 & 13.41 & 97.28 \\
\hline 6 & Amp3a & 0.3556 & 2.2762 & 12.31 & 11.364 & 40.77 & 0.7943 & 11.19 & 3.7329 & 0.3933 & 13.64 & 96.83 \\
\hline 7 & Amp4 & 0.4364 & 1.6734 & 15.16 & 7.242 & 46.45 & 0.5544 & 10.95 & 1.7720 & 0.4109 & 12.32 & 96.98 \\
\hline 8 & Amp4a & 0.4720 & 1.6368 & 15.39 & 6.758 & 47.02 & 0.5972 & 10.95 & 1.6801 & 0.4645 & 11.82 & 96.79 \\
\hline 9 & Amp5 & 0.4796 & 1.4523 & 15.15 & 6.380 & 47.07 & 0.6011 & 11.04 & 1.3263 & 0.5931 & 11.58 & 95.67 \\
\hline 10 & Amp5a & 0.4913 & 1.3241 & 16.28 & 5.560 & 48.74 & 0.5234 & 11.09 & 0.8393 & 0.5595 & 11.22 & 96.62 \\
\hline 11 & Amp6 & 0.4737 & 1.4091 & 14.62 & 5.832 & 46.54 & 0.6492 & 11.13 & 1.1621 & 0.6521 & 13.19 & 95.66 \\
\hline 12 & Bio1 & 0.4657 & 1.1591 & 7.57 & 24.752 & 42.85 & 5.9357 & 0.31 & 0.0675 & 0.0519 & 8.53 & 91.70 \\
\hline 13 & Biola & 0.4903 & 1.3940 & 6.70 & 26.475 & 42.78 & 5.8898 & 0.23 & 0.1156 & 0.0487 & 6.78 & 90.91 \\
\hline 15 & Amp7 & 0.4907 & 1.5764 & 14.54 & 7.050 & 46.98 & 0.6278 & 11.13 & 1.6519 & 0.5740 & 13.46 & 98.09 \\
\hline 16 & Amp8 & 0.4763 & 1.8550 & 14.38 & 7.971 & 44.44 & 0.6736 & 11.14 & 2.3501 & 0.3326 & 12.24 & 95.86 \\
\hline 17 & Amp8a & 0.5224 & 1.7967 & 14.67 & 7.804 & 45.03 & 0.6618 & 11.05 & 2.2259 & 0.3303 & 11.88 & 95.97 \\
\hline 18 & Bio2(?) & 1.1102 & 0.8421 & 16.40 & 12.35 & 27.90 & 2.8692 & 0.12 & 0.3643 & 0.4122 & 27.09 & 89.47 \\
\hline 19 & Bio2a(?) & 0.5490 & 0.5116 & 10.24 & 5.584 & 37.75 & 1.9754 & 0.15 & 0.4873 & 0.4214 & 35.99 & 93.66 \\
\hline
\end{tabular}

\begin{tabular}{|r|r|r|r|r|r|r|r|r|r||}
\hline \multicolumn{9}{|c|}{ Table A-9b. Site 8 Microprobe Data Heavy Minerals, Sample 8B } \\
\hline \hline Point & Label & $\mathrm{F}$ & $\mathrm{MgO}$ & $\mathrm{P}_{2} \mathrm{O}_{s}$ & $\mathrm{Cl}$ & $\mathrm{CaO}$ & $\mathrm{MnO}$ & $\mathrm{FeO}$ & \multicolumn{1}{|c|}{ Total } \\
\cline { 3 - 10 } & & $\%$ & $\%$ & $\%$ & $\%$ & $\%$ & $\%$ & $\%$ & $\%$ \\
\hline 1 & Apatite & 2.175 & 0.0634 & 40.06 & 0.7060 & 53.04 & 0.1639 & 0.3116 & 96.52 \\
\hline 2 & Apatite & 2.914 & 0.1422 & 39.61 & 0.8151 & 52.74 & 0.1683 & 0.7362 & 97.12 \\
\hline 3 & Apatite & 2.622 & 0.1835 & 40.93 & 0.6525 & 53.93 & 0.0801 & 1.4289 & 99.83 \\
\hline 4 & Apatite & 2.365 & 0.1828 & 40.43 & 0.6777 & 53.70 & 0.1152 & 1.7057 & 99.17 \\
\hline 5 & Apatite & 2.544 & 0.1616 & 40.49 & 0.7779 & 53.23 & 0.1101 & 0.9732 & 98.29 \\
\hline 6 & Apatite & 2.400 & 0.0600 & 40.04 & 0.6900 & 52.91 & 0.1800 & 0.5700 & 96.85 \\
\hline
\end{tabular}




\begin{tabular}{|r|r|r|r|r|r|r|r|r|r||}
\hline \multicolumn{8}{|c|}{ Table A-10. Sample 8B INAA Non-Mag. Heavy Minerals } \\
\hline${ }^{24} \mathrm{Na}$ & ${ }^{46} \mathrm{Sc}$ & ${ }^{59} \mathrm{Fe}$ & ${ }^{60} \mathrm{Co}$ & ${ }^{86} \mathrm{Rb}$ & ${ }^{131} \mathrm{Ba}$ & ${ }^{134} \mathrm{Cs}$ & ${ }^{140} \mathrm{La}$ & ${ }^{141} \mathrm{Ce}$ & ${ }^{147} \mathrm{Nd}$ \\
\hline 0.72 & 48.94 & 0.1355 & 72.91 & 69.95 & 638.31 & 2.58 & 147.41 & 306.22 & 110.02 \\
\hline & & & & & & & & & \\
\hline${ }^{152} \mathrm{Eu}$ & ${ }^{153} \mathrm{Sm}$ & ${ }^{160} \mathrm{~Tb}$ & ${ }^{169} \mathrm{Yb}$ & ${ }^{177} \mathrm{Lu}$ & ${ }^{181} \mathrm{Hf}$ & ${ }^{182} \mathrm{Ta}$ & ${ }^{233} \mathrm{Th}$ & ${ }^{239} \mathrm{U}$ & \\
\hline $\mathrm{ppm}$ & $\mathrm{ppm}$ & $\mathrm{ppm}$ & $\mathrm{ppm}$ & $\mathrm{ppm}$ & $\mathrm{ppm}$ & $\mathrm{ppm}$ & $\mathrm{ppm}$ & $\mathrm{ppm}$ & \\
\hline 1.87 & 22.17 & 4.17 & 20.49 & 4.31 & 210.48 & 3.25 & 38.79 & 18.68 & \\
\hline
\end{tabular}

\begin{tabular}{|c|c|c|c|c|c|c|c|c|c|c|c|}
\hline \multicolumn{12}{|c|}{ Table A-11a. Site 12 INAA Data } \\
\hline \multirow[t]{2}{*}{ Sample } & \multirow{2}{*}{$\begin{array}{l}\text { meters } \\
\text { from } \\
\text { contact }\end{array}$} & ${ }^{24} \mathrm{Na}$ & ${ }^{46} \mathrm{Sc}$ & ${ }^{59} \mathrm{Fe}$ & ${ }^{60} \mathrm{Co}$ & ${ }^{86} \mathrm{Rb}$ & ${ }^{131} \mathrm{Ba}$ & ${ }^{134} \mathrm{Cs}$ & ${ }^{140} \mathrm{La}$ & ${ }^{141} \mathrm{Ce}$ & ${ }^{147} \mathrm{Nd}$ \\
\hline & & $\%$ & ppm & $\%$ & ppm & ppm & $\mathrm{ppm}$ & ppm & ppm & ppm & ppm \\
\hline 12aw & 0.018 & 2.89 & 4.11 & 1.76 & 5.49 & 149.6 & 428.7 & 5.83 & 39.82 & 71.76 & 24.01 \\
\hline $12 \mathrm{hw}$ & 0.090 & 2.82 & 4.54 & 1.91 & 5.97 & 144.6 & 464.6 & 6.42 & 39.62 & 72.05 & 24.27 \\
\hline $12 g w$ & 0.162 & 2.74 & 4.53 & 1.87 & 6.23 & 147.1 & 465.9 & 6.5 & 40.90 & 72.67 & 25.03 \\
\hline $12 \mathrm{fw}$ & 0.251 & 2.98 & 4.29 & 1.83 & 5.62 & 151.3 & 455.9 & 5.63 & 40.03 & 70.44 & 24.42 \\
\hline 12ew & 0.431 & 2.76 & 3.60 & 1.46 & 4.08 & 165.2 & 359.0 & 5.25 & 38.40 & 69.13 & 22.01 \\
\hline $12 \mathrm{dw}$ & 0.862 & 2.78 & 3.29 & 1.34 & 3.56 & 167.6 & 392.3 & 5.08 & 36.27 & 65.82 & 19.05 \\
\hline
\end{tabular}

\begin{tabular}{||l|l|r|r|r|r|r|r|r|r|r||}
\hline \multicolumn{10}{|c|}{ Table A-11b. Site 12 INAA Data (cont.) } \\
\hline \hline \multirow{2}{*}{$\begin{array}{l}\text { Sample } \\
\end{array}$} & $\begin{array}{l}\text { meters } \\
\text { from } \\
\text { contact }\end{array}$ & ${ }^{152} \mathrm{Eu}$ & ${ }^{153} \mathrm{Sm}$ & ${ }^{160} \mathrm{~Tb}$ & ${ }^{169} \mathrm{Yb}$ & ${ }^{177} \mathrm{Lu}$ & ${ }^{181} \mathrm{Hf}$ & ${ }^{182} \mathrm{Ta}$ & ${ }^{233} \mathrm{Th}$ & ${ }^{239} \mathrm{U}$ \\
\cline { 2 - 12 } & $\mathrm{ppm}$ & $\mathrm{ppm}$ & $\mathrm{ppm}$ & $\mathrm{ppm}$ & $\mathrm{ppm}$ & $\mathrm{ppm}$ & $\mathrm{ppm}$ & $\mathrm{ppm}$ \\
\hline $12 \mathrm{aw}$ & 0.018 & 0.651 & 4.53 & 0.680 & 3.05 & 0.515 & 6.00 & 2.37 & 18.78 & 5.27 \\
\hline $12 \mathrm{hw}$ & 0.090 & 0.655 & 4.50 & 0.674 & 2.94 & 0.513 & 6.22 & 2.39 & 18.32 & 5.19 \\
\hline $12 \mathrm{gw}$ & 0.162 & 0.718 & 4.64 & 0.678 & 3.15 & 0.525 & 5.81 & 2.41 & 18.38 & 5.15 \\
\hline $12 \mathrm{fw}$ & 0.251 & 0.659 & 4.44 & 0.641 & 2.78 & 0.505 & 5.90 & 2.54 & 18.74 & 5.11 \\
\hline $12 \mathrm{ew}$ & 0.431 & 0.514 & 4.05 & 0.626 & 3.03 & 0.542 & 5.02 & 2.62 & 20.90 & 6.00 \\
\hline $12 \mathrm{dw}$ & 0.862 & 0.466 & 3.83 & 0.592 & 3.00 & 0.508 & 5.26 & 2.66 & 21.40 & 6.30 \\
\hline
\end{tabular}




\begin{tabular}{|l|r|r|r|r|r|r|r|r|r|r|r|r|r||}
\hline \multicolumn{10}{|c|}{ Table A-12. Site 12 XRF Data } \\
\hline \begin{tabular}{l}
\hline Sample \\
$\begin{array}{l}\text { meters } \\
\text { fontact }\end{array}$
\end{tabular} & $\mathrm{SiO}_{2}$ & $\mathrm{TiO}_{2}$ & $\mathrm{Al}_{2} \mathrm{O}_{3}$ & $\mathrm{Fe}_{2} \mathrm{O}_{3}$ & $\mathrm{MnO}$ & $\mathrm{MgO}$ & $\mathrm{CaO}$ & $\mathrm{Na}_{2} \mathrm{O}$ & $\mathrm{K}_{2} \mathrm{O}$ & $\mathrm{P}_{2} \mathrm{O}_{5}$ & LOI & Total \\
\hline & & $\%$ & $\%$ & $\%$ & $\%$ & $\%$ & $\%$ & $\%$ & $\%$ & $\%$ & $\%$ & $\%$ & $\%$ \\
\hline $12 \mathrm{aw}$ & 0.018 & 71.72 & 0.37 & 13.72 & 2.37 & 0.06 & 0.93 & 1.74 & 3.72 & 4.03 & 0.09 & 1.41 & 100.16 \\
\hline $12 \mathrm{hw}$ & 0.090 & 71.45 & 0.41 & 13.47 & 2.65 & 0.06 & 1.07 & 1.89 & 3.69 & 3.94 & 0.09 & 1.36 & 100.08 \\
\hline $12 \mathrm{gw}$ & 0.162 & 71.32 & 0.40 & 13.64 & 2.58 & 0.06 & 1.00 & 1.80 & 3.73 & 4.07 & 0.10 & 1.39 & 100.09 \\
\hline $12 \mathrm{fw}$ & 0.251 & 73.16 & 0.32 & 12.87 & 1.92 & 0.05 & 0.73 & 1.37 & 3.68 & 4.26 & 0.07 & 1.43 & 99.86 \\
\hline $12 \mathrm{ew}$ & 0.431 & 72.97 & 0.33 & 13.20 & 2.00 & 0.06 & 0.78 & 1.45 & 3.64 & 4.34 & 0.08 & 1.34 & 100.19 \\
\hline $12 \mathrm{dw}$ & 0.862 & 73.10 & 0.31 & 12.96 & 1.90 & 0.05 & 0.70 & 1.30 & 3.63 & 4.38 & 0.07 & 1.52 & 99.92 \\
\hline
\end{tabular}

\begin{tabular}{||l|r|r|r|r|r||}
\hline \multicolumn{6}{|c|}{ Table A-13. Site 12 Volatiles Data } \\
\hline \hline Sample & $\begin{array}{l}\text { meters } \\
\text { from } \\
\end{array}$ & Cl & F & s & \multicolumn{1}{|c|}{ D } \\
\cline { 3 - 7 } & contact & $\mathrm{ppm}$ & $\mathrm{ppm}$ & $\mathrm{ppm}$ & $\begin{array}{r}\text { per } \\
\mathrm{mil}\end{array}$ \\
\hline $12 \mathrm{aw}$ & 0.018 & 127 & 433 & 36 & -97.5 \\
\hline $12 \mathrm{hw}$ & 0.0899 & 113 & 702 & 29 & -107 \\
\hline $12 \mathrm{gw}$ & 0.162 & 154 & 619 & 43 & -104 \\
\hline $12 \mathrm{fw}$ & 0.251 & 145 & 544 & 38 & -99 \\
\hline $12 \mathrm{ew}$ & 0.431 & 270 & 357 & 25 & -108 \\
\hline $12 \mathrm{dw}$ & 0.862 & 316 & 284 & 44 & -104 \\
\hline \hline
\end{tabular}




\begin{tabular}{|c|c|c|c|c|c|c|c|c|c|c|c|}
\hline \multicolumn{12}{|c|}{ Table A-14a. Site 13 INAA Data } \\
\hline \multirow[t]{2}{*}{ Sample } & \multirow{2}{*}{$\begin{array}{l}\text { meters } \\
\text { below } \\
\text { contact }\end{array}$} & ${ }^{24} \mathrm{Na}$ & ${ }^{46} \mathrm{Sc}$ & ${ }^{59} \mathrm{Fe}$ & ${ }^{60} \mathrm{Co}$ & ${ }^{86} \mathrm{Rb}$ & ${ }^{131} \mathrm{Ba}$ & ${ }^{134} \mathrm{Cs}$ & ${ }^{140} \mathrm{La}$ & ${ }^{141} \mathrm{Ce}$ & ${ }^{147} \mathrm{Nd}$ \\
\hline & & $\%$ & ppm & $\%$ & ppm & ppm & ppm & ppm & ppm & ppm & ppm \\
\hline $13 \mathrm{~N}$ & 1.00 & 2.49 & 4.26 & 1.58 & 4.69 & 140.34 & 376.29 & 5.63 & 39.88 & 81.37 & 25.47 \\
\hline $13 \mathrm{M}$ & 1.59 & 2.58 & 3.65 & 1.46 & 4.04 & 147.96 & 382.55 & 5.52 & 37.79 & 69.53 & 23.31 \\
\hline $13 \mathrm{~L}$ & 2.27 & ND & 4.33 & 1.73 & 5.19 & 138.64 & 388.47 & 5.74 & ND & 68.51 & 23.94 \\
\hline $13 K$ & 3.08 & 2.84 & 4.28 & 1.74 & 5.33 & 143.61 & 391.21 & 5.34 & 38.05 & 69.68 & 24.50 \\
\hline $13 \mathrm{~J}$ & 3.97 & 2.57 & 4.32 & 1.81 & 5.21 & 146.07 & 414.47 & 4.95 & 38.62 & 71.67 & 26.80 \\
\hline $13 \mathrm{~A}$ & 4.58 & 2.70 & 4.08 & 1.72 & 4.99 & 143.34 & 401.12 & 4.76 & 36.95 & 68.12 & 24.90 \\
\hline 13B & 5.45 & 2.87 & 4.15 & 1.71 & 4.96 & 142.42 & 393.73 & 5.20 & 38.70 & 70.14 & 25.14 \\
\hline 13B2 & 5.45 & 2.63 & $\mathrm{ND}$ & $\mathrm{ND}$ & ND & ND & ND & ND & 37.86 & ND & $\overline{\mathrm{ND}}$ \\
\hline $13 C$ & 6.29 & 2.67 & 4.07 & 1.66 & 4.81 & 136.78 & 388.32 & 4.49 & 38.29 & 65.92 & 24.15 \\
\hline 13D & 6.77 & 2.62 & 4.49 & 1.89 & 5.59 & 127.96 & 423.03 & 4.59 & 40.17 & 70.96 & 25.98 \\
\hline$\overline{13 E}$ & 7.43 & 2.76 & 4.22 & 1.81 & 5.41 & 141.11 & 409.66 & 4.66 & 37.57 & 68.43 & 24.69 \\
\hline $13 \mathrm{~F} 1$ & 8.17 & 2.69 & 4.11 & 1.68 & 4.81 & 134.03 & 387.18 & 4.62 & 36.88 & 66.64 & 22.69 \\
\hline $13 \mathrm{~F} 2$ & 8.32 & 2.70 & 4.07 & 1.70 & 4.96 & 135.32 & 408.51 & 4.55 & 37.07 & 66.43 & 23.92 \\
\hline $13 G$ & 9.16 & 2.68 & 4.07 & 1.66 & 4.79 & 146.30 & 391.55 & 4.95 & 38.45 & 70.09 & 24.39 \\
\hline
\end{tabular}




\begin{tabular}{||l|r|r|r|r|r|r|r|r|r|r||}
\hline \multicolumn{10}{|c|}{ Table A-14b. Site 13 INAA Data (cont.) } \\
\hline \hline \multirow{2}{*}{$\begin{array}{l}\text { Sample } \\
\text { meters } \\
\text { below } \\
\text { contact }\end{array}$} & ${ }^{152} \mathrm{Eu}$ & ${ }^{153} \mathrm{Sm}$ & ${ }^{160} \mathrm{~Tb}$ & ${ }^{169} \mathrm{Yb}$ & ${ }^{177} \mathrm{Lu}$ & ${ }^{181} \mathrm{Hf}$ & ${ }^{182} \mathrm{Ta}$ & ${ }^{233} \mathrm{Th}$ & ${ }^{239} \mathrm{U}$ \\
\hline 13N & 1.00 & 0.611 & 4.80 & 0.672 & 3.05 & 0.519 & 5.42 & 2.66 & 18.96 & 5.38 \\
\hline $13 \mathrm{M}$ & 1.59 & 0.547 & 4.07 & 0.606 & 3.07 & 0.527 & 5.29 & 2.70 & 19.81 & 5.23 \\
\hline $13 \mathrm{~L}$ & 2.27 & 0.616 & $\mathrm{ND}$ & 0.742 & 3.12 & 0.530 & 5.79 & 2.53 & 18.21 & $\mathrm{ND}$ \\
\hline $13 \mathrm{~K}$ & 3.08 & 0.599 & 4.36 & 0.733 & 3.07 & 0.506 & 5.42 & 2.43 & 17.93 & 5.56 \\
\hline $13 \mathrm{~J}$ & 3.97 & 0.665 & 4.28 & 0.698 & 3.13 & 0.523 & 5.22 & 2.61 & 18.56 & 4.83 \\
\hline $13 \mathrm{~A}$ & 4.58 & 0.636 & 4.39 & 0.702 & 3.28 & 0.501 & 6.20 & 2.60 & 18.21 & 5.48 \\
\hline $13 \mathrm{~B}$ & 5.45 & 0.645 & 4.49 & 0.633 & 3.02 & 0.526 & 5.05 & 2.48 & 18.13 & 6.02 \\
\hline $13 \mathrm{~B} 2$ & 5.45 & $\mathrm{ND}$ & 4.32 & $\mathrm{ND}$ & $\mathrm{ND}$ & $\mathrm{ND}$ & $\mathrm{ND}$ & $\mathrm{ND}$ & $\mathrm{ND}$ & 4.73 \\
\hline $13 \mathrm{C}$ & 6.29 & 0.627 & 4.33 & 0.684 & 2.90 & 0.500 & 5.25 & 2.44 & 17.13 & 4.73 \\
\hline $13 \mathrm{D}$ & 6.77 & 0.721 & 4.59 & 0.702 & 3.01 & 0.505 & 5.90 & 2.18 & 16.81 & 5.29 \\
\hline $13 \mathrm{E}$ & 7.43 & 0.663 & 4.35 & 0.650 & 3.04 & 0.485 & 5.46 & 2.47 & 17.58 & 4.91 \\
\hline $13 \mathrm{~F} 1$ & 8.17 & 0.622 & 4.24 & 0.675 & 2.88 & 0.501 & 5.57 & 2.37 & 17.48 & 5.77 \\
\hline $13 \mathrm{~F} 2$ & 8.32 & 0.626 & 4.27 & 0.672 & 3.03 & 0.520 & 5.96 & 2.57 & 18.37 & 4.94 \\
\hline $13 \mathrm{G}$ & 9.16 & 0.638 & 4.29 & 0.719 & 3.04 & 0.497 & 5.42 & 2.48 & 18.64 & 5.36 \\
\hline \hline
\end{tabular}




\begin{tabular}{|c|c|c|c|c|c|c|}
\hline \multicolumn{7}{|c|}{ Table A-15. Site 13 Volatiles and \% Glass } \\
\hline Sample & meters & $\mathrm{Cl}$ & $\mathbf{s}$ & $\mathbf{F}$ & $\delta \mathrm{D}$ & glass \\
\hline & contact & ppm & ppm & ppm & per mil & $\%$ \\
\hline 13Z(obs, hydra) & -1.00 & ND & ND & ND & -104 & 100 \\
\hline $13 X$ (obs) & -0.50 & 469 & 141 & 564 & -95 & 100 \\
\hline $13 W(o b s)$ & -0.30 & 412 & 116 & 444 & -101 & 100 \\
\hline $13 N$ & 1.00 & 81 & 49 & 438 & -97 & 71 \\
\hline $13 \mathrm{M}$ & 1.59 & 134 & 33 & 325 & -101 & ND \\
\hline $13 \mathrm{~L}$ & 2.27 & 112 & 48 & 445 & -100 & 71 \\
\hline $13 \mathrm{~K}$ & 3.08 & 97 & 48 & 433 & -93 & ND \\
\hline $13 \mathrm{~J}$ & 3.97 & 102 & 51 & 419 & -75 & 64 \\
\hline $13 A$ & 4.58 & 111 & 75 & 398 & -100 & 64 \\
\hline 13B & 5.45 & 90 & 80 & 425 & -98 & 57 \\
\hline 13B2 & 5.45 & 86 & 55 & 477 & ND & ND \\
\hline $13 C$ & 6.29 & 81 & 46 & 453 & -96 & 50 \\
\hline 13D & 6.77 & 83 & 45 & 574 & -103 & ND \\
\hline $13 E$ & 7.43 & 93 & 43 & 514 & -103 & 57 \\
\hline $13 F 1$ & 8.17 & 81 & 53 & 449 & ND & ND \\
\hline $13 \mathrm{~F} 2$ & 8.32 & 93 & 54 & 477 & -98 & 71 \\
\hline $13 G$ & 9.16 & 101 & 110 & 465 & -101 & ND \\
\hline $13 \mathrm{H}$ & 9.90 & 81 & 106 & 504 & -107 & 50 \\
\hline 13I & 10.6 & 112 & 63 & 456 & -106 & ND \\
\hline 13Y(welded) & 11.4 & 292 & 28 & 335 & -106 & 100 \\
\hline 130 & 12.1 & 132 & 59 & 611 & -94 & ND \\
\hline 13P & 14.1 & 171 & 53 & 266 & ND & 100 \\
\hline $13 Q$ & 15.3 & 146 & 66 & 395 & -104 & ND \\
\hline $13 R$ & 16.4 & 162 & 51 & 418 & -107 & 93 \\
\hline $13 S$ & 18.9 & ND & ND & 384 & -103 & ND \\
\hline $13 \mathrm{~T}$ & 20.9 & 206 & 64 & 309 & -105 & 85 \\
\hline $13 U$ & 23.9 & 180 & 63 & 321 & -109 & ND \\
\hline
\end{tabular}




\begin{tabular}{|c|c|c|c|c|c|c|c|c|c|c|c|c|c|}
\hline \multicolumn{14}{|c|}{ Table A-16. Site 13 XRF Data } \\
\hline Sample & $\begin{array}{l}\text { meters } \\
\text { below } \\
\text { contact }\end{array}$ & $\mathrm{SiO}_{2}$ & $\mathrm{TiO}_{2}$ & $\mathrm{Al}_{2} \mathrm{O}_{3}$ & $\mathrm{Fe}_{2} \mathrm{O}_{3}$ & $\mathrm{MnO}$ & $\mathrm{MgO}$ & $\mathrm{CaO}$ & $\mathrm{Na}_{2} \mathrm{O}$ & $\mathrm{K} 2 \mathrm{O}$ & $\mathrm{P}_{2} \mathrm{O}_{3}$ & LOI & Total \\
\hline & & $\%$ & $\%$ & $\%$ & $\%$ & $\%$ & $\%$ & $\%$ & $\%$ & $\%$ & $\%$ & $\%$ & $\%$ \\
\hline $\begin{array}{l}13 Z \text { (obs, } \\
\text { hydra }\end{array}$ & -1.00 & 74.01 & 0.24 & 12.78 & 1.60 & 0.06 & 0.81 & 1.02 & 3.46 & 4.57 & 0.07 & 1.11 & 99.73 \\
\hline $13 \mathrm{X}$ (obs) & -0.50 & 73.25 & 0.29 & 13.42 & 2.03 & 0.05 & 0.63 & 1.50 & 3.70 & 4.22 & 0.07 & 0.35 & 99.51 \\
\hline $13 \mathrm{~W}$ (obs) & -0.25 & 74.29 & 0.26 & 12.96 & 1.79 & 0.05 & 0.55 & 1.19 & 3.52 & 4.54 & 0.06 & 0.34 & 99.55 \\
\hline $13 \mathrm{~N}$ & 1.00 & 71.09 & 0.33 & 13.50 & 2.44 & 0.06 & 0.82 & 1.66 & 3.38 & 4.25 & 0.09 & 1.82 & 99.44 \\
\hline $13 \mathrm{M}$ & 1.59 & 71.78 & 0.30 & 13.25 & 2.13 & 0.05 & 0.71 & 1.54 & 3.45 & 4.43 & 0.08 & 1.88 & 99.60 \\
\hline $13 \mathrm{~L}$ & 2.27 & 70.81 & 0.37 & 13.43 & 2.68 & 0.06 & 0.87 & 1.73 & 3.52 & 4.12 & 0.10 & 1.71 & 99.40 \\
\hline $13 \mathrm{~K}$ & 3.08 & 71.13 & 0.34 & 13.48 & 2.45 & 0.06 & 0.84 & 1.71 & 3.45 & 4.15 & 0.09 & 1.65 & 99.35 \\
\hline $13 \mathrm{~J}$ & 3.97 & 70.91 & 0.35 & 13.38 & 2.62 & 0.06 & 0.89 & 1.78 & 3.59 & 4.07 & 0.09 & 1.73 & 99.47 \\
\hline $13 \mathrm{~A}$ & 4.58 & 71.00 & 0.33 & 13.44 & 2.45 & 0.06 & 0.87 & 1.79 & 3.57 & 4.14 & 0.10 & 1.76 & 99.51 \\
\hline 13B & 5.45 & 71.05 & 0.33 & 13.47 & 2.41 & 0.05 & 0.81 & 1.79 & 3.58 & 4.21 & 0.09 & 1.77 & 99.56 \\
\hline 13B2 & 5.45 & 70.92 & 0.36 & 13.58 & 2.70 & 0.06 & 0.92 & 1.83 & 3.58 & 4.04 & 0.10 & 1.60 & 99.69 \\
\hline $13 C$ & 6.29 & 71.26 & 0.34 & 13.56 & 2.46 & 0.05 & 0.83 & 1.75 & 3.60 & 4.21 & 0.09 & 1.66 & 99.81 \\
\hline 13D & 6.77 & 70.79 & 0.37 & 13.58 & 2.64 & 0.06 & 0.89 & 1.86 & 3.58 & 3.96 & 0.10 & 1.65 & 99.48 \\
\hline $13 \mathrm{E}$ & 7.43 & 70.53 & 0.38 & 13.59 & 2.78 & 0.05 & 0.88 & 1.80 & 3.64 & 4.00 & 0.10 & 1.74 & 99.49 \\
\hline 13F1 & 8.17 & 71.36 & 0.32 & 13.40 & 2.33 & 0.05 & 0.65 & 1.79 & 3.35 & 4.12 & 0.08 & 1.80 & 99.25 \\
\hline $13 F 2$ & 8.32 & 70.88 & 0.34 & 13.46 & 2.39 & 0.05 & 0.84 & 1.75 & 3.56 & 4.09 & 0.09 & 1.90 & 99.35 \\
\hline $13 G$ & 9.16 & 70.72 & 0.34 & 13.48 & 2.54 & 0.06 & 0.85 & 1.76 & 3.59 & 4.03 & 0.09 & 1.93 & 99.39 \\
\hline $13 \mathrm{H}$ & 9.90 & 71.05 & 0.33 & 13.33 & 2.34 & 0.06 & 0.80 & 1.70 & 3.60 & 4.13 & 0.09 & 1.85 & 99.28 \\
\hline 131 & 10.61 & 70.85 & 0.33 & 13.43 & 2.38 & 0.06 & 0.82 & 1.68 & 3.54 & 4.08 & 0.09 & 2.06 & 99.32 \\
\hline $\begin{array}{l}13 \mathrm{Y} \\
\text { (welded) }\end{array}$ & 11.35 & 72.46 & 0.28 & 12.93 & 1.92 & 0.05 & 0.59 & 1.30 & 3.56 & 4.30 & 0.07 & 2.10 & 99.56 \\
\hline 130 & 12.13 & 69.60 & 0.42 & 13.90 & 2.86 & 0.06 & 1.01 & 1.82 & 3.44 & 3.99 & 0.12 & 2.40 & 99.62 \\
\hline $13 P$ & 14.09 & 72.37 & 0.27 & 13.09 & 1.90 & 0.05 & 0.61 & 1.33 & 3.48 & 4.45 & 0.09 & 1.65 & 99.29 \\
\hline $13 Q$ & 15.31 & 70.49 & 0.35 & 13.60 & 2.49 & 0.06 & 0.88 & 1.83 & 3.53 & 3.90 & 0.09 & 2.20 & 99.42 \\
\hline $13 R$ & 16.35 & 70.38 & 0.38 & 13.50 & 2.76 & 0.06 & 0.88 & 1.86 & 3.50 & 3.90 & 0.11 & 1.92 & 99.25 \\
\hline $13 S$ & 18.92 & 70.39 & 0.37 & 13.56 & 2.60 & 0.06 & 0.85 & 1.82 & 3.54 & 3.85 & 0.10 & 2.22 & 99.36 \\
\hline $13 \mathrm{~T}$ & 20.85 & 71.15 & 0.32 & 13.18 & 2.14 & 0.05 & 0.71 & 1.54 & 3.41 & 4.29 & 0.08 & 2.56 & 99.43 \\
\hline $13 \mathrm{U}$ & 23.90 & 70.78 & 0.37 & 13.45 & 2.50 & 0.06 & 0.81 & 1.77 & 3.45 & 3.85 & 0.09 & 2.26 & 99.39 \\
\hline $13 \mathrm{~V}$ & 29.92 & 70.69 & 0.38 & 13.59 & 2.69 & 0.06 & 0.91 & 1.89 & 3.47 & 3.97 & 0.10 & 2.36 & 100.1 \\
\hline
\end{tabular}


Dr. Larry Cathles

Cornell University

2134 Snee Hall

Ithaca, NY 14853

Dr. Peter Airey

ANSTO

Lucas Heights Research Labs

N.new Illawarra Road

AUS-Sutherland, NSW 2232

Dr. Russel Alexander

NAGRA

Hardstrasse 73

CH-5430 Wettingen

Switzerland

Dr. John Apps

Lawrence Berkeley Laboratory

1 Cyclotron Road

Berkeley, CA 94720

Dr. George Birchard

U.S. Nuclear Regulatory Commission

Mail Stop T-9 B 3

Washington, D.C. 20555

Dr. David L. Bish

Los Alamos National Laboratory

Earth and Environment Division

Mail Stop D469

Los Alamos, NM 87545

Ms. Deirdre Boak

SAIC

101 Convention Center Dr.

Las Vegas, NV 89109

Dr. John Bradbury

U.S. Nuclear Regulatory Commission

Mail Stop $4 \mathrm{H3}$

Washington, DC 20555

Dr. Ralph E. Cady

U.S. Nuclear Regulatory Commission Mail StopT-9 B 3

Washington, DC 20555

For Richard Codell

U.S. NRC

Mail Stop T-7

Washington, DC 20555
Mr. Willis L. Clarke

Lawrence Livermore National Laboratory

PO Box 808, L-352

Livermore, CA 94550

Dr. Paul L. Cloke

Science Applications International

Corporation

101 Convention Center Dr.

Las Vegas, NV 89109

Dr. Richard B. Codell

U.S. Nuclear Regulatory Commission

Mail Stop 4 H3

Washington, DC 20555

Dr. Gustavo Cragnolino

Center for Nuclear Waste Regulatory

Analyses

6220 Culebra Road

San Antonio, TX 78228-0510

Dr. David Curtis

Los Alamos National Laboratory

INC-BU, Mail Stop J514

Los Alamos, NM 87545

Dr. Rodney C. Ewing

University of New Mexico

Department of Geology

Albuquerque, NM 87131

Dr. June Fabryka-Martin

Los Alamos National Laboratory

Mail Stop J514

P.O. Box 1663

Los Alamos, NM 87545
Dr. Ronald T. Green

Center for Nuclear Waste

Regulatory Analyses

6220 Culebra Road

San Antonio, TX 78228-0510

Mr. Donald Gustafson

3420 Norman Dr.

Reno, NV 89509

Ms. Grace Haggerty

Weston

955 L'Enfant Plaza

Washington, DC 20023

Dr. William Hinze

Department of Earth and Atmospheric Sciences

Purdue University

West Lafayette, IN 47907

Mr. Renner Hofmann

Center for Nuclear Waste Regulatory

Analyses

6220 Culebra Road

San Antonio, TX 78228-051

Dr. Paul Hooker

BGS, Fluid Process Group

Groundwater \& Geotech Div.

Keyworth

UK-Nottingham NG12 5GG

Dr. Dwight Hoxie

US Geological Survey

Box 25046, MS 425

Denver Federal Center

Denver, CO 80225

Dr. Linda A. Kovach

U.S. Nuclear Regulatory Commission

Mail Stop T-9B 3

Washington, DC 20555

Dr. Kenneth Krupka

Battelle Pacific Northwest Laboratory

P.0. Box 999, Sigma V

Richland, WA 99352

Mr. Robert A. Levich

U.S. Department of Energy

YMSC Project Office

P. O. Box 98608

Las Vegas, NV 89193 
Dr. Hersh Manaktala

Center for Nuclear Waste

Regulatory Analyses

6220 Culebra Road

San Antonio, TX 78228-0510

Dr. Michael McNeil

Nuclear Regulatory Commission

5650 Nicholson Lane

Rockville, MD 20852

Dr. D. K. Nordstrom

US Geological Survey

Box 25046, MS 425

Denver Federal Center

Denver, CO 80225

Dr. English C. Pearcy

Center for Nuclear Waste

Regulatory Analyses

6220 Culebra Road

San Antonio, TX 78228-0510

Dr. John Russell

Ctr.for Nuclear Waste Reg. Analyses

Crystal Gateway One, Suite 1102

1235 Jefferson Davis Highway

Arlington, VA 22202-3293

Mr. Michael Shea

TerraCon/Univ. of Chicago

5050 S. Lake Shore Dr.

Chicago, IL 60615

Dr. Narasi Sridhar

Center for Nuclear Waste

Regulatory Analyses

6220 Culebra Road

San Antonio, TX 78228-0510

Dr. Henning von Maravic

CEC, DG XII/D/2

200 rue de la Loi

B-1049 Brussels

Belgium

Mr. Harold Wollenberg

Lawrence Berkeley Laboratory

\#1 Cyclotron Road

Berkeley, CA 94720
Dr. Brian Marshall

US Geological Survey

DFC Box 25046

MS 963

Denver, CO 80225

Dr. H.L. McKague

Center for Nuclear Waste

Regulatory Analyses

6220 Culebra Road

San Antonio, TX 78228-0510

Dr. Arend Meijer

Jacobs Engineering

3821 Andersen Avenue S.E.

Albuquerque, NM 87108

Dr. William Ott

U.S. Nuclear Regulatory Commission

Mail Stop T-9 B 3

Washington, DC 20555

Dr. J.-C. Petit

Commissariat a L'Energie Atomique

DCC/DESD/SCS

B.P. 6 - 92265 Fontenay-Aux-Roses

Cedex France

Dr. Budhi Sagar

Center for Nuclear Waste

Regulatory Analyses

6220 Culebra Road

San Antonio, TX 78228-0510

Ms. Ardyth Simmons

U.S. Department of Energy

101 Convention Center Drive

Suite 200

Las Vegas, NV 89109

Dr. Gerry Stirewalt

Ctr. for Nuclear Waste Reg. Analyses

Crystal Gateway One, Suite 1102

1235 Jefferson Davis Hwy.

Arlington, VA 22202-3283

Mr. Engelbrecht von Tiesenhausen

Clark County

301 E. Clark \#570

Las Vegas, NV 89101

Mr. Steve Young

Center for Nuclear Waste

Regulatory Analyses

6220 Culebra Road

San Antonio, TX 78228-0510
Dr. James Mazer

Argonne National Laboratory

Chemical Tech Division

9700 S. Cass Ave.

Argonne, IL 60439

Dr. Ian McKinley

NAGRA

Hardstrasse 73

CH-5430 Wettingen

Switzerland

Dr. William M. Murphy

Center for Nuclear Waste Regulato

Analyses

6220 Culebra Road

San Antonio, TX 78228-0510

Dr Bonnie Packer

2650 Park Tower Dr.

Suite 800

Vienna, VA 22180

Dr. Todd Rasmussen

140 Dunwoody Drive

Athens, GA 30605

Dr. Peter Sargent

AECL-Whiteshell Laboratory

Geochemistry Research Branch

Pinawa, Manitoba ROE1LO

Canada

Dr. John Smellie

Conterra AB

PO Box 493

S-751 06 Uppsala

Sweden

Dr. David Turner

Center for Nuclear Waste

Regulatory Analyses

6220 Culebra Road

San Antonio, TX 78228-0510

Dr. Gordon Wittmeyer

Ctr. for Nuclear Waste Regulatory

Analyses

6220 Culebra Road

San Antonio, TX 78228-0510 
Dr. Eric E. Ryder, 6313 MS1325

Sandia National Laboratories P. O. Box 5800

Albuquerque, NM 87185-1325

Dr. Harlan W. Stockman, 6118 (20) MS 0750

Sandia National Laboratories

P. O. Box 5800-0750

\section{NUREG Reports (1)}

G. C. Claycomb, 7151/MS 0619

Sandia National Laboratories

P. O. Box 5800

Albuquerque, NM 87185-0619

Dori Ellis, 6300

MS 1337

Sandia National Laboratories

P. O. Box 5800

Albuquerque, NM 87185-1337

Holly Dockery, 6312

MS 1326

Sandia National Laboratories

P. O. Box 5800

Albuquerque, NM 87185-1326
Dr. Peter B. Davies, 6115

MS 1324

Sandia National Laboratories

P. O. Box 5800

Albuquerque, NM 87185-1324

NUREG Reports (5)

S. A. Landenberger/MS 0899

Sandia National Laboratories

P. O. Box 5800

Albuquerque, NM 87185-0899

SAND Reports (1)

G. C. Claycomb, 7151/MS0619

Sandia National Laboratories

P. O. Box 5800

Albuquerque, NM 87185-0619

Larry Coston, 6313

MS 1326

Sandia National Laboratories

P. O. Box 5800

Albuquerque, NM 87185-1326
Dr. Henry R. Westrich, 6118 MS 0750

Sandia National Laboratories P. O. Box 5800

Albuquerque, NM 87185-0750

SAND Reports (5)

S. A. Landenberger, 7141/MS 0899

Sandia National Laboratories

P. O. Box 5800

Albuquerque, NM 87185-0899

Document Processing-DOE/OSTI (8)

7613-2/MS 0100

Sandia National Laboratories

P. O. Box 5800

Albuquerque, NM 87185-0100

R. W. Lynch, 6100

MS 0701

Sandia National Laboratories

P. O. Box 5800

Albuquerque, NM 87185-0701 


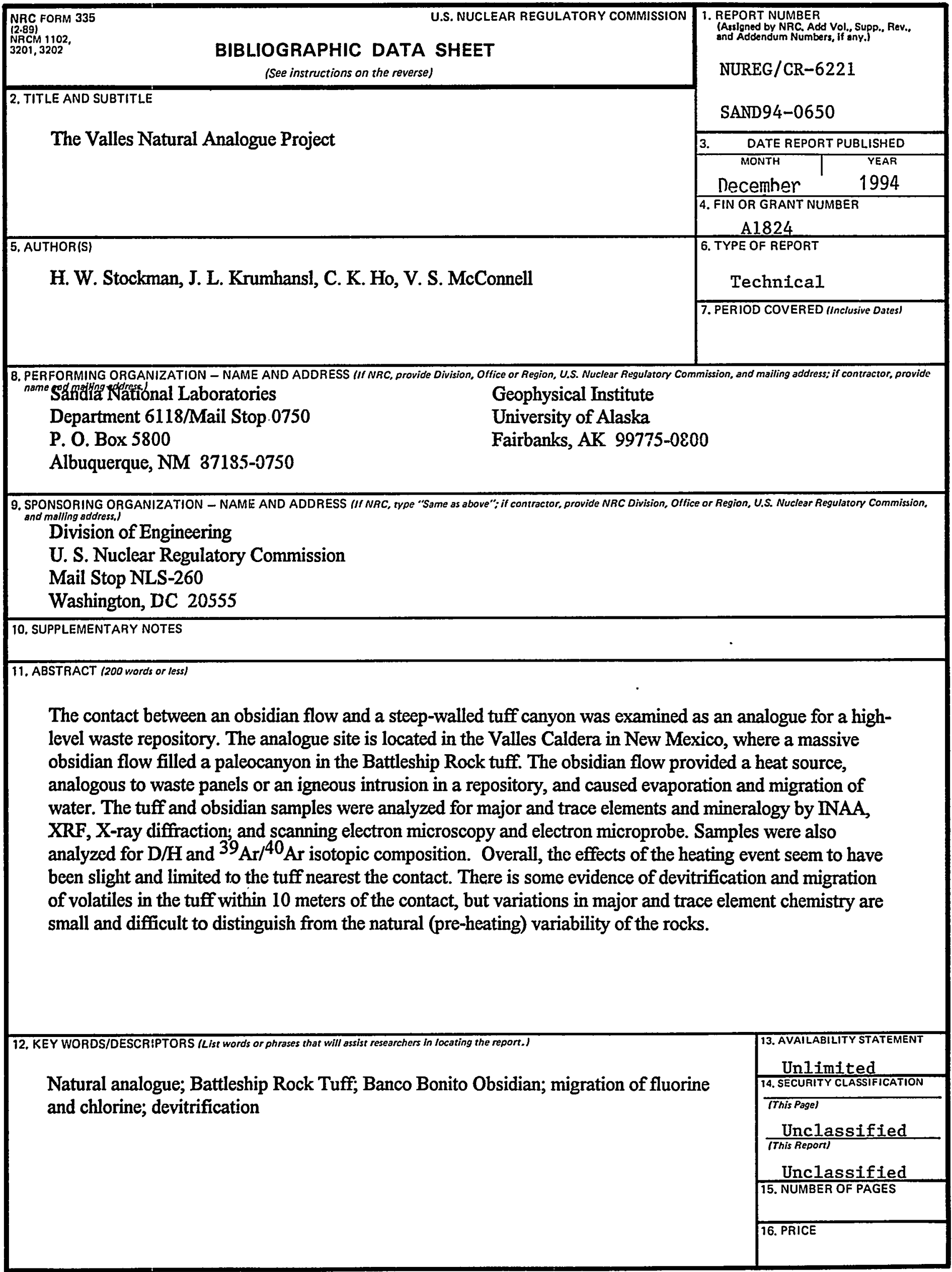

